\title{
WestVirginiaUniversity
}

THE RESEARCH REPOSITORY @ WVU

Graduate Theses, Dissertations, and Problem Reports

2003

\section{Modeling and controls for a laser glass cutting machine workcell robot}

\author{
Asif Mushtaq Mohammad \\ West Virginia University
}

Follow this and additional works at: https://researchrepository.wvu.edu/etd

\section{Recommended Citation}

Mohammad, Asif Mushtaq, "Modeling and controls for a laser glass cutting machine workcell robot" (2003). Graduate Theses, Dissertations, and Problem Reports. 1328.

https://researchrepository.wvu.edu/etd/1328

This Thesis is protected by copyright and/or related rights. It has been brought to you by the The Research Repository @ WVU with permission from the rights-holder(s). You are free to use this Thesis in any way that is permitted by the copyright and related rights legislation that applies to your use. For other uses you must obtain permission from the rights-holder(s) directly, unless additional rights are indicated by a Creative Commons license in the record and/ or on the work itself. This Thesis has been accepted for inclusion in WVU Graduate Theses, Dissertations, and Problem Reports collection by an authorized administrator of The Research Repository @ WVU. For more information, please contact researchrepository@mail.wvu.edu. 


\title{
MODELING AND CONTROLS FOR A LASER GLASS CUTTING MACHINE WORKCELL ROBOT
}

\author{
Asif M. Mohammad \\ Thesis submitted to the \\ College of Engineering and Mineral Resources \\ at West Virginia University \\ in partial fulfillment of the requirements \\ for the degree of \\ Master of Science \\ in \\ Mechanical Engineering \\ Dr. Nigel Clark \\ Dr. Victor Mucino \\ Dr. John E. Sneckenberger
}

Department of Mechanical and Aerospace Engineering

Morgantown, West Virginia

2003

Keywords: SCARA-Type Robot, Kinematics, Dynamics, Trajectory Planning, Controls 


\section{Abstract \\ Modeling and Controls for a Laser Glass Cutting Machine Workcell Robot}

\section{Asif M. Mohammad}

The SCARA (Selective Compliance Assembly Robot Arm) -Type Nimbl loader junior robot includes a four-degree of freedom robot manipulator arm. This thesis deals with three main areas of robot behavior: kinematics, dynamics and controls for the purpose of improving the performance of the Laser Glass Cutting Machine (LGCM) workcell. The thesis deals with developing kinematic and dynamic models of this robot arm and their application to task planning of this robot. In the kinematic analysis, both direct and inverse kinematic solutions, are performed. Using algebraic approach on direct kinematics, the inverse kinematic solution for the manipulator arm is derived.

The Lagrange-Euler (L-E) technique is used to derive the dynamic model of the Nimbl loader junior robot arm. The L-E method is the most systematic and organized method of solving for the dynamic behavior of the manipulator. The computer software program MATLAB is used to generate symbolic dynamic equations for the manipulator with as many as three degrees of freedom. Lagrange-Euler formulation is used to obtain the dynamic equations of the manipulator. Based on these dynamic equations and actuator dynamics, an integrated joint dynamic model was developed.

Task planning is done for SCARA-Type Nimbl loader robot, in which the robot starts from pick position to place position. A 4-3-4 joint trajectory was generated for pick-to-place path for the robot.

By applying the PID control technique to the integrated joint dynamic model, an independent joint control scheme was derived using a classical approach. An experimental verification study was done to prove the theoretical model of Work Cell robot. 


\section{Acknowledgements}

There are many people to whom the author is thankful to them for their having helped him in one-way or other with the completion of his thesis.

First, the author wishes to express his deep gratitude and indebtness to his research advisor, Dr. John E. Sneckenberger, for introducing the author to the areas of robotics and controls, for his valuable guidance and encouragement, and also for all the help and advice the author received from him throughout his graduate studies at West Virginia University. Special appreciation is also extended to the members of author's advisory and examining committee, Dr. Nigel Clark and Dr. Victor Mucino, for their support and encouragement during the course of this research.

The author would like to express appreciation to Jeff Rice who helped the author make his research a practical one and to Ranjit Menon, Padmanabhan Srinivasan and Paul Kreitzer, the author's colleagues in Room B-55, for their support, humor, encouragement and many useful discussions.

The author is thankful to the owners and employees of the Davis-Lynch Glass Company, for their support to accomplish the plant verification aspect of the project.

The author is also thankful to USDOE OIT Glass Program for their financial support and also thankful to WVDO Energy Efficiency Program for encouragement.

The author would also like to express appreciation to his friends Latha Devi Govada, Haritha Garapati, Rohit Kumar Tanagula and Gopal Manchkanti for their support during the course of the author's research.

Last, but not least, the author would like to express his indebtness and gratitude to his family, who always provide support and encouragement throughout his life. 


\section{Table of Contents}

Title Page $\quad$ i

Abstract

Acknowledgements iii

Table of Contents $\quad$ iv

List of Figures vii

List of Symbols $\quad$ x

List of Tables $\quad$ xiii

Chapter 1 - Introduction 1

1.1 Overview of Laser Glass Cutting Machine (LGCM) 1

1.2 Nomenclature Of Workcell 1

1.3 Description of SCARA-Type Robot 2

1.4 Literature Review and Background 4

1.5 Summary 5

Chapter 2 - Kinematics of SCARA-Type Robot 6

2.1 Objectives 6

2.2 Specified LGCM Task $\quad 7$

2.3 Methodology 8

2.4 Kinematic Analysis of SCARA-Type Robot 9

2.5 Homogeneous Transformation Matrices 9

2.6 Denavit-Hartenberg Representation 10

2.7 SCARA-Type Robot Coordinate frame System 12

2.8 Kinematic solution of SCARA-Type Robot 13

2.8.1 Direct Kinematic Model 13

2.8.2 Inverse Kinematic Solution 16

$\begin{array}{lll}2.9 \text { Summary } & 20\end{array}$

Chapter 3 - Dynamics of SCARA-Type Robot 21

$\begin{array}{ll}3.1 \text { Methodology } & 21\end{array}$

3.2 Lagrange-Euler Formulation 21

3.3 Equations of Motion for Manipulator 23

3.4 Determination of J Matrix 26

3.5 Torque Equations for SCARA-Type Robot 29

$\begin{array}{ll}3.6 \text { Summary } & 30\end{array}$ 
Chapter 4 - Task Planning $\quad 31$

4.1 Introduction 31

4.2 Methodology 31

4.3 Task Planning for SCARA-Type Robot 33

4.4 Trajectory Planning $\quad 33$

4.4.1 4-3-4 Trajectory Planning 33

4.5 Results of Trajectory Planning 36

\begin{tabular}{ll}
4.6 & Inverse Kinematic Verification \\
\hline
\end{tabular}

4.7 Inverse Dynamic Verification 41

Chapter 5 - Transfer Function Model of SCARA-Type Robot 48

5.1 Methodology 48

5.2 Actuator Dynamic Model 48

5.3 Integrated Joint Dynamic Model for SCARA-Type Robot 51

5.4 Open-Loop Transfer Function Model for the Three Joints of the SCARA-Type Robot 54

5.5 Transfer Function Model for Independent Link-Joint 3

$\begin{array}{ll}\text { Chapter } 6 \text { - Controller Design } & 67\end{array}$

6.1 Methodology 67

6.2 Controller Design for Joints of SCARA-Type Robot 67

6.3 PID Controller for a Single Joint 67

6.4 Controllers for the Three Link-Joints of the SCARA-Type Robot $\quad 70$

6.4.1 Controller for Link-Joint 1

6.4.2 Controller for Link-Joint $2 \quad 75$

6.4.3 Controller for Link-Joint $3 \quad 79$

6.5 Summary 82

Chapter 7 - Experimental Verification Study of SCARA-Type Robot $\quad 83$

7.1 Experimental Results $\quad 83$

7.2 Kinematic Validation Study 86

7.3 Kinematic Study of SCARA-Type Robot 95

7.4 Dynamic Study of SCARA-Type Robot 96

7.5 Workspace Study of SCARA-Type Robot 97

7.6 Summary 99

Chapter 8 - Contributions and Future Work $\quad 100$

$\begin{array}{ll}8.1 \text { Contributions } & 100\end{array}$

8.2 Future Research and Recommendations 101

$\begin{array}{ll}\text { References } & 102\end{array}$

Appendix A - Inverse Kinematic Model Verification 104

Appendix B - Calculation of Inertia, Coriolis, Centrifugal and Gravitational Terms 106

Appendix C - Torque Equations for Joints 108 
Appendix D - Matlab Code to Calculate Kinematics, Inverse Kinematics, Dynamics and Torques for SCARA-Type Robot

Appendix E - Technical Characteristics of Robot

Appendix F - Technical Characteristics of Actuators

Appendix G - Matlab Code to Determine Closed-Loop Transfer Function

115

Appendix H - Simulink Model for Three Joints 


\section{List of Figures}

Figure No.

Title

Page No.

1.1 Schematic Diagram of Laser Glass Cutting Machine 2

1.2 Components of Laser Glass Cutting Machine 3

1.3 Side-View Drawing of SCARA-Type Robot 4

2.1 Schematic of LGCM Plant Prototype Workcell 8

2.2 Coordinate Frame for i-1, i and i+1 Rigid Links, and Associated Link-Joint Parameters

2.3 Coordinate Frame Assignment and Associated Link-Joint Parameters for SCARA-Type Robot

4.1 Trajectory Planning for Joint Motion

4.2 Top View of Work Envelop of the Robot

4.3 Motion of $\theta_{1}$ with time for the Pick-to-Place Task

4.4 Motion of $\theta_{2}$ with time for the Pick-to-Place Task

4.5 Motion of $\theta_{3}$ with time for the Pick-to-Place Task

4.6 Joint 1 Position, Velocity and Acceleration for Pick-to-Place Task

4.7 Joint 2 Position, Velocity and Acceleration for Pick-to-Place Task

4.8 Joint 3 Position, Velocity and Acceleration for Pick-to-Place Task

4.9 Joint 1 input torque required for Pick-to-Place Task

4.10 Joint 2 input torque required for Pick-to-Place Task

4.11 Joint 2 real torque characteristics for Pick-to-Place Task

4.12 Joint 3 input torque (Link $1 \& 2$ fixed) required for Pick-to-Place Task 
5.3 Open-Loop Step Response for Integrated Dynamic Model of Link-Actuator 155

5.4 Open-Loop Root Locus for Integrated Dynamic Model of Link-Actuator 156

5.5 Open-Loop Bode plot for Integrated Dynamic Model of Link-Actuator 157

5.6 Open-Loop Step Response for Integrated Dynamic Model of Link-Actuator 258

5.7 Open-Loop Root Locus for Integrated Dynamic Model of Link-Actuator 259

5.8 Open-Loop Bode plot for Integrated Dynamic Model of Link-Actuator $2 \quad 60$

5.9 Open-Loop Step Response for Integrated Dynamic Model of Link-Actuator 361

5.10 Open-Loop Root Locus for Integrated Dynamic Model of Link-Actuator 362

5.11 Open-Loop Bode plot for Integrated Dynamic Model of Link-Actuator 362

5.12 Link-Joint 3 motion of Robot 63

5.13 Step Response for Independent Link-Joint 3 Model 64

5.14 Root Locus Plot for Independent Link-Joint 3 Model 65

5.15 Bode Plot for Independent Link-Joint 3 Model 66

6.1 Closed-Loop System with PID Controller 69

6.2 Transfer Function of Single Joint Closed-Loop System with PID Controller 69

6.3 Step Response for Joint 1

6.4 Bode diagram for Stability Margin of Joint 1

6.5 Root Locus Plot for Joint 1

6.6 Step Response for Joint 1 with Robot Operating in Minimum Workspace Volume

6.7 Step Response for Joint 2

6.8 Bode diagram for Stability Margin of Joint $2 \quad 78$

6.9 Root Locus Plot for Joint $2 \quad 78$ 
6.10 Step Response for Joint 3

6.11 Bode diagram for Stability Margin of Joint 3

6.12 Root Locus Plot for Joint $3 \quad 81$

7.1 Defined Pick-to-Place Positions for Experimental Verification Study 84

7.2 Pick-to-Place Trajectory in Cartesian Coordinate System 86

7.3 Top View of the Workcell $\quad 87$

7.4 Path of Robot End- Effector (In $\left.\mathrm{P}_{\mathrm{y}}-\mathrm{P}_{\mathrm{x}}\right) \quad 88$

7.5 Path of Robot End- Effector (In $\left.\mathrm{P}_{\mathrm{z}}-\mathrm{R}\right) \quad 89$

7.6 Change in acceleration of end-effector with the change in length of Link 295

7.7 Change in torque requirements at actuator 2 with the change in material of Link 2

7.8 Work Envelop of Robot for Varying Length of Link 2

97

7.9 Side View of the Work Envelop

7.10 Top View of the Work Envelop

98 


\section{List of Symbols}

\begin{tabular}{|c|c|}
\hline $\mathrm{S}_{\mathrm{i}}$ & $\sin \theta_{i}$ for $i^{\text {th }}$ Joint \\
\hline $\mathrm{C}_{\mathrm{i}}$ & $\cos \theta_{i}$ for $i^{\text {th }} j$ joint \\
\hline $\mathrm{D}_{\mathrm{ik}}$ & Inertia terms \\
\hline $\mathrm{g}$ & gravitational constant \\
\hline $\mathrm{h}_{\mathrm{ijk}}$ & Coriolis and centrifugal terms \\
\hline $\mathrm{I}_{\mathrm{xx}}, \mathrm{I}_{\mathrm{yy}}, \mathrm{I}_{\mathrm{zz}}$ & moments of inertia about coordinate frame axes \\
\hline $\mathrm{I}_{x y}, \mathrm{I}_{x z}, \mathrm{I}_{y z}$ & products of inertia with respect to coordinate frame axes \\
\hline $\mathbf{J}_{i}$ & pseudo-inertia matrix for $i^{\text {th }}$ link \\
\hline $\mathrm{m}_{i}$ & mass of $i^{\text {th }}$ link \\
\hline $\mathrm{n}_{x}, \mathrm{n}_{y}, \mathrm{n}_{z}$ & elements of orientation vector \\
\hline $\mathrm{o}_{x}, \mathrm{o}_{y}, \mathrm{o}_{z}$ & elements of sliding vector \\
\hline $\mathrm{a}_{x}, \mathrm{a}_{y}, \mathrm{a}_{z}$ & elements of approach vector \\
\hline $\mathrm{p}_{x}, \mathrm{p}_{y}, \mathrm{p}_{z}$ & elements of position vector \\
\hline $\mathrm{L}_{\mathrm{i}}$ & length of link i \\
\hline $\mathrm{H}$ & height of robot post \\
\hline$Q_{j}$ & differentiation matrix \\
\hline $\mathrm{T}_{\text {goal }}$ & general position of end-effector plate with respect to fixed base frame \\
\hline $\operatorname{Tr}$ & trace of a matrix \\
\hline $\mathrm{K}$ & kinetic energy \\
\hline
\end{tabular}




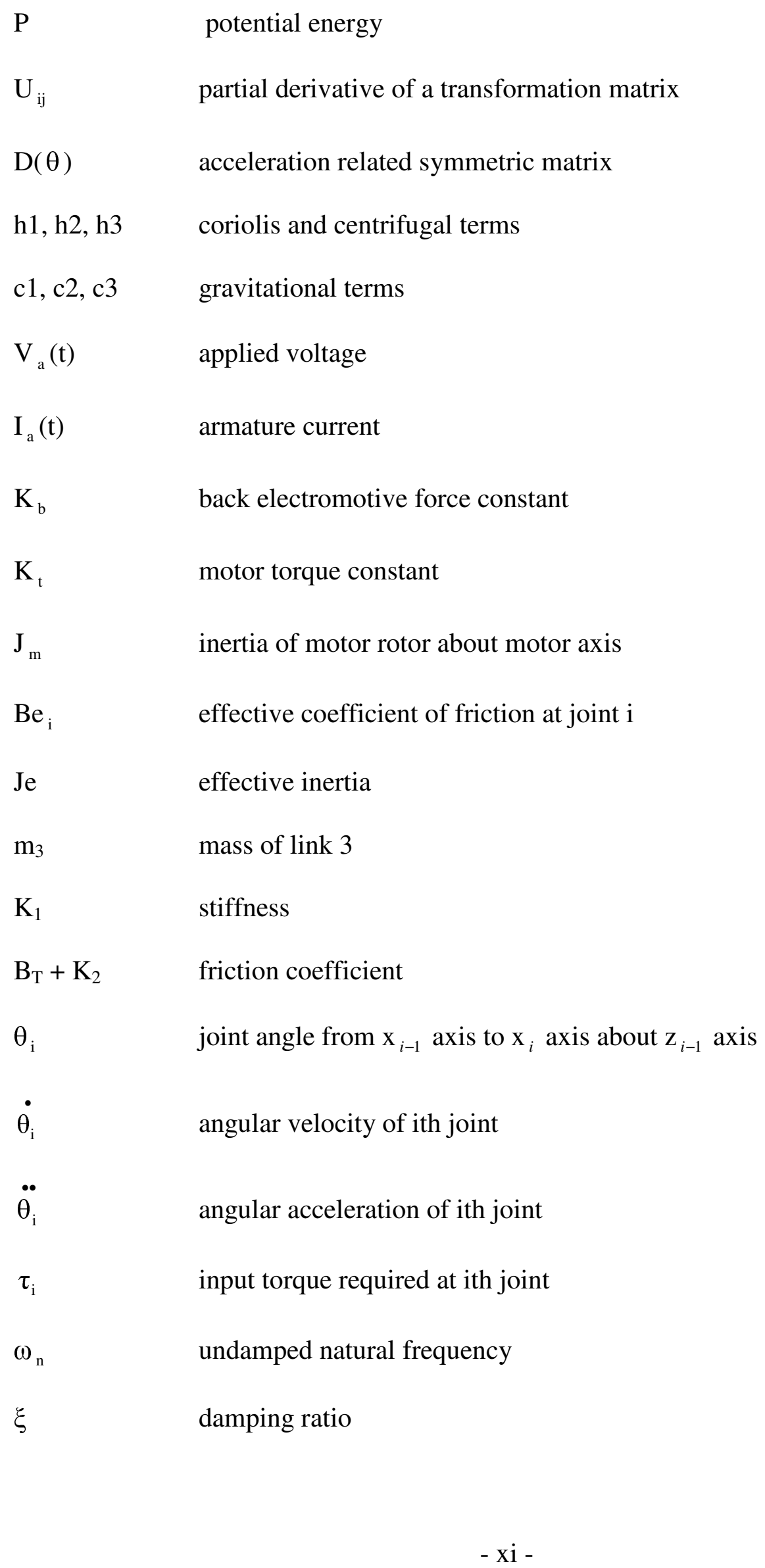


$\mathrm{K}_{\mathrm{p}}, \mathrm{K}_{\mathrm{d}}, \mathrm{K}_{\mathrm{i}} \quad$ PID controller gains

E(s) error actuating signal

$\theta_{\mathrm{L}}(\mathrm{s}) \quad$ actual angular displacement

$\theta_{L}^{d}(s) \quad$ desired angular displacement

- xii - 


\section{List of Tables}

Table No.

2.1 Link and Joint Parameters of SCARA-Type Robot

4.1 Trajectory Planning using Excel

4.2 Joint Angle Variation of Three Joints for Pick-to-Place Task

4.3 Cartesian Position for the corresponding Joint Angles

5.1 Actuator Characteristics to Compute Open \& Closed Loop Transfer Function Model for SCARA-Type Robot

5.2 Moments of inertia of the Three Links
Page No.

13

32

38

39

53

54 


\section{Chapter 1 \\ Introduction}

\subsection{OVERVIEW OF LASER GLASS CUTTING MACHINE}

The Laser Glass Cutting Machine (LGCM) is a new development in the field of automation to perform a glass-cutting operation, especially after hot glassware is removed from the mold. The traditional crack-off approach for glass cutting in the cold shop requires high skill and is a time-consuming job. Laser cutting is an emerging technology for improved product quality and reduced material cost in hand glass industries, thus minimizing waste. This technology also reduces energy usage and hazards to workers, since exposure to sharp edges and broken pieces are minimized. Hand glass manufacturers can use this enhanced technology since the speed and efficiency it offers can increase throughput and reduce costs [1]. A SCARA-Type robot work cell is used is conjunction with a laser to perform the above-mentioned task. This work cell handles the hot glassware to be cut with precision, and the laser performs the cut (see Figure 1.1). After the cut is made, the task of the SCARA-Type robot is to put the finished glassware on a turntable. This movement of the robot should be precise to place the glassware exactly into the position to be cut by the laser.

\subsection{NOMENCLATURE OF THE WORKCELL}

The Laser Glass Cutting Machine consists of several components. These components are used to accomplish the task of making a cut in the glassware. Figure 1.2 shows all the components of the LGCM. The bold words in the figure show the components on which this thesis is based. 


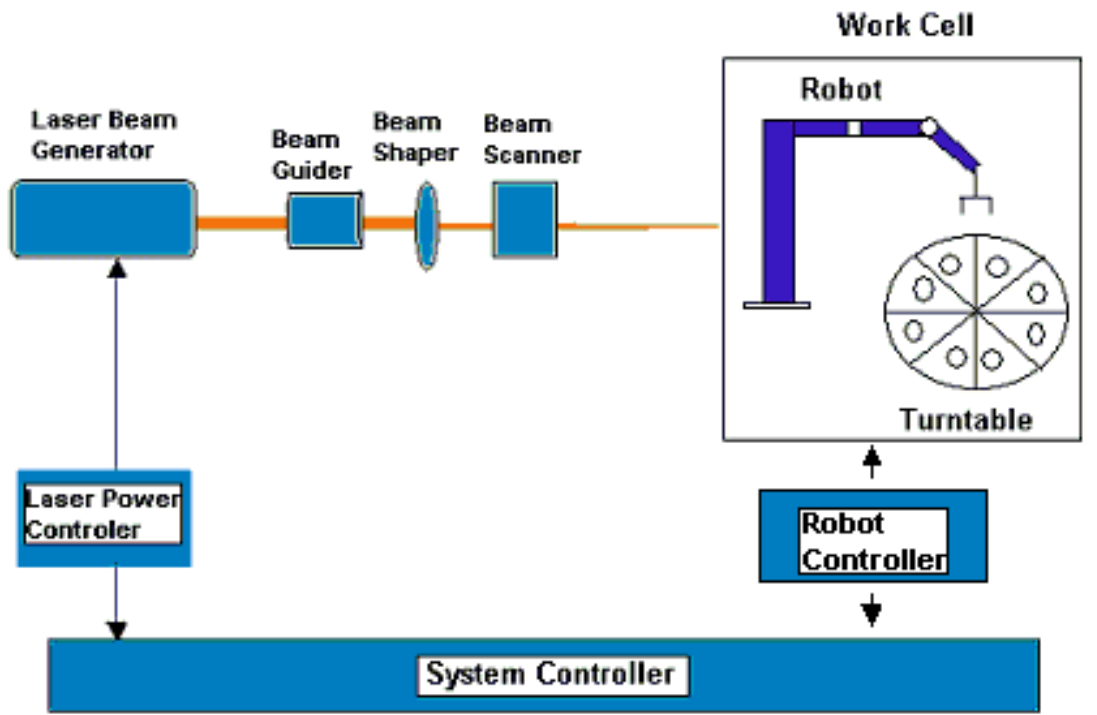

Fig 1.1 Schematic Diagram of Laser Glass Cutting Machine

\subsection{DESCRIPTION OF SCARA-TYPE NIMBL ROBOT}

The Selective Compliance Assembly Robot Arm (SCARA) is a relatively desirable robot configuration for certain industrial applications. One version of the SCARA robot arm is a SCARA-Type four-degree-of-freedom mechanism, with four links connected by three revolute joints. A conventional SCARA robot has two revolute joints and one translation motion joint. It is also called as RRP type robot. This robot is called as SCARA-Type robot since it is modified version of conventional SCARA robot. Instead of RRP type robot it is RRR robot i.e. it has three revolute joints. The modified version is made to behave as a SCARA robot by adding an extra link to third joint so that the extra link forms a parallelogram with the third link so that the end-effector moves in vertical plane like a prismatic joint. The first two revolute joints move links 1 and 2 in the horizontal plane and the third revolute joint moves a parallelogram link in the vertical plane (Figure 1.3 [2]) so that the motion is like a translational motion. These robot arms are often used for simple three-dimensional motion that uses a gripper as an end-effector, such as pick-and-place or assembly line sorting. 


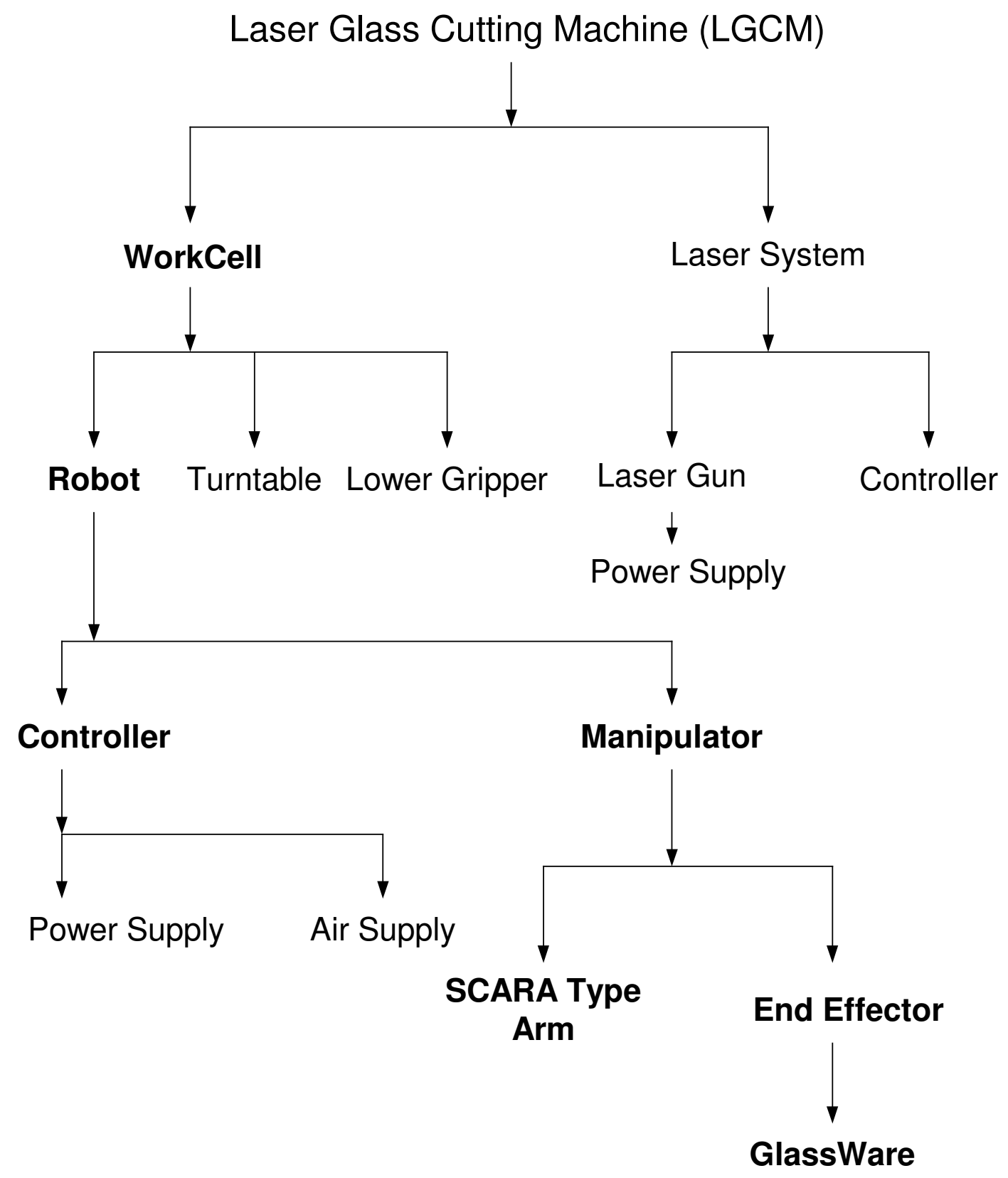

Fig 1.2 Components of the Laser Glass Cutting Machine

The bold word in Figure 1.2 shows the components on which this thesis is based. 


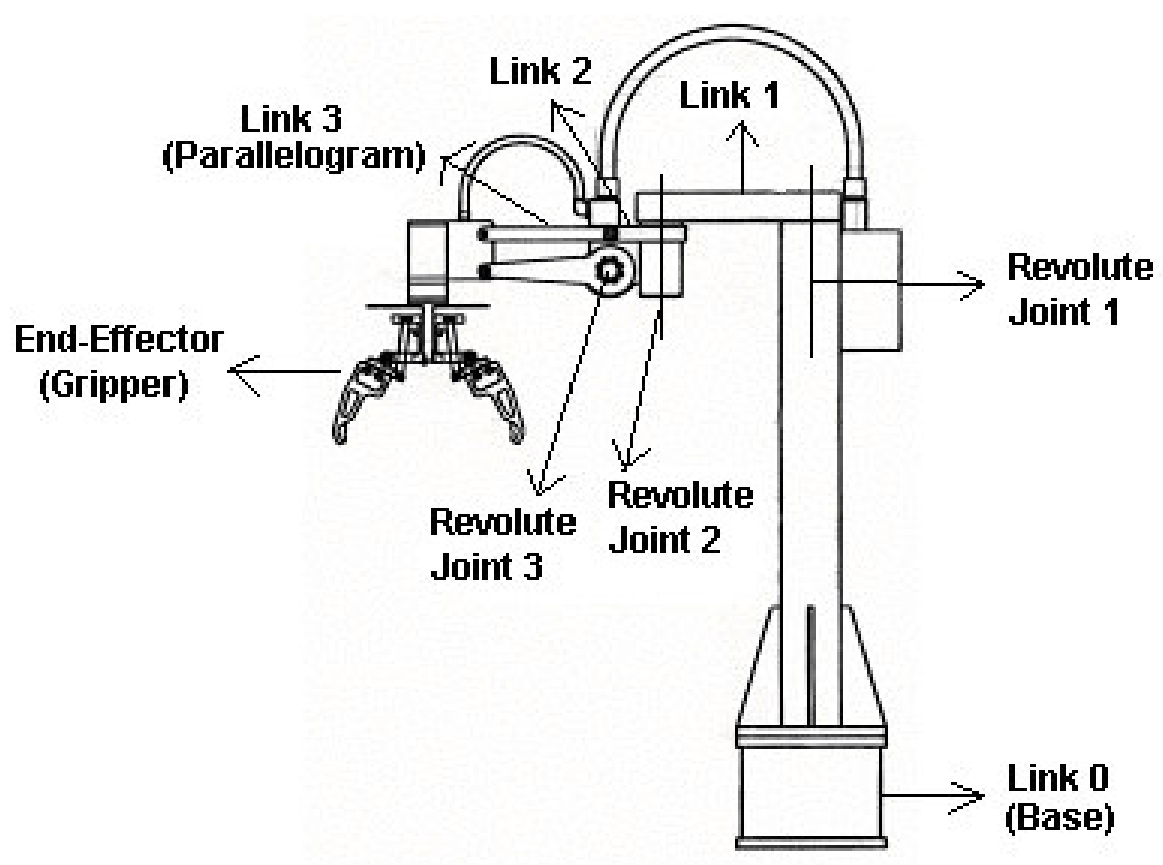

Fig 1.3 Side-view drawing of SCARA-Type Robot [2]

\subsection{LITERATURE REVIEW AND BACKGROUND}

The SCARA-Type Nimbl Robot is a three revolute joint (RRR) robot. This robot is classified as a SCARA-Type robot with none of its motion prismatic, as the revolute motion of the third joint is set perpendicular to the revolute motions of the other two joints. The revolute motion of the third joint is in the vertical plane. This is clear from Figure 1.3 [2]. This makes the kinematic mechanism of the SCARA-Type robot very interesting. For the three main links of the SCARA-Type Nimbl Junior Robot, the Denavit-Hartenberg [4] $4 \times 4$ notation to describe the links in terms of the coordinate frames will be utilized.

The work in this thesis is based mostly on the formulations presented by C.S.G.Lee, et al [4]. The formulation of the dynamic equations of motion is done using Lagrange-Euler (L-E) formulation [4]. The L-E method presents a systematic and an organized way of determining the dynamic equations of motion, but the computation involved in the L-E method makes it unsuitable for real-time control purposes [4]. The advantage of using the L-E formulation is that it provides explicit equations for the robot 
dynamics and can be utilized to analyze and design advanced joint-variable space control strategies [4].

\subsection{RESEARCH OBJECTIVES}

The eight main objectives of this research are:

1) Develop a kinematic model for the SCARA-Type robot.

2) Determine the inverse kinematics solution for the SCARA-Type robot to determine the joint angles for a specified robot task.

3) Determine the dynamic equations of motion of this SCARA-Type robot using Lagrange-Euler formulation.

4) Develop workspace trajectory motion in terms of joint space motion.

5) Develop dynamic model for actuator.

6) Develop integrated joint dynamic model for the SCARA-Type robot.

7) Develop closed-loop controller using a classical approach.

8) Perform experimental verification study of the SCARA-Type robot. 


\section{Chapter 2 \\ Kinematics of SCARA-Type Robot}

\subsection{OBJECTIVE}

A mechanical manipulator is a closed or open kinematic chain mechanism consisting of a sequence of $\mathrm{N}$ rigid links. Each pair of robot links is connected by revolute or prismatic joints. Each joint is driven by an actuator directly or via a mechanical linkage mechanism and each joint constitutes one degree of freedom. The last link is connected to a terminal device, called as end-effector, for manipulating an object. The motion of the end-effector is usually specified in terms of Cartesian space coordinates, but typically the control of robot position is performed in terms of joint space coordinates. The kinematic analysis of mechanical manipulators deals with the study of the relation between these two space coordinates and consist of two problems:

1. Given the joint positions of the manipulator, determine the position and orientation of the manipulator end-effector with respect to the Cartesian coordinate system at the manipulator base (base coordinate frame).

2. Given manipulator end-effector position and orientation with respect to a base coordinate frame, determine the joint positions required.

The position and orientation of the robot end-effector with respect to the base coordinate frame can be determined by means of homogeneous transformation [4]. This transformation is calculated by a series of rotations and translations about the manipulator links and is known as forward transformation. In case of second problem above, the elements of the forward transformation matrices are known, and the problem becomes one of solving the equations of the forward transformation for the joint angles. This is referred to as inverse transformation.

The mechanical manipulator is usually composed of an arm and a wrist attached to an end-effector. The arm typically has three DOF, which is the minimum number of DOF required to place the end-effector at any position in the workspace. Thus the arm is major positioning mechanism. In this thesis, only the kinematics analysis of the arm will be presented since the main objective is to design a positional controller. 
The objective of this chapter is to determine the forward kinematics and inverse kinematics of the SCARA-Type robot. The forward kinematics consists in part of finding the position and orientation of the end-effector of the manipulator given particular joint angles $\theta_{\mathrm{i}}$ and the geometric link parameters; i.e. what is the position and orientation of the end-effector of the robot with respect to a reference coordinate system. Inverse kinematics is important in determining the joint angles for a given end-effector location.

\subsection{SPECIFIED LGCM TASK}

The Laser Glass Cutting Machine (LGCM) is a new development in the field of glassware making technology. In the traditional process, molten glass from the batch tank is removed using a blowpipe. After the glass is blown into the required shape using a mold, the blown glassware is annealed and sent to cold shop. In the cold shop, the moil is removed from the glassware by crack-off and then the surface of the glass product is ground and polished to remove sharp edges [1]. Existing glass crack-off methods often result in considerable loss of glassware and require subsequent finishing of the edges, which is labor intensive and can result in further glass product losses [1]. Depending on the glassware piece, glass properties, and worker skill level, losses can be as high as 80 percent in some product lines and often-average 40 percent of total scrap for some products [1].

The laser-enhanced cutting and finishing method will dramatically decrease waste, which will improve productivity in the manufacture of the hand blown glass.

The LGCM Plant Prototype includes a lower gripper and turntable as shown in Figure 2.1. The function of the robot is to handle the glassware at high temperature in the hot shop i.e., to place the hot glassware in the correct position in front of laser. The task of the laser is to cut and polish the molded glassware, while the task of the robot is to move the glassware in front of laser, rotate the glassware while the cut is being performed and placing back the glassware on the turntable. After the cut is completed with glassware edges polished, the task of the robot is to then place the glassware back on the turntable. The robot arm, lower gripper and turntable together with the robot controller are known as a workcell. 


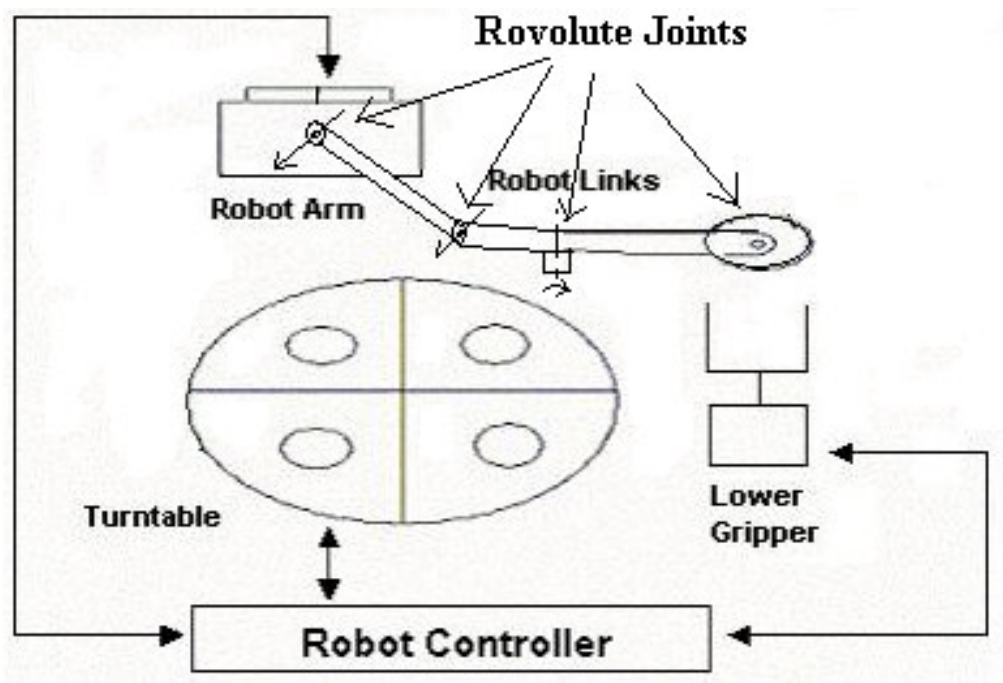

Fig. 2.1 Schematic of LGCM Plant Prototype Workcell

\subsection{METHODOLOGY}

The Denavit-Hartenberg representation [4,6] was used to develop the overall homogeneous transformation matrices for the robot arm. A goal matrix, which denotes the position and orientation that the endeffector should obtain, was defined. Then, an inverse kinematic [4,6] model was developed using matrix manipulations [7]. The goal matrix input for this model was the position and orientation of the endeffector in Cartesian coordinates as well as unit directional vectors $\mathrm{n}$, o and a. The output of this model was the angles of the three joints for the links to achieve the goal position in the robot workspace.

\section{Analysis was done using MATLAB (Appendix A)}

The homogeneous transformation matrices which are based from the coordinate frames of the robot links are entered as code into Matlab. The equations for the joint angles of the robot were calculated mathematically from the joint angle equations. 


\subsection{KINEMATIC ANALYSIS OF SCARA-TYPE ROBOT}

Robot arm kinematics [5] involve the geometry of robot arm motions with respect to a fixed reference coordinate system as a function of time without regard to the forces and moments that cause the motions. In a kinematic analysis [5], distinction is made between direct kinematics and inverse kinematics.

The direct kinematics [5] involves finding the location (position and orientation) of the end-effector given particular joint angles $\theta_{\mathrm{i}}$, whereas the inverse kinematics involves finding the joint angles for a given location of the end-effector with respect to a fixed reference coordinate system.

Inverse kinematics $[4,6]$ is important in trajectory planning [4,15]. In planning a movement of the manipulator (a component of the robot as shown in Figure 1.2), one is primarily interested in the Cartesian position of the end-effector with respect to the Cartesian space of the manipulator base. At a given end-effector position in Cartesian space, one must solve for the corresponding set of robot joint angles. This is inverse kinematics.

In this thesis, the main objective is to derive the inverse kinematic solution for a kinematic chain mechanism of a SCARA-Type robot arm. Kinematic description of spatial linkages based on Denavit-Hardenberg notation $[4,6]$ will be introduced. The assignment of coordinate frames and the definition of transformation matrices, which describe the relationship between two coordinate frames of the links, will also be presented. Once the transformation matrices are specified, the solution of the inverse kinematics can be derived.

\subsection{HOMOGENEOUS TRANSFORMATION MATRICES}

A $3 \times 3$ rotation matrix [4] can describe the orientation of a link-attached frame with respect to the frame of the robot's previous link. The matrix representation of rotation of coordinate frame with respect to coordinate frame of previous frame is represented by vectors $\mathrm{i}, \mathrm{j}, \mathrm{k}$ and the translation of the origin of the link coordinate frame with respect to the origin of the coordinate frame of the previous link is represented by 
position vector $\overline{\mathrm{p}}$. Cartesian coordinates are used to represent a link's position vector in 3-D space. The rotation matrix and position vector are then combined to form a $4 \mathrm{x} 4$ homogeneous transformation [4] matrix that defines the translational and rotational position of the link-attached coordinate frame with respect to the reference coordinate frame. Denavit and Hartenberg [4, 6] first introduced this application of a $4 \times 4$ homogeneous transformation matrix to a rigid link. The representation of the robot arm link can be expressed as the product of four homogeneous transformations [5] relating each link's coordinate frame to the previous link's coordinate frame. This mathematically expressed relationship is known as an A matrix, as shown in Equation (2.1) [4].

$$
A=\left[\begin{array}{cc}
R_{3 \times 3} & P_{3 \times 1} \\
0 & 1
\end{array}\right]
$$

This matrix defines the rotation matrix $\mathrm{R}_{3 \times 3}$ and the position vector $\mathrm{P}_{3 \times 1}$ expressed in homogeneous coordinates from one coordinate frame to the coordinate frame of the previous link frame of the link.

\subsection{DENAVIT-HARTENBERG REPRESENTATION}

To describe the transitional or rotational relationship between adjacent links, Denavit-Hartenberg (D-H) $[4,6]$ proposed a matrix method of systematically establishing a coordinate system (body-attached frames) to each rigid link (see Figure 2.2 [7]). The D-H representation results in a 4 x 4 homogeneous transformation matrix representing each rigid link's coordinate system with respect to the previous link. Thus, through sequential transformations, the end-effector frame expressed in end-effector coordinates $\left(\mathrm{X}_{\mathrm{E}}, \mathrm{Y}_{\mathrm{E}}, \mathrm{Z}_{\mathrm{E}}\right)$ can be expressed in base coordinates $\left(\mathrm{X}_{\mathrm{O}}, \mathrm{Y}_{\mathrm{O}}, \mathrm{Z}_{\mathrm{O}}\right)$. According to the $\mathrm{D}-\mathrm{H}$ representation, an orthogonal Cartesian coordinate system $\left(\mathrm{X}_{\mathrm{i}}, \mathrm{Y}_{\mathrm{i}}, \mathrm{Z}_{\mathrm{i}}\right)$ can be established for each rigid link at its joint axis, where $\mathrm{i}=1,2, \ldots \mathrm{n} \quad(\mathrm{n}=$ number of degrees of freedom). Thus, for this SCARA-Type robot in the LGCM, the location of the endeffector can be described in terms of four link coordinate frames, namely $\left(\mathrm{x}_{0}, \mathrm{y}_{0}, \mathrm{z}_{0}\right),\left(\mathrm{x}_{1}\right.$, $\left.\mathrm{y}_{1}, \mathrm{z}_{1}\right),\left(\mathrm{x}_{2}, \mathrm{y}_{2}, \mathrm{z}_{2}\right)$ and $\left(\mathrm{x}_{3}, \mathrm{y}_{3}, \mathrm{z}_{3}\right)$. 


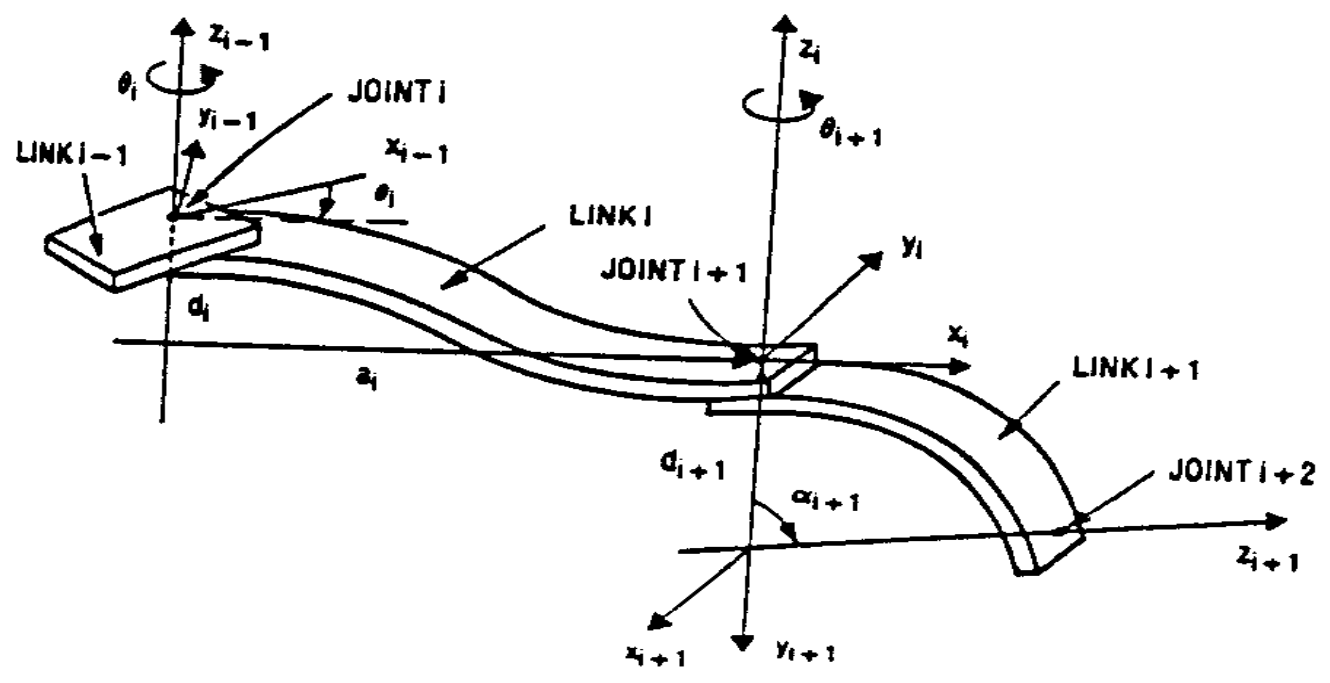

Fig 2.2 Coordinate Frames for i-1, i and i+1 Rigid Links, and Associated Link-Joint Parameters [7]

- $\quad \theta_{\mathrm{i}}$ - angle from $\mathrm{x}_{\mathrm{i}-1}$ axis to $\mathrm{x}_{\mathrm{i}}$ about $\mathrm{z}_{\mathrm{i}-1}$ axis using right-hand rule.

- $\quad \mathrm{d}_{\mathrm{i}}$ - distance from origin of (i-1) ${ }^{\text {th }}$ coordinate frame to intersection of $\mathrm{z}_{\mathrm{i}-1}$ axis with $\mathrm{x}_{\mathrm{i}}$ axis along $\mathrm{z}_{\mathrm{i}-1}$ axis.

- $\quad \mathrm{a}_{\mathrm{i}}$-distance from intersection of $\mathrm{z}_{\mathrm{i}-1}$ axis with $\mathrm{x}_{\mathrm{i}}$ axis to intersection of $\mathrm{z}_{\mathrm{i}}$ axis with $\mathrm{x}_{\mathrm{i}}$ axis.

- $\quad \alpha_{\mathrm{i}} \quad$-angle from $\mathrm{z}_{\mathrm{i}-1}$ axis to $\mathrm{z}_{\mathrm{i}}$ axis about $\mathrm{x}_{\mathrm{i}}$ axis using right-hand rule. 


\subsection{SCARA-TYPE ROBOT COORDINATE FRAME SYSTEM}

Side View of Workcell

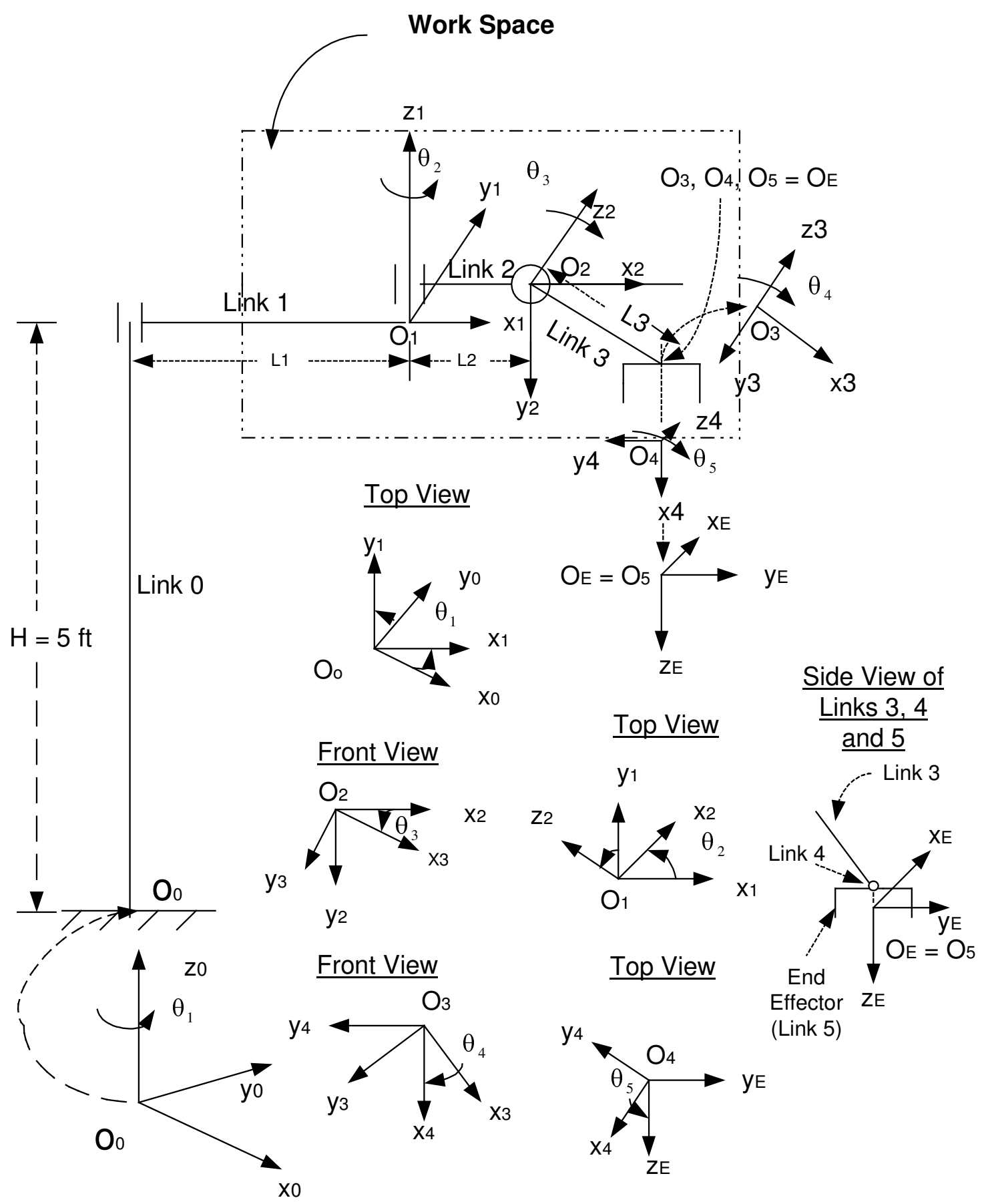

Fig. 2.3 Coordinate Frame Assignments and Associated Link-Joint Parameters for SCARA-Type Robot 
$\theta_{1}, \theta_{2}, \theta_{3}, \theta_{4}$ and $\theta_{5}$ are the angles of rotation for joint 1 , joint 2 , joint 3 , joint 4 , and joint 5 respectively. Joint 1 and joint 2 of the robot rotate in the horizontal plane, joint 3 and joint 4 rotate in vertical plane and joint 5 rotates in horizontal plane. The lengths of link 4 and link 5 are assumed to be zero so that the end-effector can be considered at the end of link 3. For the cut to be perfect, the SCARA-Type robot should handle the glassware such that the end-effector always rotates in the horizontal plane i.e. the end-effector should always face down. To achieve this, the sum of angles $\theta_{3}$ and $\theta_{4}$ is equal to 90 degrees i.e. $\theta_{3}+\theta_{4}=90$. This assumption will always make the endeffector rotate in horizontal plane. To simplify the calculations, the rotation of joint 5 is fixed i.e. $\theta_{5}=0$.

\section{$2.8 \quad$ KINEMATIC SOLUTION OF SCARA-TYPE ROBOT}

\subsubsection{Direct Kinematic Model}

Direct kinematic [4, 6] modeling involves computing basic rotation matrices as discussed in Section 2.2 using D-H representation. Direct kinematic modeling is also

used to find homogeneous transformation matrix ${ }^{\mathrm{i}-1} \mathrm{~A}_{\mathrm{i}}$ between link $\mathrm{i}$ and link $\mathrm{i}-1$. After determining the homogeneous transformation matrices, the overall homogenous transformation matrix ${ }^{\mathrm{O}} \mathrm{T}_{\mathrm{E}}$ is calculated.

Table 2.1 Link and Joint Parameters of SCARA-Type robot

\begin{tabular}{|c|c|c|c|c|}
\hline I & $\mathrm{a}_{\mathrm{i}}$ & $\alpha_{\mathrm{i}}$ & $\mathrm{d}_{\mathrm{i}}$ & $\theta_{\mathrm{i}}$ \\
\hline 1 & $\mathrm{~L} 1$ & 0 & $\mathrm{H}$ & $\theta_{1}$ \\
\hline 2 & $\mathrm{~L} 2$ & $-90^{\circ}$ & 0 & $\theta_{2}$ \\
\hline 3 & $\mathrm{~L} 3$ & 0 & 0 & $\theta_{3}$ \\
\hline
\end{tabular}


Dimensions of the Links:

$$
\begin{aligned}
& \mathrm{L} 1=1.70 \text { feet. } \\
& \mathrm{L} 2=0.72 \text { feet. } \\
& \mathrm{L} 3=1.27 \text { feet. } \\
& \mathrm{H}=5.00 \text { feet. }
\end{aligned}
$$

In case of a link $i$ with a revolute joint, $\mathrm{d}_{\mathrm{i}}, \mathrm{L}_{\mathrm{i}}, \alpha_{\mathrm{i}}$ are the three link-joint parameters that remain constant, while $\theta_{\mathrm{i}}$ is the joint variable that changes when link i rotates with respect to $Z_{i-1}$ of the link i-1 frame [4].

The next step is to determine the homogenous transformation matrix ${ }^{\circ} \mathrm{T}_{\mathrm{i}}$ which specifies the location of the $\mathrm{i}^{\text {th }}$ coordinate frame with respect to the fixed base coordinate frame. The matrix representation [4] which accomplishes this is the product of the successive coordinates transformation matrices of ${ }^{\mathrm{i}-1} \mathrm{~A}_{\mathrm{i}}$ matrices. ${ }^{\mathrm{i}-1} \mathrm{~A}_{\mathrm{i}}$ refers to the $4 \mathrm{x} 4$ homogeneous transformation matrix which establishes the position and orientation of the link i with respect to link i-1 frame. Thus, the ${ }^{\circ} \mathrm{T}_{\mathrm{n}}$ matrix can be expressed as shown in Equation (2.2) [4].

$$
{ }^{\mathrm{o}} \mathrm{T}_{\mathrm{n}}={ }^{\mathrm{o}} \mathrm{A}_{1}{ }^{* 1} \mathrm{~A}_{2} \ldots \ldots \cdot{ }^{\mathrm{n}-1} \mathrm{~A}_{\mathrm{n}}
$$

To determine the $4 \times 4{ }^{\mathrm{i}-1} \mathrm{~A}_{\mathrm{i}}$ homogenous transformation matrices [4, pg 41], the following general form of matrix for a rotation link is used:

$$
{ }^{\mathrm{i}-1} \mathrm{~A}_{\mathrm{i}}=\left[\begin{array}{cccc}
\mathrm{C} \theta_{\mathrm{i}} & -\mathrm{S} \theta_{\mathrm{i}} \mathrm{C} \alpha_{\mathrm{i}} & \mathrm{S} \theta_{\mathrm{i}} \mathrm{S} \alpha_{\mathrm{i}} & \operatorname{LiC} \theta_{\mathrm{i}} \\
\mathrm{S} \theta_{\mathrm{i}} & \mathrm{C} \theta_{\mathrm{i}} \mathrm{C} \alpha_{\mathrm{i}} & -\mathrm{C} \theta_{\mathrm{i}} \mathrm{S} \alpha_{\mathrm{i}} & \operatorname{LiS} \theta_{\mathrm{i}} \\
0 & \mathrm{~S} \alpha_{\mathrm{i}} & \mathrm{C} \alpha_{\mathrm{i}} & \mathrm{di} \\
0 & 0 & 0 & 1
\end{array}\right]
$$

The basic matrices for this SCARA-Type robot are ${ }^{0} \mathrm{~A}_{1},{ }^{1} \mathrm{~A}_{2},{ }^{2} \mathrm{~A}_{3},{ }^{3} \mathrm{~A}_{4}$ and ${ }^{4} \mathrm{~A}_{\mathrm{E}}$ and which are computed as: 


$$
\begin{array}{rlrl}
{ }^{0} \mathrm{~A}_{1} & =\left[\begin{array}{cccc}
\mathrm{C} 1 & -\mathrm{S} 1 & 0 & \mathrm{~L} 1 \mathrm{C} 1 \\
\mathrm{~S} 1 & \mathrm{C} 1 & 0 & \mathrm{~L} 1 \mathrm{~S} 1 \\
0 & 0 & 1 & \mathrm{H} \\
0 & 0 & 0 & 1
\end{array}\right] & { }^{1} \mathrm{~A}_{2}=\left[\begin{array}{cccc}
\mathrm{C} 2 & 0 & -\mathrm{S} 2 & \mathrm{~L} 2 \mathrm{C} 2 \\
\mathrm{~S} 2 & 0 & \mathrm{C} 2 & \mathrm{~L} 2 \mathrm{~S} 2 \\
0 & -1 & 0 & 0 \\
0 & 0 & 0 & 1
\end{array}\right] \\
{ }^{2} \mathrm{~A}_{3} & =\left[\begin{array}{cccc}
0 & -\mathrm{S} 3 & \mathrm{C} 3 & \mathrm{~L} 3 \mathrm{C} 3 \\
0 & \mathrm{C} 3 & \mathrm{~S} 3 & \mathrm{~L} 3 \mathrm{~S} 3 \\
1 & 0 & 0 & 0 \\
0 & 0 & 0 & 1
\end{array}\right] & { }^{3} \mathrm{~A}_{4}=\left[\begin{array}{cccc}
\mathrm{C} 4 & -\mathrm{S} 4 & 0 & 0 \\
\mathrm{~S} 4 & \mathrm{C} 4 & 0 & 0 \\
0 & 0 & 1 & 0 \\
0 & 0 & 0 & 1
\end{array}\right] \\
{ }^{4} \mathrm{~A}_{\mathrm{E}} & =\left[\begin{array}{cccc}
0 & -\mathrm{S} 5 & \mathrm{C} 5 & 0 \\
0 & -\mathrm{C} 5 & -\mathrm{S} 5 & 0 \\
1 & 0 & 0 & 0 \\
0 & 0 & 0 & 1
\end{array}\right] & &
\end{array}
$$

since $\theta_{5}$ is assumed to be zero for simplification, ${ }^{4} \mathrm{~A}_{\mathrm{E}}$ can be rewritten as:

$$
{ }^{4} \mathrm{~A}_{\mathrm{E}}=\left[\begin{array}{cccc}
0 & 0 & 1 & 0 \\
0 & -1 & 0 & 0 \\
1 & 0 & 0 & 0 \\
0 & 0 & 0 & 1
\end{array}\right]
$$

where Si represents $\sin \theta_{\mathrm{i}}$,

Ci represents $\cos \theta_{\mathrm{i}}$,

Li represents the length of link i

Also,

$$
\begin{aligned}
& { }^{1} \mathrm{~A}_{\mathrm{o}}={ }^{\mathrm{o}} \mathrm{A}_{1}^{-1} \\
& { }^{2} \mathrm{~A}_{1}={ }^{1} \mathrm{~A}_{2}^{-1} \\
& { }^{3} \mathrm{~A}_{2}={ }^{2} \mathrm{~A}_{3}^{-1} \\
& { }^{4} \mathrm{~A}_{3}={ }^{3} \mathrm{~A}_{4}^{-1}
\end{aligned}
$$


Thus, the overall homogeneous transformation matrix ${ }^{0} \mathrm{~T}_{\mathrm{E}}$ is:

$$
\begin{gathered}
{ }^{0} \mathrm{~T}_{\mathrm{E}}={ }^{0} \mathrm{~A}_{1} * 1 \mathrm{~A}_{2} *{ }^{2} \mathrm{~A}_{3} *{ }^{3} \mathrm{~A}_{4} *{ }^{4} \mathrm{~A}_{\mathrm{E}} \\
{ }^{0} \mathrm{~T}_{\mathrm{E}}=\left[\begin{array}{lrrr}
-\mathrm{S} 12, & \mathrm{C} 12, & 0, & 1 / 2 * \mathrm{~L} 3 * \cos \left(\theta_{1}+\theta_{2}-\theta_{3}\right)+1 / 2 * \mathrm{~L} 3 * \cos \left(\theta_{1}+\theta_{2}+\theta_{3}\right) \\
+\mathrm{L} 2 * \mathrm{C} 12+\mathrm{L} 1 * \mathrm{C} 1 & \\
\mathrm{C} 12, & \mathrm{~S} 12, & 0, & 1 / 2 * \mathrm{~L} 3 * \sin \left(\theta_{1}+\theta_{2}+\theta_{3}\right)+1 / 2 * \mathrm{~L} 3 * \sin \left(\theta_{1}+\theta_{2}-\theta_{3}\right) \\
+\mathrm{L} 2 * \mathrm{~S} 12+\mathrm{L} 1 * \mathrm{~S} 1 & & \\
0, & 0, & -1, & -\mathrm{L} 3 * \sin \left(\theta_{3}\right)+\mathrm{H} \\
0, & 0, & 0, & 1
\end{array}\right]
\end{gathered}
$$

\subsubsection{INVERSE KINEMATIC SOLUTION}

An inverse kinematic solution is necessary when one considers moving the endeffecter through a specified motion. For this SCARA-Type robot, a specified endeffector location ${ }^{\circ} \mathrm{T}_{\text {goal }}$ is equal to the product of four homogeneous transformation matrices ${ }^{0} \mathrm{~T}_{\mathrm{E}}$ shown in Equation (2.4) [4].

$$
{ }^{0} \mathrm{~T}_{\text {goal }}=\left[\begin{array}{cccc}
\mathrm{nx} & \text { ox } & \text { ax } & \mathrm{px} \\
\mathrm{ny} & \text { oy } & \text { ay } & \mathrm{py} \\
\mathrm{nz} & \mathrm{oz} & \text { az } & \mathrm{pz} \\
0 & 0 & 0 & 1
\end{array}\right]
$$

Thus, the goal matrix is equal to the product of four homogeneous transformation matrices.

$$
{ }^{0} \mathrm{~T}_{\mathrm{E}}={ }^{0} \mathrm{~T}_{\text {goal }}
$$

where ${ }^{0} \mathrm{~T}_{\text {goal }}$ is the desired position and orientation of the end-effector.

Equation (2.4) is also called the direct kinematic equation for this robot arm. For the inverse kinematic solution, the transformation matrix ${ }^{0} \mathrm{~T}_{\mathrm{E}}$, which relates the $\mathrm{E}^{\text {th }}$ 
coordinate frame to $0^{\text {th }}$ coordinate frame, is given for a certain position and orientation of the end-effector [6]. Thus, the elements of the right-hand-side matrix of Equation (2.4) are known but the joint angles of the left-hand-side matrix are not known.

The technique by Paul [4] is applied to solve for joint angle variables from Equation (2.6). This technique is based on equating matrices. Each successive variable is isolated from the right-hand side of Equation (2.4) by pre-multiplying successive inverse matrices on both sides. Knowing that ${ }^{\mathrm{i}} \mathrm{A}_{\mathrm{i}-1}=\left({ }^{\mathrm{i}-1} \mathrm{~A}_{\mathrm{i}}\right)^{-1}$, three equations are obtained as shown in Equations (2.7), (2.8) and (2.9):

$$
\begin{aligned}
& { }^{1} \mathrm{~A}_{0} *{ }^{0} \mathrm{~T}_{\text {goal }}={ }^{1} \mathrm{~A}_{2} *{ }^{2} \mathrm{~A}_{3} *{ }^{3} \mathrm{~A}_{4} *{ }^{4} \mathrm{~A}_{\mathrm{E}} \\
& { }^{0} \mathrm{~T}_{\text {goal }}{ }^{*} \mathrm{~A}_{4} *{ }^{4} \mathrm{~A}_{3} *{ }^{3} \mathrm{~A}_{2}={ }^{0} \mathrm{~A}_{1} *{ }^{1} \mathrm{~A}_{2} \\
& { }^{1} \mathrm{~A}_{0} *{ }^{0} \mathrm{~T}_{\text {goal }} *{ }^{\mathrm{E}} \mathrm{A}_{4} *{ }^{4} \mathrm{~A}_{3}{ }^{*} \mathrm{~A}_{2}={ }^{1} \mathrm{~A}_{2}
\end{aligned}
$$

By equating corresponding elements of these equated matrices in Equations (2.7), (2.8), and (2.9), the robot joint angles are determined.

Also, ${ }^{0} \mathrm{~T}_{\mathrm{E}}={ }^{0} \mathrm{~T}_{\text {goal }}$ when the arm matrix matches the goal matrix.

To solve for $\theta_{1}$, consider Equation (2.7). The left-hand side of Equation (2.7) is:

$$
\begin{gathered}
{\left[\begin{array}{cccc}
\mathrm{C} 1 & \mathrm{~S} 1 & 0 & -\mathrm{L} 1 \\
-\mathrm{S} 1 & \mathrm{C} 1 & 0 & 0 \\
0 & 0 & 1 & -\mathrm{H} \\
0 & 0 & 0 & 1
\end{array}\right] *\left[\begin{array}{cccc}
\mathrm{nx} & \mathrm{ox} & \mathrm{ax} & \mathrm{px} \\
\mathrm{ny} & \text { oy } & \text { ay } & \mathrm{py} \\
\mathrm{nz} & \mathrm{oz} & \mathrm{az} & \mathrm{pz} \\
0 & 0 & 0 & 1
\end{array}\right]} \\
=\left[\begin{array}{cccc}
\mathrm{nx} * \mathrm{C} 1+\mathrm{ny} * \mathrm{~S} 1, & \mathrm{ox} * \mathrm{C} 1+\mathrm{oy} * \mathrm{~S} 1, & \mathrm{ax} * \mathrm{C} 1+\mathrm{ay} * \mathrm{~S} 1, & \mathrm{px} * \mathrm{C} 1+\mathrm{py} * \mathrm{~S} 1-\mathrm{L} 1 \\
\mathrm{nx} * \mathrm{~S} 1+\mathrm{ny} * \mathrm{C} 1, & \mathrm{ox} * \mathrm{~S} 1+\mathrm{oy} * \mathrm{C} 1, & \mathrm{ax} * \mathrm{~S} 1+\mathrm{ay} * \mathrm{C} 1, & \mathrm{px} * \mathrm{~S} 1+\mathrm{py} * \mathrm{C} 1 \\
\mathrm{nz}, & \mathrm{oz}, & \mathrm{az}, & \mathrm{pz}-\mathrm{H} \\
0, & 0, & 0, & 1
\end{array}\right]
\end{gathered}
$$


and the right-hand side of the Equation (2.7) is,

$$
\left[\begin{array}{rrrc}
-\mathrm{S} 2, & \mathrm{C} 2, & 0, & \mathrm{C} 2 *(\mathrm{~L} 3 * \mathrm{C} 3+\mathrm{L} 2) \\
\mathrm{C} 2, & \mathrm{~S} 2, & 0, & \mathrm{~S} 2 *(\mathrm{~L} 3 * \mathrm{C} 3+\mathrm{L} 2) \\
0, & \mathrm{C} 3, & -1, & -\mathrm{L} 3 * \mathrm{~S} 3 \\
0, & 0, & 0, & 1
\end{array}\right]
$$

Now, equating the $(3,4)$ elements and the $(3,2)$ elements in Equation $(2.7)$ yields,

$$
-\mathrm{S} 3 * \mathrm{~L} 3=\mathrm{pz}-\mathrm{H}
$$

Thus,

$$
\mathrm{S} 3=\frac{\mathrm{H}-\mathrm{pz}}{\mathrm{L} 3}
$$

Hence from the Pythagoras theorem,

$$
\tan \theta_{3}=\frac{\mathrm{H}-\mathrm{pz}}{\left(\mathrm{L} 3^{2}-(\mathrm{H}-\mathrm{pz})^{2}\right)^{\wedge} 0.5}
$$

Therefore,

$$
\theta_{3}=\operatorname{Atan} 2\left(\frac{\mathrm{H}-\mathrm{pz}}{\left(\mathrm{L} 3^{2}-(\mathrm{H}-\mathrm{pz})^{2}\right)^{\wedge} 0.5}\right)
$$

From Equation (2.8),

$$
{ }^{0} \mathrm{~T}_{\text {goal }} *{ }^{\mathrm{E}} \mathrm{A}_{4} *{ }^{4} \mathrm{~A}_{3} *{ }^{3} \mathrm{~A}_{2}={ }^{0} \mathrm{~A}_{1} *{ }^{1} \mathrm{~A}_{2}
$$

The left-hand side of Equation (2.8) is:

$$
=\left[\begin{array}{cccc}
\text { ox }, & \text { ax, } & \text { nx, } & - \text { ax } * \mathrm{~L} 3 * \mathrm{~S} 3-\text { ox } * \mathrm{~L} 3 * \mathrm{C} 3+\mathrm{px} \\
\mathrm{oy}, & \text { ay, } & \mathrm{ny}, & -\mathrm{ay} * \mathrm{~L} 3 * \mathrm{~S} 3-\mathrm{oy} * \mathrm{~L} 3 * \mathrm{C} 3+\mathrm{py} \\
\mathrm{oz}, & \mathrm{az}, & \mathrm{nz}, & -\mathrm{az} * \mathrm{~L} 3 * \mathrm{~S} 3-\mathrm{L} 3 * \mathrm{oz} * \mathrm{C} 3+\mathrm{pz} \\
0, & 0, & 0, & 1
\end{array}\right]
$$

while the right-hand side of Equation (2.8) is:

$$
=\left[\begin{array}{rrrc}
\mathrm{C} 12, & 0, & -\mathrm{S} 12, & \mathrm{~L} 2 * \mathrm{C} 12+\mathrm{L} 1 * \mathrm{C} 1 \\
\mathrm{~S} 12, & 0, & \mathrm{C} 12, & \mathrm{~L} 2 * \mathrm{~S} 12+\mathrm{L} 1 * \mathrm{~S} 1 \\
0, & -1, & 0, & \mathrm{H} \\
0, & 0, & 0, & 1
\end{array}\right]
$$

Equating the $(1,4)$ elements and $(2,4)$ elements in Equation $(2.8)$ yields

$$
\mathrm{L} 2 * \mathrm{C} 12+\mathrm{L} 1 \mathrm{C} 1=-\mathrm{ax} * \mathrm{~L} 3 * \mathrm{~S} 3-\mathrm{ox} * \mathrm{~L} 3 * \mathrm{C} 3+\mathrm{px} \text {, and }
$$




$$
\mathrm{L} 2 * \mathrm{~S} 12+\mathrm{L} 1 \mathrm{~S} 1=- \text { ay } * \mathrm{~L} 3 * \mathrm{~S} 3-\mathrm{oy} * \mathrm{~L} 3 * \mathrm{C} 3+\text { py }
$$

Equating the $(1,1)$ and $(2,1)$ elements in Equation $(2.8)$ yields,

$$
\begin{aligned}
& \mathrm{C} 12=\mathrm{ox}, \text { and } \\
& \mathrm{S} 12=\mathrm{oy}
\end{aligned}
$$

Substituting Equations (2.13) and (2.14) in Equations (2.11) and (2.12) yields,

$$
\theta_{1}=\operatorname{Atan} 2\left[\frac{-\mathrm{L} 3^{*} \mathrm{ay} y^{*}(\mathrm{H}-\mathrm{pz})-\mathrm{L} 3^{*} \mathrm{oy} *\left(\mathrm{~L} 3^{2}-(\mathrm{H}-\mathrm{pz})^{2}\right)^{0.5}+\mathrm{py}^{*} \mathrm{~L} 3-\mathrm{L} 2^{*} \mathrm{~L} 3^{*} \mathrm{oy}}{-\mathrm{L} 3^{*} \mathrm{ax} *(\mathrm{H}-\mathrm{pz})-\mathrm{L} 3^{*} \mathrm{ox} *\left(\mathrm{~L} 3^{2}-(\mathrm{H}-\mathrm{pz})^{2}\right)^{0.5}+\mathrm{px}{ }^{*} \mathrm{~L} 3-\mathrm{L} 2^{*} \mathrm{~L}^{*} \mathrm{ox}}\right](2 .
$$

To solve for $\theta_{2}$, Equation (2.7) is used:

$$
{ }^{1} \mathrm{~A}_{0} *{ }^{0} \mathrm{~T}_{\text {goal }}={ }^{1} \mathrm{~A}_{2} *{ }^{2} \mathrm{~A}_{3} *{ }^{3} \mathrm{~A}_{4} *{ }^{4} \mathrm{~A}_{\mathrm{E}}
$$

The right-hand side of Equation (2.7) is:

$$
\left[\begin{array}{rrrc}
-\mathrm{S} 2, & \mathrm{C} 2, & 0, & \mathrm{C} 2 *(\mathrm{~L} 3 * \mathrm{C} 3+\mathrm{L} 2) \\
\mathrm{C} 2, & \mathrm{~S} 2, & 0, & \mathrm{~S} 2 *(\mathrm{~L} 3 * \mathrm{C} 3+\mathrm{L} 2) \\
0, & \mathrm{C} 3, & -1, & -\mathrm{L} 3 * \mathrm{~S} 3 \\
0, & 0, & 0, & 1
\end{array}\right]
$$

The left-hand side of the Equation (2.7) is:

$$
\left[\begin{array}{cccc}
\mathrm{nx} * \mathrm{C} 1+\mathrm{ny} * \mathrm{~S} 1, & \mathrm{ox} * \mathrm{C} 1+\mathrm{oy} * \mathrm{~S} 1, & \mathrm{ax} * \mathrm{C} 1+\mathrm{ay} * \mathrm{~S} 1, & \mathrm{px} * \mathrm{C} 1+\mathrm{py} * \mathrm{~S} 1-\mathrm{L} 1 \\
\mathrm{nx} * \mathrm{~S} 1+\mathrm{ny} * \mathrm{C} 1, & \mathrm{ox} * \mathrm{~S} 1+\mathrm{oy} * \mathrm{C} 1, & \mathrm{ax} * \mathrm{~S} 1+\mathrm{ay} * \mathrm{C} 1, & \mathrm{px} * \mathrm{~S} 1+\mathrm{py} * \mathrm{C} 1 \\
\mathrm{nz}, & \mathrm{oz}, & \mathrm{az}, & \mathrm{pz}-\mathrm{H} \\
0, & 0, & 0, & 1
\end{array}\right]
$$

Equating the $(1,4)$ and $(2,4)$ elements in Equation $(2.7)$ yields,

$$
\begin{aligned}
& \mathrm{S} 2 *(\mathrm{~L} 3 * \mathrm{C} 3+\mathrm{L} 2)=-\mathrm{S} 1 * \mathrm{px}+\mathrm{C} 1 * \mathrm{py}, \text { and } \\
& \mathrm{C} 2 *(\mathrm{~L} 3 * \mathrm{C} 3+\mathrm{L} 2)=\mathrm{C} 1 * \mathrm{px}+\mathrm{S} 1 * \mathrm{py}-\mathrm{L} 1
\end{aligned}
$$

Dividing Equation (2.16) by (2.17) and simplifying then yields,

$$
\theta_{2}=\operatorname{Atan} 2\left[\frac{-\mathrm{S} 1 * \mathrm{px}+\mathrm{C} 1 * \mathrm{py}}{\mathrm{C} 1 * \mathrm{px}+\mathrm{S} 1 * \mathrm{py}-\mathrm{L} 1}\right]
$$

Verification of inverse kinematic model is shown in Appendix A. 


\subsection{SUMMARY}

In this chapter, the procedure for obtaining the inverse kinematic solution for the LGCM robot was presented. Starting by introducing the coordinate frames assignments and homogeneous transformations, the equations for the inverse kinematic solution for this SCARA-Type robot were obtained. Kinematics validation study was done to verify different positions of end-effector in the workspace. 


\section{Chapter 3 \\ Dynamics of SCARA-Type Robot}

\subsection{METHODOLOGY}

The dynamic equations of motion are used to develop the dynamic model [5] for the arm. These dynamic equations of motion for three joints, which give the torques required by the actuators to perform the motion, are developed using Lagrange-Euler (L-E) formulation [4]. The simulation for torques vs time is done using Excel. The input to this dynamic model is the angle, velocity and acceleration of each joint. The output will be the torque required by the actuator to move the joint at any given time of the pickto-place trajectory.

\section{Analysis using Matlab (Appendix D) and EXCEL}

The torques for the three joints of the SCARA-Type robot were derived using the L-E formulation. Matlab produces results using the inertia, Coriolis and centrifugal and gravitational terms. The equations for torque for the three joints were also derived using Matlab. Excel was used to plot the torque equations.

\subsection{LAGRANGE-EULER FORMULATION}

The equations of motion of the manipulator can be derived through direct application of the L-E formulation [4, 8] to conservative systems. The DenavitHartenberg [4, 6] matrix representation is used to describe the spatial displacement between adjacent link coordinate frames to obtain link kinematic information. The L-E formulation is utilized to find the dynamics equations of motion for this SCARA-Type robot. The L-E formulation coupled with the Denavit-Hartenberg link-joint parameters representation provided a systematic approach to and description of the equations of motion $[4,8]$. 
The Lagrange-Euler equation is:

$$
\frac{\mathrm{d}}{\mathrm{dt}}\left[\frac{\partial \mathrm{L}}{\partial \mathrm{qi}}\right]-\frac{\partial \mathrm{L}}{\partial \mathrm{qi}}=\tau_{\mathrm{i}} \quad \mathrm{i}=1,2,3, \ldots \ldots, \mathrm{n}
$$

where,

$\mathrm{L}=$ Lagrangian function $=$ Kinetic energy $\mathrm{K}-$ Potential energy $\mathrm{P}$

$\mathrm{K}=$ Total kinetic energy of the robot arm

$\mathrm{P}=$ Total potential energy of the robot arm

$\mathrm{qi}=$ Generalized coordinates of the robot

$\dot{\mathrm{qi}}=$ First time derivative of the generalized coordinates of the robot arm

$\tau_{\mathrm{i}}=$ Generalized force (or torque) applied to the system at joint $\mathrm{i}$ to drive link i.

The Kinetic energy K of the system is [4]:

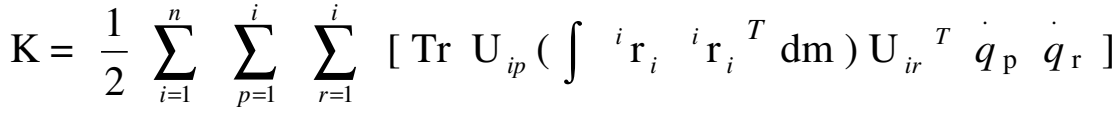

$$
\begin{aligned}
& \mathrm{K}=\frac{1}{2} \sum_{i=1}^{n} \sum_{p=1}^{i} \sum_{r=1}^{i}\left[\operatorname{Tr}\left(\mathrm{U}_{i p} \mathrm{~J}_{\mathrm{i}} \mathrm{U}_{i r}{ }^{T}\right) \dot{q}_{\mathrm{p}} \dot{q}_{\mathrm{r}}\right] \\
& \text { where: } \quad \mathrm{J}_{\mathrm{i}}=\int{ }^{i} \mathrm{r}_{i}{ }^{i} \mathrm{r}_{i}{ }^{T} \mathrm{dm}
\end{aligned}
$$

$\mathrm{U} i j=\left\{\begin{array}{l}{ }^{0} \mathrm{~A}_{\mathrm{j}-1} \mathrm{Q}_{\mathrm{j}}{ }^{\mathrm{j}-1} \mathrm{~A}_{\mathrm{i}}------------------->\mathrm{j} \leq \mathrm{i} \\ 0---------------------------->\mathrm{j} \phi \mathrm{i}\end{array}\right.$

The matrix $Q_{j}$ is:

$$
\mathrm{Q}_{\mathrm{j}}=\left[\begin{array}{cccc}
0 & -1 & 0 & 0 \\
1 & 0 & 0 & 0 \\
0 & 0 & 0 & 0 \\
0 & 0 & 0 & 0
\end{array}\right] \quad \text { (for revolute joints) }
$$

The partial derivative of ${ }^{j-1} \mathrm{~A}_{j}$ with respect to $q i$ can be determined by premultiplying ${ }^{j-1} \mathrm{~A}_{j}$ with $\mathrm{Q}_{\mathrm{j}}$ matrix. 
The matrix Uij is the rate of change of the points $\left({ }^{i} r_{i}\right)$ on the link i relative to the base coordinate frame [4]. It is constant for all points on link i and independent of mass distribution of link i. Also qi is independent of the mass distribution of the link $i$.

Matrix Ji is a pseudo-inertia matrix [4]. The moments of inertia of the link's [4,9] are determined for the three links of the LGCM robot and are used to calculate the $\mathrm{J}_{\mathrm{i}}$ for each of the three links.

The potential energy $\mathrm{P}$ of the robot arm is given by [4]:

$$
\mathrm{P}=\sum_{\mathrm{i}=1}^{\mathrm{n}}-\mathrm{m}_{\mathrm{i}} \mathrm{g}\left({ }^{\mathrm{o}} \mathrm{A}_{\mathrm{i}}{ }^{\mathrm{i}} \mathrm{r}_{\mathrm{i}}\right)
$$

where,

$$
\begin{aligned}
& \mathrm{g}=\text { Gravitational constant } \\
& \mathrm{m}_{\mathrm{i}}=\text { Mass of ith link } \\
& { }^{\mathrm{i}} \mathrm{r}_{\mathrm{i}}=\text { Fixed point in link } \mathrm{i} \text { and expressed in homogeneous coordinates with } \\
& \quad \text { respect to the ith link coordinate frame. }
\end{aligned}
$$

\subsection{EQUATIONS OF MOTION FOR THE MANIPULATOR}

The Lagrangian function ( $\mathrm{L}=\mathrm{K}-\mathrm{P})$ for the robot is [4]:

$$
\mathrm{L}=\frac{1}{2} \sum_{i=1}^{n} \sum_{p=1}^{i} \sum_{r=1}^{i}\left[\operatorname{Tr}\left(\mathrm{U}_{\mathrm{ip}} \mathrm{J}_{\mathrm{i}} \mathrm{U}_{i r}{ }^{T}\right) \dot{q}_{\mathrm{p}} \dot{q}_{\mathrm{r}}\right]+\sum_{i=1}^{n} m_{i} g\left({ }^{o} A_{i}{ }^{i} r_{i}\right)
$$

Applying the Lagrangian function to the Lagrange-Euler formulation of the robot arm yields the generalized torque $\tau_{i}$ for the joint $i$ actuator to drive the ith link of the manipulator. That is,

$$
\begin{aligned}
\tau_{\mathrm{i}}=\frac{\mathrm{d}}{\mathrm{dt}}\left[\frac{\partial \mathrm{L}}{\partial \dot{\mathrm{q} i}}\right]-\frac{\partial \mathrm{L}}{\partial \dot{\mathrm{q} i}} \quad \mathrm{i}=1,2,3, \ldots \ldots, \mathrm{n} \\
=\sum_{j=i}^{n} \sum_{k=1}^{j}\left[\operatorname{Tr}\left(\mathrm{U}_{j k} \mathrm{~J}_{i} \mathrm{U}^{T}{ }_{j i}\right) \ddot{q}_{k}\right]+\sum_{j=i}^{n} \sum_{k=1}^{j} \sum_{m=1}^{j}\left[\operatorname{Tr}\left(\mathrm{U}_{j k m} \mathrm{~J}_{\mathrm{i}} \mathrm{U}_{j i} i^{T}\right) \dot{q}_{\mathrm{k}} \dot{q}_{\mathrm{m}}\right] \\
-\sum_{j=i}^{n} \mathrm{~m}_{j} \mathrm{~g} \mathrm{U}_{i j}{ }_{j} \bar{r}_{j}
\end{aligned}
$$


Equation (3.6) can also be written as:

$$
\tau_{\mathrm{i}}=\sum_{k=1}^{n} \mathrm{D}_{\mathrm{ik}} \ddot{q}_{k}+\sum_{k=1}^{n} \sum_{m=1}^{n} \mathrm{~h}_{i k m} \dot{q}_{k} \dot{q}_{m}+\mathrm{C}_{i}
$$

or, in matrix form:

$$
\tau(\mathrm{t})=\mathrm{D}[\theta(\mathrm{t})] \ddot{\theta}(\mathrm{t})+\mathrm{h}[\theta(\mathrm{t}), \dot{\theta}(\mathrm{t})]+\mathrm{c}[\theta(\mathrm{t})]
$$

Here,

$$
\begin{aligned}
& \mathrm{D}(\theta)=\text { an } \mathrm{n} \mathrm{x} \mathrm{n} \text { inertial acceleration-related matrix whose elements } \mathrm{D}_{\mathrm{ik}} \text { are } \\
& \mathrm{D}_{i k}=\sum_{j=\max (i, k)}^{n} \operatorname{Tr}\left(\mathrm{U}_{j k} \mathrm{~J}_{i} \mathrm{U}^{T}{ }_{j i}\right) \quad \mathrm{i}, \mathrm{k}=1,2 \ldots \mathrm{n}
\end{aligned}
$$

Also,

$\mathrm{h}\left(\dot{\theta}_{i}, \theta_{i}\right)=$ an $\mathrm{n} x 1$ non-linear Coriolis and centrifugal force vector whose elements $\mathrm{h}_{i}$ are,

$$
\mathrm{h}_{i}=\sum_{k=1}^{n} \sum_{m=1}^{n} \mathrm{~h}_{i k m} \dot{q}_{k} \dot{q}_{m} \quad \mathrm{i}=1,2 \ldots \mathrm{n}
$$

with,

$$
\mathrm{h}_{i k m}=\sum_{j=\max (i, k, m)}^{n} \operatorname{Tr}\left(\mathrm{U}_{j k m} \mathrm{~J}_{\mathrm{i}} \mathrm{U}_{j i}{ }^{T}\right) \quad \mathrm{i}, \mathrm{k}, \mathrm{m}=1,2 \ldots, \mathrm{n}
$$

and,

$c(\theta)=$ an $n \times 1$ gravity loading force vector whose elements $c_{i}$ are

$$
\mathrm{c}_{i}=\sum_{j=i}^{n}\left(-\mathrm{m}_{j} \mathrm{~g} \mathrm{U}_{i j}^{j} \bar{r}_{j}\right) \quad \mathrm{i}=1,2 \ldots, \mathrm{n}
$$

where ${ }^{j} \bar{r}_{j}$ is a fixed point in link $\mathrm{j}$ and expressed in homogeneous coordinates with respect to the $\mathrm{j}^{\text {th }}$ link coordinate frame.

The coefficient $D_{i k}$ is related to the acceleration of the joint variable. For the case of $\mathrm{i}=\mathrm{k}$, the $\mathrm{D}_{i i}$ is related to the acceleration of the joint $\mathrm{i}$ where the driving torque $\tau_{\mathrm{i}}$ acts. In the case $\mathrm{i} \neq \mathrm{k}, \mathrm{D}_{i k}$ is related to the reaction torque induced by acceleration of joint $\mathrm{k}$ acting at joint i [8]. 
The coefficient $\mathrm{h}_{i k m}$ [4] is related to the velocity of the two associated joint variables. Indices $(\mathrm{k}, \mathrm{m})$ refer to the velocities of joints $\mathrm{k}$ and $\mathrm{m}$, whose dynamic interaction induces a torque at joint $\mathrm{i}$.

Coefficient $c_{i}$ [4] represents the gravity loading terms due to the weight of the links.

For this three-axis robot arm with rotary joints, the terms that form the acceleration-related symmetric matrix $\mathrm{D}(\theta)$ are:

$$
D(\theta)=\left[\begin{array}{lll}
D_{11} & D_{12} & D_{13} \\
D_{12} & D_{22} & D_{23} \\
D_{13} & D_{23} & D_{33}
\end{array}\right]
$$

The inertia terms $\left(\mathrm{D}_{\mathrm{ij}}\right.$ 's) of the acceleration-related symmetric matrix are obtained using Matlab and are presented in Appendix B1.

The velocity-related matrix is:

$$
\mathrm{h}(\theta, \dot{\theta})=\left[\begin{array}{l}
\mathrm{h}_{1} \\
\mathrm{~h}_{2} \\
\mathrm{~h}_{3}
\end{array}\right]
$$

The Coriolis and Centrifugal terms ( $\mathrm{h}_{\mathrm{i}}$ 's) are obtained using Matlab and the results are presented in Appendix B2.

The gravity-related matrix is given by:

$$
c(\theta)=\left[\begin{array}{l}
c_{1} \\
c_{2} \\
c_{3}
\end{array}\right]
$$

The gravitational terms $\left(\mathrm{c}_{\mathrm{i}}\right.$ 's) are obtained using Matlab and the results are presented in Appendix B3. 


\subsection{DETERMINATION OF THE J MATRIX}

From Equation (3.2) [4], it can be seen that the term inside the bracket, $\int{ }^{i} \mathrm{r}_{i}{ }^{i} \mathrm{r}_{i}{ }^{T} \mathrm{dm}$, is the inertia of all points on link $\mathrm{i}$, hence,

$$
\mathbf{J}_{\mathrm{i}}=\int{ }^{i} \mathrm{r}_{i}{ }^{i} \mathrm{r}_{i}{ }^{T} \mathrm{dm}=\left[\begin{array}{cccc}
\int \mathrm{x}_{\mathrm{i}}{ }^{2} \mathrm{dm} & \int \mathrm{x}_{\mathrm{i}} \mathrm{y}_{\mathrm{i}} \mathrm{dm} & \int \mathrm{x}_{\mathrm{i}} \mathrm{z}_{\mathrm{i}} \mathrm{dm} & \int \mathrm{x}_{\mathrm{i}} \mathrm{dm} \\
\int \mathrm{x}_{\mathrm{i}} \mathrm{y}_{\mathrm{i}} \mathrm{dm} & \int \mathrm{y}_{\mathrm{i}}{ }^{2} \mathrm{dm} & \int \mathrm{y}_{\mathrm{i}} \mathrm{z}_{\mathrm{i}} \mathrm{dm} & \int \mathrm{y}_{\mathrm{i}} \mathrm{dm} \\
\int \mathrm{x}_{\mathrm{i}} \mathrm{z}_{\mathrm{i}} \mathrm{dm} & \int \mathrm{y}_{\mathrm{i}} \mathrm{z}_{\mathrm{i}} \mathrm{dm} & \int \mathrm{z}_{\mathrm{i}}{ }^{2} \mathrm{dm} & \int \mathrm{z}_{\mathrm{i}} \mathrm{dm} \\
\int \mathrm{x}_{\mathrm{i}} \mathrm{dm} & \int \mathrm{y}_{\mathrm{i}} \mathrm{dm} & \int \mathrm{z}_{\mathrm{i}} \mathrm{dm} & \int \mathrm{dm}
\end{array}\right]
$$

where ${ }^{i} \mathrm{r}_{i}=\left(\mathrm{x}_{i}, \mathrm{y}_{i}, \mathrm{z}_{i}, 1\right)$. If we use inertia tensor $\mathrm{I}_{\mathrm{ij}}$ which is defined as [1]:

$$
\mathrm{I}_{\mathrm{ij}}=\int\left[\delta_{\mathrm{ij}}\left(\sum_{\mathrm{k}} \mathrm{x}_{\mathrm{k}}^{2}\right)-\mathrm{x}_{\mathrm{i}} \mathrm{x}_{\mathrm{j}}\right] \mathrm{dm}
$$

where the indices $\mathrm{i}, \mathrm{j}, \mathrm{k}$ indicates principal axes of ith coordinate frame and $\delta_{\mathrm{ij}}$ is called Kronecker delta, then $\mathrm{J}_{\mathrm{i}}$ can be expressed in inertia tensor as [4]:

$$
\mathbf{J}_{\mathrm{i}}=\left[\begin{array}{cccc}
\left(-\mathrm{I}_{\mathrm{xx}}+\mathrm{I}_{\mathrm{yy}}+\mathrm{I}_{\mathrm{zz}}\right) / 2 & \mathrm{I}_{\mathrm{xy}} & \mathrm{I}_{\mathrm{xz}} & \mathrm{m}_{\mathrm{i}} \overline{\mathrm{X}}_{\mathrm{i}} \\
\mathrm{I}_{\mathrm{xy}} & \left(\mathrm{I}_{\mathrm{xx}}-\mathrm{I}_{\mathrm{yy}}+\mathrm{I}_{\mathrm{zz}}\right) / 2 & \mathrm{I}_{\mathrm{yz}} & \mathrm{m}_{\mathrm{i}} \overline{\mathrm{y}}_{\mathrm{i}} \\
\mathrm{I}_{\mathrm{xz}} & \mathrm{I}_{\mathrm{yz}} & \left(\mathrm{I}_{\mathrm{xx}}+\mathrm{I}_{\mathrm{yy}}-\mathrm{I}_{\mathrm{zz}}\right) / 2 & \mathrm{~m}_{\mathrm{i}} \mathrm{Z}_{\mathrm{i}} \\
\mathrm{m}_{\mathrm{i}} \overline{\mathrm{x}}_{\mathrm{i}} & \mathrm{m}_{\mathrm{i}} \mathrm{y}_{\mathrm{i}} & \mathrm{m}_{\mathrm{i}} \mathrm{Z}_{\mathrm{i}} & \mathrm{m}_{\mathrm{i}}
\end{array}\right]
$$

where,

$I_{x x}=$ Moment of inertia of the ith link about the $x$-axis with respect to the $i^{\text {th }}$ coordinate frame,

$I_{y y}=$ Moment of inertia of the ith link about the $y$-axis with respect to the $i^{\text {th }}$ coordinate frame,

$I_{z z}=$ Moment of inertia of the ith link about the $\mathrm{z}$-axis with respect to the $i^{\text {th }}$ coordinate frame,

$\mathrm{I}_{\mathrm{xy}}, \mathrm{I}_{\mathrm{xz}}, \mathrm{I}_{\mathrm{yz}}=$ Products of inertia for $\mathrm{i}^{\text {th }}$ link,

$\mathrm{m}_{\mathrm{i}}=$ Mass of $\mathrm{i}^{\text {th }}$ link,

$\overline{\mathrm{X}}_{\mathrm{i}}=$ Distance from center of mass of the $\mathrm{i}^{\mathrm{th}}$ link to which coordinate frame in the direction of the $\mathrm{x}$-axis 
$\bar{y}_{i}=$ Distance from center of mass of the $i^{\text {th }}$ link to which coordinate frame in the direction of the $y$-axis

$\overline{\mathrm{Z}}_{\mathrm{i}}=$ Distance from center of mass of the $\mathrm{i}^{\text {th }}$ link to which coordinate frame in the direction of the $\mathrm{z}$-axis

The exact values of the moments of inertia cannot be determined exactly since the robot is not able to be dismantled. Therefore, estimated values have been determined by geometric approximation of the links of the SCARA-Type robot.

\section{Moments of Inertia for Link 1:}

Mass $=0.981 \mathrm{lbm}$.

Length $=1.70 \mathrm{ft}$.

Width $=0.42 \mathrm{ft}$.

Thickness $=0.26 \mathrm{ft}$.

The moments of inertia of link 1 are:

$$
\begin{aligned}
& I_{z z}=9.6 E-4 l b-\mathrm{ft}^{2} \\
& I_{y y}=9.37 E-4 l b-\mathrm{ft}^{2} \\
& I_{x x}=1.96 E-5 \mathrm{lb}-\mathrm{ft}^{2}
\end{aligned}
$$

\section{Moments of Inertia for Link 2:}

Mass $=1.44 \mathrm{E}-4 \mathrm{lbm}$.

Length $=0.72 \mathrm{ft}$.

Width $=0.30 \mathrm{ft}$.

Thickness $=0.131 \mathrm{ft}$.

The moments of inertia of link 2 are:

$$
\begin{aligned}
& \mathrm{I}_{\mathrm{zz}}=2.6 \mathrm{E}-5 \mathrm{lb}-\mathrm{ft}^{2} \\
& \mathrm{I}_{\mathrm{yy}}=2.5 \mathrm{E}-5 \mathrm{lb}-\mathrm{ft}^{2} \\
& \mathrm{I}_{\mathrm{xx}}=1.28 \mathrm{E}-6 \mathrm{lb}-\mathrm{ft}^{2}
\end{aligned}
$$




\section{Moments of Inertia for actuator on Link 2:}

The actuator in joint 2 of the robot has been modeled as a cylinder. The mass and dimensions of the cylinder are given below.

Mass $=0.513 \mathrm{lbm}$.

Height $=0.68 \mathrm{ft}$.

Radius $=0.18 \mathrm{ft}$.

The moments of inertia of the actuator for link 2 are:

$$
\begin{aligned}
& \mathrm{I}_{\mathrm{zz}}=2.27 \mathrm{E}-5 \mathrm{lb}-\mathrm{ft}^{2} \\
& \mathrm{I}_{\mathrm{yy}}=7.35 \mathrm{E}-5 \mathrm{lb}-\mathrm{ft}^{2} \\
& \mathrm{I}_{\mathrm{xx}}=7.37 \mathrm{E}-5 \mathrm{lb}-\mathrm{ft}^{2}
\end{aligned}
$$

Total moments of inertia of link 2 are:

$$
\begin{aligned}
& \mathrm{I}_{\mathrm{zz}}=2.6 \mathrm{E}-5 \mathrm{lb}-\mathrm{ft}^{2}+2.28 \mathrm{E}-5 \mathrm{lb}-\mathrm{ft}^{2}=4.8 \mathrm{E}-5 \mathrm{lb}-\mathrm{ft}^{2} \\
& \mathrm{I}_{\mathrm{yy}}=2.5 \mathrm{E}-5 \mathrm{lb}-\mathrm{ft}^{2}+7.35 \mathrm{E}-5 \mathrm{lb}-\mathrm{ft}^{2}=9.8 \mathrm{E}-5 \mathrm{lb}-\mathrm{ft}^{2} \\
& \mathrm{I}_{\mathrm{xx}}=1.28 \mathrm{E}-6 \mathrm{lb}-\mathrm{ft}^{2}+7.37 \mathrm{E}-5 \mathrm{slug}-\mathrm{ft}^{2}=7.5 \mathrm{E}-5 \mathrm{lb}-\mathrm{ft}^{2}
\end{aligned}
$$

\section{Moments of Inertia for Link 3:}

$$
\begin{aligned}
& \text { Mass }=1.4 \mathrm{E}-4 \mathrm{lbm} . \\
& \text { Length }=1.27 \mathrm{ft} . \\
& \text { Width }=0.164 \mathrm{ft} . \\
& \text { Thickness }=0.131 \mathrm{ft} . \\
& \mathrm{I}_{\mathrm{zz}}=7.53 \mathrm{E}-5 \mathrm{lb}-\mathrm{ft}^{2} \\
& \mathrm{I}_{\mathrm{yy}}=7.5 \mathrm{E}-5 \mathrm{lb}-\mathrm{ft}^{2} \\
& \mathrm{I}_{\mathrm{xx}}=5.12 \mathrm{E}-7 \mathrm{lb}-\mathrm{ft}^{2}
\end{aligned}
$$

\section{Moments of Inertia for actuator on Link 3:}

The actuator in joint 3 of the robot has been modeled as a cylinder. The mass and dimensions are given below.

$$
\begin{aligned}
& \text { Mass }=0.611 \mathrm{lbm} . \\
& \text { Height }=0.78 \mathrm{ft} .
\end{aligned}
$$


Radius $=0.18 \mathrm{ft}$.

The moments of inertia of the actuator for link 3 are:

$$
\begin{aligned}
& \mathrm{I}_{\mathrm{zz}}=6.62 \mathrm{E}-6 \mathrm{lb}-\mathrm{ft}^{2} \\
& \mathrm{I}_{\mathrm{yy}}=3.71 \mathrm{E}-5 \mathrm{lb}-\mathrm{ft}^{2} \\
& \mathrm{I}_{\mathrm{xx}}=3.71 \mathrm{E}-5 \mathrm{lb}-\mathrm{ft}^{2}
\end{aligned}
$$

The moments of inertia of the supporting link forming a parallogram, as shown in Figure 2.3, with link 3 is:

$$
\begin{aligned}
& \text { Mass }=0.0014 \mathrm{lbm} . \\
& \text { Length }=1.14 \mathrm{ft} . \\
& \text { Width }=0.098 \mathrm{ft} . \\
& \text { Thickness }=0.098 \mathrm{ft} . \\
& I_{z z}=2.44 \mathrm{E}-5 \mathrm{lb}-\mathrm{ft}^{2} \\
& I_{y y}=3.71 \mathrm{E}-5 \mathrm{lb}-\mathrm{ft}^{2} \\
& I_{x x}=1.27 \mathrm{E}-5 \mathrm{lb}-\mathrm{ft}^{2}
\end{aligned}
$$

Total moments of inertia of Link 3 including actuator and supporting link are:

$$
\begin{aligned}
& \mathrm{I}_{\mathrm{zz}}=7.53 \mathrm{E}-5 \mathrm{lb}-\mathrm{ft}^{2}+6.62 \mathrm{E}-6 \mathrm{lb}-\mathrm{ft}^{2}+2.44 \mathrm{E}-5 \mathrm{lb}-\mathrm{ft}^{2}=1.06 \mathrm{E}-4 \mathrm{lb}-\mathrm{ft}^{2} \\
& \mathrm{I}_{\mathrm{yy}}=7.5 \mathrm{E}-5 \mathrm{lb}-\mathrm{ft}^{2}+3.71 \mathrm{E}-5 \mathrm{lb}-\mathrm{ft}^{2}+3.71 \mathrm{E}-5 \mathrm{lb}-\mathrm{ft}^{2}=1.5 \mathrm{E}-4 \mathrm{lb}-\mathrm{ft}^{2} \\
& \mathrm{I}_{\mathrm{xx}}=5.12 \mathrm{E}-7 \mathrm{lb}-\mathrm{ft}^{2}+3.71 \mathrm{E}-5 \mathrm{lb}-\mathrm{ft}^{2}+1.27 \mathrm{E}-5 \mathrm{lb}-\mathrm{ft}^{2}=5 \mathrm{E}-5 \mathrm{lb}-\mathrm{ft}^{2}
\end{aligned}
$$

\subsection{TORQUE EQUATIONS FOR THE SCARA-TYPE ROBOT}

From the Lagrange-Euler formulation [1,5], the torque equations for each of the joints of the SCARA-type robot are given as below.

$$
\begin{aligned}
& \tau_{1}=\mathrm{D}_{11} \ddot{\theta 1}+\mathrm{D}_{12} \ddot{\theta} 2+\mathrm{D}_{13} \ddot{\theta} 3+\mathrm{h} 1+\mathrm{c} 1 \\
& \tau_{2}=\mathrm{D}_{12} \ddot{\theta} 1+\mathrm{D}_{22} \ddot{\theta} 2+\mathrm{D}_{23} \ddot{\theta} \ddot{3}+\mathrm{h} 2+\mathrm{c} 2
\end{aligned}
$$




$$
\tau_{3}=\mathrm{D}_{13} \ddot{\theta} 1+\mathrm{D}_{23} \ddot{\theta} 2+\mathrm{D}_{33} \ddot{\theta} \ddot{3}+\mathrm{h} 3+\mathrm{c} 3
$$

More detailed equations of the torques for the three joints of the SCARA-Type robot are shown in Appendix C.

\subsection{SUMMARY}

In this chapter, the formulation for obtaining the dynamics for the LGCM robot is presented. Starting with equations of motion for the manipulator and the moments of inertia of the links, the torque equations for this SCARA-Type robot are obtained. 


\section{Chapter 4 \\ Trajectory Planning}

\subsection{INTRODUCTION}

Trajectory planning $[4,15]$ is defining the movement of the robot arm through an end-effector path by interpolating the desired path by a set of polynomial functions and generating a sequence of time-based set points for the control of the manipulator from the start point to the end point. Path start and end points can be expressed in either joint or Cartesian coordinates [4]. Usually the path is specified in Cartesian coordinates because it is easier to visualize the correct end-effector configuration in Cartesian coordinates than in joint coordinates. Planning of the trajectory in joint coordinates has some advantages. The first one is that the trajectory is planned directly in terms of the controlled motion variables $[4, \mathrm{pg}$. 151]. Real time trajectory planning can be done. The disadvantage is that the end-effector motion is hard to visualize [4, pg.149]. The preferred method in which the planned motion can be approached is that the trajectory be planned in Cartesian coordinates and then the inverse kinematic solution is used to convert the Cartesian trajectory to corresponding joint angles at each point. To plan the trajectory in Cartesian coordinates, the path has to be divided into segments and desired path continuity constraints have to be maintained [4, pg.155]. Planning and execution of a defined task which would be expected to be performed in industry is task planning. In this chapter, Section 4.3 introduces the task that was planned for the 'pick-to-place' studies for the SCARA-Type robot. The chapter then goes through the trajectory planning.

\subsection{METHODOLOGY}

Trajectory planning for the manipulator is done using Excel. The 4-3-4 trajectory planning [4, pg.157, 15] is done mathematically in Excel to obtain three equations for three segments of the trajectory. The simulation of the trajectories is done in Excel as presented in Table 4.1 . 


\section{Analysis using EXCEL}

EXCEL is used to generate the required path of the trajectory. The lift-off and set-down positions are the inputs to determine the required trajectories for the three joints.

Table 4.1 Trajectory Planning Using Excel

\begin{tabular}{|c|c|c|c|}
\hline Theta0 & Theta1 & Theta2 & Theta3 \\
\hline 70.00 & 65.00 & 25.00 & 20.00 \\
\hline Delta1 (Theta1-Theta0) & Delta2 (Theta2-Theta1) & Delta3 (Theta3-Theta2) & \\
\hline-5.00 & -40.00 & -5.00 & \\
\hline $\begin{array}{c}\text { t1 (time for first segment } \\
\text { of trajectory) }\end{array}$ & $\begin{array}{c}\text { t2 (time for second } \\
\text { segment of trajectory) }\end{array}$ & $\begin{array}{r}\text { t3 (time for third } \\
\text { segment of trajectory) }\end{array}$ & \\
\hline 0.50 & 1.00 & 0.50 & \\
\hline & & & \\
\hline F & G & & \\
\hline-70.00 & 10.50 & & \\
\hline Zeta & & & \\
\hline-6.67 & & & \\
\hline v1 & A1 & & \\
\hline-26.67 & A2 & & \\
\hline v2 & 80.00 & & \\
\hline-26.67 & & & \\
\hline
\end{tabular}

Table 4.1 cont. Trajectory Planning Using Excel

\begin{tabular}{|c|c|c|c|}
\hline Time (sec) & Angle (degrees) & Velocity $(\mathrm{deg} / \mathrm{sec})$ & Acceleration $\left(\mathrm{deg} / \mathrm{sec}^{\wedge} 2\right)$ \\
\hline 0.00 & 70.00 & 0.00 & 0.00 \\
\hline 0.10 & 69.95 & -1.49 & -28.80 \\
\hline 0.20 & 69.62 & -5.55 & -51.20 \\
\hline 0.30 & 68.78 & -11.52 & -67.20 \\
\hline 0.40 & 67.27 & -18.77 & -76.80 \\
\hline 0.50 & 65.00 & -26.67 & -80.00 \\
\hline 0.60 & 61.96 & -33.87 & -64.00 \\
\hline 0.70 & 58.28 & -39.47 & -48.00 \\
\hline 0.80 & 54.12 & -43.47 & -32.00 \\
\hline 0.90 & 49.64 & -45.87 & -16.00 \\
\hline 1.00 & 45.00 & -46.67 & 0.00 \\
\hline 1.10 & 40.36 & -45.87 & 16.00 \\
\hline 1.20 & 35.88 & -43.47 & 32.00 \\
\hline
\end{tabular}




\begin{tabular}{|c|c|c|c|}
\hline 1.30 & 31.72 & -39.47 & 48.00 \\
\hline 1.40 & 28.04 & -33.87 & 64.00 \\
\hline 1.50 & 25.00 & -26.67 & 80.00 \\
\hline 1.60 & 22.73 & -18.77 & 76.80 \\
\hline 1.70 & 21.22 & -11.52 & 67.20 \\
\hline 1.80 & 20.38 & -5.55 & 51.20 \\
\hline 1.90 & 20.05 & -1.49 & 28.80 \\
\hline 2.00 & 20.00 & 0.00 & 0.00 \\
\hline
\end{tabular}

\subsection{TASK PLANNING FOR THE SCARA-TYPE ROBOT}

A pick-to-place task for the SCARA-Type robot has been defined. The robot arm moves the end-effector from the soft home position to the glassware pick position to pickup the glassware. The robot arm then moves the glassware to the place position in front of the laser gun for the cut in the glassware to be performed by the laser. After the cut is made, the robot arm moves the glassware back to the pick position and the robot arm moves back to the soft home position. The robot end-effector follows a minimum time trajectory [15] to accomplish its pick-to-place task. Theoretical trajectory planning is done for its task from pick position to place position of the glassware.

\subsection{TRAJECTORY PLANNING}

\subsubsection{4-3-4 Trajectory Planning}

In planning a 4-3-4 trajectory [4, pg.157] for a joint motion, the first segment is a fourth-degree polynomial and specifies the trajectory from initial position to lift-off position as shown in Figure 4.1 [4, pg.155]. The second segment is the third-degree polynomial and specifies the path trajectory from lift-off position to set-down position as shown in Figure 4.1 [4, pg.155]. The set-down position to final position as shown in Figure 4.1 is specified using a fourth-degree polynomial. The planning of the 4-3-4 trajectory is done using the following procedure. A normalized time variable, $t(0,1)$, is introduced to simplify the procedure to compute the 4-3-4 trajectory equations $[4,15]$. The three polynomial equations are follows:

$$
\begin{aligned}
& \mathrm{h}_{1}(\mathrm{t})=\mathrm{a}_{14} \mathrm{t}^{4}+\mathrm{a}_{13} \mathrm{t}^{3}+\mathrm{a}_{12} \mathrm{t}^{2}+\mathrm{a}_{11} \mathrm{t}+\mathrm{a}_{10} \text { (first segment: } 0 \leq \mathrm{t} \leq \mathrm{t}_{1} \text { ) } \\
& \left.\mathrm{h}_{2}(\mathrm{t})=\mathrm{a}_{23} \mathrm{t}^{3}+\mathrm{a}_{22} \mathrm{t}^{2}+\mathrm{a}_{21} \mathrm{t}+\mathrm{a}_{20} \text { (second segment: } \mathrm{t}_{1} \leq \mathrm{t} \leq \mathrm{t}_{2}\right)
\end{aligned}
$$




$$
\left.\mathrm{h}_{3}(\mathrm{t})=\mathrm{a}_{34} \mathrm{t}^{4}+\mathrm{a}_{33} \mathrm{t}^{3}+\mathrm{a}_{32} \mathrm{t}^{2}+\mathrm{a}_{31} \mathrm{t}+\mathrm{a}_{30} \text { (third segment: } \mathrm{t}_{2} \leq \mathrm{t} \leq \mathrm{t}_{3}\right)
$$

where $t$ is the normalized time.

The following 14 boundary conditions are specified in order to determine the 14 coefficient of these equations [4].

1. Initial position (at time $\left.\mathrm{t}_{0}\right)=\theta_{0}$

2. Magnitude of the initial velocity $=\mathrm{v}_{0}$

3. Magnitude of the initial acceleration $=a_{0}$

4. Lift-off position (at time $\left.\mathrm{t}_{1}\right)=\theta_{1}$

5. Continuity in position (at time $t_{1}$ )

$$
\theta\left(\bar{t}_{1}\right)=\theta\left(t_{1}^{+}\right)
$$

6. Continuity in velocity (at time $t_{1}$ )

$\dot{\theta}\left(\bar{t}_{1}\right)=\dot{\theta}\left(\stackrel{+}{t_{1}}\right)$

7. Continuity in acceleration (at time $t_{1}$ )

$\ddot{\theta}\left(\mathrm{t}_{1}\right)=\ddot{\theta}\left(\stackrel{+}{t_{1}}\right)$

8. Set down position (at time $\left.t_{2}\right)=\theta_{2}$

9. Continuity in position (at time $\mathrm{t}_{2}$ )

$\theta\left(\bar{t}_{2}\right)=\theta\left(t_{2}^{+}\right)$

10. Continuity in velocity (at time $t_{2}$ )

$\dot{\theta}\left(\vec{t}_{2}^{-}\right)=\dot{\theta}\left(t_{2}^{+}\right)$

11. Continuity in acceleration (at time $t_{2}$ )

$\ddot{\theta}\left(t_{2}^{-}\right)=\ddot{\theta}\left(t_{2}^{+}\right)$

12. Final position (at time $\left.t_{3}\right)=\theta_{3}$

13. Magnitude of final velocity $=v_{3}$

14. Magnitude of final acceleration $=a_{3}$ 


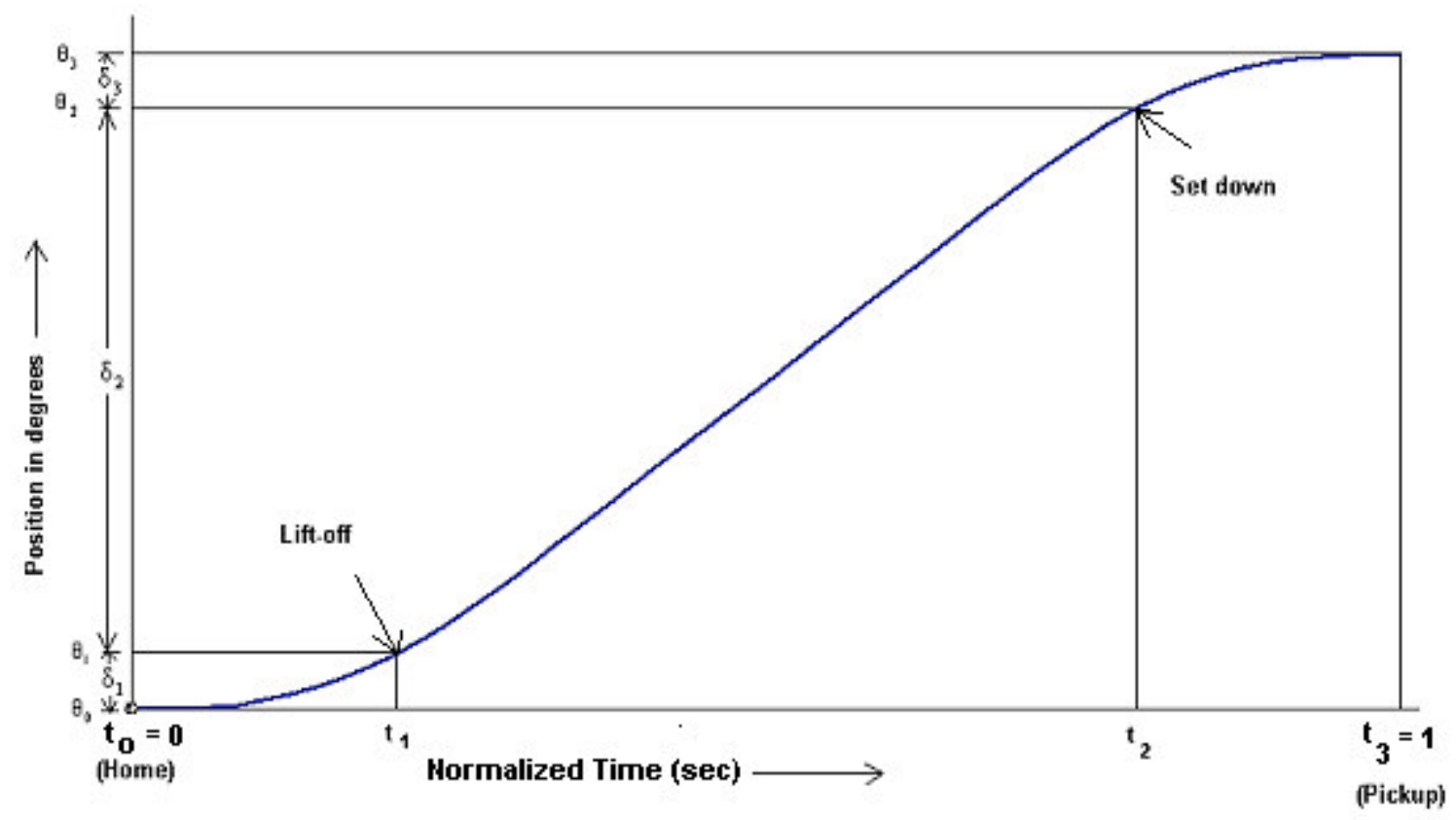

\subsection{Trajectory Planning for Joint Motion}

The resultant polynomial equations for the defined 4-3-4 trajectory are given as follows [4, pg.158]:

First trajectory segment:

$$
\mathrm{h}_{1}(\mathrm{t})=\left(\delta_{1}-\mathrm{v}_{0} \mathrm{t}_{1}-\mathrm{a}_{0} \mathrm{t}_{1}{ }^{2} / 2-\sigma\right) \mathrm{t}^{4}+\sigma \mathrm{t}^{3}+\left(\mathrm{a}_{0} \mathrm{t}_{1}{ }^{2} / 2\right) \mathrm{t}^{2}+\left(\mathrm{v}_{0} \mathrm{t}_{1}\right) \mathrm{t}+\theta_{0}
$$

where,

$$
\begin{aligned}
& \delta_{1}=\theta_{1}-\theta_{0} \\
& \sigma=\mathrm{f} / \mathrm{g}, \text { for which } \\
& \mathrm{f}=2 \delta_{1}\left(4+2 \mathrm{t}_{3} / \mathrm{t}_{2}+2 \mathrm{t}_{3} / \mathrm{t}_{1}+3 \mathrm{t}_{2} / \mathrm{t}_{1}\right)-\left(\delta_{2} \mathrm{t}_{1} / \mathrm{t}_{2}\right) *\left(3+\mathrm{t}_{3} / \mathrm{t}_{2}\right)+2 \delta_{3} \mathrm{t}_{1} / \mathrm{t}_{3}- \\
& \quad \mathrm{v}_{0}\left(6+6 \mathrm{t}_{2} / \mathrm{t}_{1}+4 \mathrm{t}_{3} / \mathrm{t}_{1}+3 \mathrm{t}_{3} / \mathrm{t}_{2}\right)-\mathrm{v}_{3} \mathrm{t}_{1}-\mathrm{a}_{0} \mathrm{t}_{1} \mathrm{t}_{3}\left(5 / 3+\mathrm{t}_{1} / \mathrm{t}_{2}+2 \mathrm{t}_{1} / \mathrm{t}_{3}+5 \mathrm{t}_{2} / 2 \mathrm{t}_{3}\right)+ \\
& \quad \mathrm{a}_{3} \mathrm{t}_{1} \mathrm{t}_{3} \\
& \mathrm{~g}=\mathrm{t}_{3} / \mathrm{t}_{2}+2 \mathrm{t}_{3} / \mathrm{t}_{1}+2+3 \mathrm{t}_{2} / \mathrm{t}_{1}
\end{aligned}
$$

Second trajectory segment:

$$
\mathrm{h}_{2}(\mathrm{t})=\left(\delta_{2}-\mathrm{v}_{1} \mathrm{t}_{2}-\mathrm{a}_{1} \mathrm{t}_{2}^{2} / 2\right) \mathrm{t}^{3}+\left(\mathrm{a}_{1} \mathrm{t}_{2}^{2} / 2\right) \mathrm{t}^{2}+\left(\mathrm{v}_{1} \mathrm{t}_{2}\right) \mathrm{t}+\theta_{1}
$$

where,

$$
\begin{aligned}
\delta_{2} & =\theta_{2}-\theta_{1} \\
\mathrm{v}_{1} & =4 \delta_{1} / \mathrm{t}_{1}-3 \mathrm{v}_{0}-\mathrm{a}_{0} \mathrm{t}_{1}-\sigma / \mathrm{t}_{1}
\end{aligned}
$$




$$
\mathrm{a}_{1}=12 \delta_{1} / \mathrm{t}_{1}^{2}-12 \mathrm{v}_{0} / \mathrm{t}_{1}-5 \mathrm{a}_{0}-6 \sigma / \mathrm{t}_{1}^{2}
$$

Third trajectory segment:

$$
\begin{aligned}
\mathrm{h}_{3}(\mathrm{t})= & \left(9 \delta_{3}-4 \mathrm{v}_{2} \mathrm{t}_{3}-\mathrm{a}_{2} \mathrm{t}_{3}{ }^{2} / 2-5 \mathrm{v}_{3} \mathrm{t}_{3}+\mathrm{a}_{3} \mathrm{t}_{3}{ }^{2} / 2\right) \mathrm{t}^{4}+\left(-8 \delta_{3}+5 \mathrm{v}_{3} \mathrm{t}_{3}-\mathrm{a}_{3} \mathrm{t}_{3}{ }^{2} / 2\right. \\
& \left.+3 \mathrm{v}_{2} \mathrm{t}_{3}\right) \mathrm{t}^{3}+\left(\mathrm{a}_{2} \mathrm{t}_{3}{ }^{2} / 2\right) \mathrm{t}^{2}+\left(\mathrm{v}_{2} \mathrm{t}_{3}\right) \mathrm{t}+\theta_{2}
\end{aligned}
$$

where,

$$
\begin{aligned}
& \delta_{3}=\theta_{3}-\theta_{2} \\
& \mathrm{v}_{2}=3 \delta_{2} / \mathrm{t}_{2}-2 \mathrm{v}_{1}-\mathrm{a}_{1} \mathrm{t}_{2} / 2 \\
& \mathrm{a}_{2}=6 \delta_{2} / \mathrm{t}_{2}{ }^{2}-6 \mathrm{v}_{1} / \mathrm{t}_{2}-2 \mathrm{a}_{1} \mathrm{t}_{2}
\end{aligned}
$$

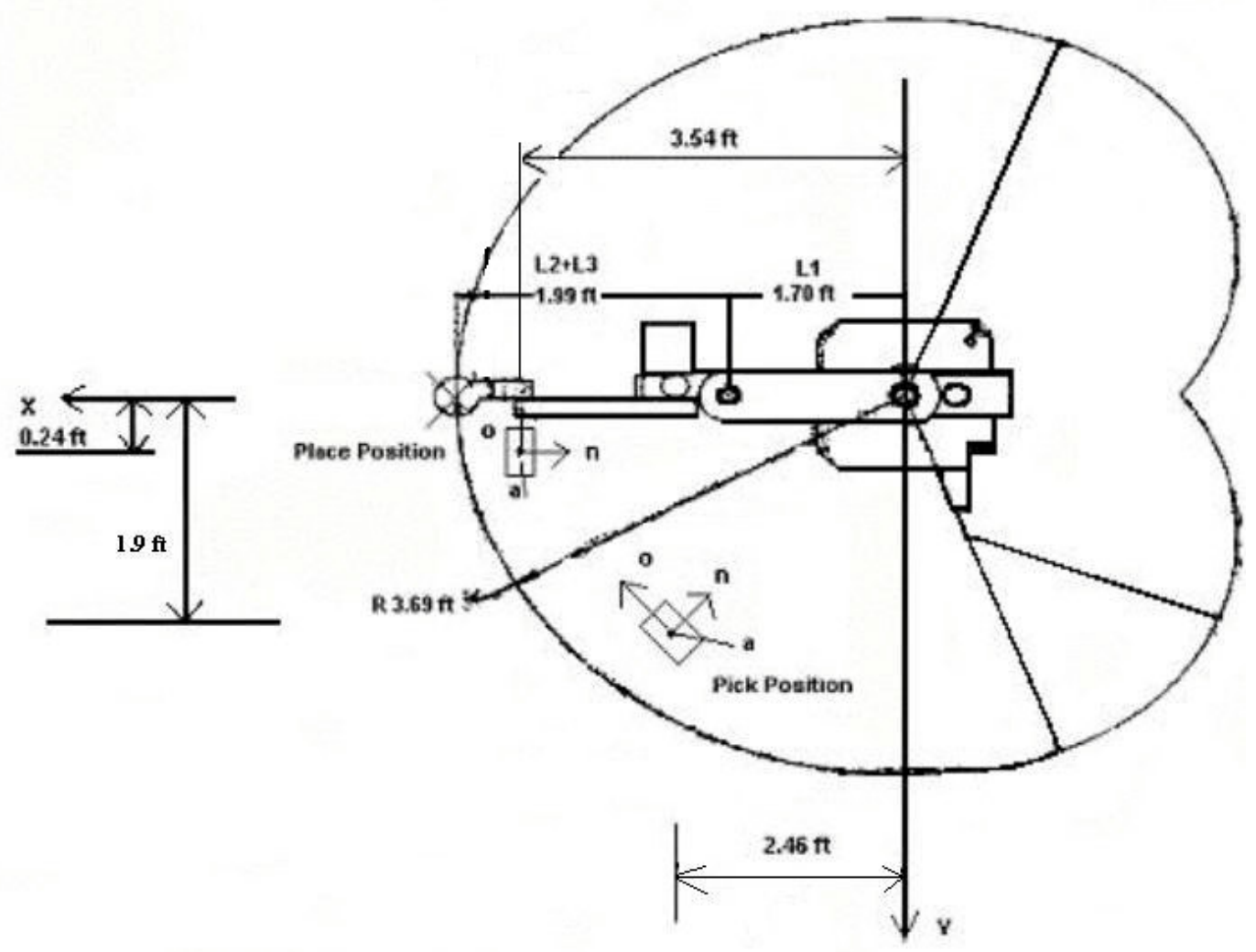

Figure 4.2 Top View of Work Envelop of the Robot [3]

\subsection{RESULTS OF TRAJECTORY PLANNING}

The 4-3-4 trajectory equations for the motion of three joints to complete the specified pick-to-place task (Figure 4.2 [3]) of the end-effector were determined. The 
trajectory equations for the three segments of the pick-to-place motion for joint 1 were determined as:

$$
\begin{array}{lc}
\mathrm{h} 1=-10.04 * \mathrm{t}^{4}-7.54 * \mathrm{t}^{3}+70 & \text { (first segment) } \\
\mathrm{h} 2=30.2521 *(\mathrm{t}-0.5)^{3}-45.3782 *(\mathrm{t}-0.5)^{2}-24.8739 *(\mathrm{t}-0.5)+65 & (\text { second segment }) \\
\mathrm{h} 3=10.04 *(\mathrm{t}-1.5)^{4}-35.6714 *(\mathrm{t}-1.5)^{3}+45.37815 *(\mathrm{t}-1.5)^{2}-24.8739(\mathrm{t}-1.5)+25 \\
& \text { (third segment) }
\end{array}
$$

where $t$ is the actual time associated with the robot traversing the trajectory. These equations have been used to generate the desired trajectory.

\subsection{INVERSE KINEMATIC VERIFICATION}

Inverse kinematic verification of the SCARA-Type robot was presented in Chapter 2. In this section the solution will be used to determine the joint angles $\theta_{1}, \theta_{2}$, $\theta_{3}$ and $\theta_{4}=\left(90-\theta_{3}\right)$ for the pick-to-place trajectory presented in Section 4.3. The first step for this process is to convert the path into corresponding position and orientations of the end-effector. The pick and place position in the workspace has the following positions and orientations:

Cartesian components of the Pick Position (p) and Orientation (n, o, a) of the robot end-effector with respect to the fixed base coordinate frame are:

$$
\begin{array}{lll}
\mathrm{Px}=2.46 \text { feet } & \mathrm{Py}=1.92 \text { feet } & \mathrm{Pz}=4.56 \text { feet } \\
\mathrm{n}_{x}=-0.1736 & \mathrm{n}_{y}=0.9848 & \mathrm{n}_{z}=0 \\
\mathrm{o}_{x}=0.9848 & \mathrm{o}_{y}=0.1736 & \mathrm{o}_{z}=0 \\
\mathrm{a}_{x}=0 & \mathrm{a}_{y}=0 & \mathrm{a}_{z}=-1
\end{array}
$$

Place position and orientation of the robot with respect to the fixed base are:

$$
\begin{array}{lll}
\mathrm{Px}=3.54 \text { feet } & \mathrm{Py}=0.24 \text { feet } & \mathrm{Pz}=4.78 \text { feet } \\
\mathrm{n}_{x}=0.1736 & \mathrm{n}_{y}=0.9848 & \mathrm{n}_{z}=0 \\
\mathrm{o}_{x}=0.9848 & \mathrm{o}_{y}=-0.1736 & \mathrm{o}_{z}=0 \\
\mathrm{a}_{x}=0 & \mathrm{a}_{y}=0 & \mathrm{a}_{z}=-1
\end{array}
$$


The intermediate points are a function of the path and follow the same related path with respect to time since the position and orientation of the pick and place are known. The inverse kinematic solution is applied to convert the Cartesian coordinates to joint coordinates. Applying inverse kinematic solution to previously mentioned Cartesian coordinates gives corresponding joint coordinates. Hence, the corresponding values for joint coordinate system for pick and place positions are calculated as:

Pick position:

$$
\begin{aligned}
& \text { Joint } 1=70 \text { degrees } \\
& \text { Joint } 2=-60 \text { degrees } \\
& \text { Joint } 3=20 \text { degrees }
\end{aligned}
$$

Place Position:

$$
\begin{aligned}
& \text { Joint } 1=20 \text { degrees } \\
& \text { Joint } 2=-30 \text { degrees } \\
& \text { Joint } 3=10 \text { degrees }
\end{aligned}
$$

The joint angle variation of the three joints for the pick-to-place task to be initially accomplished in $2 \mathrm{sec}$ (arbitrary choice) is shown in Table 4.2.

Table 4.2: Joint Angle Variation of Three Joints for Pick-to-Place Task

\begin{tabular}{|c|c|c|c|}
\hline Time (sec) & $\begin{array}{c}\text { Ө1 (joint 1) } \\
\text { degrees }\end{array}$ & $\begin{array}{c}\text { Ө2 (joint 2) } \\
\text { degrees }\end{array}$ & $\begin{array}{c}\text { Ө3 (joint 3) } \\
\text { degrees }\end{array}$ \\
\hline 0 & 70.00 & -60.00 & 20.00 \\
\hline 0.1 & 69.95 & -59.93 & 19.97 \\
\hline 0.2 & 69.62 & -59.49 & 19.78 \\
\hline 0.3 & 68.78 & -58.49 & 19.37 \\
\hline 0.4 & 67.27 & -56.93 & 18.74 \\
\hline 0.5 & 65.00 & -55.00 & 18.00 \\
\hline 0.6 & 61.96 & -53.00 & 17.30 \\
\hline 0.7 & 58.28 & -51.00 & 16.67 \\
\hline 0.8 & 54.12 & -49.00 & 16.09 \\
\hline 0.9 & 49.64 & -47.00 & 15.54 \\
\hline 1.0 & 45.00 & -45.00 & 15.00 \\
\hline
\end{tabular}


Table 4.2 (cont.): Joint Angle Variation of Three Joints for Pick-to-Place Task

\begin{tabular}{|l|l|l|l|}
\hline 1.1 & 40.36 & -43.00 & 14.46 \\
\hline 1.2 & 35.88 & -41.00 & 13.91 \\
\hline 1.3 & 31.72 & -39.00 & 13.33 \\
\hline 1.4 & 28.04 & -37.00 & 12.70 \\
\hline 1.5 & 25.00 & -35.00 & 12.00 \\
\hline 1.6 & 22.73 & -33.07 & 11.26 \\
\hline 1.7 & 21.22 & -31.51 & 10.63 \\
\hline 1.8 & 20.38 & -30.51 & 10.22 \\
\hline 1.9 & 20.05 & -30.07 & 10.03 \\
\hline 2.0 & 20.00 & -30.00 & 10.00 \\
\hline
\end{tabular}

Using the inverse kinematic solution the corresponding Cartesian positions of the end-effector are computed, which are shown in Table 4.3.

Table 4.3: Cartesian Position for the corresponding Joint Angles

\begin{tabular}{|c|c|c|c|}
\hline Time $(\mathrm{sec})$ & $\mathrm{Px}$ & $\mathrm{Py}$ & $\mathrm{Pz}$ \\
\hline 0 & 2.4658 & 1.9297 & 4.5656 \\
\hline 0.1 & 2.4673 & 1.93 & 4.5663 \\
\hline 0.2 & 2.4772 & 1.9305 & 4.5702 \\
\hline 0.3 & 2.5026 & 1.9274 & 4.5789 \\
\hline 0.4 & 2.5483 & 1.9131 & 4.592 \\
\hline 0.5 & 2.617 & 1.8755 & 4.6075 \\
\hline 0.6 & 2.7081 & 1.8014 & 4.6222 \\
\hline 0.7 & 2.8148 & 1.6915 & 4.6356 \\
\hline 0.8 & 2.9289 & 1.5506 & 4.6481 \\
\hline 0.9 & 3.0424 & 1.3849 & 4.6598 \\
\hline 1.0 & 3.1488 & 1.2021 & 4.6713 \\
\hline 1.1 & 3.2431 & 1.0111 & 4.6828 \\
\hline 1.2 & 3.3224 & 0.82209 & 4.6947 \\
\hline 1.3 & 3.3861 & 0.64597 & 4.7072 \\
\hline 1.4 & 3.4355 & 0.49405 & 4.7209 \\
\hline 1.5 & 3.4732 & 0.37771 & 4.736 \\
\hline 1.6 & 3.5016 & 0.304 & 4.752 \\
\hline 1.7 & 3.5213 & 0.26367 & 4.7656 \\
\hline 1.8 & 3.5327 & 0.24549 & 4.7747 \\
\hline 1.9 & 3.5375 & 0.23989 & 4.7788 \\
\hline 2.0 & 3.5382 & 0.23922 & 4.7795 \\
\hline
\end{tabular}

where, Px, Py, and Pz are Cartesian coordinate for corresponding joint angles.

Figures 4.3 to 4.5 show the joint angles, which are required for the end-effector to traverse the specified pick-to-place motion. 


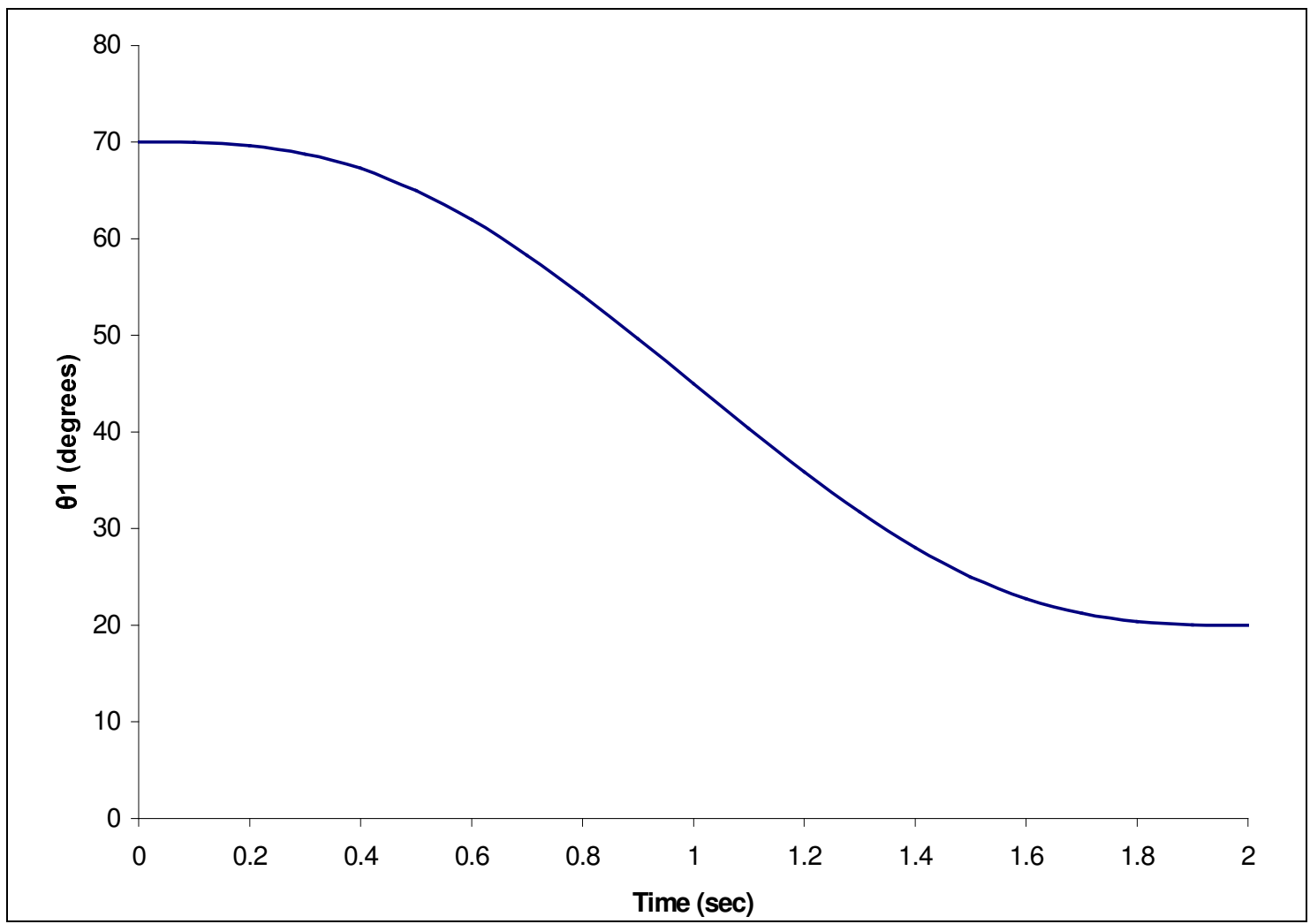

Figure 4.3 Motion of $\theta_{1}$ with time for the Pick-to-Place Task

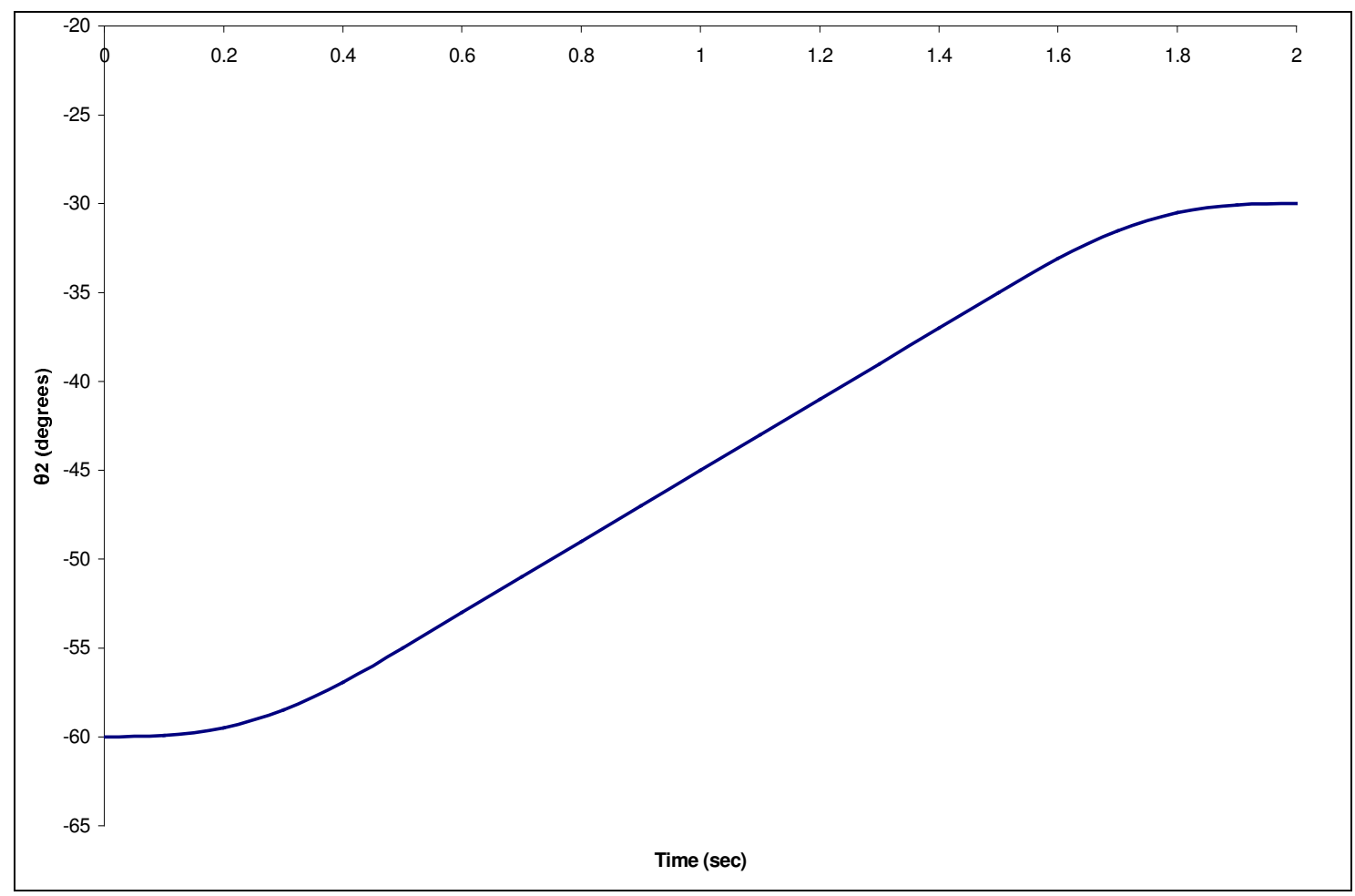

Figure 4.4 Motion of $\theta_{2}$ with time for the Pick-to-Place Task 


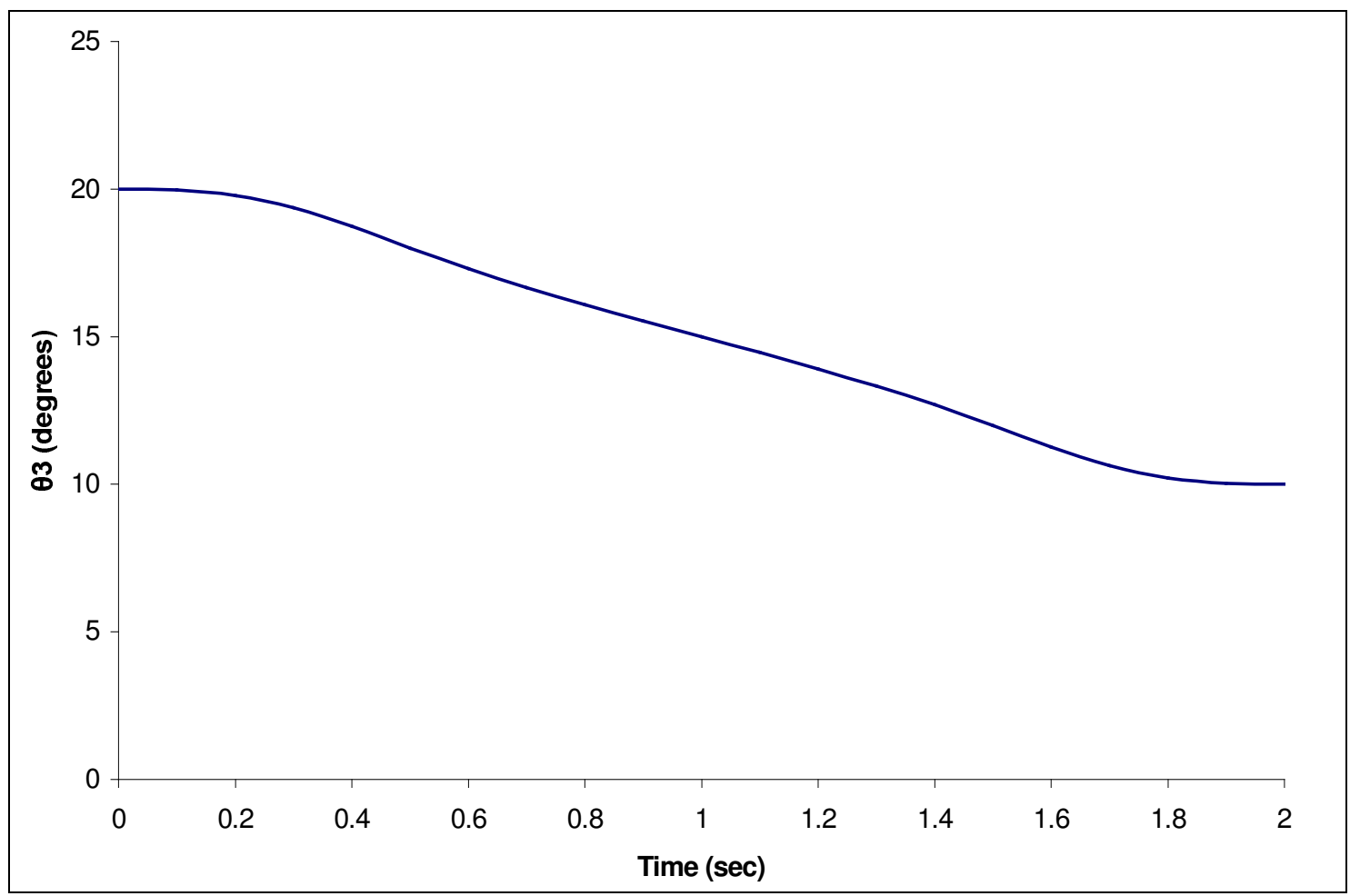

Figure 4.5 Motion of $\theta_{3}$ with time for the Pick-to-Place Task

\subsection{INVERSE DYNAMIC VERIFICATION}

This section determines the torques required at the joints using the dynamic equations [4] determined in Chapter 3. The angular velocities and angular accelerations of each joint are required to determine the torques. To achieve this, Matlab and Excel are used. There are three equations, which calculate the torques for the joints. This code first uses inverse kinematic solution to determine the joint angles for the SCARA-Type robot. Thereafter, the joint velocities and joint accelerations are determined by differentiating the joint angles with respect to time. Figures 4.6 to 4.8 show the angular positions, velocities and accelerations of the three joints. Figures 4.9, $4.10 \& 4.12$ show the comparison of real torque and independent torque required by the three joints of the robot. The real torque characteristic shown in Figure 4.10 does not follow the angular acceleration characteristic of joint 2. Real torque characteristic of Joint 2 is shown in Figure 4.11. From the Figure 4.11 it can be seen that the inertia term of the link 2 is dominated by the inertias and coriolis \& centrifugal terms of link 1 and link 3 since link 2 is small (0.7 feet) compared to link 1 (1.7 feet) and link 3 (1.27 feet). The angular 
positions, velocities and accelerations are in radians, radians per second and radians per second square, respectively.

The velocity for the first joint shown in Figure 4.6 shows that the angular velocity for joint 1 is negative, which was expected, because the first joint angle decreases to produce a trajectory. Figure 4.7 shows that the angular velocity for joint 2 increases rapidly and decreases rapidly to zero velocity. The velocity for the third joint shown in Figure 4.8 shows that the angular velocity is negative and it first decreases rapidly then becomes constant and finally increases rapidly again to zero velocity. For all the three joints, the angular velocity goes through a smooth angular motion transition at the lift-off and the set-down positions, which were specified.

The angular acceleration for joint 1 in Figure 4.6 shows that there is a rapid deceleration at the beginning of the path and then there is a constant acceleration during the major part of the trajectory, finally at the end it decelerates to come to a stop. The same trend is followed for the angular acceleration of the second joint shown in Figure 4.7, except that it accelerates at the beginning and then decelerates during the actual trajectory, finally at the end it accelerates to come to a stop. Figure 4.8 for joint 3 shows that the angular acceleration decelerates and accelerates rapidly and it is smooth during its course of the trajectory. It then accelerates and decelerates to come to zero.

The real and independent torque curves for all three joints for the SCARA-Type robot are shown in Figures 4.9, 4.10 and 4.12. From Figure 4.9 it is seen that the real torque required for joint 1 at time $\mathrm{t} 1=0.5 \mathrm{sec}$ is $-24.62 \mathrm{lb}-\mathrm{ft}$. The angular acceleration of joint 1 at time $\mathrm{t} 1=0.5 \mathrm{sec}$ is $-1.4 \mathrm{rad} / \mathrm{sec}^{2}$. Hence the inertia for link 1 can be calculated from Torque $=$ Inertia $*$ Angular Acceleration. The inertia calculated from the equation mentioned is $-24.62 /-1.4=17.6 \mathrm{lb}-\mathrm{ft}^{2}$. From the geometry of the robot the inertia of link 1 , which incorporates the effects of link 2 and link 3 is $13.4 \mathrm{lb}-\mathrm{ft}^{2}$. Independent torque from Figure 4.9 at time $\mathrm{t} 1=0.5 \mathrm{sec}$ is $-11.58 \mathrm{lb}-\mathrm{ft}$. Angular acceleration is $-1.4 \mathrm{rad} / \mathrm{sec}^{2}$. Inertia calculated for independent torque is $-11.58 /-1.4=8.21 \mathrm{lb}-\mathrm{ft}^{2}$. From the geometry of the robot, the inertia of link 1, independent of link 2 and link 3 , is $8.3 \mathrm{lb}-\mathrm{ft}^{2}$. The input torque required at joint 1 shows that the torque follows the same trend as the acceleration, which indicates that the major portion of the torque consists of acceleration- 
related terms. The input torque required at joint 2 varies from $+8.29 \mathrm{lb}-\mathrm{ft}$ to $-9.75 \mathrm{lb}-\mathrm{ft}$. The torque for the second joint is dominated by the inertia and coriolis \& centrifugal terms of link 1 and link 3.

The torque curve for the third joint is shown in Figure 4.12. There is a decrease in of magnitude of torque. This is because the third link moves in the vertical plane to accomplish this task and hence it is dominated by the gravitational term. Input torque required for the third joint follows the acceleration, but it starts from $11.70 \mathrm{lb}-\mathrm{ft}$ instead of zero because of the acceleration due to gravity term, which always exists throughout its motion.

It can be studied from Figure 4.6 that the robot will go through small jerk of 2.79 $\mathrm{rad} / \mathrm{sec}^{3}$ at time $\mathrm{t}=0.5 \mathrm{sec}$ and $\mathrm{t}=1.5 \mathrm{sec}$. For designing the trajectory of the robot the 4-3-4 trajectory planning method was used. This method doesn't apply boundary condition on the jerk. It applies boundary conditions on position, velocities and acceleration and makes them continuous between each segment of the trajectory. The jerk is small and can be eliminated by applying an extra boundary condition on jerk. This can be achieved by planning the trajectory using 5-4-5 trajectory planning method.

The links of the SCARA-Type robot are rigid as defined in Chapter 2. The torques calculated from the dynamic equations of motion for the SCARA-Type robot, is for rigid links. If the links and joints of the work cell robot are flexible, the torque requirement at the joint will increase. If only the link is rigid and not the joint, the change in torque requirement will not be significant unless the length of the link is considerably large. The torque requirement changes considerably if the joint is flexible. The actuator inside the flexible joint has to counteract the torque generated by jerk, due to flexible joint. But in reality the links and joints of the robots are made rigid to make the robot system more stable to perform a task with optimal torque requirements at the joints. 


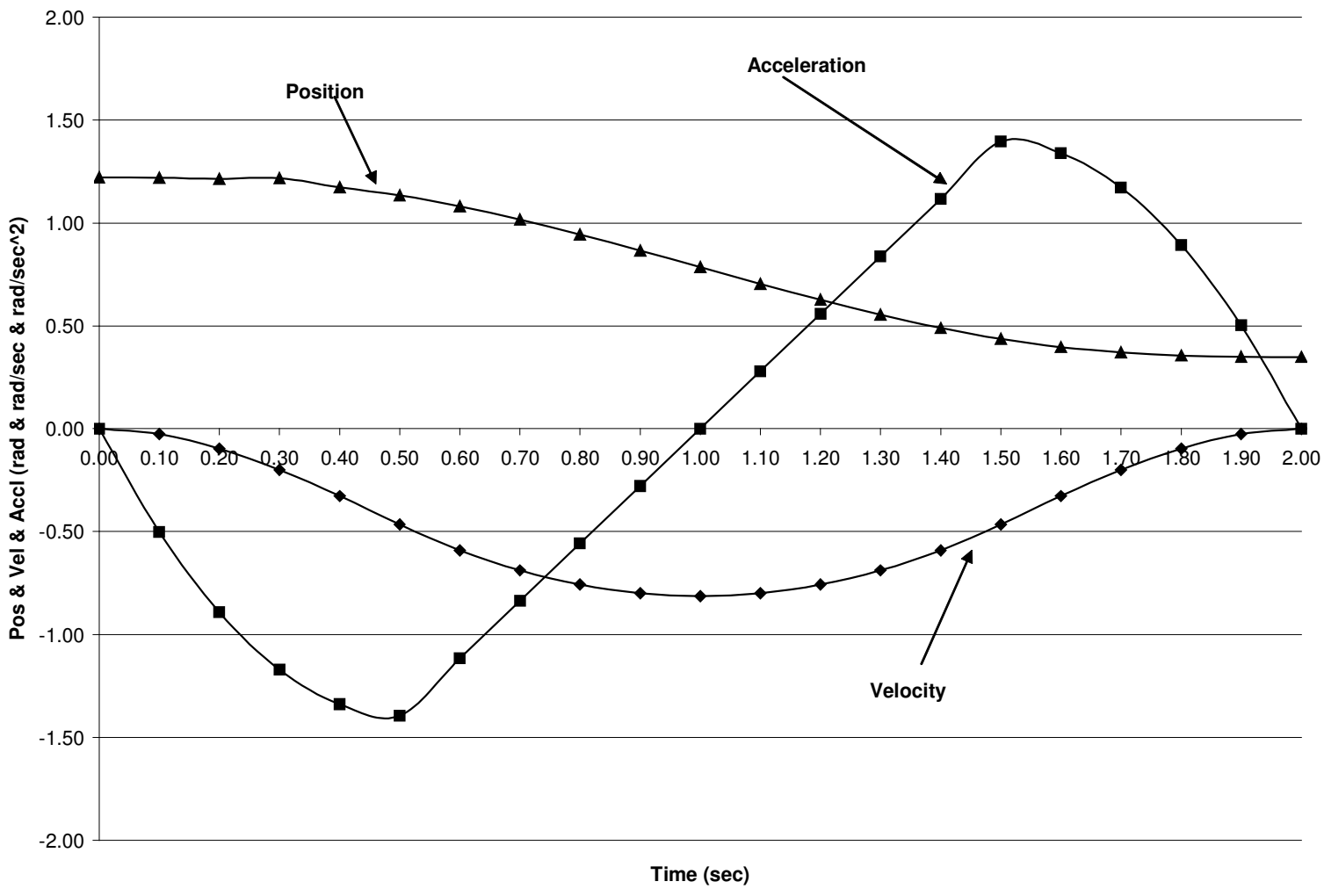

Figure 4.6 Joint 1 Position, Velocity and Acceleration for Pick-to-Place Task

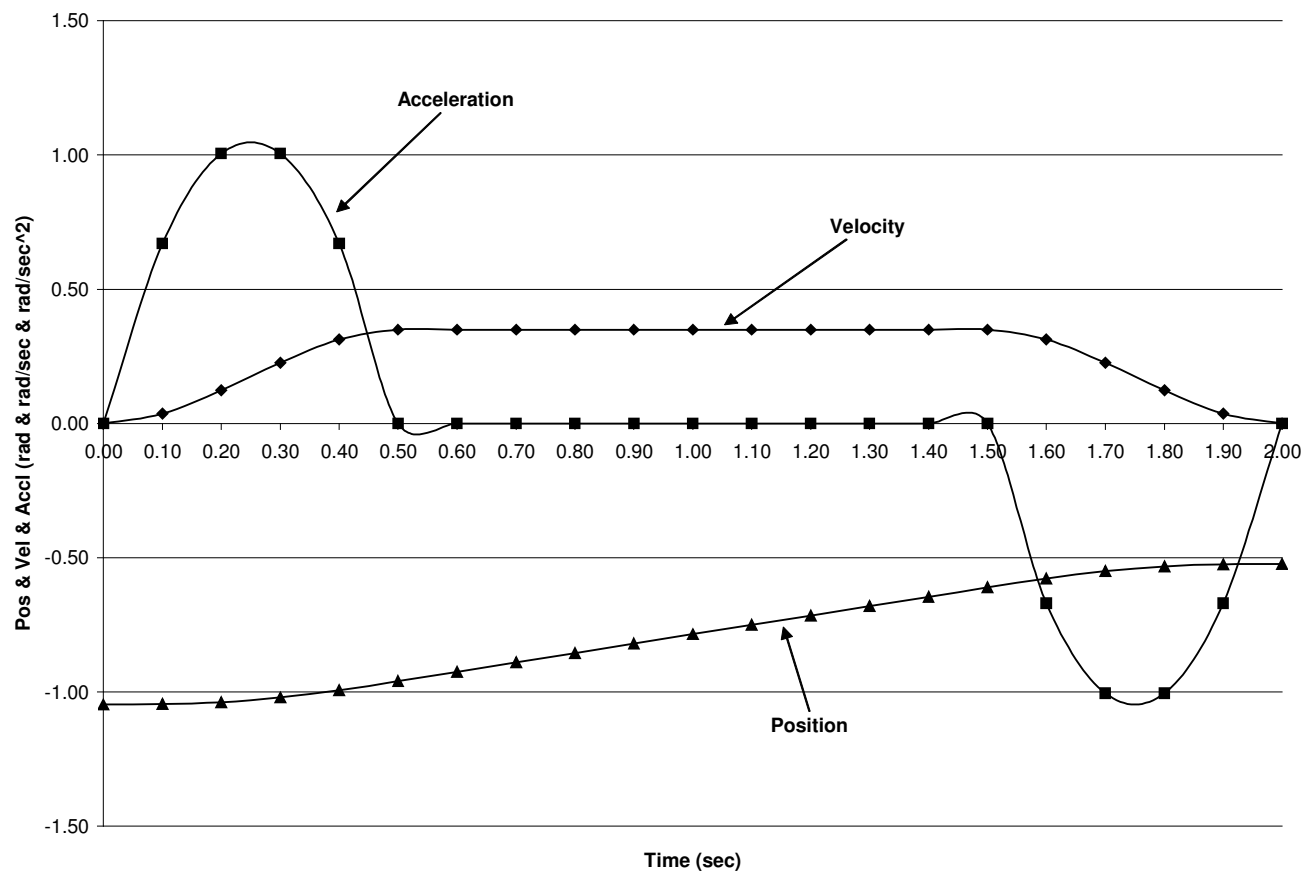

Figure 4.7 Joint 2 Position, Velocity and Acceleration for Pick-to-Place Task 


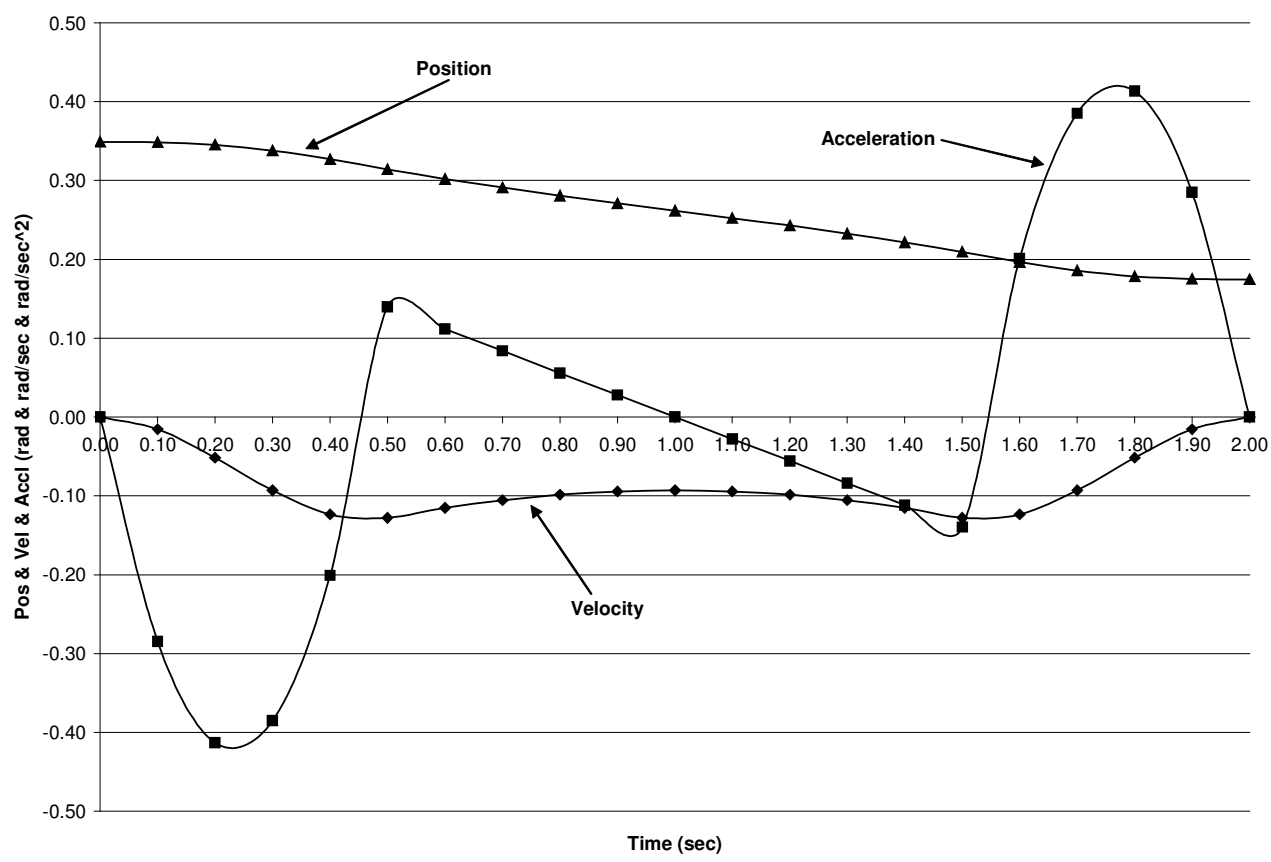

Figure 4.8 Joint 3 Position, Velocity and Acceleration for Pick-to-Place Task

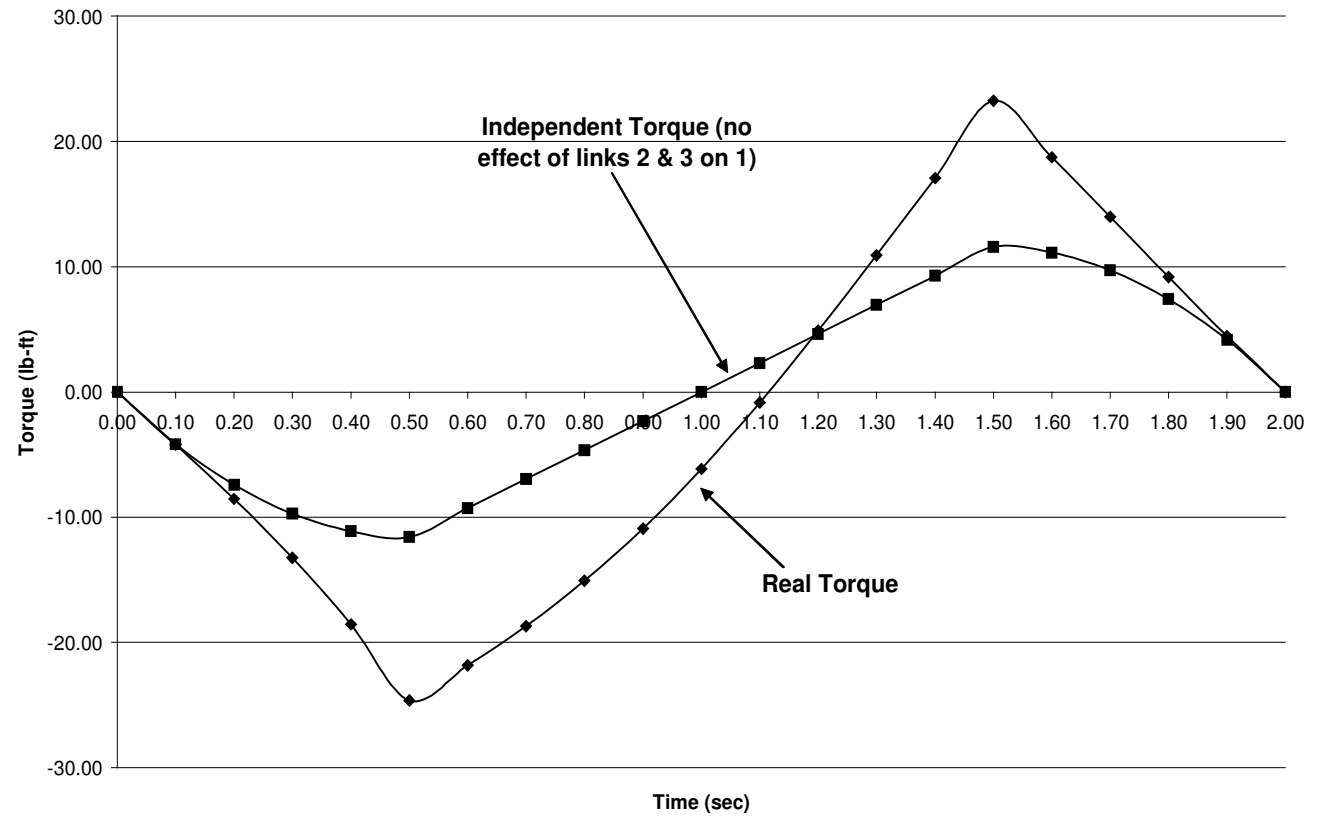

Figure 4.9 Joint 1 input torque required for Pick-to-Place Task 


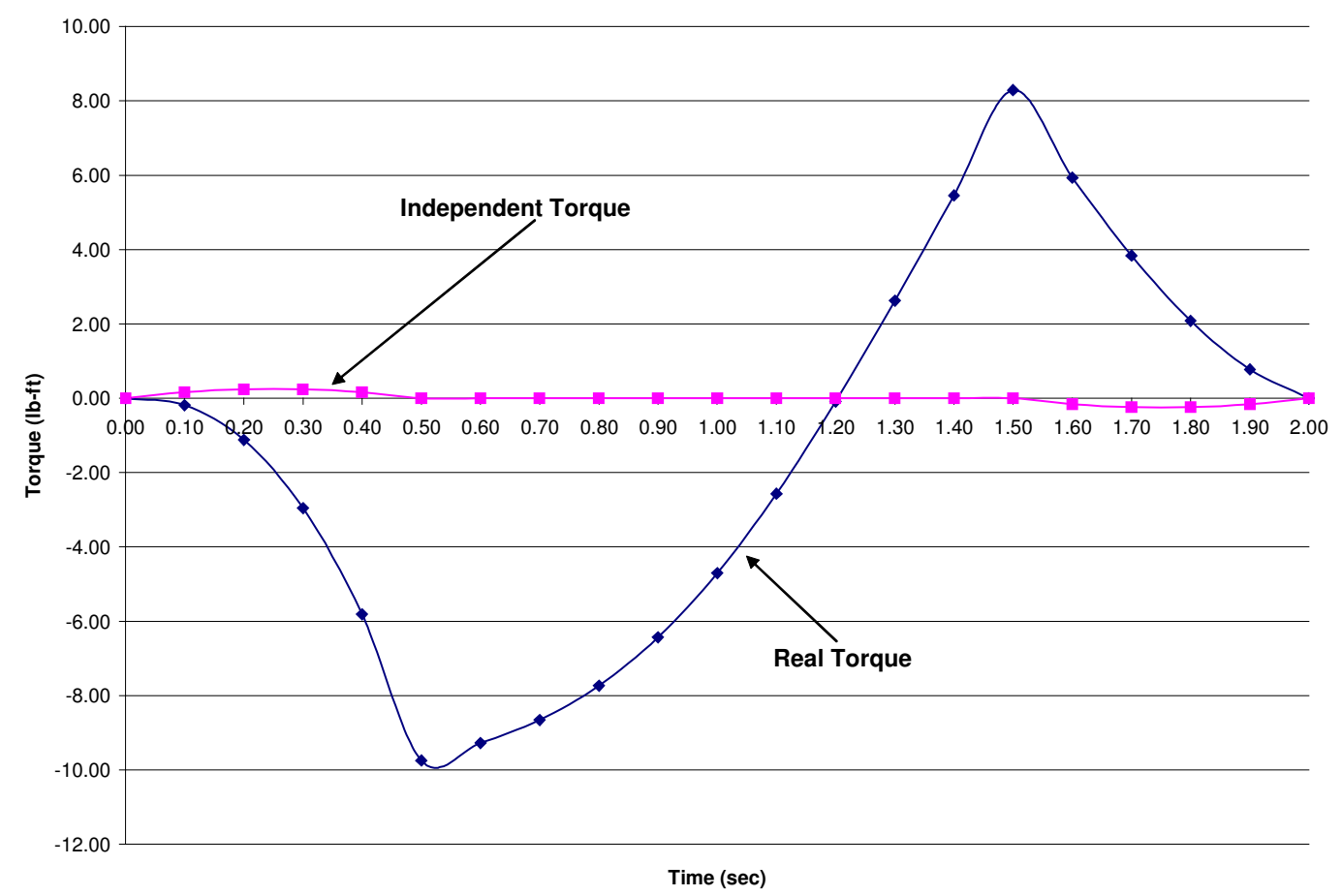

Figure 4.10 Joint 2 input torque required for Pick-to-Place Task

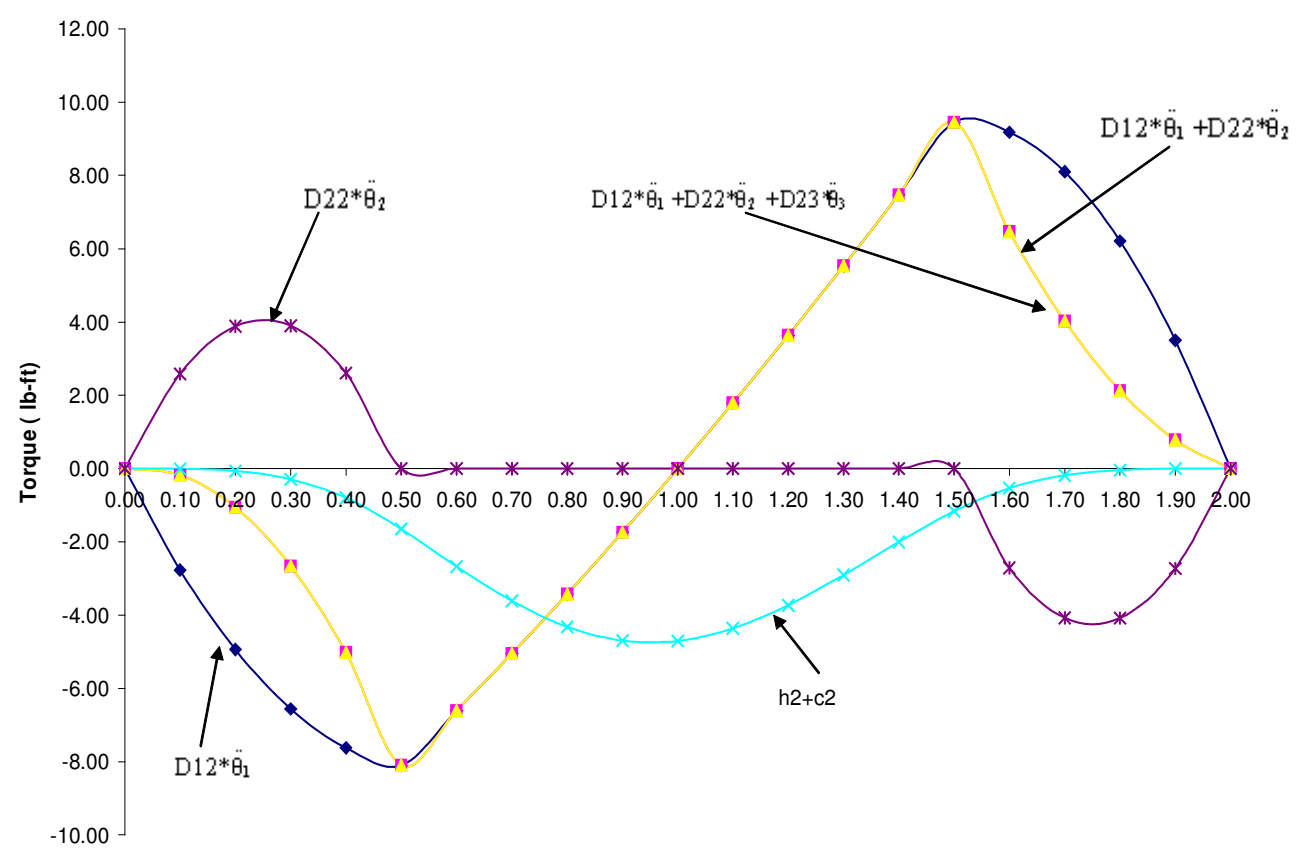

Time (sec)

Figure 4.11 Joint 2 real torque characteristics for Pick-to-Place Task 


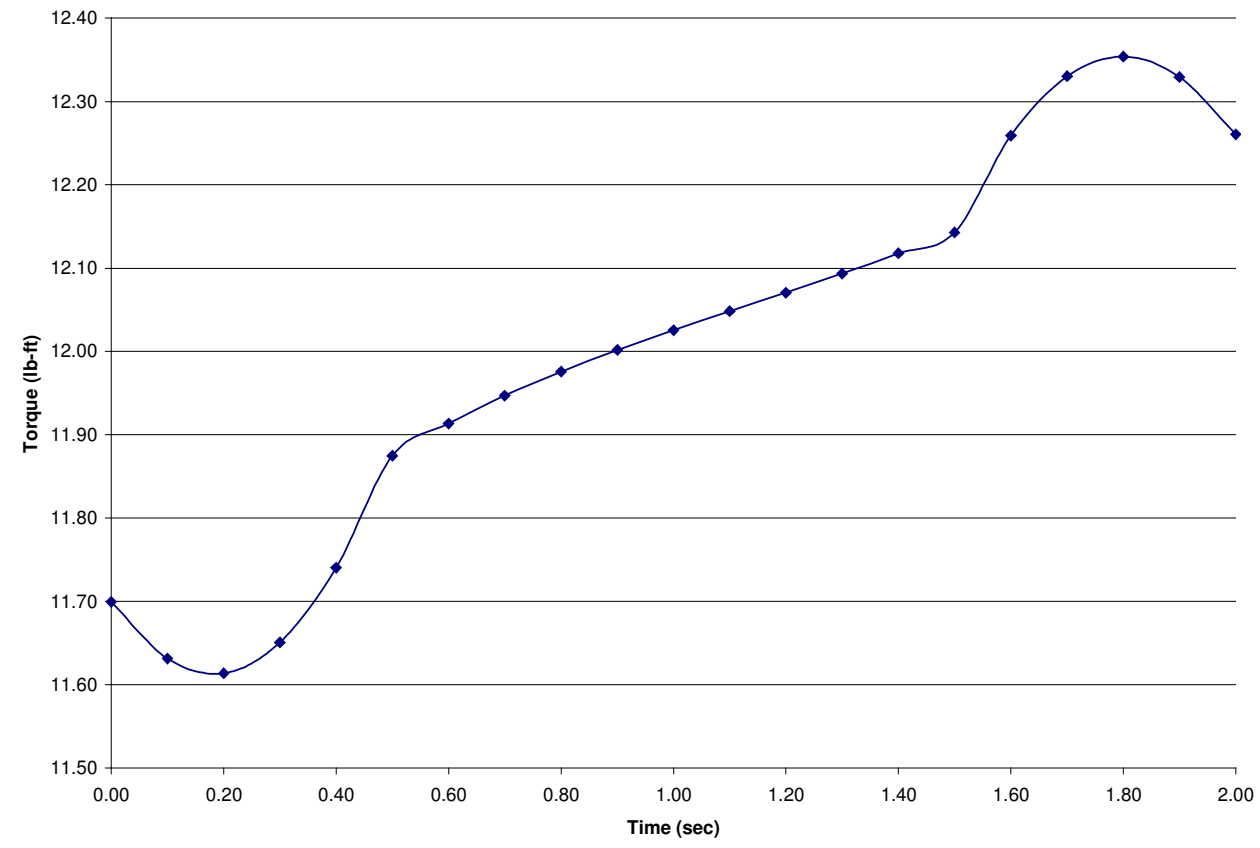

Figure 4.12 Joint 3 input torque (Link $1 \& 2$ are fixed) required for Pick-to-Place Task 


\section{Chapter 5 \\ Transfer Function Model for SCARA-Type Robot}

\subsection{METHODOLOGY}

The integrated model [8] for the DC motor and manipulator was developed using kinematic and dynamic analysis of motor and manipulator. The input for this model is the desired angle for the joints and the output is the actual angle achieved by the joint. Matlab was used to simulate the output of the models of three joints for the step input.

\subsection{ACTUATOR DYNAMIC MODEL}

Three actuators located in the three joints of the robot drive the SCARA-Type robot. The schematic diagram of an actuator is shown in Figure 5.1 [4, pg.206]. These actuators are permanent magnet DC servomotors [13] with armature current control.

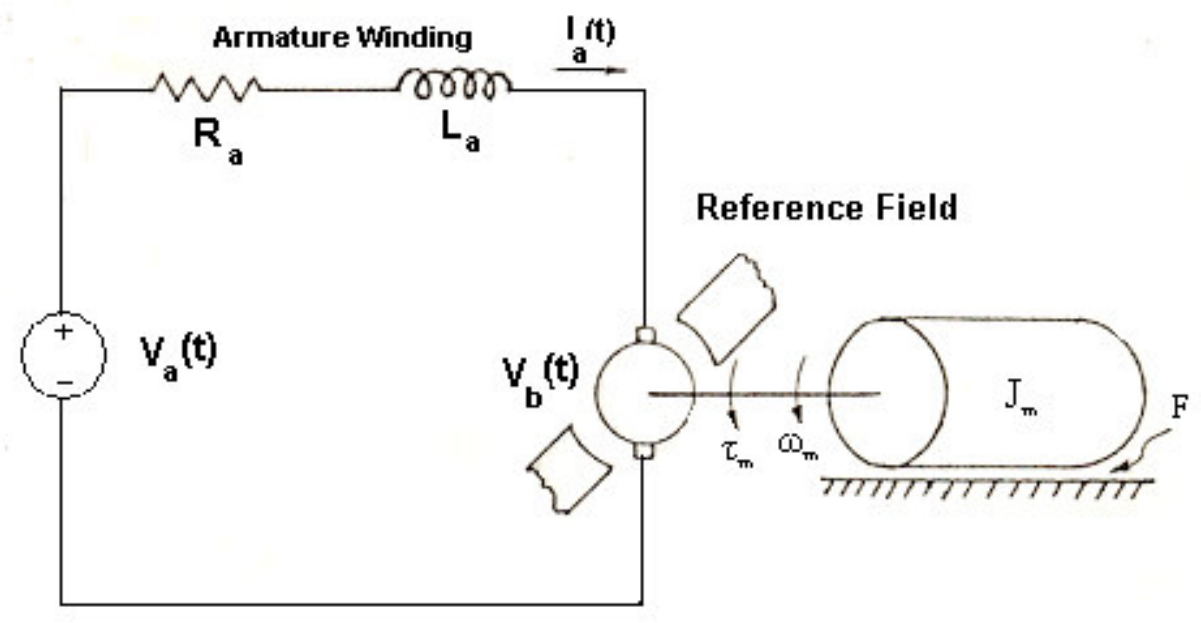

Figure 5.1 Armature Controlled DC Motor [4]

For an armature controlled DC motor [8, 14], the actuator dynamics can be represented as follows:

$$
V_{a}(t)=R_{a} I_{a}(t)+L_{a} \frac{d}{d t}\left[I_{a}(t)\right]+K_{b} \omega_{m}(t)
$$


where,

$$
\begin{aligned}
& \mathrm{V}_{\mathrm{a}}(\mathrm{t})=\text { Applied Voltage } \\
& \mathrm{I}_{\mathrm{a}}(\mathrm{t})=\text { Armature Current } \\
& \mathrm{L}_{\mathrm{a}}=\text { Armature Inductance } \\
& \mathrm{R}_{\mathrm{a}}=\text { Armature Resistance } \\
& \mathrm{K}_{\mathrm{b}}=\text { Back Electromotive Force (emf) constant } \\
& \omega_{\mathrm{m}}(\mathrm{t})=\text { Angular Velocity of motor shaft }
\end{aligned}
$$

For an armature controlled DC motor, the electrical time constant $\tau=\mathrm{L}_{\mathrm{a}} / \mathrm{R}_{\mathrm{a}}$ is very small. Since the electrical time constant of the motor is much smaller than the mechanical time constant, $\tau=\mathrm{L}_{\mathrm{a}} / \mathrm{R}_{\mathrm{a}}$ can be neglected. Thus, Equation 5.1 can be written as:

$$
\mathrm{V}_{\mathrm{a}}(\mathrm{t})=\mathrm{R}_{\mathrm{a}} \mathrm{I}_{\mathrm{a}}(\mathrm{t})+\mathrm{K}_{\mathrm{b}} \omega_{\mathrm{m}}(\mathrm{t})
$$

When the armature controlled DC motor is operated in its linear range, the generated torque is proportional to the armature current [13]. The relation between the generated torque and armature current is written as [4]:

$$
T_{m}(t)=K_{t} I_{a}(t)
$$

where,

$$
\begin{aligned}
& T_{m}(t)=\text { Torque generated by DC motor } \\
& \mathrm{K}_{\mathrm{t}}=\text { Motor torque constant }
\end{aligned}
$$

Now, substituting I $(\mathrm{t})$ from Equation (5.2) into Equation (5.1) gives,

$$
\mathrm{V}_{\mathrm{a}}(\mathrm{t})=\frac{\mathrm{R}_{\mathrm{a}}}{\mathrm{K}_{\mathrm{t}}} \mathrm{T}_{\mathrm{m}}(\mathrm{t})+\mathrm{K}_{\mathrm{b}} \omega_{\mathrm{m}}(\mathrm{t})
$$

Equation (5.3) represents the armature controlled DC motor dynamics. When an actuator, through gear reduction drives a manipulator link, the torque generated by an actuator must be equal to the torque required to overcome the actuator inertia and friction and the load from the manipulator link. This can be written as

$$
\mathrm{T}_{\mathrm{m}}(\mathrm{t})=\mathrm{J}_{\mathrm{m}} \omega_{\mathrm{m}}(\mathrm{t})+\mathrm{B}_{v} \omega_{\mathrm{m}}(\mathrm{t})+\mathrm{T}_{\mathrm{d}}(\mathrm{t})
$$


where,

$\mathrm{J}_{\mathrm{m}}=$ Inertia of motor rotor about motor axis

$\mathrm{B}_{v}=$ Combined friction coefficient of motor about motor axis

$\omega_{\mathrm{m}}(\mathrm{t})=$ Angular acceleration of motor shaft

$\mathrm{T}_{\mathrm{d}}(\mathrm{t})=$ Load torque on motor about motor axis

If a harmonic drive with speed reduction ratio equal to $\mathrm{n}$ is used, then,

$$
\mathrm{n}=>>1
$$

Hence, for manipulator link i,

$\mathrm{T}_{\mathrm{i}}^{\mathrm{L}}(\mathrm{t})=$ Load on motor from manipulator link $\mathrm{i}$ about joint $\mathrm{i}$.

$\dot{\theta}_{\mathrm{i}}(\mathrm{t})=$ Angular velocity of manipulator link i about joint $i$.

$\ddot{\theta}_{\mathrm{i}}(\mathrm{t})=$ Angular acceleration of the manipulator link $\mathrm{i}$ about joint $\mathrm{i}$.

Then,

$$
\begin{aligned}
& T_{d}(t)=\frac{T_{i}^{L}(t)}{n} \\
& \omega_{m}(t)=n \dot{\theta}_{i}(t) \\
& \dot{\omega}_{m}(t)=n \ddot{\theta}_{i}(t)
\end{aligned}
$$

Substituting Equations (5.5), (5.6) and (5.7) into Equations (5.3) and (5.4) gives

$$
\mathrm{T}_{\mathrm{i}}^{\mathrm{L}}(\mathrm{t})=\frac{\mathrm{nV}_{\mathrm{a}} \mathrm{K}_{\mathrm{t}}}{\mathrm{R}_{\mathrm{a}}}-\frac{\mathrm{K}_{\mathrm{b}} \mathrm{K}_{\mathrm{t}}}{\mathrm{R}_{\mathrm{a}}} \mathrm{n}^{2} \dot{\theta_{\mathrm{i}}}-\mathrm{J}_{\mathrm{m}} \mathrm{n}^{2} \ddot{\theta}_{\mathrm{i}}-\mathrm{B}_{\nu} \mathrm{n}^{2} \dot{\theta}_{\mathrm{i}}
$$

Equation (5.8) shows the relationship between the load $\mathrm{T}_{\mathrm{i}}{ }^{\mathrm{L}}(\mathrm{t})$ from the manipulator link and link angular acceleration and angular velocity. This equation is used in developing the integrated model for joint dynamics in Section 5.3. 


\subsection{INTEGRATED JOINT DYNAMIC MODEL FOR THE SCARA-TYPE ROBOT}

In this section the combined dynamics for both manipulator link $\mathrm{i}$ and link $\mathrm{i}$ actuator, called the integrated joint dynamic model [8], is derived. The dynamic equation of manipulator link i can be written as:

$$
\mathrm{T}_{\mathrm{i}}=\mathrm{D}_{\mathrm{ii}} \ddot{\theta}_{\mathrm{i}}+\mathrm{h}_{\mathrm{i}}+\mathrm{c}_{\mathrm{i}}+\sum_{\mathrm{j}=1}^{3} \mathrm{D}_{\mathrm{ij}} \ddot{\theta}_{\mathrm{j}}
$$

Let the coefficient of friction at joint $\mathrm{i}$ be equal to $\mathrm{B}_{\mathrm{i}}$. Then the torque $\mathrm{T}_{\mathrm{i}}$ required at joint $i$ must overcome the frictional torque $B_{i} \theta_{i}$ due to this friction as well. Equation (5.9), when joint friction is considered, becomes

$$
\mathrm{T}_{\mathrm{i}}=\mathrm{D}_{\mathrm{ii}} \ddot{\theta}_{\mathrm{i}}+\mathrm{B}_{\mathrm{i}} \dot{\theta}_{\mathrm{i}}+\sum_{\mathrm{j}=1}^{3} \mathrm{D}_{\mathrm{ij}} \ddot{\theta}_{\mathrm{j}}+\mathrm{h}_{\mathrm{i}}+\mathrm{c}_{\mathrm{i}}
$$

Let ,

$$
\mathrm{Tc}_{\mathrm{i}}=\sum_{\mathrm{j}=1}^{3} \mathrm{D}_{\mathrm{ij}} \ddot{\theta}_{\mathrm{j}}+\mathrm{h}_{\mathrm{i}}+\mathrm{c}_{\mathrm{i}}
$$

where,

$\mathrm{Tc}_{\mathrm{i}}=$ Effective coupling torque from all other links to joint $\mathrm{i}$.

$\mathrm{B}_{\mathrm{i}}=$ Coefficient of friction at joint $\mathrm{i}$.

Hence, Equation (5.10) can be written as:

$$
\mathrm{T}_{\mathrm{i}}=\mathrm{D}_{\mathrm{ii}} \ddot{\theta}_{\mathrm{i}}+\mathrm{B}_{\mathrm{i}} \dot{\theta}_{\mathrm{i}}+\mathrm{Tc}_{\mathrm{i}}
$$

The $\mathrm{T}_{\mathrm{i}}$ in Equation (5.11) represents the joint torque required at joint $\mathrm{i}$ to drive

link $\mathrm{i}$ at velocity $\dot{\theta}_{\mathrm{i}}$ and acceleration $\ddot{\theta}_{\mathrm{i}}$. $\mathrm{T}_{\mathrm{i}}$ can also be viewed as the load $\mathrm{T}_{\mathrm{L}}$ from link $i$ to the actuator at joint $i$. By ignoring effective coupling torque from all other links to joint i term $\left(\mathrm{Tc}_{\mathrm{i}}\right)$, Equations (5.8) and (5.11) yields, 


$$
\mathrm{D}_{\mathrm{ii}} \ddot{\theta_{\mathrm{i}}}+\mathrm{B}_{\mathrm{i}} \dot{\theta}_{\mathrm{i}}=\frac{\mathrm{V}_{\mathrm{a}} \mathrm{K}_{\mathrm{t}}}{\mathrm{nR}_{\mathrm{a}}}-\frac{\mathrm{K}_{\mathrm{b}} \mathrm{K}_{\mathrm{t}}}{\mathrm{n}^{2} \mathrm{R}_{\mathrm{a}}} \dot{\theta}_{\mathrm{i}}-\frac{\mathrm{J}_{\mathrm{m}}}{\mathrm{n}^{2}} \ddot{\theta}_{\mathrm{i}}-\frac{\mathrm{B}_{\mathrm{v}}}{\mathrm{n}^{2}} \dot{\theta_{\mathrm{i}}}
$$

Combining terms, Equation (5.12) can be written as,

$$
\ddot{\theta_{i}}\left[D_{i i} n^{2}+J_{m}\right]+\dot{\theta}_{i}\left[B_{i} n^{2}+B_{v}+\frac{K_{b} K_{t}}{R_{a}}\right]=\frac{n_{a} K_{t}}{R_{a}}
$$

Simplifying coefficients by defining effective coefficient $\mathrm{Je}_{\mathrm{i}}$ and $\mathrm{Be}_{\mathrm{i}}$ as:

$$
\begin{aligned}
& \mathrm{Je}_{\mathrm{i}}=\frac{\mathrm{D}_{\mathrm{ii}}}{\mathrm{n}^{2}}+\mathrm{J}_{\mathrm{m}} \\
& \mathrm{Be}_{\mathrm{i}}=\frac{\mathrm{B}_{\mathrm{i}}}{\mathrm{n}^{2}}+\mathrm{B}_{v}
\end{aligned}
$$

Now, Equation (5.13) can be rewritten as:

$$
\mathrm{Je}_{\mathrm{i}} \ddot{\theta_{\mathrm{i}}}+\mathrm{Be}_{\mathrm{i}} \dot{\theta}_{\mathrm{i}}+\frac{\mathrm{K}_{\mathrm{b}} \mathrm{K}_{\mathrm{t}}}{\mathrm{R}_{\mathrm{a}}} \dot{\theta}_{\mathrm{i}}=\frac{\mathrm{nK} \mathrm{K}_{\mathrm{t}}}{\mathrm{R}_{\mathrm{a}}} \mathrm{V}_{\mathrm{a}_{\mathrm{i}}}
$$

where,

$\mathrm{Je}_{\mathrm{i}}=\mathrm{J}_{\text {eff }}=$ Effective inertia of joint $\mathrm{i}$

$\mathrm{Be}_{\mathrm{i}}=\mathrm{B}_{\text {eff }}=$ Effective coefficient of friction at joint $\mathrm{i}$

$\mathrm{Tc}_{\mathrm{i}}=$ Effective coupling torque from other links to joint $\mathrm{i}$

$\mathrm{V}_{\mathrm{a}_{\mathrm{i}}}=$ Voltage applied to actuator at joint $\mathrm{i}$

$\mathrm{n}=$ Harmonic drive speed ratio

$\ddot{\theta_{i}}=$ Angular acceleration of link $\mathrm{i}$

$\dot{\theta}_{i}=$ Angular velocity of link $\mathrm{i}$

The output of the integrated transfer function model of the joint $\mathrm{i}$ is the angular position of the joint, $\theta_{L}(s)$. The relation between the angular position $\theta_{L}(s)$ to the armature voltage $\mathrm{V}_{\mathrm{a}}$ (s) is obtained by taking the Laplace Transform of Equation (5.14), i.e.,

$$
\frac{\theta_{\mathrm{L}}(\mathrm{s})}{\mathrm{V}_{\mathrm{a}}(\mathrm{s})}=\frac{\mathrm{K}_{\mathrm{t}}}{\mathrm{ns}\left(\mathrm{sR}_{\mathrm{a}} \mathrm{J}_{\text {eff }}+\mathrm{R}_{\mathrm{a}} \mathrm{B}_{\text {eff }}+\mathrm{K}_{\mathrm{t}} \mathrm{K}_{\mathrm{b}}\right)}
$$


The relation between the angular velocity $\dot{\theta}_{\mathrm{m}}(\mathrm{s})$ to the armature voltage $\mathrm{V}_{\mathrm{a}}(\mathrm{s})$ is given by:

$$
\frac{\dot{\theta_{\mathrm{m}}}(\mathrm{s})}{\mathrm{V}_{\mathrm{a}}(\mathrm{s})}=\frac{\mathrm{K}_{\mathrm{t}}}{\mathrm{sR}_{\mathrm{a}} \mathrm{J}_{\text {eff }}+\mathrm{R}_{\mathrm{a}} \mathrm{B}_{\text {eff }}+\mathrm{K}_{\mathrm{t}} \mathrm{K}_{\mathrm{b}}}
$$

Equation (5.15) is the open-loop transfer function of the single joint relating the angular displacement to the applied voltage of the joint. The block diagram is shown in Figure 5.2 [4,pg.210].

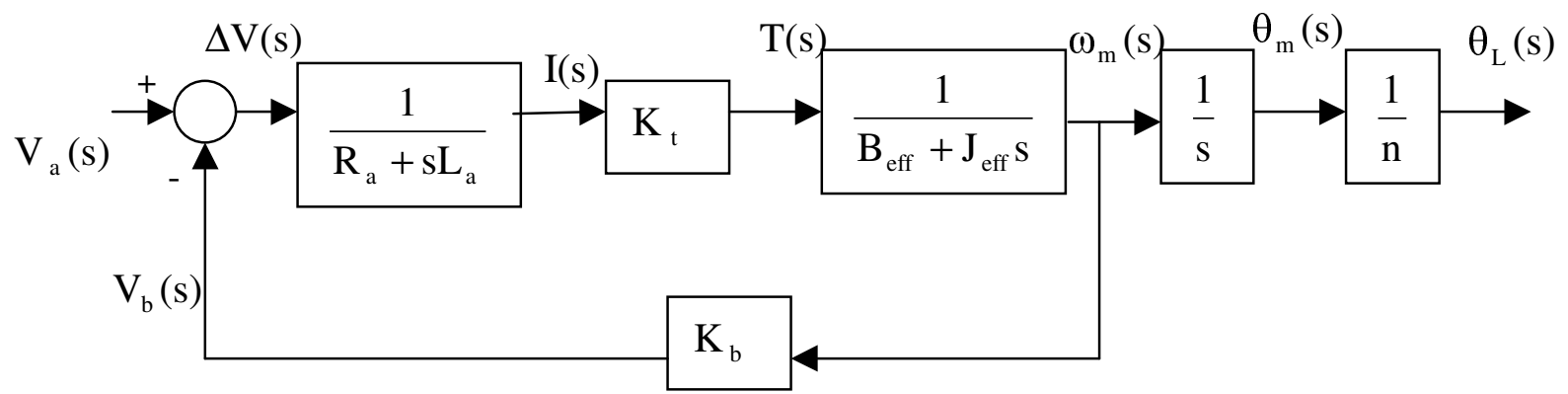

Figure 5.2 Block Diagram of Integrated Joint Dynamic Model for One Link

The motors in the joints of the SCARA-Type robot are SM series servomotors made by Parker Hannifin Corporation and all the three joints have similar actuators. The technical characteristics of the actuators are shown in Table 5.1.

\section{Table 5.1 Actuator Characteristics to Compute Open \& Closed Loop Transfer Function Model for SCARA-Type Robot}

\begin{tabular}{|c|c|}
\hline Resistance (Ra) & 9.65 ohms \\
\hline Inductance (La) & $4.08 \mathrm{mH}$ \\
\hline Viscous Damping (Bv) & 3.78E-3 Nm/Krpm \\
\hline Rotor Inertia (Jm) & $1.3 \mathrm{E}-4 \mathrm{~kg}-\mathrm{m}^{2}$ \\
\hline Voltage Constant $\left(\mathrm{K}_{\mathrm{b}}\right)$ & $0.484 \mathrm{volts} / \mathrm{rad} / \mathrm{sec}$ \\
\hline Torque Constant $\left(\mathrm{K}_{\mathrm{t}}\right)$ & $0.48 \mathrm{Nm} / \mathrm{Amp} \mathrm{DC}$ \\
\hline Effective Inertia $\left(\mathrm{J}_{\mathrm{eff}_{1}}, \mathrm{~J}_{\mathrm{eff}_{2}}, \mathrm{~J}_{\mathrm{eff}_{3}}\right)$ & $4.072 \mathrm{~kg}-\mathrm{m}^{2}, 0.4344 \mathrm{~kg}-\mathrm{m}^{2}, 0.116 \mathrm{~kg}-\mathrm{m}^{2}$ \\
\hline Effective Friction $\left(\mathrm{B}_{\mathrm{eff}}\right)$ & 3.81E-3 Nm/Krpm \\
\hline
\end{tabular}

For deriving the transfer function model for the SCARA-Type robot the moment of inertias [4, 9] of the links play an important role. The moments of inertia of the actuators and the links are added to get the effective moments of inertia to derive the 
transfer function model for the three joints. The inertias of three links are shown in Table 5.2 .

Table 5.2 Moments of Inertia of the Three Links

\begin{tabular}{|c|c|}
\hline Link & Inertias \\
\hline 1. & 0.031 slug- $\mathrm{ft}^{\wedge} 2$ or $0.35 \mathrm{~kg}-\mathrm{m}^{\wedge} 2$ \\
\hline 2. & $1.55^{*} 10^{\wedge}-3$ slug- $\mathrm{ft}^{\wedge} 2$ or $0.01 \mathrm{~kg}-\mathrm{m}^{\wedge} 2$ \\
\hline 3. & $3.11^{*} 10^{\wedge}-3$ slug- $\mathrm{ft}^{\wedge} 2$ or $0.0358 \mathrm{~kg}-\mathrm{m}^{\wedge} 2$ \\
\hline
\end{tabular}

\subsection{OPEN-LOOP TRANSFER FUNCTION MODEL FOR THE THREE JOINTS OF THE SCARA-TYPE ROBOT}

The open-loop transfer function $[10,11]$ for the integrated joint dynamics for joint 1 , whose output is the angular velocity of the motor, is derived by substituting the constants in Table 5.1 and 5.2 in Equation (5.16) to obtain:

$$
\mathrm{G}_{1}(\mathrm{~s})=\frac{\dot{\theta_{\mathrm{m}}}(\mathrm{s})}{\mathrm{V}_{\mathrm{a}}(\mathrm{s})}=\frac{0.0096}{39 \mathrm{~s}+0.27}
$$

The step response $[11,14]$ for this transfer function is shown in Figure 5.3.

The coefficient "39" in Equation (5.17) represents a case when the robot is fully stretched out and hence the moments of inertia of link 2 and link 3 are added to the moment of inertia of link 1 to calculate the coefficient "39". The coefficient changes with the change in the angles of joint 2 and joint 3 . The coefficient has to be changed for different angles of joint 2 and joint 3 to maintain controlled trajectory.

The moment of inertia at joint 1 is calculated for the case when the robot is operating in minimum workspace volume. The open-loop transfer function for the integrated joint dynamics for joint 1 , with the robot working in minimum workspace volume is:

$$
\mathrm{G}_{1}(\mathrm{~s})=\frac{\dot{\theta_{\mathrm{m}}}(\mathrm{s})}{\mathrm{V}_{\mathrm{a}}(\mathrm{s})}=\frac{0.0096}{17 \mathrm{~s}+0.27}
$$

The relative stability and the transient performance of the system are directly related to the location of roots of the characteristic equation in s-plane. Often it is required to adjust system parameters in order to obtain suitable root locations. Hence it is 
worthwhile to determine the roots of the characteristic equation $[4,11,12]$ of a given system to study the behavior of the system.

The open loop transfer function of the system is:

$$
\mathrm{G}(\mathrm{s})=\frac{\dot{\theta}_{\mathrm{m}}(\mathrm{s})}{\mathrm{V}_{\mathrm{a}}(\mathrm{s})}=\frac{\mathrm{nK}_{\mathrm{t}}}{\mathrm{sR}_{\mathrm{a}} \mathrm{J}_{\text {eff }}+\mathrm{R}_{\mathrm{a}} \mathrm{B}_{\text {eff }}+\mathrm{K}_{\mathrm{t}} \mathrm{K}_{\mathrm{b}}}
$$

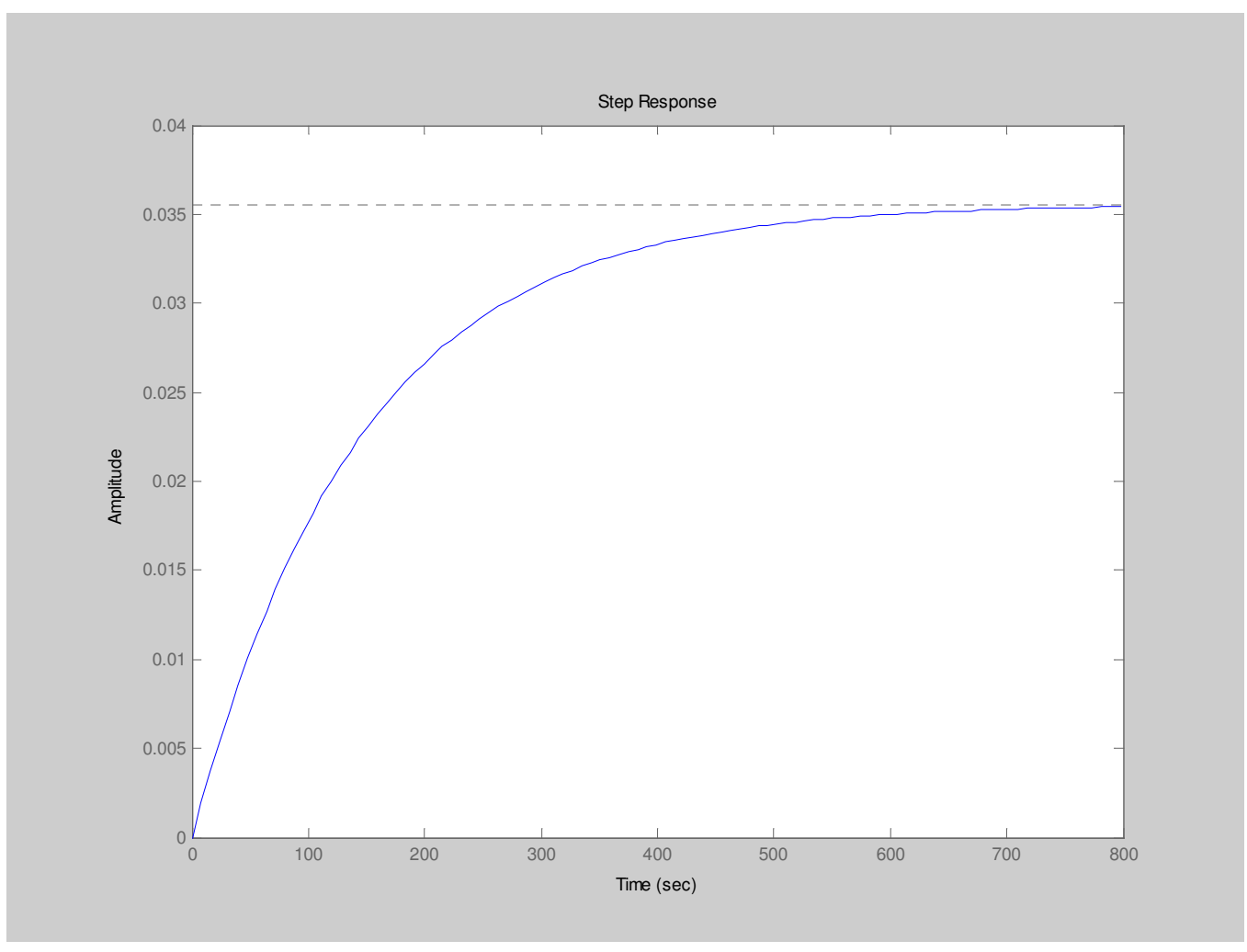

Figure 5.3 Open-Loop Step Response for Integrated Dynamic Model of Link-Actuator 1

Let the system have a unity feedback. Therefore the characteristic equation for joint 1 is written as,

$$
1+\mathrm{G}_{1}(\mathrm{~s})=0
$$

where,

$$
\mathrm{G}_{1}(\mathrm{~s})=\frac{0.0096}{39 \mathrm{~s}+0.27}
$$


Therefore the characteristic equation for joint 1 (with gain $\mathrm{K}=1$ ) is:

$$
\begin{aligned}
& 1+\frac{0.0096}{39 s+0.27}=0 \\
& 39 \mathrm{~s}+0.2796=0 \\
& \mathrm{~s}=0.00717
\end{aligned}
$$

The root-locus plot using Matlab is shown in Figure 5.4

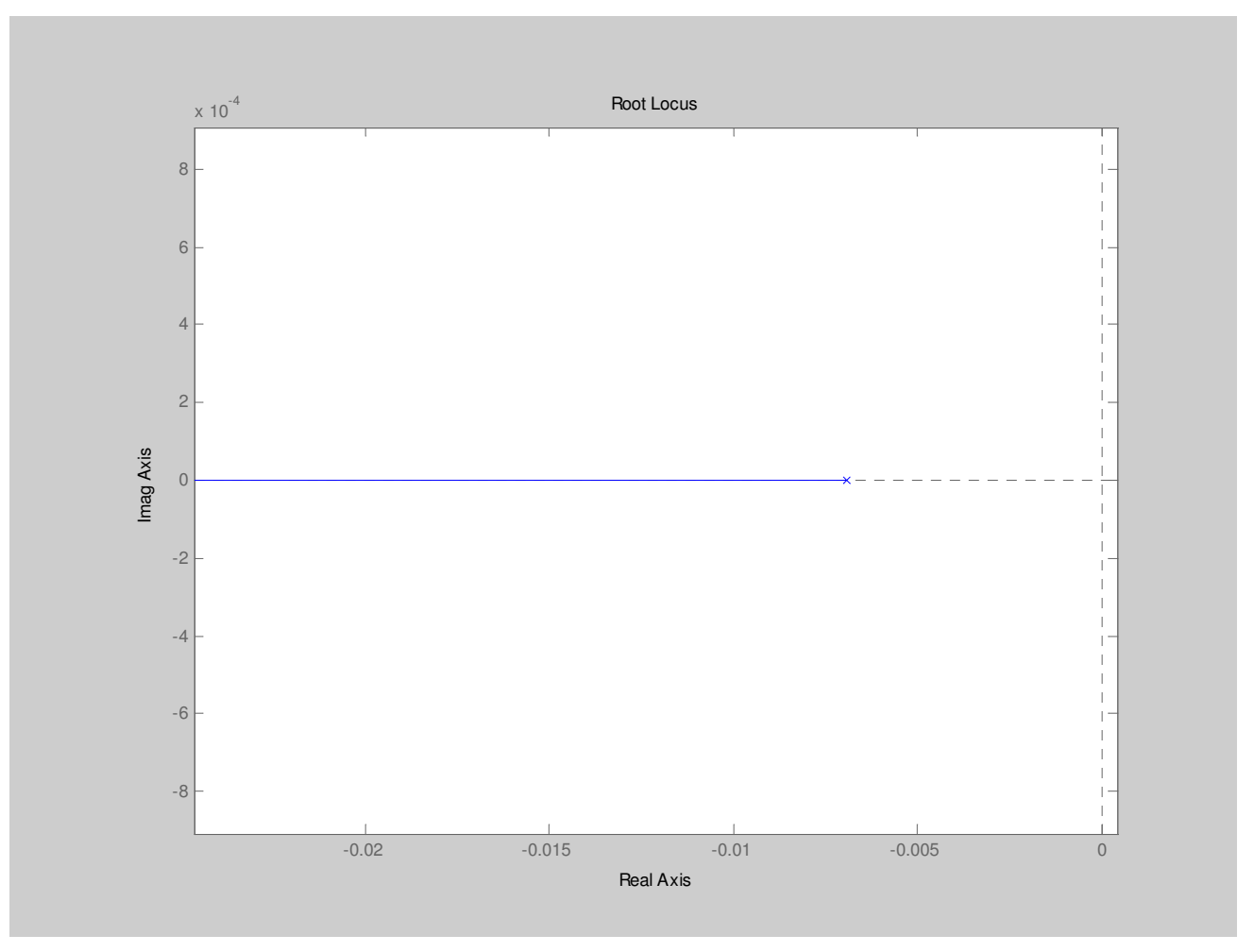

Figure 5.4 Open-Loop Root Locus for Integrated Dynamic Model of Link-Actuator 1

From the root-locus plot $[11,14]$ of the open-loop transfer function (Equation (5.17)) as shown in Figure 5.4, the pole is determined as:

$$
s=-0.00716
$$

The graphical representation of the frequency response method is called as Bode plot $[11,14]$. Bode plot of the system gives the steady state response of the system for 
sinusoidal input signal. It was tedious to locate the poles and zeros using frequency response method therefore Bode plot was introduce by H.W.Bode to get graphical representation of poles and zeros [14].

Bode plot for joint 1 with gain $(\mathrm{K}=1)$ is shown in Figure 5.5.

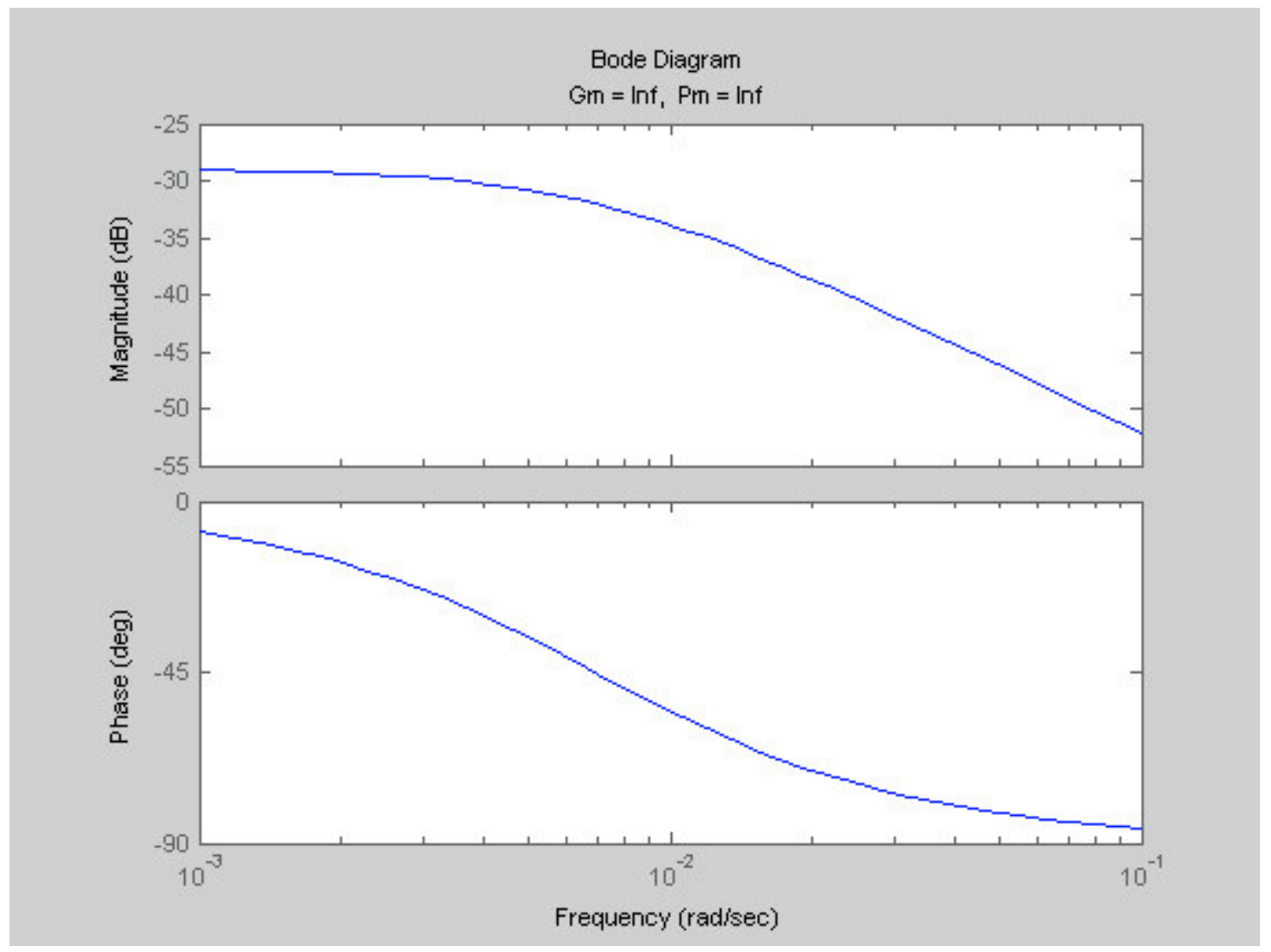

Figure 5.5 Open-Loop Bode Plot for Integrated Dynamic Model of Link-Actuator 1

The gain margin and phase margin [11] of the open-loop transfer function model for Joint $1(\mathrm{~K}=1)$ are,

$\mathrm{Gm}=\inf \mathrm{db}$

$\mathrm{Pm}=$ inf degrees

The open-loop transfer function model for joint 2 is computed using values shown in Table 5.1 and Table 5.2 as: 


$$
\mathrm{G}_{2}(\mathrm{~s})=\frac{\dot{\theta_{\mathrm{m}}}(\mathrm{s})}{\mathrm{V}_{\mathrm{a}}(\mathrm{s})}=\frac{0.0096}{4.2 \mathrm{~s}+0.27}
$$

The step response of the transfer function model for joint 2 is shown in Figure 5.6

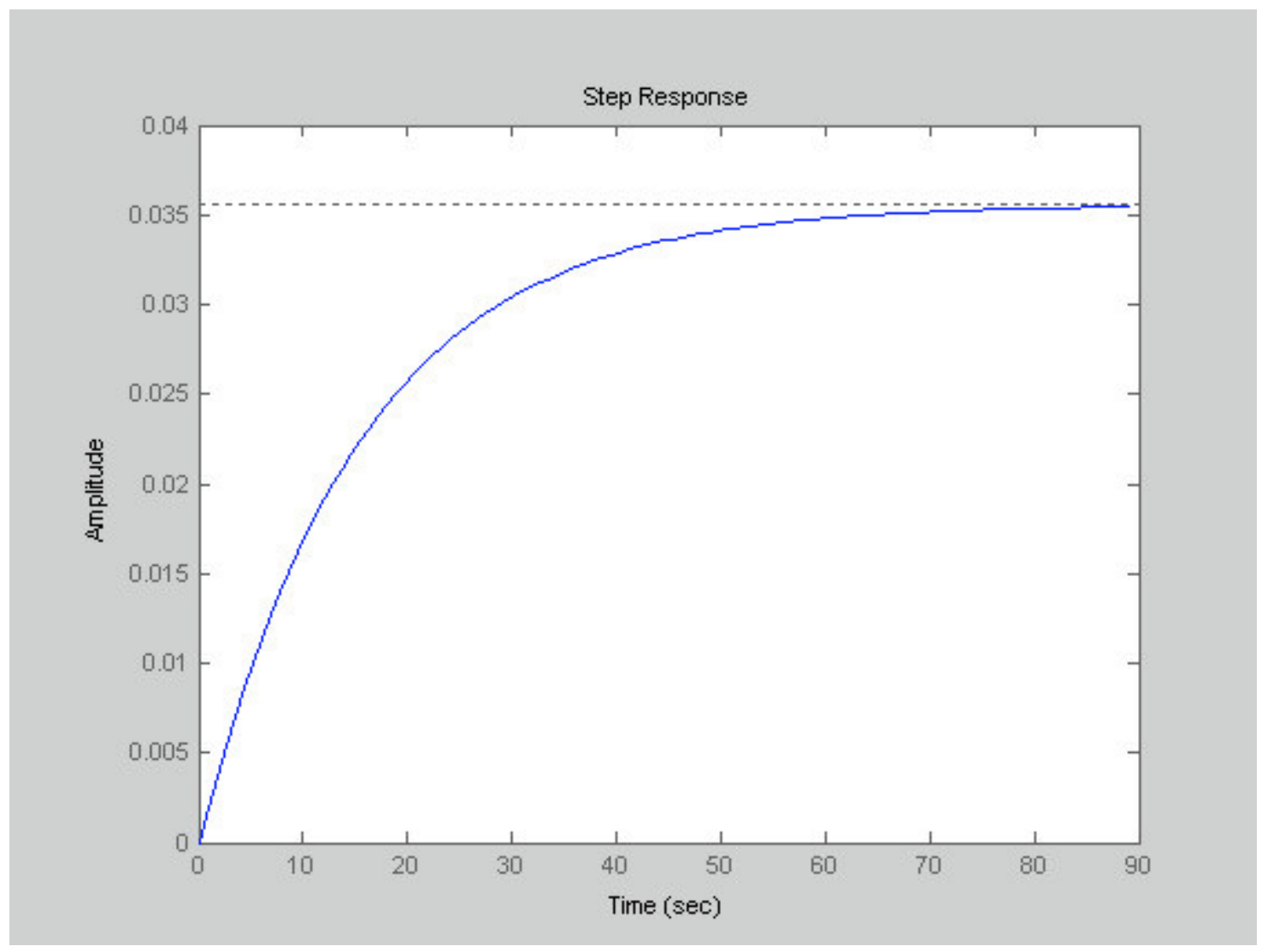

Figure 5.6 Open-Loop Step Response for Integrated Dynamic Model of Link-Actuator 2

The characteristic equation for joint $2($ with gain $\mathrm{k}=1$ ) is:

$$
\begin{aligned}
& 1+\mathrm{G}_{2}(\mathrm{~s})=0 \\
& \mathrm{G}_{2}(\mathrm{~s})=\frac{0.0096}{4.2 \mathrm{~s}+0.27}
\end{aligned}
$$

Therefore the characteristic equation for joint 2 is:

$$
\begin{aligned}
& 1+\frac{0.0096}{4.2 \mathrm{~s}+0.27}=0 \\
& 4.2 \mathrm{~s}+0.2796=0
\end{aligned}
$$


$s=-0.066$

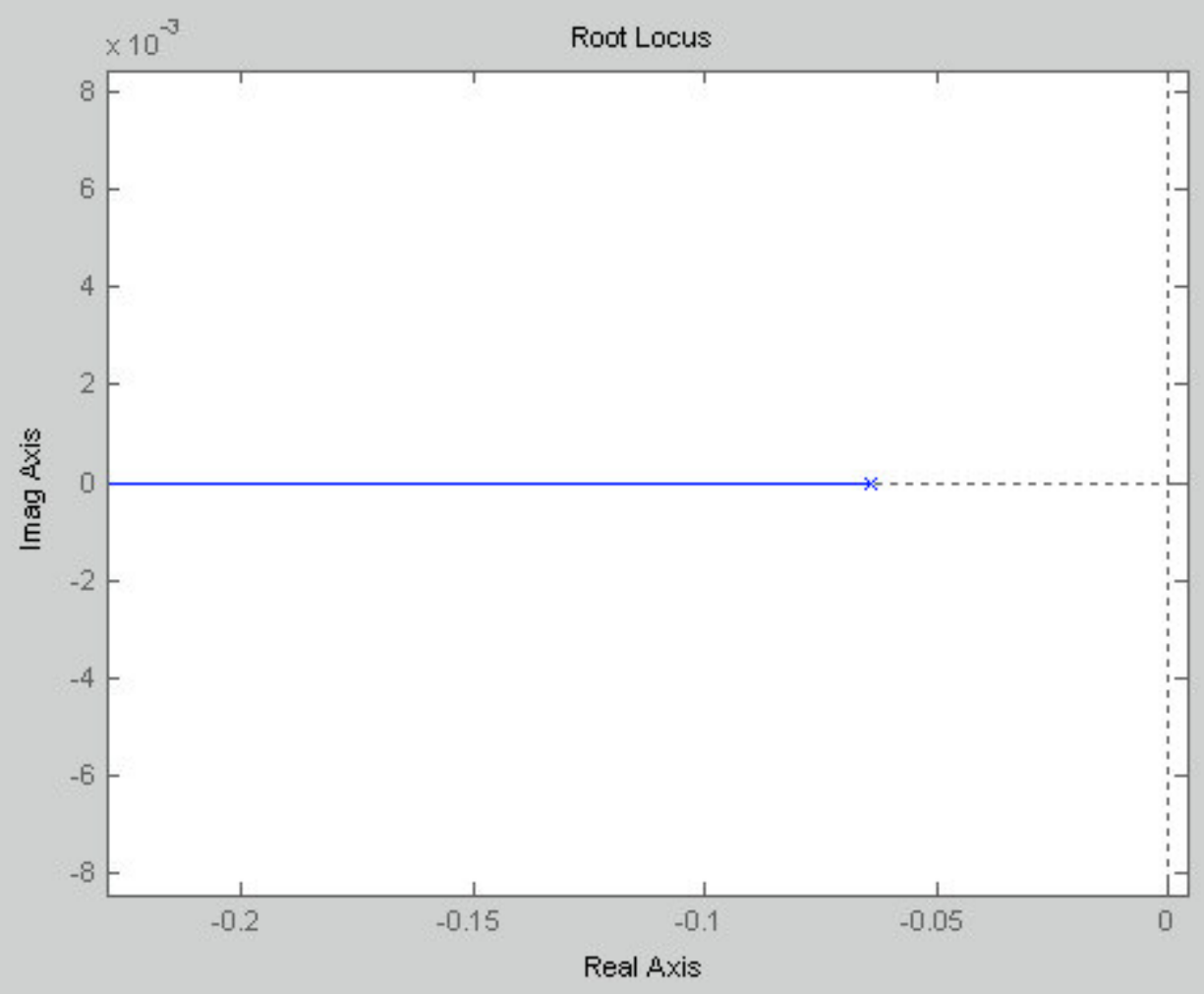

Figure 5.7 Open Loop Root Locus for Integrated Dynamic model of Link-Actuator2

From the root-locus plot of the open loop transfer function as shown in Figure 5.7, the pole is determined as:

$s=-0.066$

Bode plot for joint 2 is shown in Figure 5.8 with gain $\mathrm{K}=1$. 


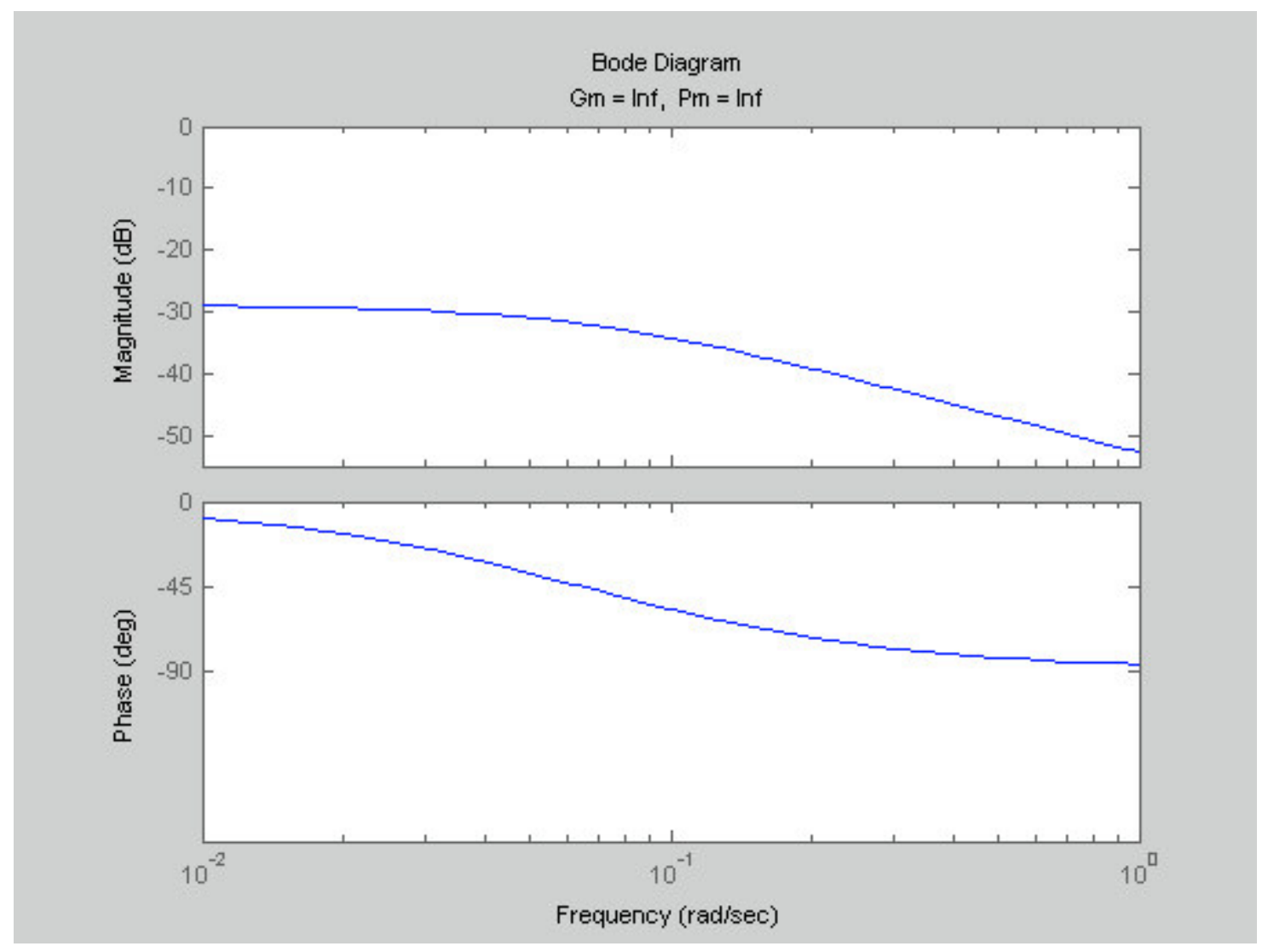

Figure 5.8 Open-Loop Bode Plot for Integrated Dynamic Model of Link-Actuator 2

The open-loop transfer function for joint 3 is computed using Equations from (5.1) to (5.14). As mentioned earlier that link 3 moves in vertical plane. Therefore, to derive the open-loop transfer function for joint 3 of the robot the acceleration due to gravity factor has to be considered. As seen from Figure 5.9 the torque for the link 3 at joint 3 is [12]:

$$
\mathrm{T}_{3}(\mathrm{~L})=\mathrm{m}_{3} * \mathrm{~g} * \mathrm{Lc} * \cos (\theta)+\mathrm{m}_{3} * \mathrm{Lc}^{2} * \ddot{\theta}+\mathrm{B}_{\mathrm{L}} * \dot{\theta}
$$

Equation (5.20) is simplified for calculation and written as:

$$
\mathrm{T}_{3}(\mathrm{~L})=\mathrm{m}_{3} * \mathrm{~g} * \mathrm{Lc} * \theta_{\mathrm{L}}+\mathrm{m}_{3} * \mathrm{Lc}^{2} * \ddot{\theta}_{\mathrm{L}}+\mathrm{B}_{\mathrm{T}} * \dot{\theta_{\mathrm{L}}}
$$

The motor torque referred to motor shaft is given as:

$$
\mathrm{T}_{\mathrm{m}}(\mathrm{t})=\mathrm{J}_{\mathrm{m}} \ddot{\theta}_{\mathrm{m}}+\mathrm{B}_{\mathrm{m}} \dot{\theta_{\mathrm{m}}}
$$


Also,

$$
\mathrm{T}_{\mathrm{L}}^{*}=\mathrm{n}^{*} \mathrm{~T}_{3}(\mathrm{~L})
$$

Hence the net torque becomes:

$$
\mathrm{T}=\mathrm{T}_{\mathrm{m}}(\mathrm{t})+\mathrm{T}_{\mathrm{L}}^{*}
$$

After simplification the open-loop transfer function for joint 3 is calculated as:

$$
\frac{\theta_{\mathrm{L}}(\mathrm{s})}{\mathrm{V}_{\mathrm{a}}(\mathrm{s})}=\frac{\mathrm{nK}_{\mathrm{t}}}{\mathrm{s}^{2}\left[\mathrm{~J}_{\text {eff }} \mathrm{R}_{\mathrm{a}}+\mathrm{n}^{2} \mathrm{~m}_{3} \mathrm{~L}_{\mathrm{c}}{ }^{2} \mathrm{R}_{\mathrm{a}}\right]+\mathrm{s}\left[\mathrm{B}_{\mathrm{m}} \mathrm{R}_{\mathrm{a}}+\mathrm{n}^{2} \mathrm{~B}_{\mathrm{L}} \mathrm{R}_{\mathrm{a}}+\mathrm{K}_{\mathrm{t}} \mathrm{K}_{\mathrm{b}}\right]+\mathrm{n}^{2} \mathrm{~m}_{3} \mathrm{gL}_{\mathrm{c}} \mathrm{R}_{\mathrm{a}}}
$$

where,

$$
\begin{aligned}
& \mathrm{m}_{3}=\text { mass of link } 3=2.1 \mathrm{~kg} \\
& \mathrm{~g}=\text { acceleration due to gravity }=9.8 \mathrm{~m} / \mathrm{sec}^{2} \\
& \mathrm{n}=\text { gear ratio }=1 / 50 \\
& \mathrm{Lc}=\mathrm{L} 3 / 2=0.39 / 2=0.195 \mathrm{~m} \\
& \mathrm{~J}_{\text {eff }}=0.1159 \mathrm{~kg}-\mathrm{m}^{2}
\end{aligned}
$$

Substituting the values from Table 5.1 in Equation (5.22) and simplifying, the open-loop transfer function for joint 3 is computed as:

$$
\mathrm{G}_{3}(\mathrm{~s})=\frac{\theta_{\mathrm{L}}(\mathrm{s})}{\mathrm{V}_{\mathrm{a}}(\mathrm{s})}=\frac{0.0096}{1.12 \mathrm{~s}^{2}+0.27 \mathrm{~s}+0.016}
$$

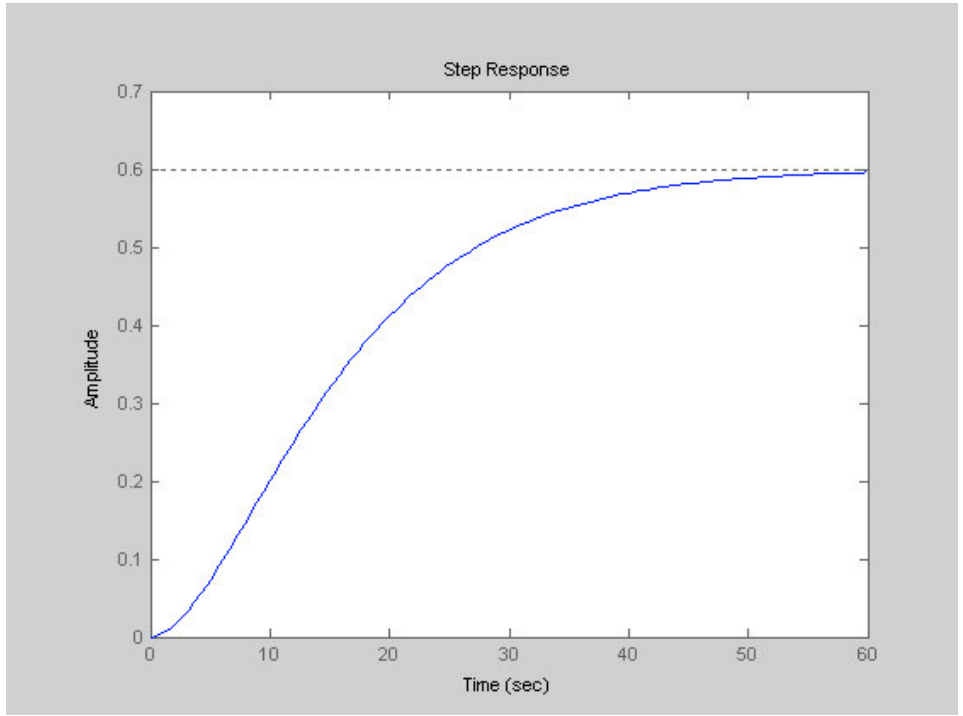

Figure 5.9 Open-Loop Step Response for Integrated Dynamic Model of Link-Actuator 3 
The root-locus plot for open-loop transfer function for joint 3 is:

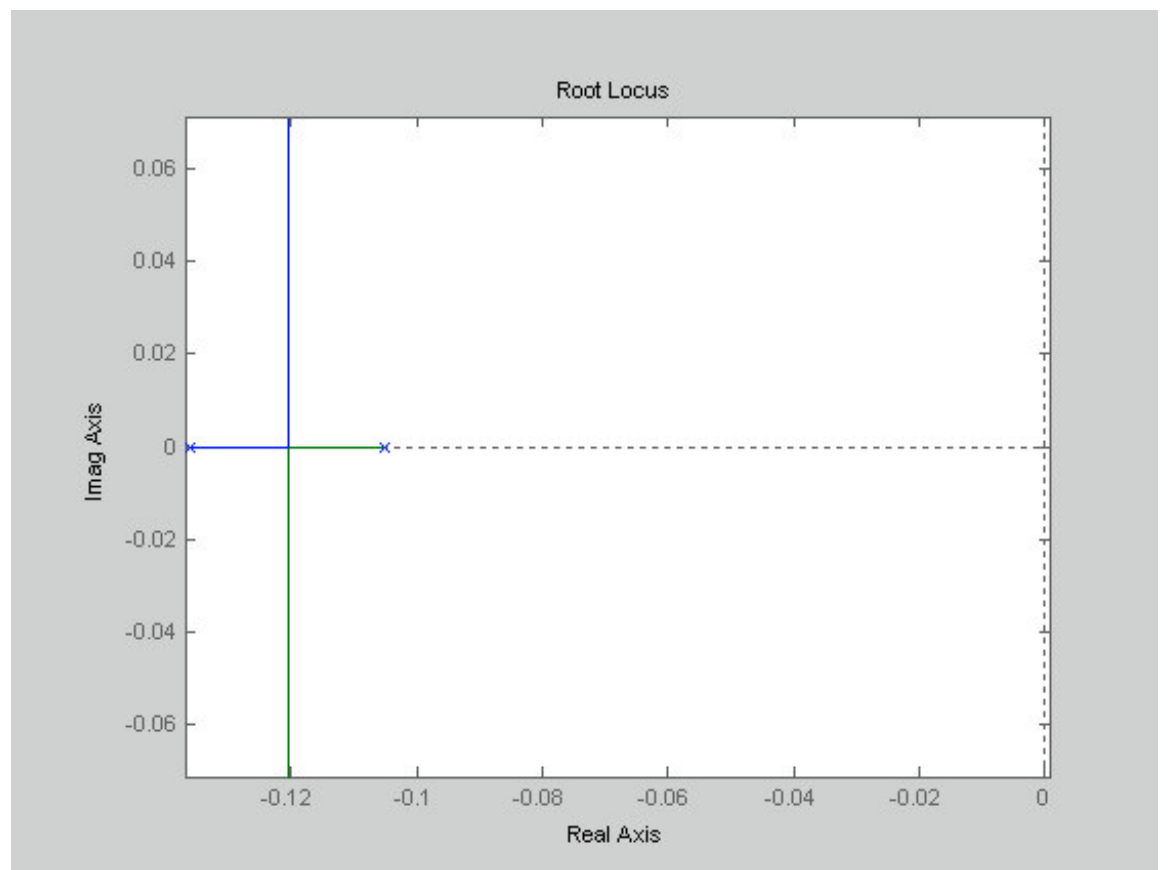

Figure 5.10 Open Loop Root Locus for Integrated Dynamic Model of Link-Actuator 3

The roots of the open-loop transfer function from the root-locus plot are determined as:

$$
\begin{aligned}
& s=-0.1361 \\
& s=-0.1049
\end{aligned}
$$

The Bode plot of the open-loop transfer function for joint 3 is shown in Figure 5.11

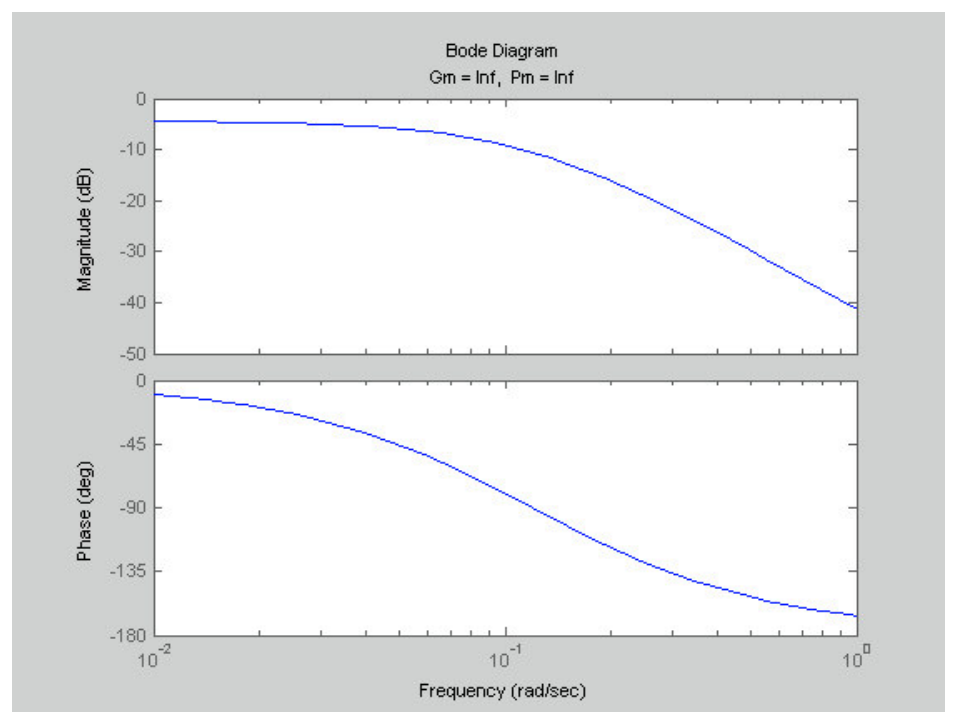

Figure 5.11 Open-Loop Bode Plot for Integrated Dynamic Model of Link-Actuator 3 


\subsection{TRANSFER FUNCTION MODEL FOR INDEPENDENT LINK-JOINT 3}

Joint 3 of the robot moves the third link of the robot in vertical plane. Therefore, link 3 can be treated as free link moving in the vertical plane under the influence of acceleration due to gravity as shown in Figure 5.12.

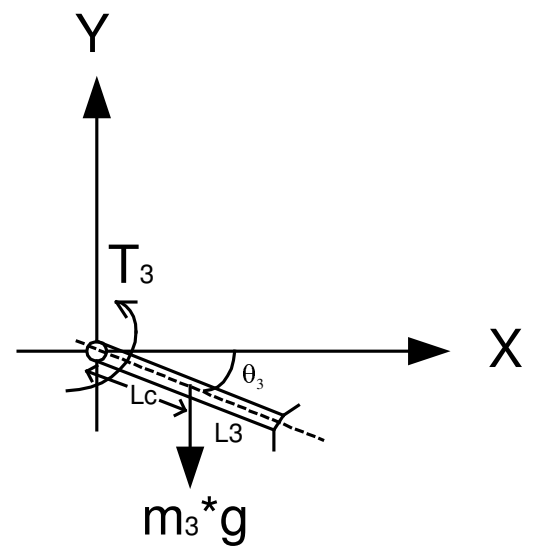

Figure 5.12 Link-Joint 3 Motion of Robot

The governing equation for link 3 is written as:

$$
\mathrm{T}_{3}=\mathrm{m}_{3} * \mathrm{~g} * \mathrm{Lc} * \cos (\theta)+\mathrm{m}_{3} * \mathrm{Lc}^{2} * \ddot{\theta}+\mathrm{B}_{\mathrm{T}} * \dot{\theta}
$$

The control law equation for joint 3 can be written as:

$$
\mathrm{m}_{3} * \mathrm{Lc}^{2} * \ddot{\theta}+\left(\mathrm{B}_{\mathrm{T}}+\mathrm{K}_{2}\right) \dot{\theta}+\mathrm{K}_{1} * \theta=0 ;
$$

By applying Laplace Transform to Equation (5.25), it can be written as:

$$
\left[\mathrm{s}^{2} * \mathrm{~m}_{3} * \mathrm{Lc}^{2}+\left(\mathrm{B}_{\mathrm{T}}+\mathrm{K}_{2}\right) \mathrm{s}+\mathrm{K}_{1}\right] * \theta=0 ;
$$

where:

$$
\begin{aligned}
& \mathrm{B}_{\mathrm{T}}=\text { Rotational Friction Coefficient; } \\
& \mathrm{L}_{3}=\text { Length of Link } 3 \\
& \mathrm{Lc}=\mathrm{L}_{3} / 2 ; \\
& \mathrm{K}_{1}=\text { Stiffness; } \\
& \mathrm{B}_{\mathrm{T}}+\mathrm{K}_{2}=\text { Friction Coefficient; }
\end{aligned}
$$

To control the position of link 3, $\mathrm{K}_{1}$ and $\mathrm{K}_{2}$ can be adjusted. 
Therefore the transfer function model for link-joint 3 is:

$$
\frac{\theta_{3}(\mathrm{~s})}{\mathrm{T}(\mathrm{s})}=\frac{1}{\mathrm{~s}^{2} *(0.3) *(0.2)^{2}+\left(3.78 * 10^{-3}+\mathrm{K}_{2}\right) * \mathrm{~s}+\mathrm{K}_{1}}
$$

Appropriate gain values were chosen to make torque proportional to angle.

Hence, the transfer function model for link-joint 3 becomes:

$$
\frac{\theta_{3}(\mathrm{~s})}{\mathrm{T}(\mathrm{s})}=\frac{1}{0.012 * \mathrm{~s}^{2}+0.061 * \mathrm{~s}+0.1}
$$

The step response for the Equation (5.27) is shown in Figure 5.13

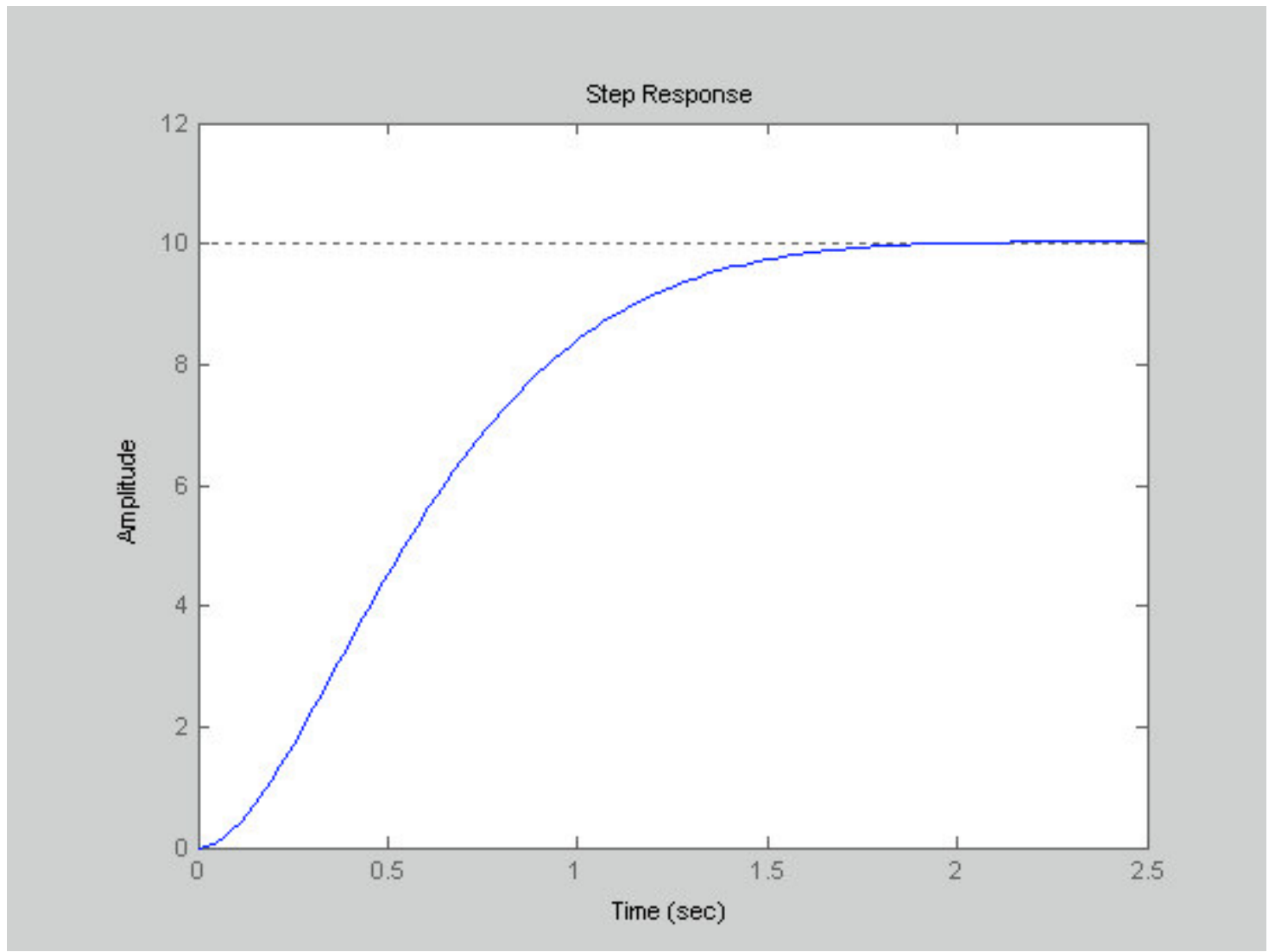

Figure 5.13 Step Response for Independent Link-Joint 3 Model 


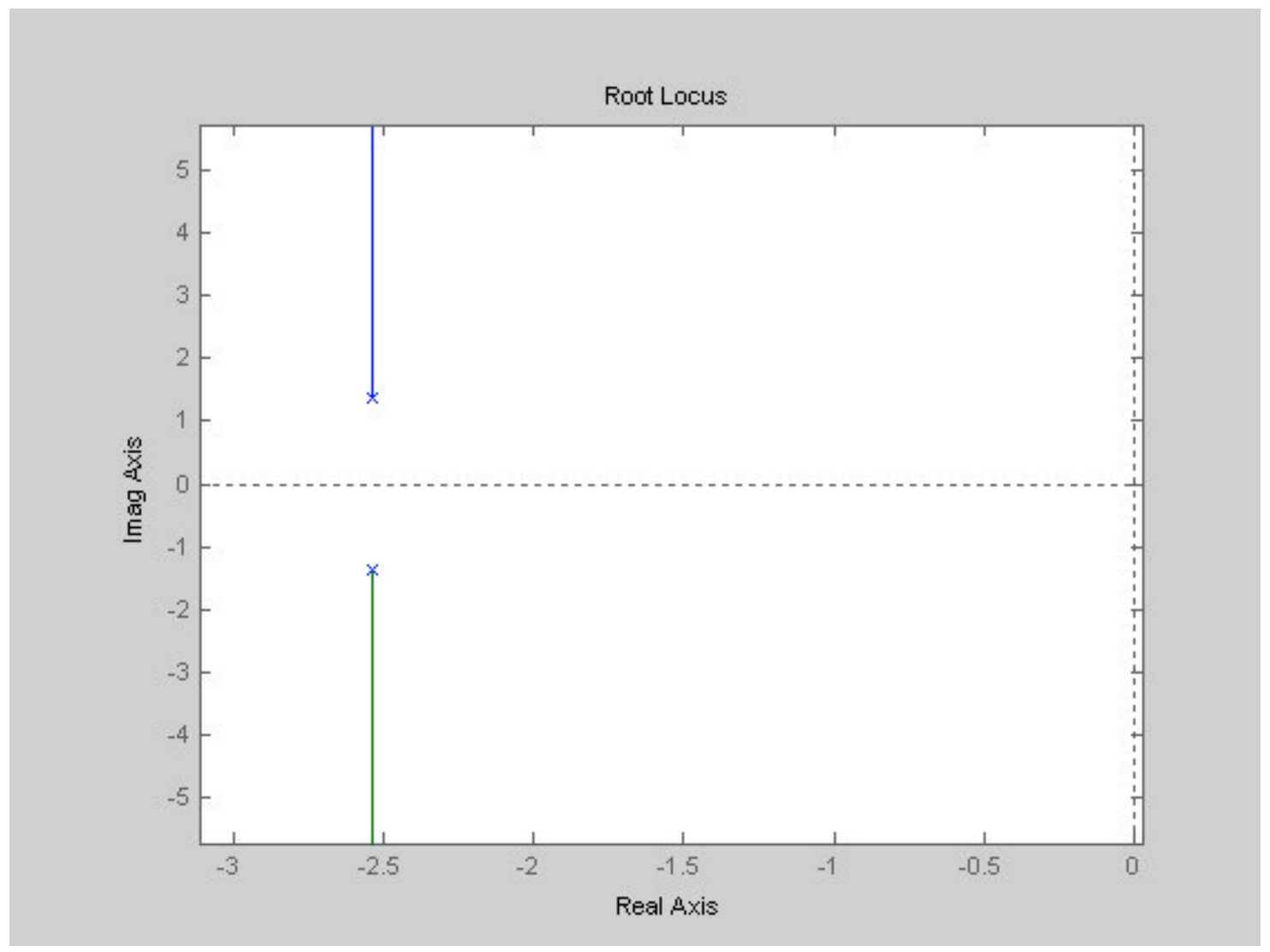

Figure 5.14 Root Locus Plot for Independent Link-Joint 3 Model

From the root locus plot of the transfer function model of Equation (5.25) as shown in Figure 5.14, the poles are determined as:

$$
\begin{aligned}
& \mathrm{s}_{1}=-2.5417+1.3687 \mathrm{i} \\
& \mathrm{s}_{2}=-2.5417-1.3687 \mathrm{i}
\end{aligned}
$$

The link-joint 3 system is stable since the root locus plot shows that the roots lie in the left hand side of s-plane.

Bode plot is shown in Figure 5.15. 


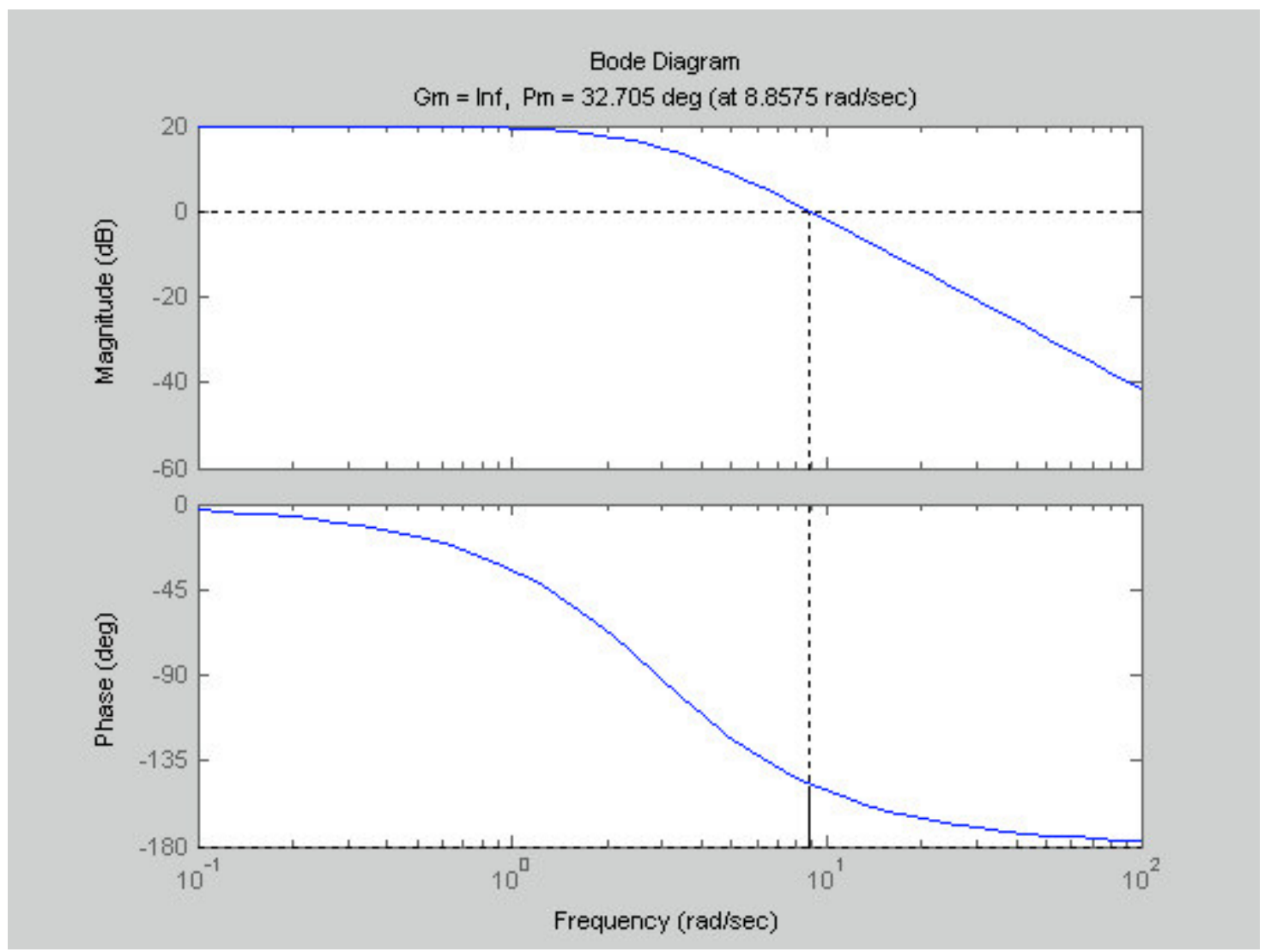

Figure 5.15 Bode Plot for Independent Link-Joint 3 Model

The independent link-joint 3 system position can be controlled by changing the values of $\mathrm{K}_{1}$ and $\mathrm{K}_{2}$. 


\section{Chapter 6 \\ Controller Design}

\subsection{METHODOLOGY}

PID controllers [10, 11, 14] were designed using classical control theory to achieve reasonable gain and phase margin, over-damped system and zero steady state error.

\subsection{CONTROLLER DESIGNS FOR JOINTS OF SCARA-TYPE ROBOT}

The goal for this section is to design controllers and derive transfer functions for the three joints of the SCARA-Type robot and to analyze the performance of a controller designed for the joint dynamic model for the SCARA-Type robot. The controllers will be developed based on the desired operating behavior (pick-to-place task) of the joints and physical characteristics of the three links of the robot.

The controller can be classified as many types but some of the four main types of controllers [8] are: Proportional (P), Proportional plus Integral (PI), Proportional plus Derivative (PD) and Proportional plus Integral plus Derivative (PID). A PID controller is designed and analyzed for each joint of the SCARA-Type robot.

Each joint of the robot can be treated independently but the inertias of the other joints are included to design a controller for a particular link-joint.

\subsection{PROPORTIONAL, DERIVATIVE AND INTEGRAL (PID) CONTROLLER FOR A SINGLE JOINT}

The purpose of the three PID controllers is to servo the three actuators in the joints of the robot manipulator so that the actual angular displacement of the joint will track a desired angular displacement specified by a planned pick-to-place trajectory. The trajectory derivation and description is given in Chapter 4. The designing of a PID controller and then deriving the transfer function for the closed-loop system is based on using the error signal between the desired and actual angular positions of the joint to actuate an appropriate voltage. The applied voltage $\mathrm{V}_{\mathrm{a}}(\mathrm{t})$ to the motor is linearly 
proportional to the error between the desired and actual angular displacements, error in angular velocities and error in integral of angular displacements of the joint as shown in Equation (6.1).

$$
V_{a}(t)=\frac{K_{p}\left[\theta_{L}{ }^{d}(t)-\theta_{L}(t)\right]+K_{d} \frac{d}{d t}\left[\theta_{L}{ }^{d}(t)-\theta_{L}(t)\right]+K_{i}\left[\int\left(\theta_{L}{ }^{d}(t)-\theta_{L}(t)\right) d t\right]}{n}
$$

where $\mathrm{K}_{\mathrm{p}}$ is the proportional feedback gain, $\mathrm{K}_{\mathrm{d}}$ is the derivative feedback gain and $\mathrm{K}_{\mathrm{i}}$ is integral feedback gain in volts per radian, volts per radian per sec and volts per radiansec. Also e $(\mathrm{t})=\left[\theta_{\mathrm{L}}{ }^{\mathrm{d}}(\mathrm{t})-\theta_{\mathrm{L}}(\mathrm{t})\right]$, (defined as the system error), $\dot{\mathrm{e}}(\mathrm{t})=\left[\dot{\theta}_{\mathrm{L}}{ }^{\mathrm{d}}(\mathrm{t})-\dot{\theta}_{\mathrm{L}}(\mathrm{t})\right]$ and $\int e(t) d t=\int\left[\theta_{L}{ }^{d}(t)-\theta_{L}(t)\right] d t$. Speed ratio is $n$, which is included in Equation (6.1) to compute the applied voltage, referred to the motor shaft speed. By adding a PID controller and unity negative feedback, the open-loop link-actuator system is converted into a closed-loop control system.

Taking the Laplace Transform of Equation (6.1), yields:

$$
V_{a}(s)=\frac{K_{p} E(s)+K_{d} s E(s)+K_{i} \frac{E(s)}{s}}{n}
$$

Substituting $\mathrm{V}_{\mathrm{a}}(\mathrm{s})$ into Equation (5.16) yields an open-loop transfer function $\mathrm{G}_{\mathrm{o}}(\mathrm{s})$ for single link relating the error actuating signal $\mathrm{E}(\mathrm{s})$ to the actual displacement of the joint:

$$
\mathrm{G}_{\mathrm{o}}(\mathrm{s})=\frac{\theta_{\mathrm{L}}(\mathrm{s})}{\mathrm{E}(\mathrm{s})}=\frac{\mathrm{nK}_{\mathrm{t}}}{\left.\mathrm{s}_{(} \mathrm{sR}_{\mathrm{a}} \mathrm{J}_{\text {eff }}+\mathrm{R}_{\mathrm{a}} \mathrm{B}_{\text {eff }}+\mathrm{K}_{\mathrm{t}} \mathrm{K}_{\mathrm{b}}\right)} * \frac{1}{\mathrm{n}} * \frac{\mathrm{K}_{\mathrm{p}} \mathrm{s}+\mathrm{K}_{\mathrm{i}}+\mathrm{K}_{\mathrm{d}} \mathrm{s}^{2}}{\mathrm{~s}}
$$

One can obtain the closed-loop transfer function $\mathrm{T}_{\mathrm{c}}(\mathrm{s})$ relating the actual angular displacement $\theta_{\mathrm{L}}(\mathrm{s})$ to desired angular displacement $\theta^{\mathrm{d}}{ }_{\mathrm{L}}(\mathrm{s})$, with some simple algebraic manipulations.

The closed-loop system with PID controller is shown in Figure 6.1 [1]. 


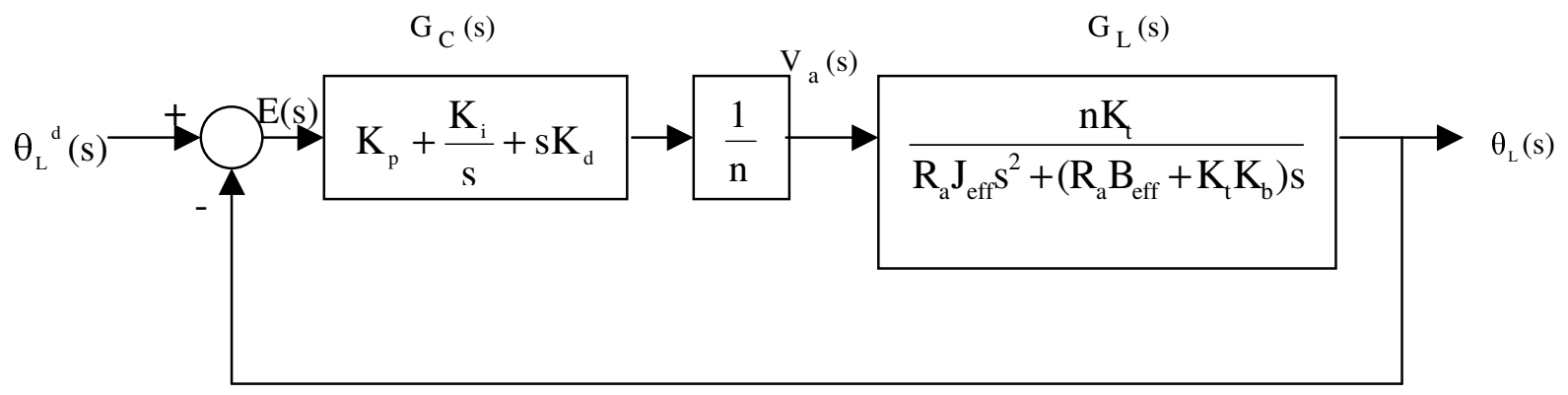

Figure 6.1 Closed-Loop System with PID Controller

From Figure 6.1, the overall transfer function for a single joint of the robot from $\theta_{\mathrm{L}}{ }^{\mathrm{d}}(\mathrm{s})$ to $\theta_{\mathrm{L}}(\mathrm{s})$ is shown in Figure 6.2

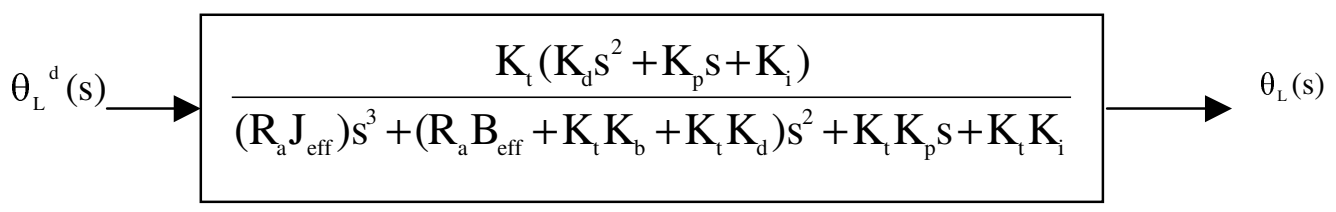

Figure 6.2 Transfer Function of Single Joint Closed-Loop System with PID Controller

Therefore the closed-loop transfer function is written as:

$$
\begin{aligned}
& \mathrm{T}_{\mathrm{c}}(\mathrm{s})=\frac{\theta_{\mathrm{L}}(\mathrm{s})}{\theta^{\mathrm{d}}{ }_{\mathrm{L}}(\mathrm{s})} \\
& =\frac{\mathrm{K}_{\mathrm{t}}\left(\mathrm{K}_{\mathrm{d}} \mathrm{s}^{2}+\mathrm{K}_{\mathrm{p}} \mathrm{s}+\mathrm{K}_{\mathrm{i}}\right) / \mathrm{R}_{\mathrm{a}} \mathrm{J}_{\text {eff }}}{\mathrm{s}^{3}+\left[\left(\mathrm{R}_{\mathrm{a}} \mathrm{B}_{\text {eff }}+\mathrm{K}_{\mathrm{t}} \mathrm{K}_{\mathrm{b}}+\mathrm{K}_{\mathrm{t}} \mathrm{K}_{\mathrm{d}}\right) / \mathrm{R}_{\mathrm{a}} \mathrm{J}_{\text {eff }}\right] \mathrm{s}^{2}+\mathrm{K}_{\mathrm{t}} \mathrm{K}_{\mathrm{p}} \mathrm{s} / \mathrm{R}_{\mathrm{a}} \mathrm{J}_{\text {eff }}+\mathrm{K}_{\mathrm{t}} \mathrm{K}_{\mathrm{i}} / \mathrm{R}_{\mathrm{a}} \mathrm{J}_{\text {eff }}}
\end{aligned}
$$

Equation (6.3) shows that adding the PID controller for the single link-joint results in a third-order system. Controlling the amount of proportional or derivative or integral action makes it possible to design the control system to achieve desired transient performance characteristics. In order to change the system response time, positional feedback gain $\mathrm{K}_{\mathrm{p}}$ is changed, to reduce the steady state error of the system, the integral of 
the positional error $\left(\mathrm{K}_{\mathrm{i}}\right)$ is added and some damping is incorporated into the system by adding a derivative of positional error $\left(\mathrm{K}_{\mathrm{d}}\right)$.

Simplifying Equation (6.3), the closed-loop transfer function $\mathrm{T}_{\mathrm{c}}(\mathrm{s})$ relating the actual angular displacement $\theta_{\mathrm{L}}(\mathrm{s})$ to desired angular displacement $\theta^{\mathrm{d}}{ }_{\mathrm{L}}(\mathrm{s})$, is given as:

$$
\begin{aligned}
& T_{c}(s)=\frac{\theta_{L}(s)}{\theta^{d}{ }_{L}(s)} \\
& =\frac{K_{t}\left(K_{d} s^{2}+K_{p} s+K_{i}\right)}{R_{a} J_{\text {eff }} s^{3}+\left[\left(R_{a} B_{\text {eff }}+K_{t} K_{b}+K_{t} K_{d}\right)\right] s^{2}+K_{t} K_{p} s+K_{t} K_{i}}
\end{aligned}
$$

\subsection{CONTROLLERS FOR THE THREE LINK-JOINTS OF THE SCARA- TYPE ROBOT}

A PID controller is designed for each link-joint of the workcell robot. The performance of the closed-loop control system is based on several criteria's like fast rise time, small or zero steady state error, response damping and fast settling time [14]. The performance of a closed-loop control system is based on its natural un-damped frequency $\omega_{\mathrm{n}}$ and damping ratio $\xi$. For the system to have a good performance, it should have a critically damped or an over-damped behavior, which requires the system damping ratio to be greater than or equal to unity.

Using the transfer function from Equation (6.4), the error for the system is given by:

$$
\begin{aligned}
& E(s)=\theta_{L}{ }^{d}(s)-\theta_{L}(s) \\
& =\frac{\left.R_{a} J_{\text {eff }} s^{3}+\left(R_{a} B_{\text {eff }}+K_{t} K_{b}\right)\right] s^{2}}{R_{a} J_{\text {eff }} s^{3}+\left[\left(R_{a} B_{\text {eff }}+K_{t} K_{b}+K_{t} K_{d}\right)\right] s^{2}+K_{t} K_{p} s+K_{t} K_{i}} \theta_{L}{ }^{d}(s) \\
& =F(s) \theta_{L}{ }^{d}(s)
\end{aligned}
$$

For the system it is expected that the steady state error becomes zero for a step input in $\theta_{\mathrm{L}}(\mathrm{t})$. Therefore, using Final Value Theorem: 
$\lim _{s \rightarrow 0} \mathrm{~s} E(\mathrm{~s})=\frac{0}{\mathrm{~K}_{\mathrm{t}} \mathrm{K}_{\mathrm{i}}}$

From Equation (6.6) it can be shown that the steady state error can be made equal to zero as long as $\mathrm{K}_{\mathrm{i}}$ and $\mathrm{K}_{\mathrm{t}}$ are not zeroes. Also, if $\mathrm{K}_{\mathrm{i}}=0$, the steady state error goes to infinity. So any gain can be chosen except $\mathrm{K}_{\mathrm{i}}=0$, as long as steady state error is concerned.

\subsubsection{Controller for Link-Joint 1}

The main design principle on which the controller is designed is that the system should be critically damped or over-damped. The general form $\mathrm{G}_{\mathrm{c}}(\mathrm{s})$ for a PID controller is:

$$
\mathrm{G}_{\mathrm{c}}(\mathrm{s})=\mathrm{K}_{\mathrm{d}} \mathrm{s}+\mathrm{K}_{\mathrm{p}}+\frac{\mathrm{K}_{\mathrm{i}}}{\mathrm{s}}
$$

Design of the controller is based on choosing the appropriate values of the position feedback gain $\mathrm{K}_{\mathrm{p}}$, velocity feedback gain $\mathrm{K}_{\mathrm{d}}$ and integral gain $\mathrm{K}_{\mathrm{i}}$. The proportionality, derivative and integral gain values for link-joint 1 for stable system behavior are:

$$
\begin{aligned}
& \mathrm{K}_{\mathrm{p}}=1500 \text { volts } / \mathrm{rad} \\
& \mathrm{K}_{\mathrm{d}}=1330 \mathrm{volts} / \mathrm{rad} / \mathrm{sec} \\
& \mathrm{K}_{\mathrm{i}}=0.4 \text { volts } / \mathrm{rad}-\mathrm{sec}
\end{aligned}
$$

The proportionality, derivative and integral gain values for joint 1 were chosen after many simulations. The simulation was done using Matlab. A code is written in Matlab where the variables are the proportionality, derivative and integral gains. The study was done for the step response behavior of the system by changing the variables and finally a stable system was achieved for a particular combination of the proportionality, derivative and integral gains. The Matlab code for this simulation is shown in Appendix G.

Hence, the PID controller $\mathrm{G}_{\mathrm{C} 1}$ (s) for joint 1 is: 


$$
\mathrm{G}_{\mathrm{Cl}}(\mathrm{s})=\frac{1330 \mathrm{~s}^{2}+1500 \mathrm{~s}+0.4}{\mathrm{~s}}
$$

The overall closed-loop transfer function $\mathrm{T}_{\mathrm{Cl}}(\mathrm{s})$ for joint 1 relating the actual angular displacement $\theta_{\mathrm{L}}(\mathrm{s})$ to desired angular displacement $\theta^{\mathrm{d}}{ }_{\mathrm{L}}(\mathrm{s})$ with the work cell robot operating in maximum workspace volume is:

$$
\begin{aligned}
& \frac{\theta_{\mathrm{L}}(\mathrm{s})}{\theta_{\mathrm{L}}^{\mathrm{d}}(\mathrm{s})}=\frac{0.48\left(\mathrm{~K}_{\mathrm{d}} \mathrm{s}^{2}+\mathrm{K}_{\mathrm{p}} \mathrm{s}+\mathrm{K}_{\mathrm{i}}\right)}{39 \mathrm{~s}^{3}+\left(0.27+0.48 \mathrm{~K}_{\mathrm{d}}\right) \mathrm{s}^{2}+0.48 \mathrm{~K}_{\mathrm{p}} \mathrm{s}+0.48 \mathrm{~K}_{\mathrm{i}}} \\
& \text { or, } \mathrm{T}_{\mathrm{Cl}}(\mathrm{s})=\frac{\theta_{\mathrm{L}}(\mathrm{s})}{\theta_{\mathrm{L}} \mathrm{d}(\mathrm{s})}=\frac{638.4 \mathrm{~s}^{2}+720 \mathrm{~s}+0.192}{39 \mathrm{~s}^{3}+638.7 \mathrm{~s}^{2}+720 \mathrm{~s}+0.192}
\end{aligned}
$$

The unit step response of the closed-loop transfer function of the link-joint 1 , which is determined using Matlab, is shown in Figure 6.3. It can be seen from Figure 6.3 that the link-actuator system rise time is $0.114 \mathrm{sec}$, and its settling time is 1.21 seconds and the system is stable.

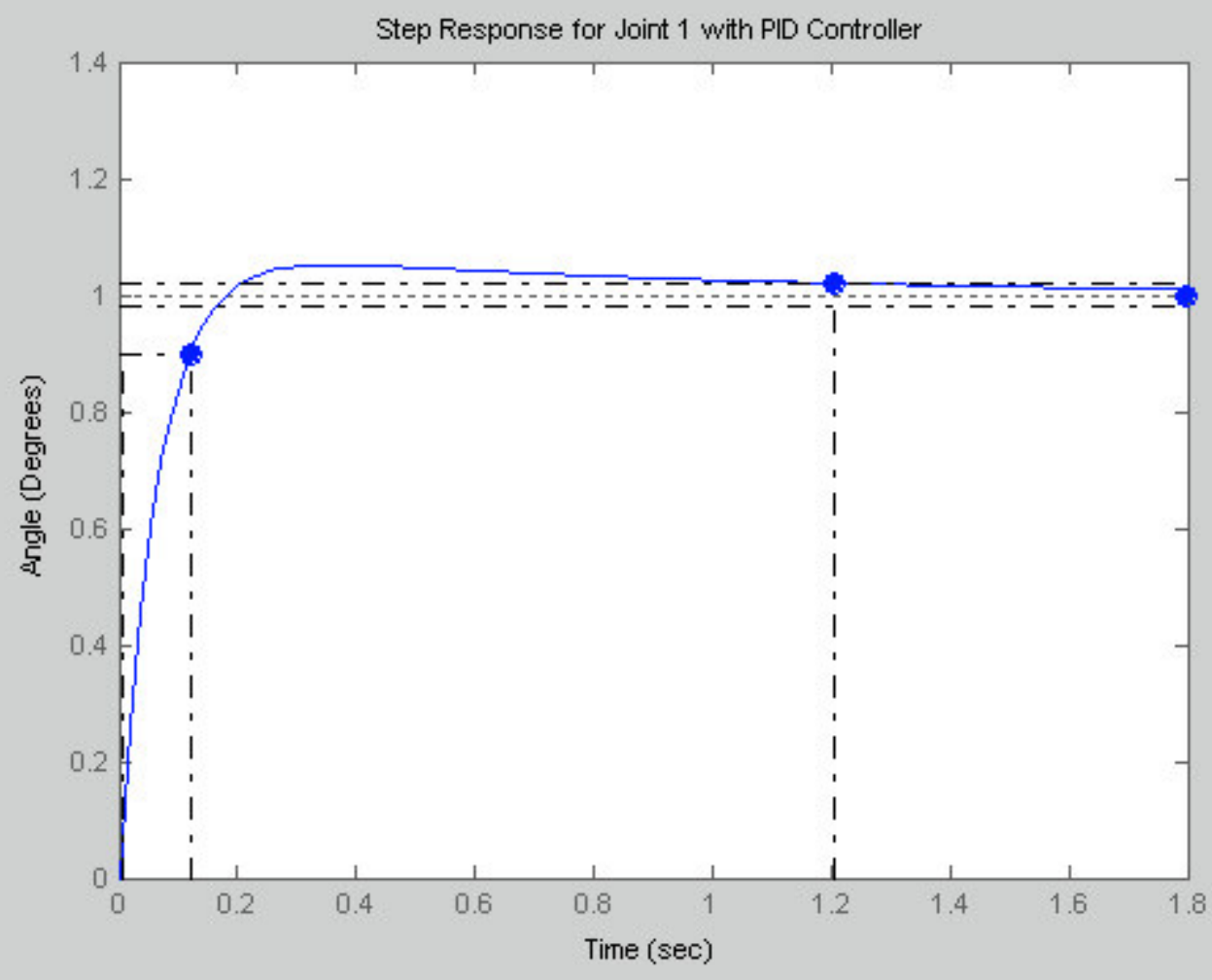

Figure 6.3 Step Response for Joint 1 
The stability for the system is determined using both Bode plot and root locus plot for the system. The stability margins (gain and phase margin) for the joint 1 is determined using Bode plot for the system as shown in Figure 6.4. The stability margins, i.e. gain margin and phase margin for the joint 1 are determined as:

Phase Margin = 159 degrees

Gain Margin = infinity

The stability criteria for a system from the Bode plot is that the phase margin should always be greater than -180 degrees and gain margin should always be positive. From the stability margin values determined from the Bode plot, the system for joint 1 is stable for given controller [11].

The root locus plot of the system is shown in Figure 6.5. According to the control definitions, for the system to be stable, the poles and zeros should lie on the left- hand plane. It can be seen from the plot that the poles and zeros of the system lie on the left hand side of the s-plane. Hence, the system is stable for the given controller.

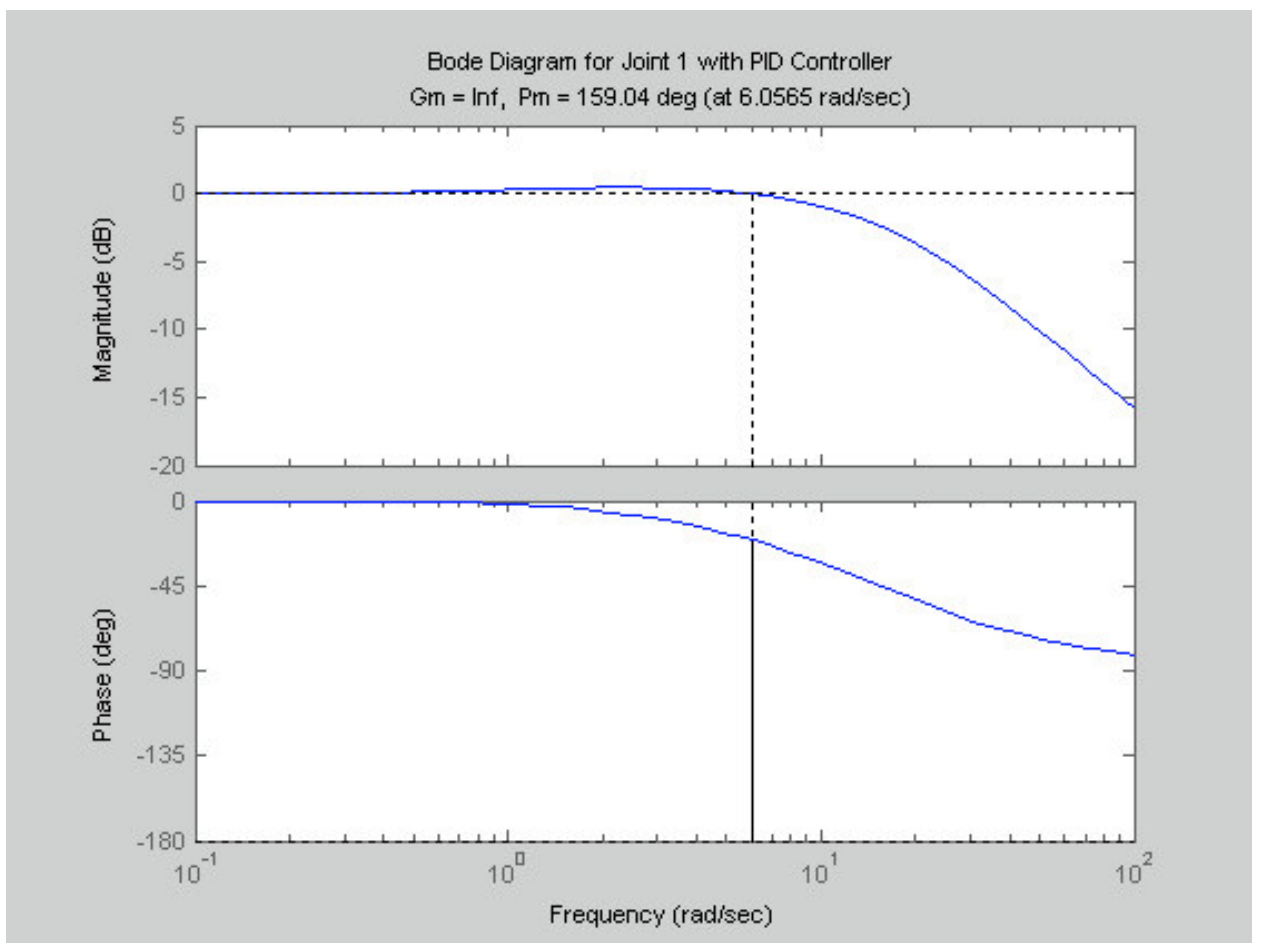

Figure 6.4 Bode Diagram for Stability Margin of Joint 1 


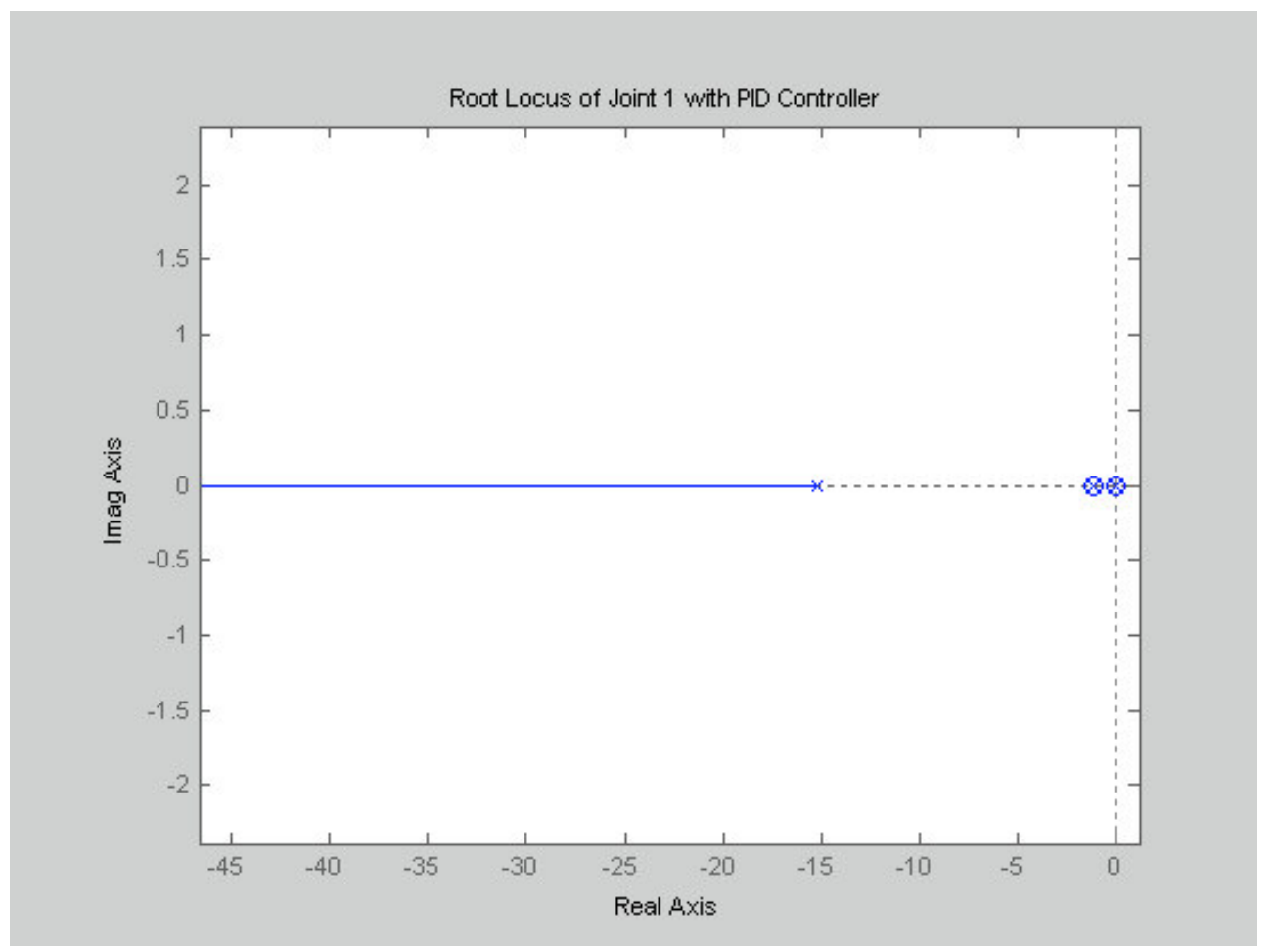

Figure 6.5 Root Locus Plot for Joint 1

The poles of the link-actuator system for joint 1 are determined using Matlab as:

$$
\begin{aligned}
& \mathrm{s}_{1}=-15.16 ; \\
& \mathrm{s}_{2}=-1.22 ; \\
& \mathrm{s}_{3}=-0.000313 ;
\end{aligned}
$$

The overall closed-loop transfer function $\mathrm{T}_{\mathrm{Cl}}(\mathrm{s})$ for joint 1 relating the actual angular displacement $\theta_{\mathrm{L}}(\mathrm{s})$ to desired angular displacement $\theta_{\mathrm{L}}^{\mathrm{d}}(\mathrm{s})$ with the work cell robot operating in minimum workspace volume with same controller is:

$$
\begin{aligned}
& \frac{\theta_{\mathrm{L}}(\mathrm{s})}{\theta_{\mathrm{L}}^{\mathrm{d}}(\mathrm{s})}=\frac{0.48\left(\mathrm{~K}_{\mathrm{d}} \mathrm{s}^{2}+\mathrm{K}_{\mathrm{p}} \mathrm{s}+\mathrm{K}_{\mathrm{i}}\right)}{17 \mathrm{~s}^{3}+\left(0.27+0.48 \mathrm{~K}_{\mathrm{d}}\right) \mathrm{s}^{2}+0.48 \mathrm{~K}_{\mathrm{p}} \mathrm{s}+0.48 \mathrm{~K}_{\mathrm{i}}} \\
& \text { or, } \mathrm{T}_{\mathrm{C} 1}(\mathrm{~s})=\frac{\theta_{\mathrm{L}}(\mathrm{s})}{\theta_{\mathrm{L}}^{\mathrm{d}}(\mathrm{s})}=\frac{638.4 \mathrm{~s}^{2}+720 \mathrm{~s}+0.192}{17 \mathrm{~s}^{3}+638.7 \mathrm{~s}^{2}+720 \mathrm{~s}+0.192}
\end{aligned}
$$




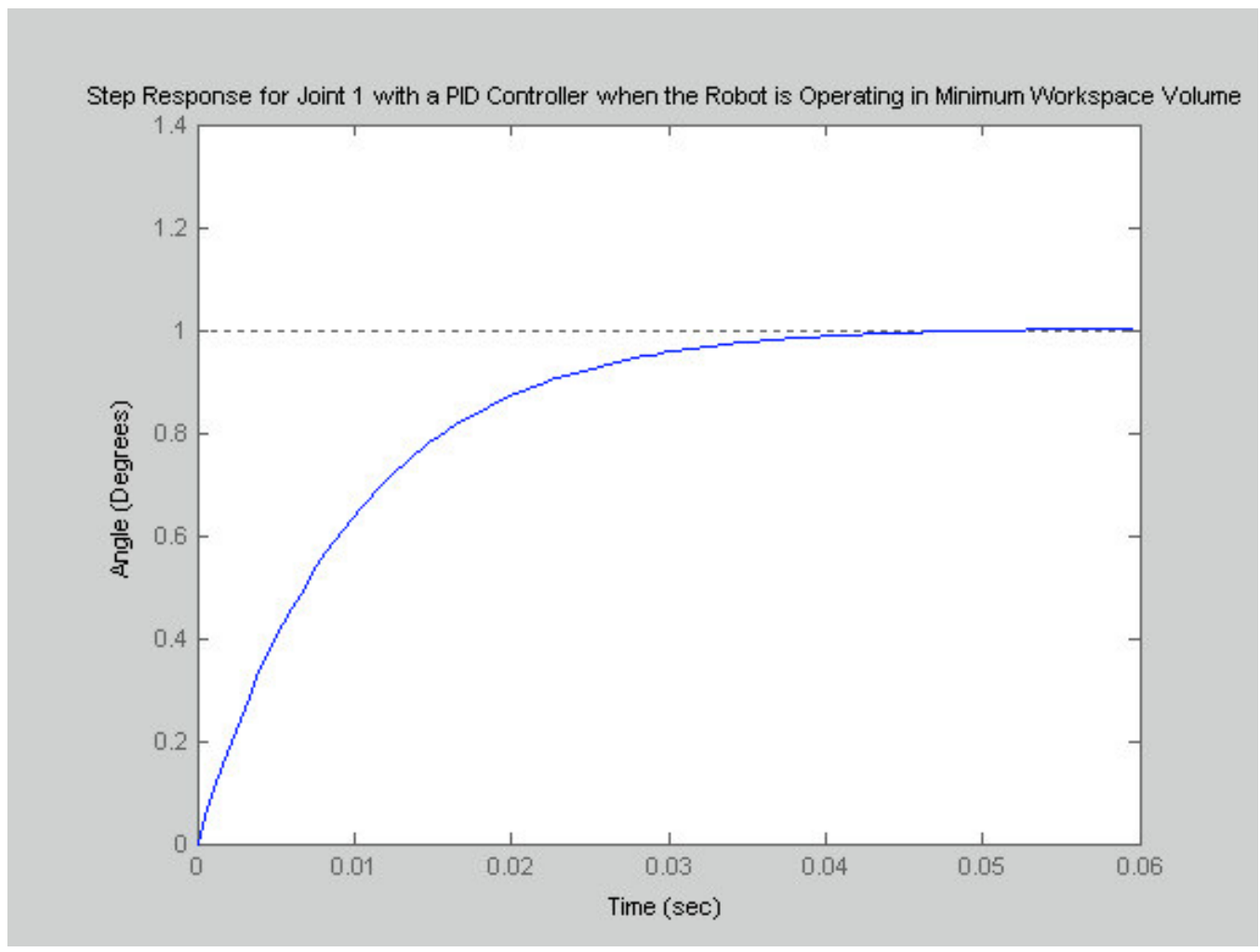

Figure 6.6 Step Response for Joint 1 with Robot Operating in Minimum Workspace Volume

The unit step response of the closed-loop transfer function of the link-joint 1 with the robot operating in minimum workspace volume is shown in Figure 6.6. The linkactuator system rise time is $0.02 \mathrm{sec}$, and its settling time is 0.03 seconds and the system is stable. Hence it can be concluded that same PID controller can be used for both cases.

\subsubsection{Controller for Link-Joint 2}

A PID controller is designed for joint 2 based on the same principles as discussed in designing controller for joint 1 . The proportional feedback gain $\mathrm{K}_{\mathrm{p}}$, derivative feedback gain $\mathrm{K}_{\mathrm{d}}$ and integral feedback gain $\mathrm{K}_{\mathrm{i}}$ for the joint 2 are determined as:

$$
\begin{aligned}
& \mathrm{K}_{\mathrm{p}}=140 \text { volts } / \mathrm{rad} \\
& \mathrm{K}_{\mathrm{d}}=160 \mathrm{volts} / \mathrm{rad} / \mathrm{sec} \\
& \mathrm{K}_{\mathrm{i}}=0.4 \mathrm{volts} / \mathrm{rad}-\mathrm{sec}
\end{aligned}
$$


Hence, the PID controller $\mathrm{G}_{\mathrm{C} 2}(\mathrm{~s})$ for link-joint 2 is:

$$
\mathrm{G}_{\mathrm{C} 2}(\mathrm{~s})=\frac{160 \mathrm{~s}^{2}+140 \mathrm{~s}+0.4}{\mathrm{~s}}
$$

The overall closed-loop transfer function $\mathrm{T}_{\mathrm{C} 2}(\mathrm{~s})$ of joint 2 relating the actual angular displacement $\theta_{\mathrm{L}}(\mathrm{s})$ to desired angular displacement $\theta_{\mathrm{L}}^{\mathrm{d}}(\mathrm{s})$ is:

$$
\begin{aligned}
& \frac{\theta_{\mathrm{L}}(\mathrm{s})}{\theta_{\mathrm{L}}^{\mathrm{d}}(\mathrm{s})}=\frac{0.48\left(\mathrm{~K}_{\mathrm{d}} \mathrm{s}^{2}+\mathrm{K}_{\mathrm{p}} \mathrm{s}+\mathrm{K}_{\mathrm{i}}\right)}{4.2 \mathrm{~s}^{3}+\left(0.27+0.48 \mathrm{~K}_{\mathrm{d}}\right) \mathrm{s}^{2}+0.48 \mathrm{~K}_{\mathrm{p}} \mathrm{s}+0.48 \mathrm{~K}_{\mathrm{i}}} \\
& \text { or, } \mathrm{T}_{\mathrm{C} 2}(\mathrm{~s})=\frac{\theta_{\mathrm{L}}(\mathrm{s})}{\theta_{\mathrm{L}}^{\mathrm{d}}(\mathrm{s})}=\frac{76.8 \mathrm{~s}^{2}+67.2 \mathrm{~s}+0.192}{4.2 \mathrm{~s}^{3}+77.07 \mathrm{~s}^{2}+67.2 \mathrm{~s}+0.192}
\end{aligned}
$$

The unit step response of the closed-loop transfer function of the system is shown in Figure 6.7. It is evident from Figure 6.7 that the link-actuator system rise time is 0.107 sec, its settling time is 1.04 seconds and the system is stable.

The stability margins for the system are determined using Bode plot and rootlocus plot for the system. The Bode plot for the system is shown in Figure 6.8. The stability margins, i.e. gain margin and phase margin for the joint 1 is determined as:

Phase Margin = 163.1 degrees

Gain Margin = infinity

The stability criteria for a system from the Bode plot is that the phase margin should be always be greater than -180 degrees and gain margin should always be positive. From the stability margin values determined from the Bode plot, the system for joint 2 is stable for the given controller. 


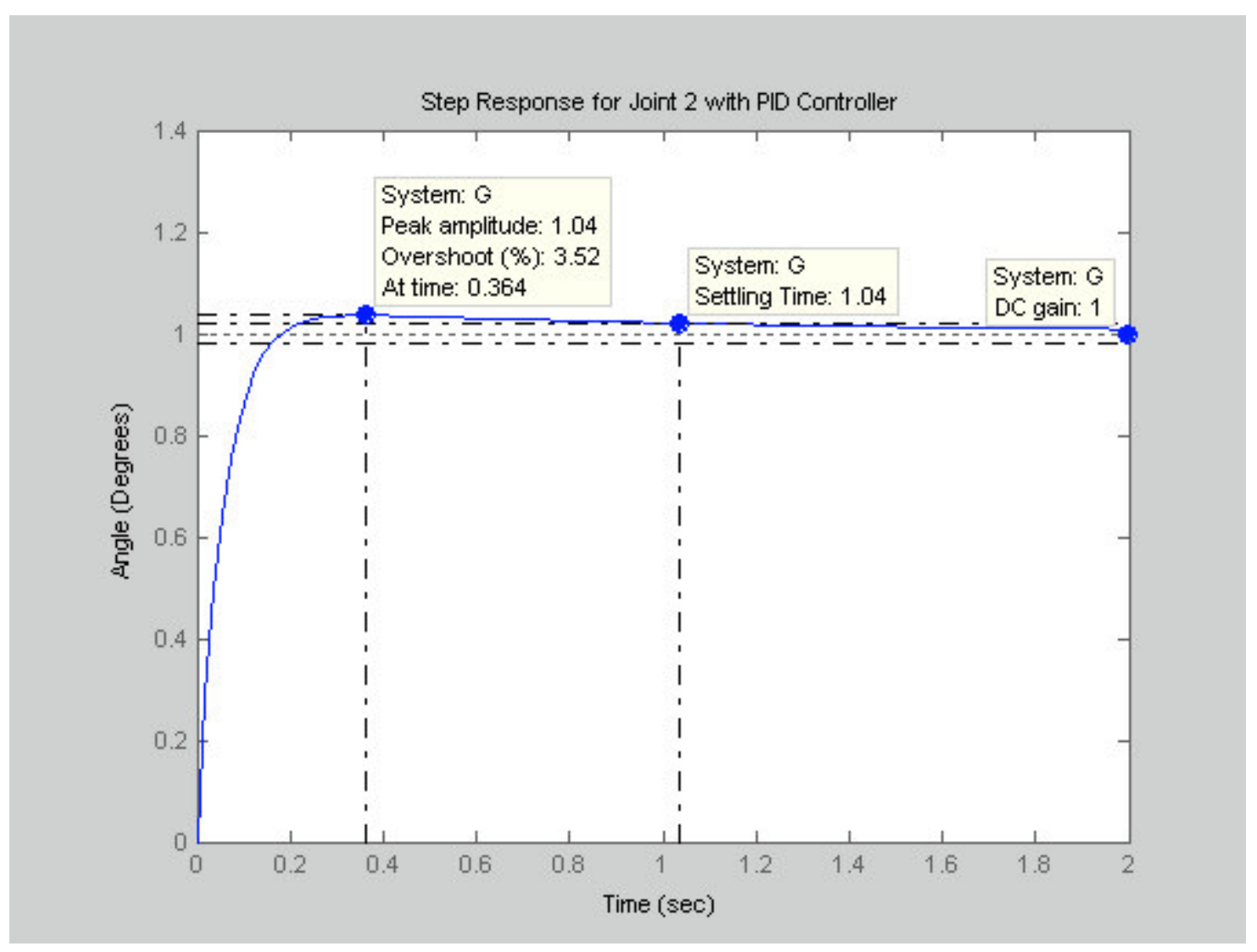

Figure 6.7 Step Response for Joint 2

The root locus plot of the system is shown in Figure 6.9. It can be seen from the plot that the poles and zeros of the system lie in the left hand side of the s-plane. Hence, the system for joint 2 is stable for the given controller.

The poles of the link-actuator system for joint 2 are determined using Matlab as:

$$
\begin{aligned}
& \mathrm{s}_{1}=-17.43 \\
& \mathrm{~s}_{2}=-0.91 \\
& \mathrm{~s}_{3}=-0.0029
\end{aligned}
$$




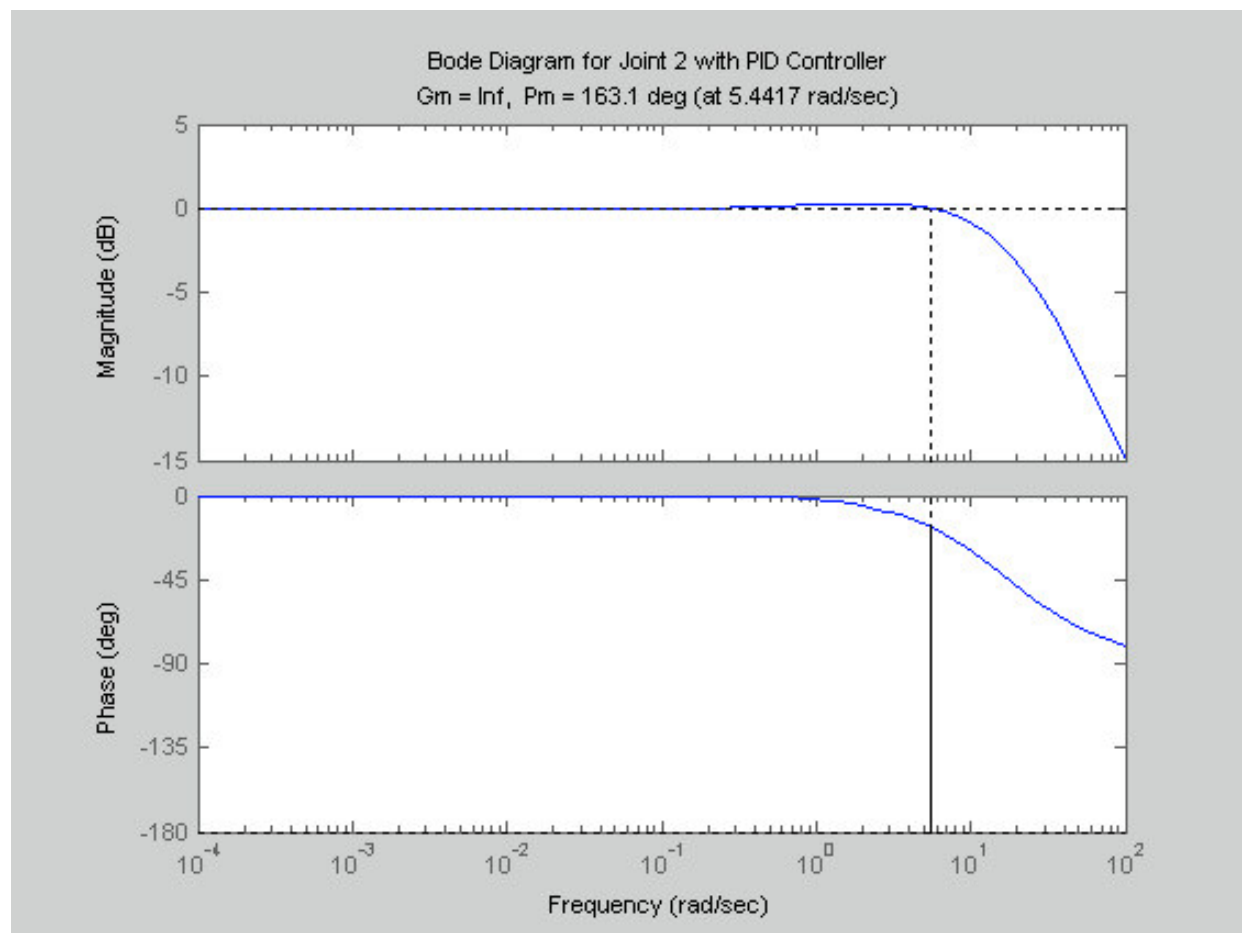

Figure 6.8 Bode Diagram for Stability Margin of Joint 2

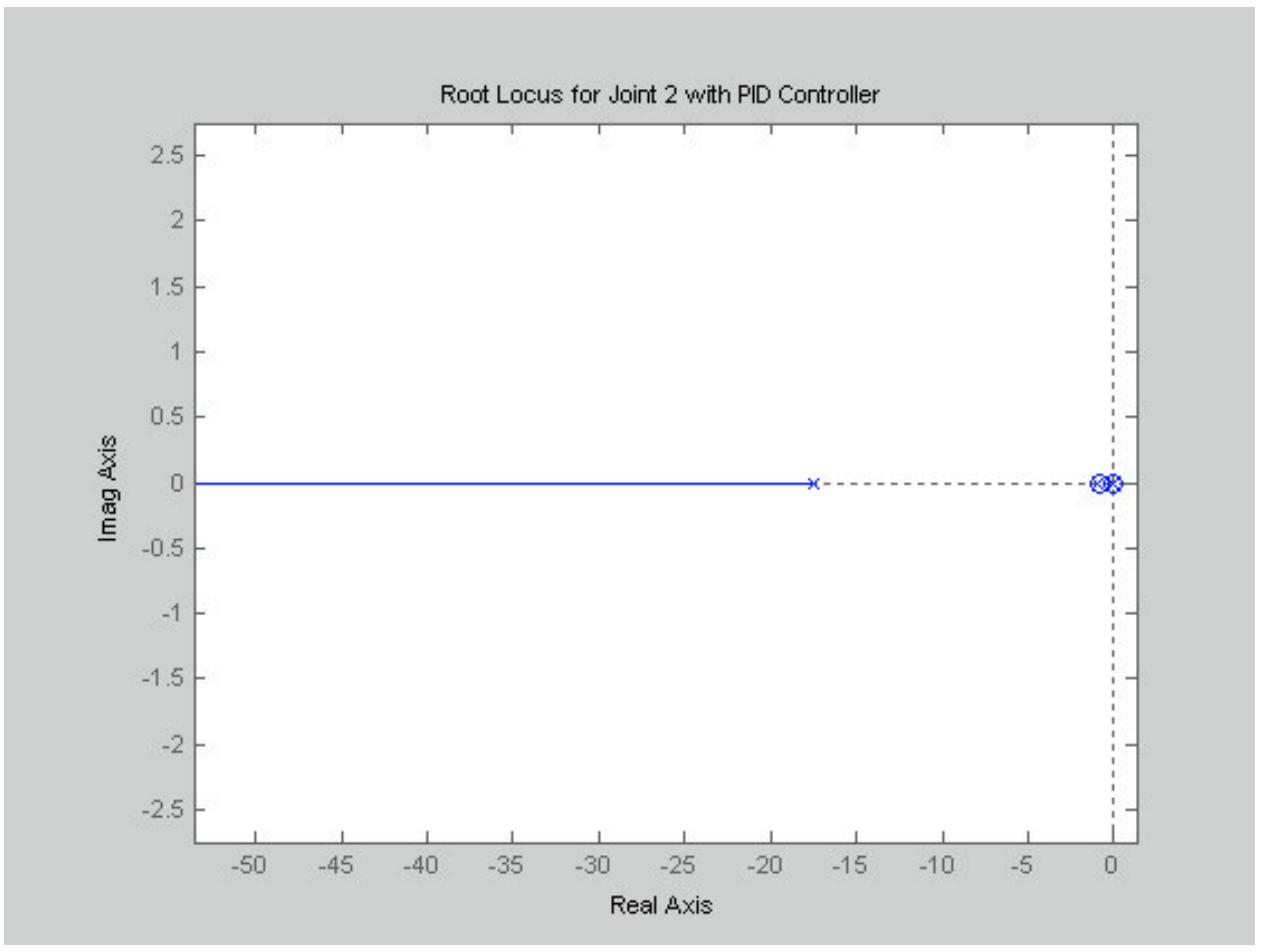

Figure 6.9 Root Locus Plot for Joint 2 


\subsubsection{Controller for joint 3}

A PID controller is designed for joint 3 based on the same principles as discussed in designing controller for joint 1 and joint 2. The proportional feedback gain $\mathrm{K}_{\mathrm{p}}$, derivative feedback gain $\mathrm{K}_{\mathrm{d}}$ and integral feedback gain $\mathrm{K}_{\mathrm{i}}$ for the joint 3 are determined as:

$$
\begin{aligned}
& \mathrm{K}_{\mathrm{p}}=100 \mathrm{volts} / \mathrm{rad} \\
& \mathrm{K}_{\mathrm{d}}=90 \text { volts } / \mathrm{rad} / \mathrm{sec} \\
& \mathrm{K}_{\mathrm{i}}=10 \text { volts } / \mathrm{rad}-\mathrm{sec}
\end{aligned}
$$

Hence, the PID controller $\mathrm{G}_{\mathrm{C} 3}$ (s) for joint 3 is:

$$
\mathrm{G}_{\mathrm{C} 3}(\mathrm{~s})=\frac{90 \mathrm{~s}^{2}+100 \mathrm{~s}+10}{\mathrm{~s}}
$$

The overall closed-loop transfer function $\mathrm{T}_{\mathrm{C} 3}(\mathrm{~s})$ of joint 3 relating the actual angular displacement $\theta_{\mathrm{L}}(\mathrm{s})$ to desired angular displacement $\theta_{\mathrm{L}}^{\mathrm{d}}(\mathrm{s})$ is:

$$
\begin{gathered}
\frac{\theta_{\mathrm{L}}(\mathrm{s})}{\theta_{\mathrm{L}}^{\mathrm{d}}(\mathrm{s})}= \\
\frac{\mathrm{K}_{\mathrm{t}}\left(\mathrm{K}_{\mathrm{d}} \mathrm{s}^{2}+\mathrm{K}_{\mathrm{p}} \mathrm{s}+\mathrm{K}_{\mathrm{i}}\right)}{\mathrm{s}^{3}\left[\mathrm{~J}_{\mathrm{m}} \mathrm{R}_{\mathrm{a}}+\mathrm{n}^{2} \mathrm{~m}_{3} \mathrm{~L}_{\mathrm{c}}{ }^{2} \mathrm{R}_{\mathrm{a}}\right]+\mathrm{s}^{2}\left[\mathrm{~B}_{\mathrm{m}} \mathrm{R}_{\mathrm{a}}+\mathrm{n}^{2} \mathrm{~B}_{1} \mathrm{R}_{\mathrm{a}}+\mathrm{K}_{\mathrm{t}} \mathrm{K}_{\mathrm{b}}+\mathrm{K}_{\mathrm{d}} \mathrm{K}_{\mathrm{t}}\right]+\mathrm{s}\left[\mathrm{K}_{\mathrm{t}} \mathrm{K}_{\mathrm{p}}\right]+\mathrm{n}^{2} \mathrm{~m}_{3} \mathrm{gL}_{\mathrm{c}} \mathrm{R}_{\mathrm{a}}+\mathrm{K}_{\mathrm{t}} \mathrm{K}_{\mathrm{i}}} \\
\text { or, } \mathrm{T}_{\mathrm{C} 3}(\mathrm{~s})=\frac{\theta_{\mathrm{L}}(\mathrm{s})}{\theta_{\mathrm{L}}(\mathrm{s})}=\frac{43.2 \mathrm{~s}^{2}+48 \mathrm{~s}+4.8}{1.12 \mathrm{~s}^{3}+43.47 \mathrm{~s}^{2}+48 \mathrm{~s}+4.816}
\end{gathered}
$$

The unit step response of the closed-loop transfer function of the system is shown in Figure 6.10. It can be seen from Figure 6.10 that the link-actuator system rise time is 0.053 seconds, its settling time is 0.38 seconds and the system is stable. 


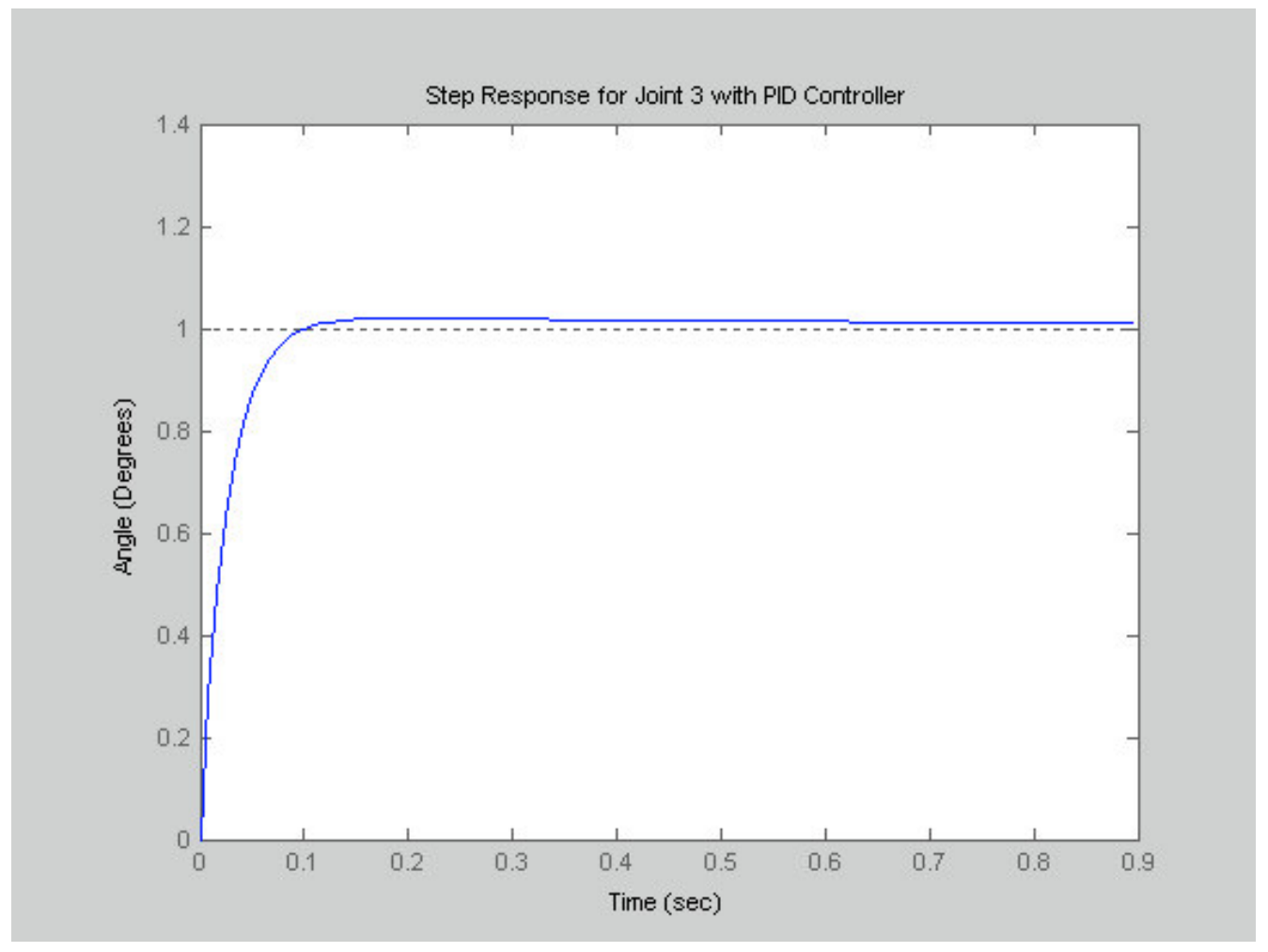

Figure 6.10 Step Response for Joint 3

The stability margins for the system are determined using Bode plot and rootlocus plot for the system. The Bode plot for the system is shown in Figure 6.11. The stability margins, i.e. gain margin and phase margin for the joint 3 is determined as:

Phase Margin = 167.8 degrees

Gain Margin = infinity

The stability criteria for a system from the Bode plot is that the phase margin should be always greater be than -180 degrees and gain margin should always be positive [11]. From the stability margin values determined from the Bode plot, the system for joint 3 is stable for the given controller.

The root locus plot of the system is shown in Figure 6.12. It is known from the plot that the poles and zeros of the system lie on the left hand side of the s-plane. According to the control definitions, for the system to be stable, the poles and zeros should lie on the left hand plane. Hence, the system for joint 3 is stable for the designed controller. 


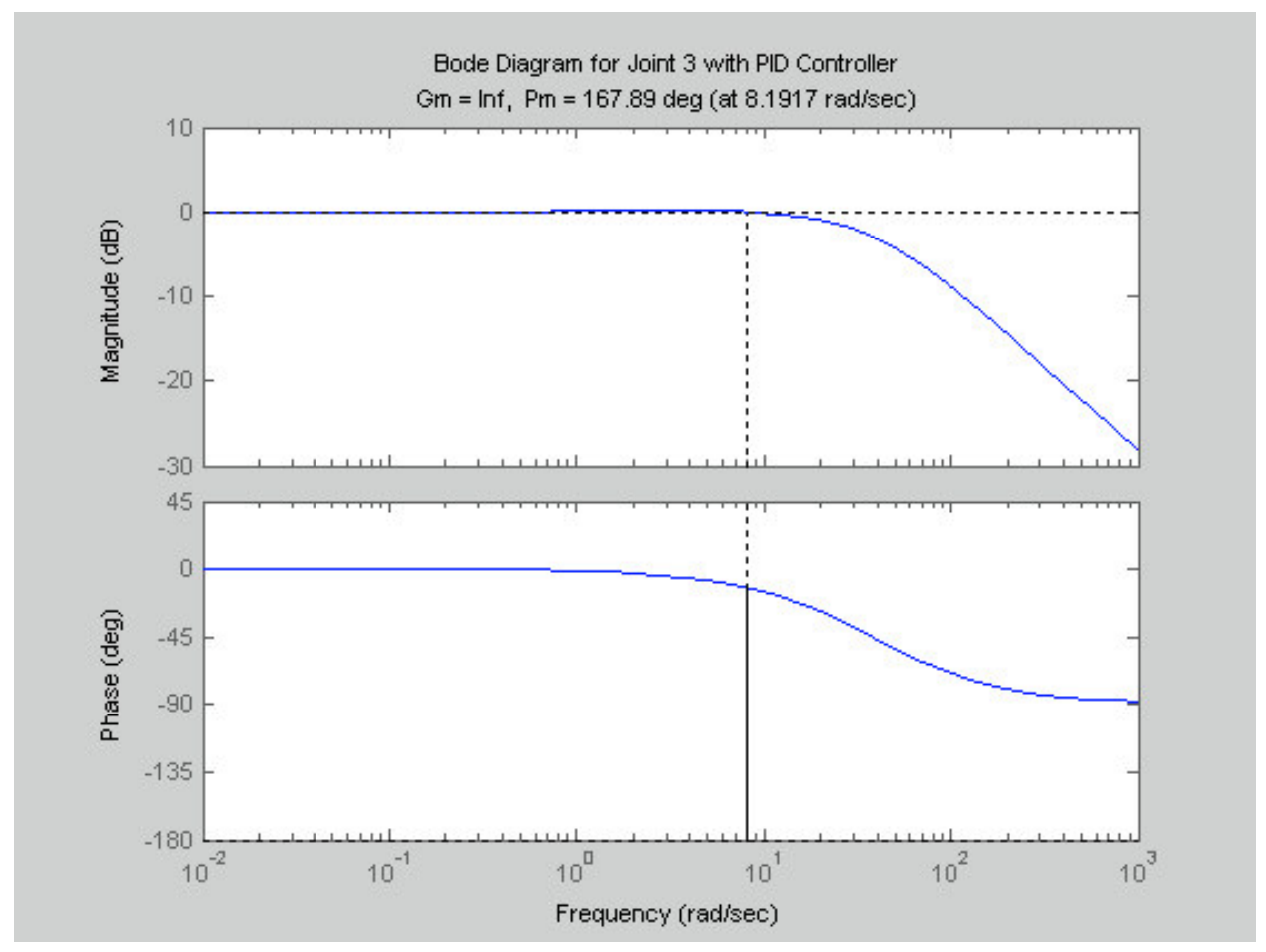

Figure 6.11 Bode Diagram for Stability Margin of Joint 3

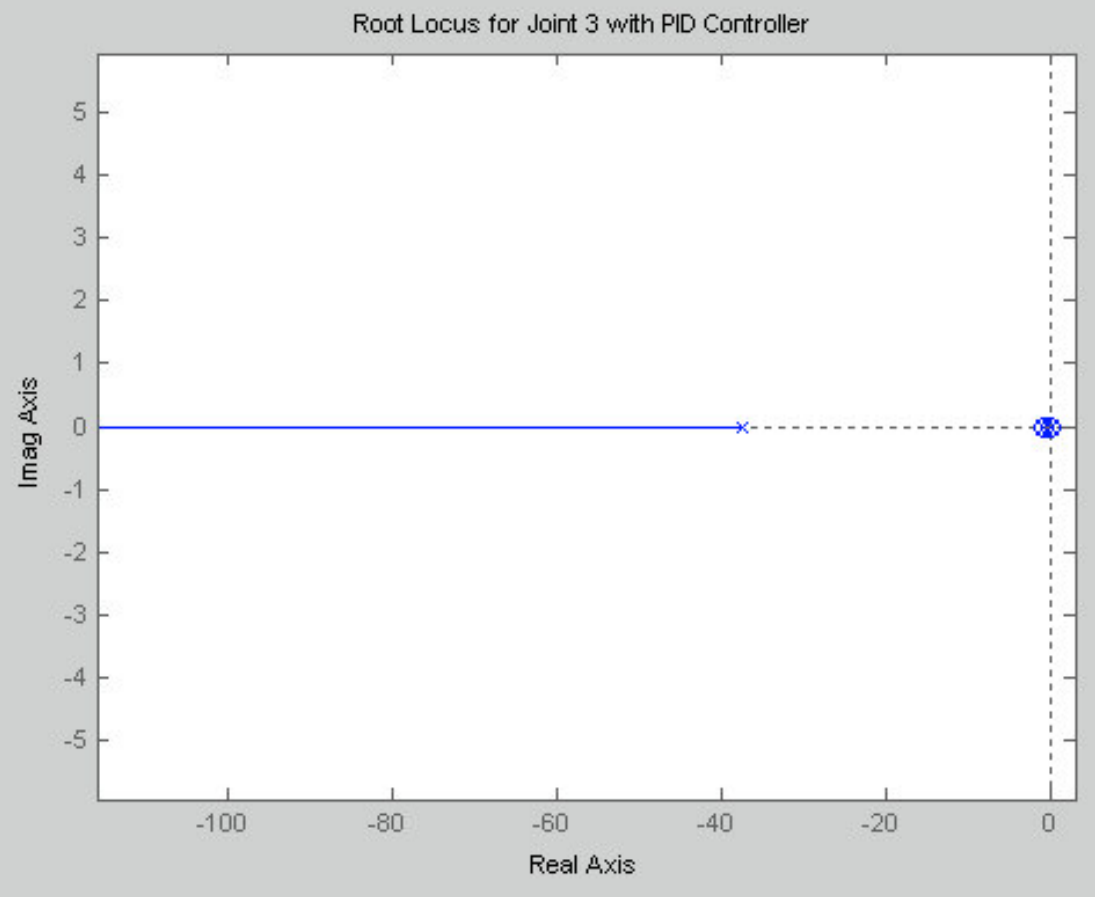

Figure 6.12 Root Locus Plot for Joint 3 
The poles of the system for joint 3 are determined using Matlab as:

$$
\begin{aligned}
& s_{1}=-37.67 \\
& s_{2}=-1.02 \\
& s_{3}=-0.11 ;
\end{aligned}
$$

\subsection{SUMMARY}

The controlled joint motion of the three joints allows the robot manipulator to perform the pick-to-place task in minimum time depending on the values of the gains for the PID controllers. The time can be changed depending on the task to be performed by the robot. The pick-to-place task was accomplished in $2 \mathrm{sec}$ as described in Chapter 4. This time can be changed depending on the task. PID controllers for three joints were designed to achieve desired angle in minimum time. 


\section{Chapter 7 \\ Experimental Verification Study of SCARA-Type Robot}

\subsection{EXPERIMENTAL RESULTS}

Experiments were carried on the LGCM workcell robot to verify the theoretical kinematic model. The primary goals of this experimental verification study were to determine the position of the end-effector given the joint angles of the three joints.

The SCARA-Type robot, placed at the Davis-Lynch glass plant in Star City, WV, was studied with various joint angles for a specified task and the results were compared with the values obtained from the theoretical model.

A pick-to-place routine was run to verify the theoretical model for the SCARAType robot. The robot was run with different set of pick and place positions as compared to pick and place positions defined in Chapter 4. This was done to cross verify the model. The motion of the robot was programmed such that the robot picked up the glassware at the pick position and placed the glassware at the place position in front of the laser.

Experiments were carried out using the robot controller. The robot is first homed so that it determines the exact position within the workspace. The robot arm was moved using the built-in program with the robot controller. The pick position and place position were defined in the workspace of the robot arm as shown in Figure 7.1. The controller program was run and the Cartesian coordinates were noted from the computer monitor for the corresponding joint angles of the robot arm. A timer was used to record the time it took for the robot to move from the pick position to the place position and it was noted that the robot took 3.2 seconds to complete the task.

The pick position as shown in Figure 7.1, defined for the SCARA-Type robot inside the workspace is:

$$
\begin{aligned}
& \theta_{1}=30.3 \text { degrees } \\
& \theta_{2}=44.88 \text { degrees } \\
& \theta_{3}=-25.46 \text { degrees }
\end{aligned}
$$


The corresponding Cartesian coordinates for the pick position are:

$$
\mathrm{px}=1.8734 \mathrm{ft} ; \mathrm{py}=2.5891 \mathrm{ft} ; \mathrm{pz}=-0.53 \mathrm{ft}
$$

The joint angles for the place position, as shown in Figure 7.1, for the robot arm inside the workspace, are:

$$
\begin{aligned}
& \theta_{1}=-5.03 \text { degrees } \\
& \theta_{2}=0 \text { degrees } \\
& \theta_{3}=-31.75 \text { degrees }
\end{aligned}
$$

The corresponding Cartesian coordinates for the place position are:

$$
\mathrm{px}=3.3549 \mathrm{ft} ; \mathrm{py}=-0.2898 \mathrm{ft} ; \mathrm{pz}=-0.6386 \mathrm{ft}
$$

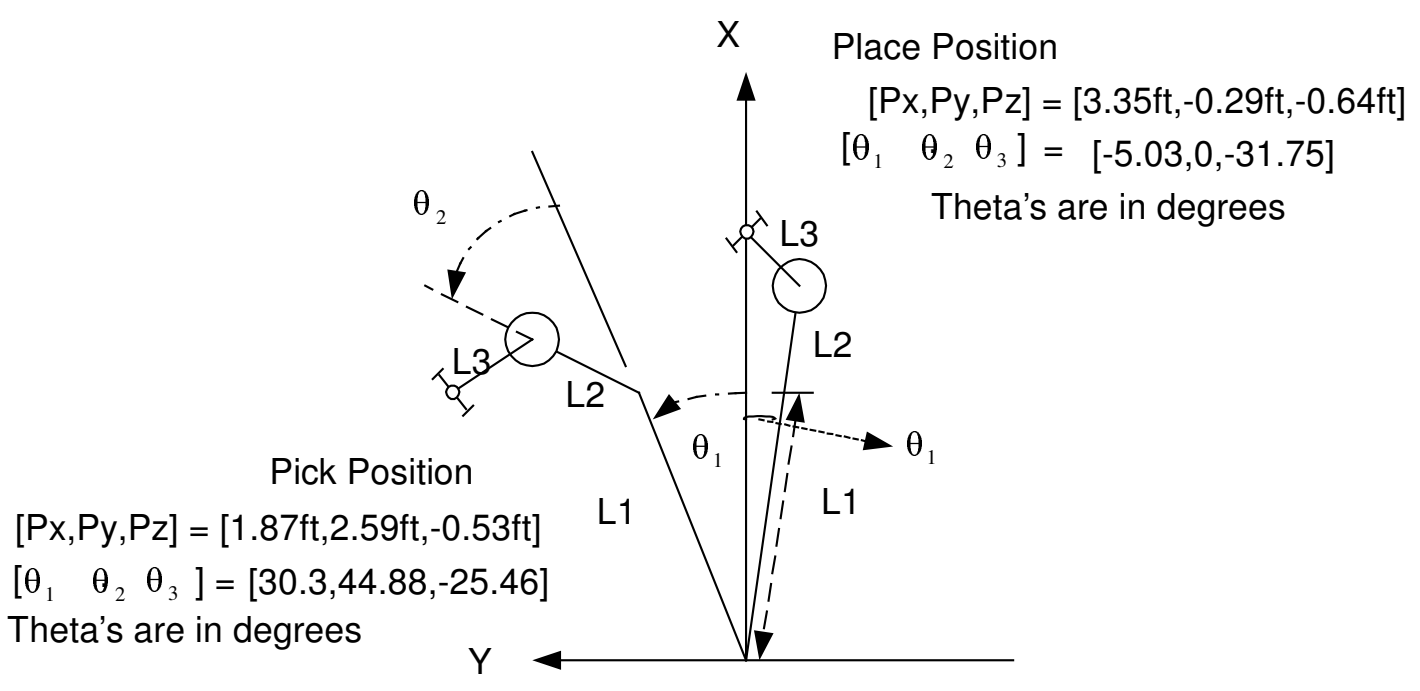

Figure 7.1 Defined Pick-to- Place Positions for Experimental Verification Study

The above joint and Cartesian values, which were obtained from experimentally positioning the robot, were compared with the values obtained from the theoretical kinematic model. The joint angles obtained experimentally were substituted in the theoretical inverse kinematic model of the robot and the corresponding end-effector position was calculated.

The Cartesian coordinates calculated with the theoretical kinematic model for the pickup position are:

$$
\mathrm{px}=1.9452 \mathrm{ft} ; \mathrm{py}=2.6623 ; \mathrm{pz}=-0.5459 ;
$$

And the place position coordinates are calculated as:

$$
\mathrm{px}=3.4865 \mathrm{ft} ; \mathrm{py}=-0.3069 \mathrm{ft} ; \mathrm{pz}=-0.6683 \mathrm{ft} \text {; }
$$


The time was noted for the robot to complete the task from pick position to place position. It was noted that the time taken for the robot to complete the task was 3.2 seconds. From the theoretical controller, which was designed in Chapter 6, it was determined that it takes 1.21 seconds for the joint 1 to complete its path, and 1.04 second for joint 2 and 1.01 for joint 3 to complete their paths, which is equivalent to 3.26 seconds for complete task. The gains of the PID controllers can be changed to match the real time with theoretical time to complete the task.

There was a 3-4\% error in calculating the exact Cartesian coordinate positions. This is due to the error in measuring the exact length of the three links of the robot.

Three PID controllers were used for the SCARA-Type robot to control the path. There were three PID controllers for the three actuators in the joints of the robot. Accordingly, three theoretical PID controllers were designed for each joint using a classical approach. These theoretical controllers were designed considering the kinematics and dynamics of the robot. The designed controller can behave like an actual controller by adjusting the values of the gain of the PID controller. The results of the PID controllers for three joints were discussed in Chapter 6.

A 4-3-4 approach was used to plan a trajectory for pick-to-place task for the robot. The actual trajectory for the robot at Davis-Lynch Glass Plant to perform the pickto-place task was determined as straight line trajectory. When compared to the actual trajectory, the trajectory derived in Chapter 4 was not a Straight line trajectory. While planning the trajectory, it was taken care that the path for pick-to-place task follows the straight line as close as possible. Figure 7.2 shows the theoretical trajectory in Cartesian coordinate system. 


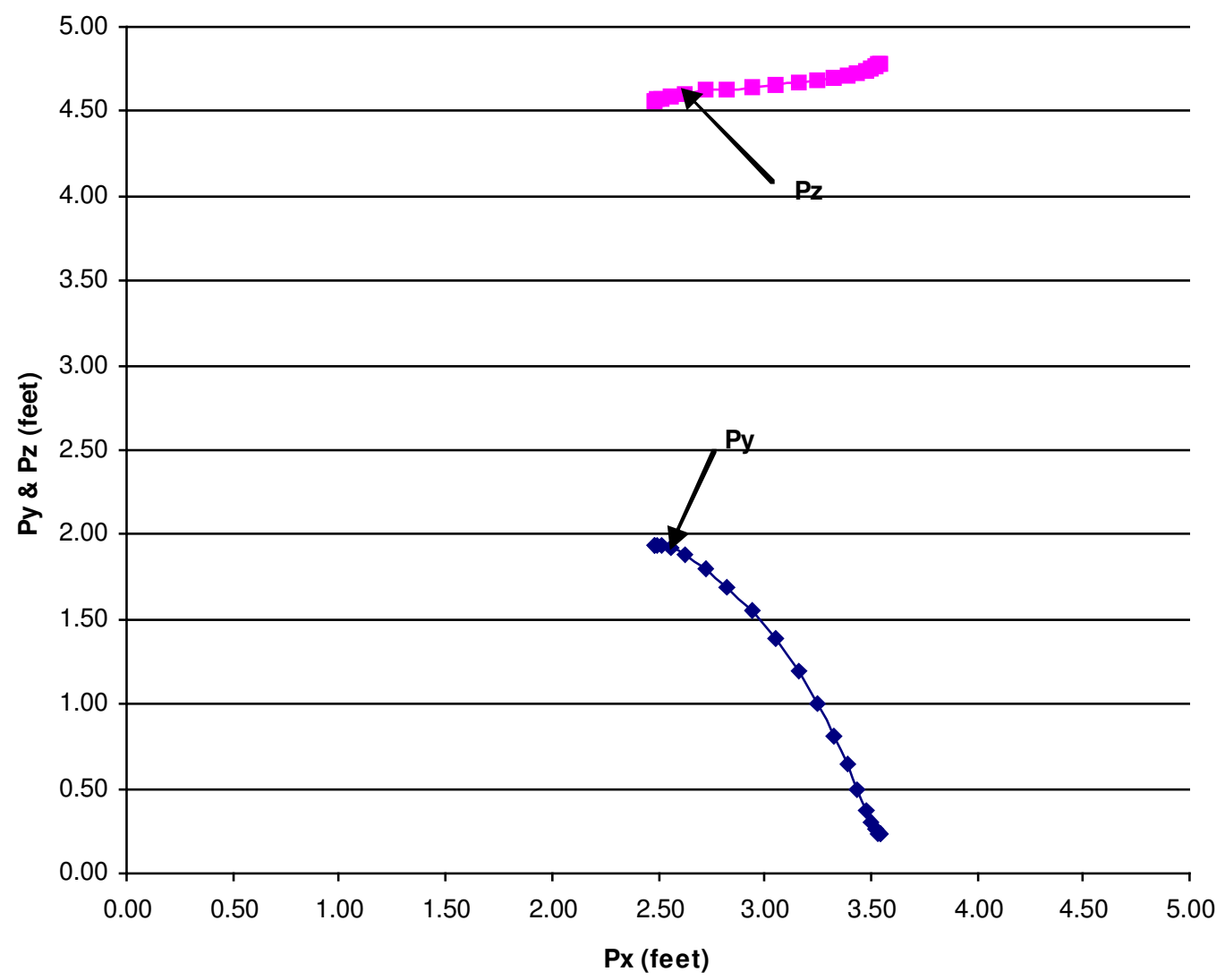

Figure 7.2 Pick-to-Place Trajectory in Cartesian Coordinate System

\subsection{KINEMATICS VALIDATION STUDY}

The goal of this section is to determine whether the robot should reach the desired position in the workspace for an input of a desired position to the robot in Cartesian coordinates. In this study the joint angles and the Cartesian coordinates of the endeffector of the robot in the workspace are already defined. Validation study of kinematics of the SCARA-Type robot was performed for different positions of the endeffector in the workspace. Now the desired position in Cartesian coordinates system in the workcell is input to the robot and the joint angles obtained were compared to the known values of the joint angles. Figure 7.3 shows the workcell of the robot with laser gun and turn table. The pick position of the robot is defined on the turntable where the glassware is available to be picked up and the place position of the robot is defined in front of the laser gun where the glassware is rotated by the robot and the cut made by the laser gun. Cases 1 to 8 in this chapter indicates the results of the validation study which 
shows that using the end-effector position as input to the inverse kinematics of the robot, the corresponding joint angles are determined for various positions inside the workspace. Figure 7.4 and 7.5 shows all the defined positions in the workspace. The soft home position shown in Figure 7.4 is defined as the position where the robot starts before reaching the pick position. A hard home position of the robot is defined as a position inside the workspace, which is set by the user to which the robot reverts when the power supply is removed.

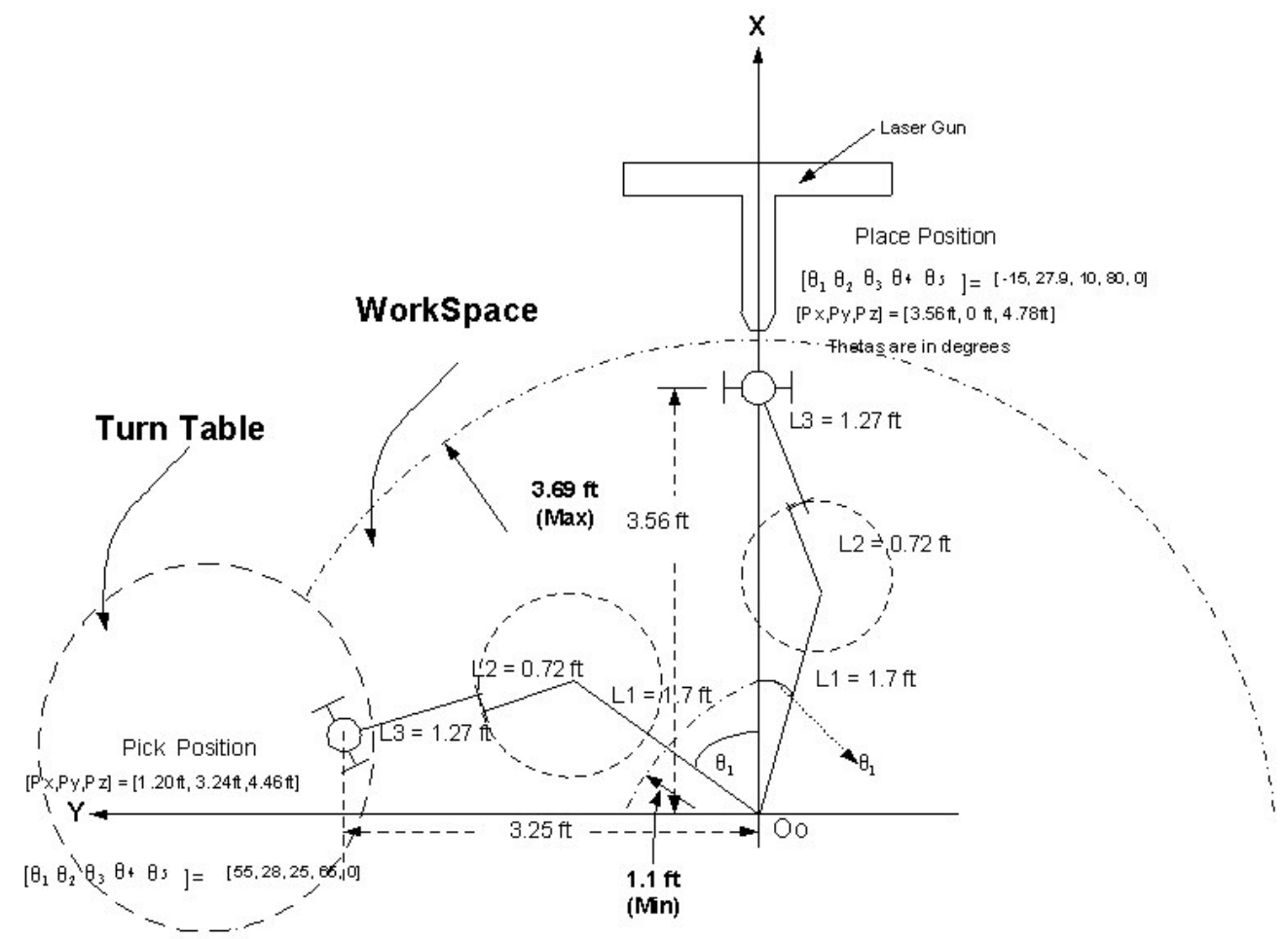

Views of Link 4 and Link 5

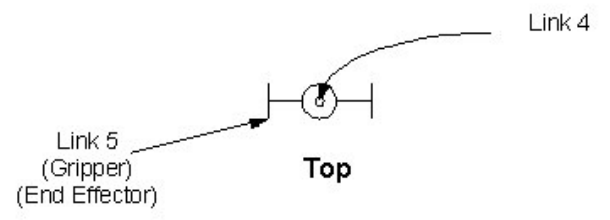

Figure 7.3 Top View of the WorkCell

$(\mathrm{L} 1=1.7 \mathrm{ft}, \quad \mathrm{L} 2=0.72 \mathrm{ft}, \quad \mathrm{L} 3=1.27 \mathrm{ft}, \quad \mathrm{L} 4=0, \quad \mathrm{~L} 5=0, \mathrm{H}=5 \mathrm{ft})$

- Work Space Limits: X-Y Plane

- Max: $\mathrm{L} 1+\mathrm{L} 2+\mathrm{L} 3=3.69 \mathrm{ft}$

- Min: L1 $-\mathrm{L} 2-\mathrm{L} 3=-0.29 \mathrm{ft}=>0 \mathrm{ft}$ (Not physically possible) 
口 Work Space Limits: X, Y - Z Plane

- Max: H + L3 = $6.27 \mathrm{ft}$

- Min: $\mathrm{H}-\mathrm{L} 3=3.73 \mathrm{ft}$

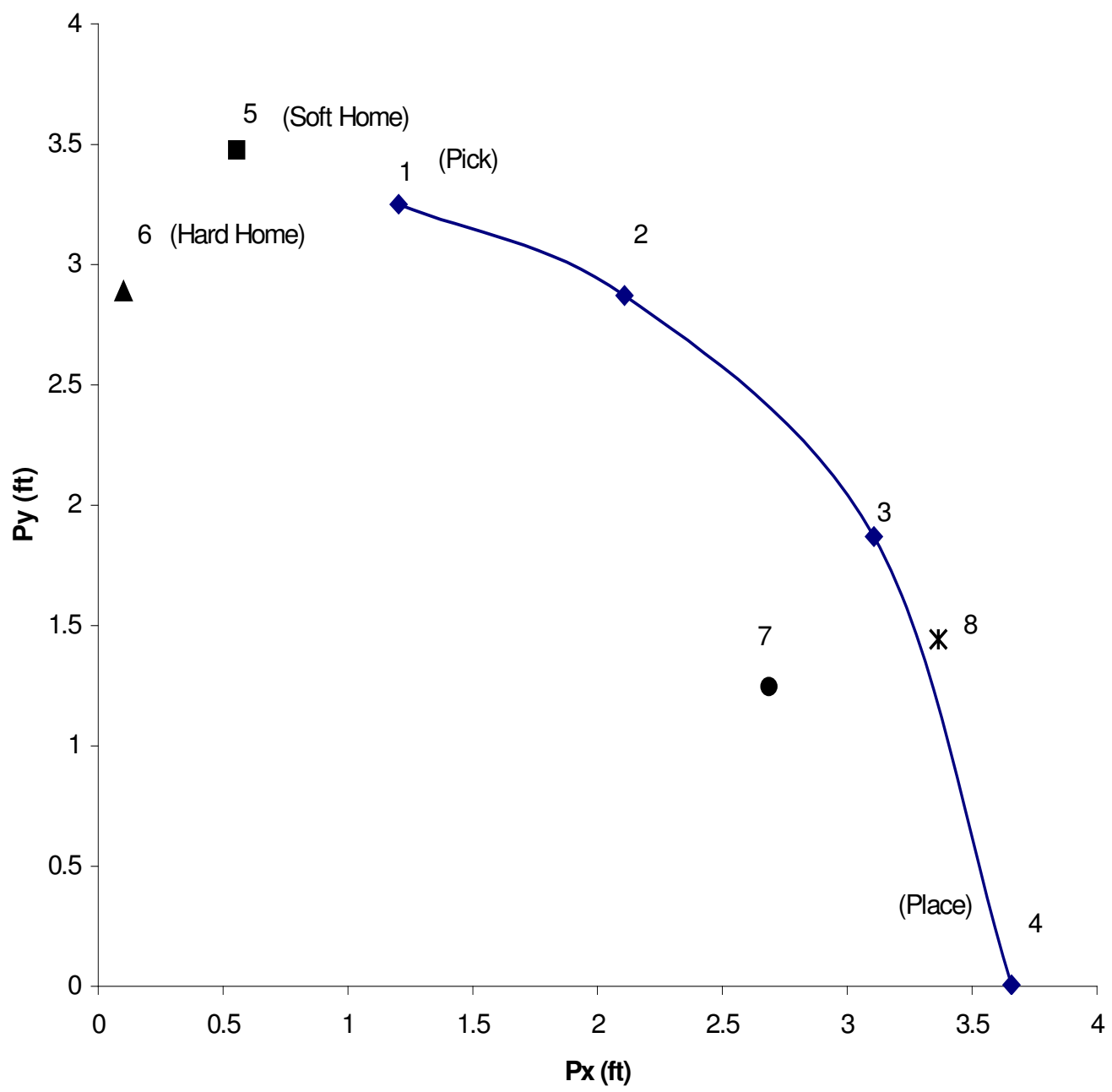

Figure 7.4 Path of Robot End-Effector (In Py - Px) 


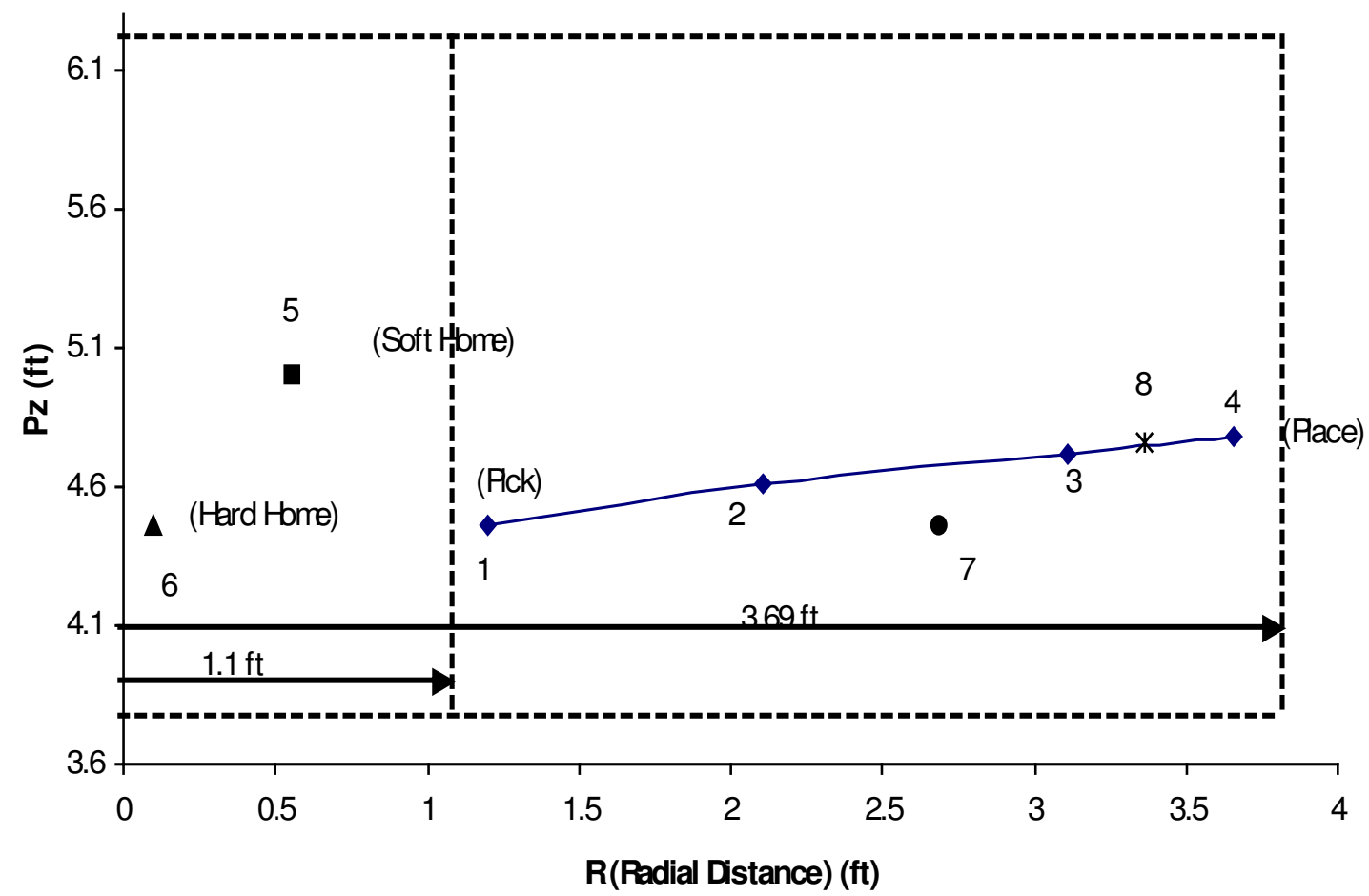

Figure 7.5 Path of Robot End-Effector (In Pz - R)

\section{Case 1: Pick Position (1)}

Given Kinematics:

Theta $1=55 \mathrm{deg}$, Theta $2=28 \mathrm{deg}$, Theta $3=25 \mathrm{deg}$, Theta $4=65$, Theta $5=0$;

Computed Inverse Kinematics:

$$
\mathrm{T} 0 \mathrm{E}=\left[\begin{array}{cccc}
-0.9925 & 0.1219 & 0 & 1.2031 \\
0.1219 & 0.9925 & 0 & 3.2496 \\
0 & 0 & -1 & 4.4633 \\
0 & 0 & 0 & 1
\end{array}\right]=\left[\begin{array}{cccc}
\mathrm{n}_{\mathrm{x}} & \mathrm{o}_{\mathrm{x}} & \mathrm{a}_{\mathrm{x}} & \mathrm{p}_{\mathrm{x}} \\
\mathrm{n}_{\mathrm{y}} & \mathrm{o}_{\mathrm{y}} & \mathrm{a}_{\mathrm{y}} & \mathrm{p}_{\mathrm{y}} \\
\mathrm{n}_{\mathrm{z}} & \mathrm{o}_{\mathrm{z}} & \mathrm{a}_{\mathrm{z}} & \mathrm{p}_{\mathrm{z}} \\
0 & 0 & 0 & 1
\end{array}\right]
$$

we know that:

$$
\begin{aligned}
& \theta_{1}=\operatorname{Atan} 2\left[\frac{-\mathrm{L} 3 * \mathrm{ay} *(\mathrm{H}-\mathrm{pz})-\mathrm{L} 3^{*} \mathrm{oy} *\left(\mathrm{~L} 3^{2}-(\mathrm{H}-\mathrm{pz})^{2}\right)^{0.5}+\mathrm{py} * \mathrm{~L} 3-\mathrm{L} 2 * \mathrm{~L} 3^{*} \mathrm{oy}}{-\mathrm{L} 3^{*} \mathrm{ax} *(\mathrm{H}-\mathrm{pz})-\mathrm{L} 3^{*} \mathrm{ox} *\left(\mathrm{~L} 3^{2}-(\mathrm{H}-\mathrm{pz})^{2}\right)^{0.5}+\mathrm{px} \mathrm{L}^{*}-\mathrm{L} 2 * \mathrm{~L} 3^{*} \mathrm{ox}}\right] \\
& \theta_{2}=\operatorname{Atan} 2\left[\frac{-\mathrm{S} 1 * \mathrm{px}+\mathrm{C} 1 * \mathrm{py}}{\mathrm{C} 1 * \mathrm{px}+\mathrm{S} 1 * \mathrm{py}-\mathrm{L} 1}\right]
\end{aligned}
$$




$$
\begin{aligned}
& \theta_{3}=\operatorname{Atan} 2\left(\frac{\mathrm{H}-\mathrm{Pz}}{\left(\mathrm{L} 3^{2}-(\mathrm{H}-\mathrm{pz})^{2}\right)^{0.5}}\right) \\
& \theta_{4}=90-\theta_{3} ; \\
& \theta_{4}=90-\operatorname{Atan} 2\left(\frac{\mathrm{H}-\mathrm{Pz}}{\left(\mathrm{L} 3^{2}-(\mathrm{H}-\mathrm{pz})^{2}\right)^{0.5}}\right) \\
& \theta_{5}=0 ;
\end{aligned}
$$

Substituting the computed inverse kinematics values of the end-effector in the inverse kinematic equations to compute the joint angles of the robot. The results are computed using Excel.

\begin{tabular}{|c|c|c|c|c|c|c|c|}
\hline $\mathbf{P x}$ & $\mathbf{P y}$ & $\mathbf{P z}$ & Theta1 & Theta3 & Theta2 & Theta4 & Theta5 \\
\hline 1.2031 & 3.2496 & 4.4633 & 55.00 & 25.00 & 28.00 & 65.00 & 0 \\
\hline & & & & & & & \\
\hline $\mathbf{n x}$ & $\mathbf{n y}$ & $\mathbf{n z}$ & & & & & \\
\hline-0.9925 & 0.1219 & 0 & & & & & \\
\hline & & & & & & & \\
\hline $\mathbf{0 x}$ & $\mathbf{0 y}$ & $\mathbf{0 z}$ & & $\mathbf{H}$ & & & \\
\hline 0.1219 & 0.9925 & 0 & & 5.00 & & & \\
\hline & & & & & & & \\
\hline $\mathbf{a x}$ & $\mathbf{a y}$ & $\mathbf{a z}$ & & & & & \\
\hline 0 & 0 & -1 & & & & & \\
\hline & & & & & & & \\
\hline $\mathbf{L 1}$ & $\mathbf{L 2}$ & $\mathbf{L 3}$ & & & & & \\
\hline 1.7 & 0.72 & 1.27 & & & & & \\
\hline
\end{tabular}

\section{Case 2: Intermediate Position (2)}

Theta $1=42 \mathrm{deg}$, Theta $2=22 \mathrm{deg}$, Theta $3=18 \mathrm{deg}$, Theta $4=72$, Theta $5=0$;

Computed Inverse Kinematics:

$$
\mathrm{T} 0 \mathrm{E}=\left[\begin{array}{cccc}
-0.8988 & 0.4384 & 0 & 2.1085 \\
0.4384 & 0.8988 & 0 & 2.8703 \\
0 & 0 & -1 & 4.6075 \\
0 & 0 & 0 & 1
\end{array}\right]
$$




\begin{tabular}{|c|c|c|c|c|c|c|c|}
\hline $\mathbf{P x}$ & $\mathbf{P y}$ & $\mathbf{P z}$ & Theta1 & Theta3 & Theta2 & Theta4 & Theta5 \\
\hline 2.1085 & 2.8703 & 4.6075 & 42.00 & 18.00 & 22.00 & 72.00 & 0 \\
\hline & & & & & & & \\
\hline $\mathbf{n x}$ & $\mathbf{n y}$ & $\mathbf{n z}$ & & & & & \\
\hline-0.8988 & 0.4384 & 0 & & & & & \\
\hline & & & & & & & \\
\hline $\mathbf{0 x}$ & $\mathbf{0 y}$ & $\mathbf{0 z}$ & & $\mathbf{H}$ & & & \\
\hline 0.4384 & 0.8988 & 0 & & 5.00 & & & \\
\hline & & & & & & & \\
\hline $\mathbf{a x}$ & $\mathbf{a y}$ & $\mathbf{a z}$ & & & & & \\
\hline 0 & 0 & -1 & & & & & \\
\hline & & & & & & & \\
\hline $\mathbf{L 1}$ & $\mathbf{L 2}$ & $\mathbf{L 3}$ & & & & & \\
\hline 1.7 & 0.72 & 1.27 & & & & & \\
\hline
\end{tabular}

\section{Case 3: Intermediate Position (3)}

Theta $1=23 \mathrm{deg}$, Theta $2=15 \mathrm{deg}$, Theta $3=13 \mathrm{deg}$, Theta $4=77$, Theta $5=0$;

Computed Inverse Kinematics:

$$
\mathrm{T} 0 \mathrm{E}=\left[\begin{array}{cccc}
-0.6157 & 0.7880 & 0 & 3.1073 \\
0.7880 & 0.6157 & 0 & 1.8694 \\
0 & 0 & -1 & 4.7143 \\
0 & 0 & 0 & 1
\end{array}\right]
$$

\begin{tabular}{|c|c|c|c|c|c|c|c|}
\hline $\mathbf{P x}$ & $\mathbf{P y}$ & $\mathbf{P z}$ & Theta1 & Theta3 & Theta2 & Theta4 & Theta5 \\
\hline 3.1073 & 1.8694 & 4.7143 & 23.00 & 13.00 & 15.00 & 77.00 & 0 \\
\hline & & & & & & & \\
\hline $\mathbf{n x}$ & $\mathbf{n y}$ & $\mathbf{n z}$ & & & & & \\
\hline-0.6157 & 0.788 & 0 & & & & & \\
\hline & & & & & & & \\
\hline $\mathbf{0 x}$ & $\mathbf{0 y}$ & $\mathbf{0 z}$ & & $\mathbf{H}$ & & & \\
\hline 0.788 & 0.6157 & 0 & & 5.00 & & & \\
\hline & & & & & & & \\
\hline $\mathbf{a x}$ & $\mathbf{a y}$ & $\mathbf{a z}$ & & & & & \\
\hline 0 & 0 & -1 & & & & & \\
\hline & & & & & & & \\
\hline L1 & L2 & L3 & & & & & \\
\hline 1.7 & 0.72 & 1.27 & & & & & \\
\hline
\end{tabular}




\section{Case 4: Place Position (4)}

Theta $1=-5 \mathrm{deg}$, Theta $2=9.5 \mathrm{deg}$, Theta $3=10 \mathrm{deg}$, Theta $4=80$, Theta $5=0$;

Computed Inverse Kinematics:

$$
\mathrm{T} 0 \mathrm{E}=\left[\begin{array}{cccc}
-0.0785 & 0.9969 & 0 & 3.6582 \\
0.9969 & 0.0785 & 0 & 0.0065 \\
0 & 0 & -1 & 4.7795 \\
0 & 0 & 0 & 1
\end{array}\right]
$$

\begin{tabular}{|c|c|c|c|c|c|c|c|}
\hline Px & Py & Pz & Theta1 & Theta3 & Theta2 & Theta4 & Theta5 \\
\hline 3.6582 & 0.0065 & 4.7795 & -5.00 & 10.00 & 9.50 & 80.00 & 0 \\
\hline & & & & & & & \\
\hline $\mathbf{n x}$ & $\mathbf{n y}$ & $\mathbf{n z}$ & & & & & \\
\hline-0.0785 & 0.9969 & 0 & & & & & \\
\hline & & & & & & & \\
\hline $\mathbf{0 x}$ & oy & $\mathbf{0 z}$ & & $\mathbf{H}$ & & & \\
\hline 0.9969 & 0.0785 & 0 & & 5.00 & & & \\
\hline & & & & & & & \\
\hline $\mathbf{a x}$ & $\mathbf{a y}$ & $\mathbf{a z}$ & & & & & \\
\hline 0 & 0 & -1 & & & & & \\
\hline & & & & & & & \\
\hline $\mathbf{L 1}$ & $\mathbf{L 2}$ & $\mathbf{L 3}$ & & & & & \\
\hline 1.7 & 0.72 & 1.27 & & & & & \\
\hline
\end{tabular}

\section{Case 5: Soft Home Position (5)}

Theta $1=62$ deg, Theta $2=35 \mathrm{deg}$, Theta $3=0$ deg, Theta $4=90$, Theta $5=0$;

Computed Inverse Kinematics:

$\mathrm{T} 0 \mathrm{E}=\left[\begin{array}{cccc}-0.9925 & -0.1219 & 0 & 0.5556 \\ -0.1219 & 0.9925 & 0 & 3.4762 \\ 0 & 0 & -1 & 5.0000 \\ 0 & 0 & 0 & 1\end{array}\right]$

\begin{tabular}{|c|c|c|c|c|c|c|c|}
\hline Px & Py & Pz & Theta1 & Theta3 & Theta2 & Theta4 & Theta5 \\
\hline 0.5556 & 3.4762 & 5 & 62.00 & 0.00 & 35.00 & 90.00 & 0.00 \\
\hline & & & & & & & \\
\hline nx & ny & $\mathbf{n z}$ & & & & & \\
\hline-0.9925 & -0.1219 & 0 & & & & & \\
\hline
\end{tabular}




\begin{tabular}{|c|c|c|c|c|c|c|c|}
\hline & & & & & & & \\
\hline ox & oy & oz & & H & & & \\
\hline-0.1219 & 0.9925 & 0 & & 5.00 & & & \\
\hline & & & & & & & \\
\hline ax & ay & az & & & & & \\
\hline 0 & 0 & -1 & & & & & \\
\hline & & & & & & & \\
\hline L1 & L2 & L3 & & & & & \\
\hline 1.7 & 0.72 & 1.27 & & & & & \\
\hline
\end{tabular}

\section{Case 6: Hard Home Position (6)}

Theta $1=50 \mathrm{deg}$, Theta $2=72 \mathrm{deg}$, Theta $3=25 \mathrm{deg}$, Theta $4=65$, Theta $5=0$;

Computed Inverse Kinematics:

$\mathrm{T} 0 \mathrm{E}=\left[\begin{array}{cccc}-0.8480 & 0.5299 & 0 & 0.1013 \\ -0.5299 & 0.8480 & 0 & 2.8890 \\ 0 & 0 & -1 & 4.4633 \\ 0 & 0 & 0 & 1\end{array}\right]$

\begin{tabular}{|c|c|c|c|c|c|c|c|}
\hline $\mathbf{P x}$ & $\mathbf{P y}$ & $\mathbf{P z}$ & Theta1 & Theta3 & Theta2 & Theta4 & Theta5 \\
\hline 0.1013 & 2.889 & 4.4633 & 50.00 & 25.00 & 72.00 & 65.00 & 0.00 \\
\hline & & & & & & & \\
\hline $\mathbf{n x}$ & $\mathbf{n y}$ & $\mathbf{n z}$ & & & & & \\
\hline-0.848 & -0.5299 & 0 & & & & & \\
\hline & & & & & & & \\
\hline $\mathbf{0 x}$ & $\mathbf{0 y}$ & $\mathbf{0 z}$ & & $\mathbf{H}$ & & & \\
\hline-0.5299 & 0.848 & 0 & & 5.00 & & & \\
\hline & & & & & & & \\
\hline $\mathbf{a x}$ & $\mathbf{a y}$ & $\mathbf{a z}$ & & & & & \\
\hline 0 & 0 & -1 & & & & & \\
\hline & & & & & & & \\
\hline L1 & L2 & L3 & & & & & \\
\hline 1.7 & 0.72 & 1.27 & & & & & \\
\hline
\end{tabular}

\section{Case 7: Arbitrary Position (7)}

Theta $1=-11 \mathrm{deg}$, Theta $2=68 \mathrm{deg}$, Theta $3=25 \mathrm{deg}$, Theta $4=65$, Theta $5=0 ;$ 
Computed Inverse Kinematics:

$\mathrm{T} 0 \mathrm{E}=\left[\begin{array}{cccc}-0.8387 & 0.5446 & 0 & 2.6878 \\ 0.5446 & 0.8387 & 0 & 1.2448 \\ 0 & 0 & -1 & 4.4633 \\ 0 & 0 & 0 & 1\end{array}\right]$

\begin{tabular}{|c|c|c|c|c|c|c|c|}
\hline $\mathbf{P x}$ & $\mathbf{P y}$ & $\mathbf{P z}$ & Theta1 & Theta3 & Theta2 & Theta4 & Theta5 \\
\hline 2.6878 & 1.2448 & 4.4633 & -11.00 & 25.00 & 68.00 & 65.00 & 0 \\
\hline & & & & & & & \\
\hline $\mathbf{n x}$ & $\mathbf{n y}$ & $\mathbf{n z}$ & & & & & \\
\hline-0.8387 & 0.5446 & 0 & & & & & \\
\hline & & & & & & & \\
\hline ox & oy & $\mathbf{0 z}$ & & $\mathbf{H}$ & & & \\
\hline 0.5446 & 0.8387 & 0 & & 5.00 & & & \\
\hline & & & & & & & \\
\hline ax & ay & az & & & & & \\
\hline 0 & 0 & -1 & & & & & \\
\hline & & & & & & & \\
\hline L1 & L2 & L3 & & & & & \\
\hline 1.7 & 0.72 & 1.27 & & & & & \\
\hline
\end{tabular}

\section{Case 8: Arbitrary Position (8)}

Theta $1=20 \mathrm{deg}$, Theta $2=6 \mathrm{deg}$, Theta $3=11 \mathrm{deg}$, Theta $4=79$, Theta $5=0$;

Computed Inverse Kinematics:

$\mathrm{T} 0 \mathrm{E}=\left[\begin{array}{cccc}-0.4384 & 0.8988 & 0 & 3.3651 \\ 0.8988 & 0.4384 & 0 & 1.4436 \\ 0 & 0 & -1 & 4.7577 \\ 0 & 0 & 0 & 1\end{array}\right]$

\begin{tabular}{|c|c|c|c|c|c|c|c|}
\hline $\mathbf{P x}$ & $\mathbf{P y}$ & $\mathbf{P z}$ & Theta1 & Theta3 & Theta2 & Theta4 & Theta5 \\
\hline 3.3651 & 1.4436 & 4.7577 & 20.00 & 11.00 & 6.00 & 79.00 & 0 \\
\hline & & & & & & & \\
\hline $\mathbf{n x}$ & $\mathbf{n y}$ & $\mathbf{n z}$ & & & & & \\
\hline-0.4384 & 0.8988 & 0 & & & & & \\
\hline & & & & & & & \\
\hline ox & oy & $\mathbf{0 z}$ & & $\mathbf{H}$ & & & \\
\hline 0.8988 & 0.4384 & 0 & & 5.00 & & & \\
\hline & & & & & & & \\
\hline $\mathbf{a x}$ & ay & $\mathbf{a z}$ & & & & & \\
\hline 0 & 0 & -1 & & & & & \\
\hline
\end{tabular}




\begin{tabular}{|c|c|c|c|c|c|c|c|}
\hline & & & & & & & \\
\hline L1 & L2 & L3 & & & & & \\
\hline 1.7 & 0.72 & 1.27 & & & & & \\
\hline & & & & & & & \\
\hline
\end{tabular}

\subsection{KINEMATIC STUDY OF SCARA-TYPE ROBOT}

The SCARA-Type robot was studied by changing the length of link 2 to improve the kinematics of the robot. This study was done by varying the length of link 2 and calculating the maximum acceleration achieved by the end-effector.

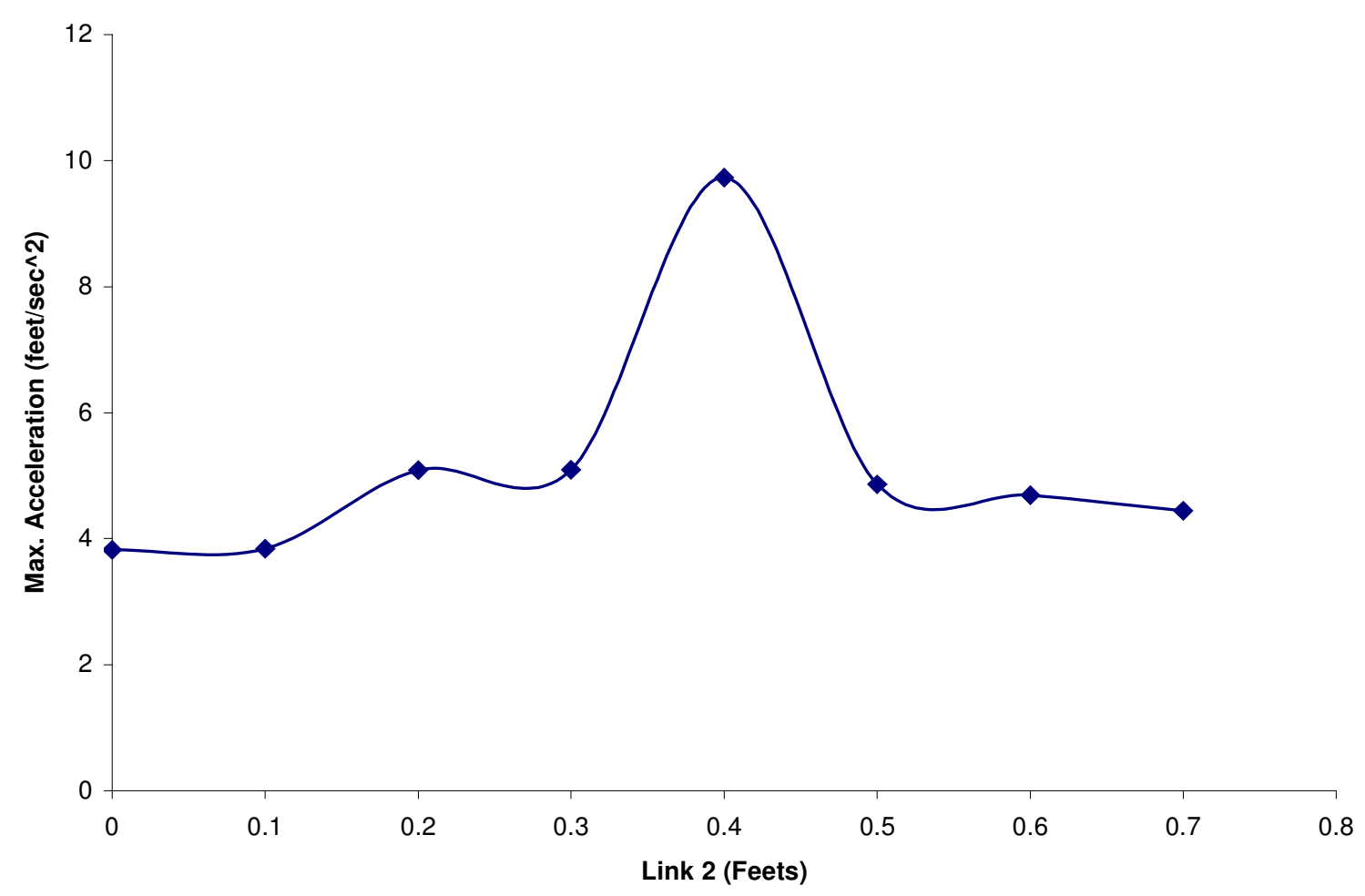

Figure 7.6 Change in acceleration of end-effector with the change in length of Link 2

Figure 7.6 illustrates that the maximum acceleration occurs when the length of link 2 is changed to 0.4 feet. The original length of the link 2 is 0.72 feet. A Study was carried on to find whether the change in length would save money to manufacture the robot with same kinematics. It can be seen from Figure 7.6 that if link 2 is eliminated, the performance will remain the same i.e. the maximum acceleration achieved by the end-effector remains the same. 


\subsection{DYNAMIC STUDY OF SCARA-TYPE ROBOT}

Dynamics study of the SCARA-Type robot was conducted to see the effects on torque characteristic of the actuator in joint 2 by selecting different materials for link 2 . The study was done by selecting different materials like steel, aluminum alloy and titanium alloy for link 2. The original system of SCARA-Type robot was constructed using aluminum. The study shows that steel requires maximum torque at the actuator in joint 2 and aluminum alloy requires less torque at actuator in joint 2 as illustrated in Figure 7.7.

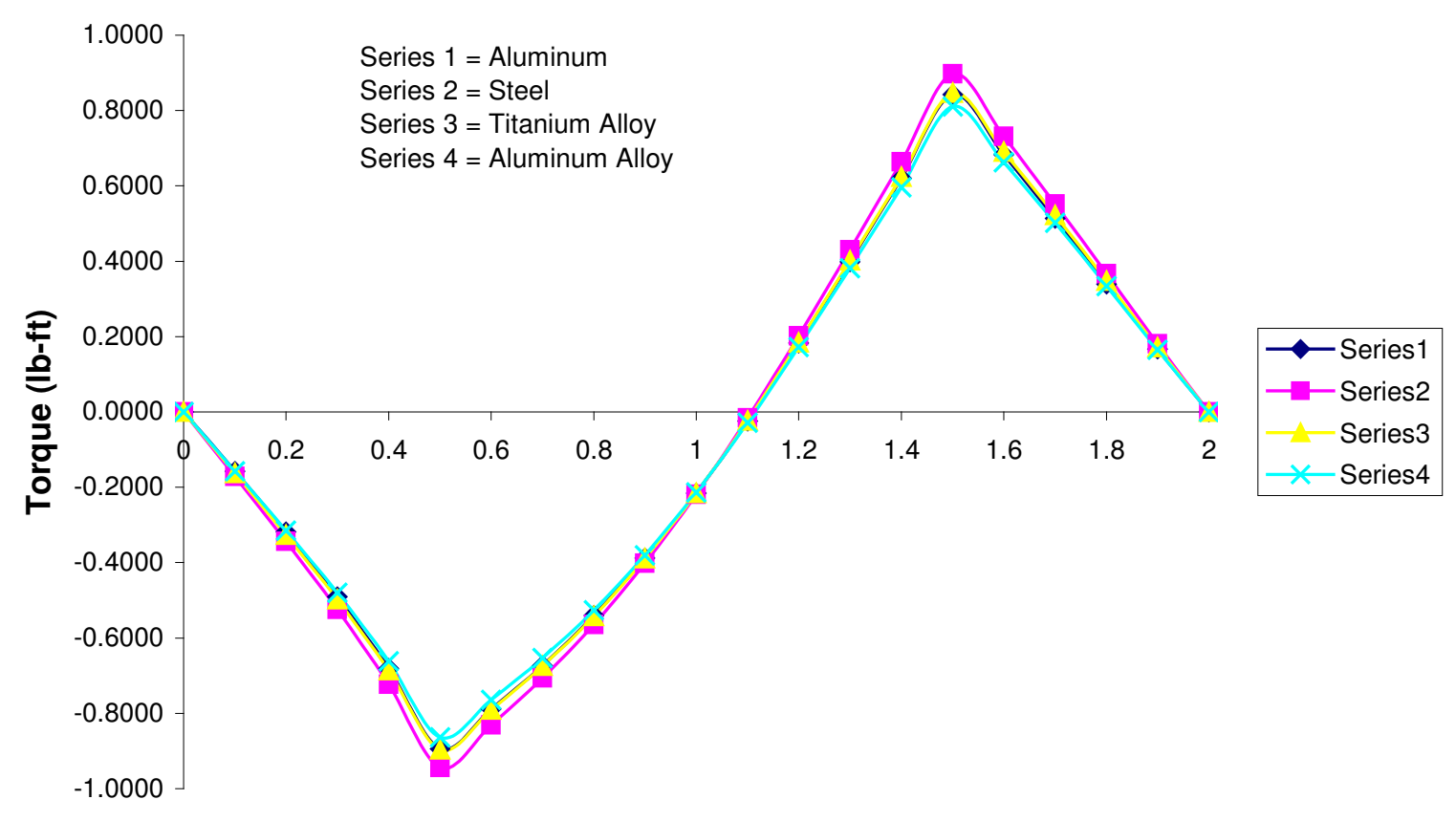

Time (Sec)

Figure 7.7 Change in torque requirements at actuator 2 with the change in material of Link 2

\subsection{WORKSPACE STUDY OF SCARA-TYPE ROBOT}

The other factor, which was studied, is the workspace. The changes in workspace are studied by changing the length of link 2 as shown in Figure 7.8. Studies were first done by keeping the original lengths of the link 2 and then the length of link 2 was changed to 0.3 feet. Finally, link 2 was eliminated completely and the effects on 
workspace were seen. Figure 7.8 will show how the workspace varies by changing the length of link 2. The side view and top view of the robot are shown in Figure 7.9 and Figure 7.10 respectively.

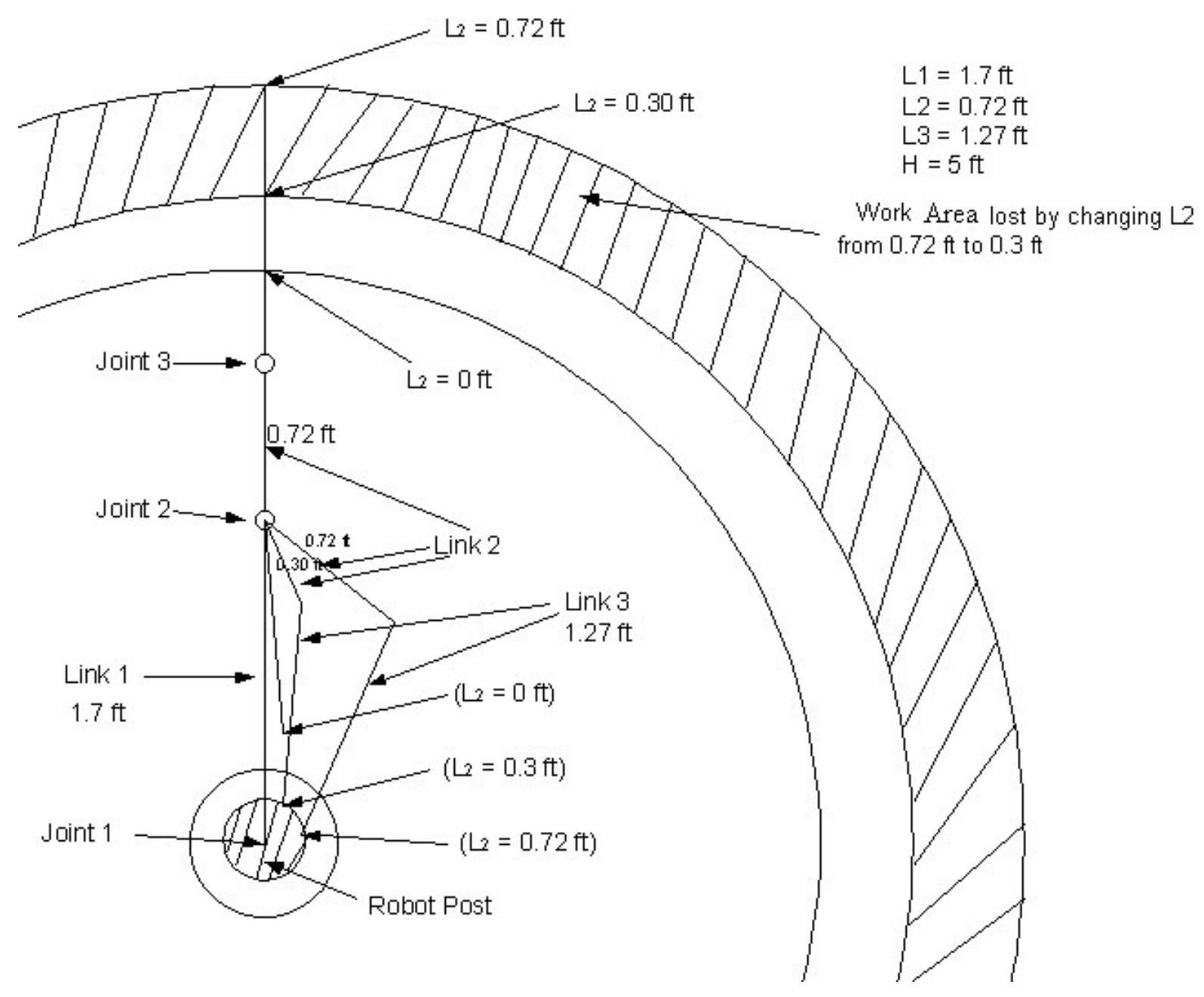

Figure 7.8 Work Envelop of Robot for Varying Length of Link 2. 


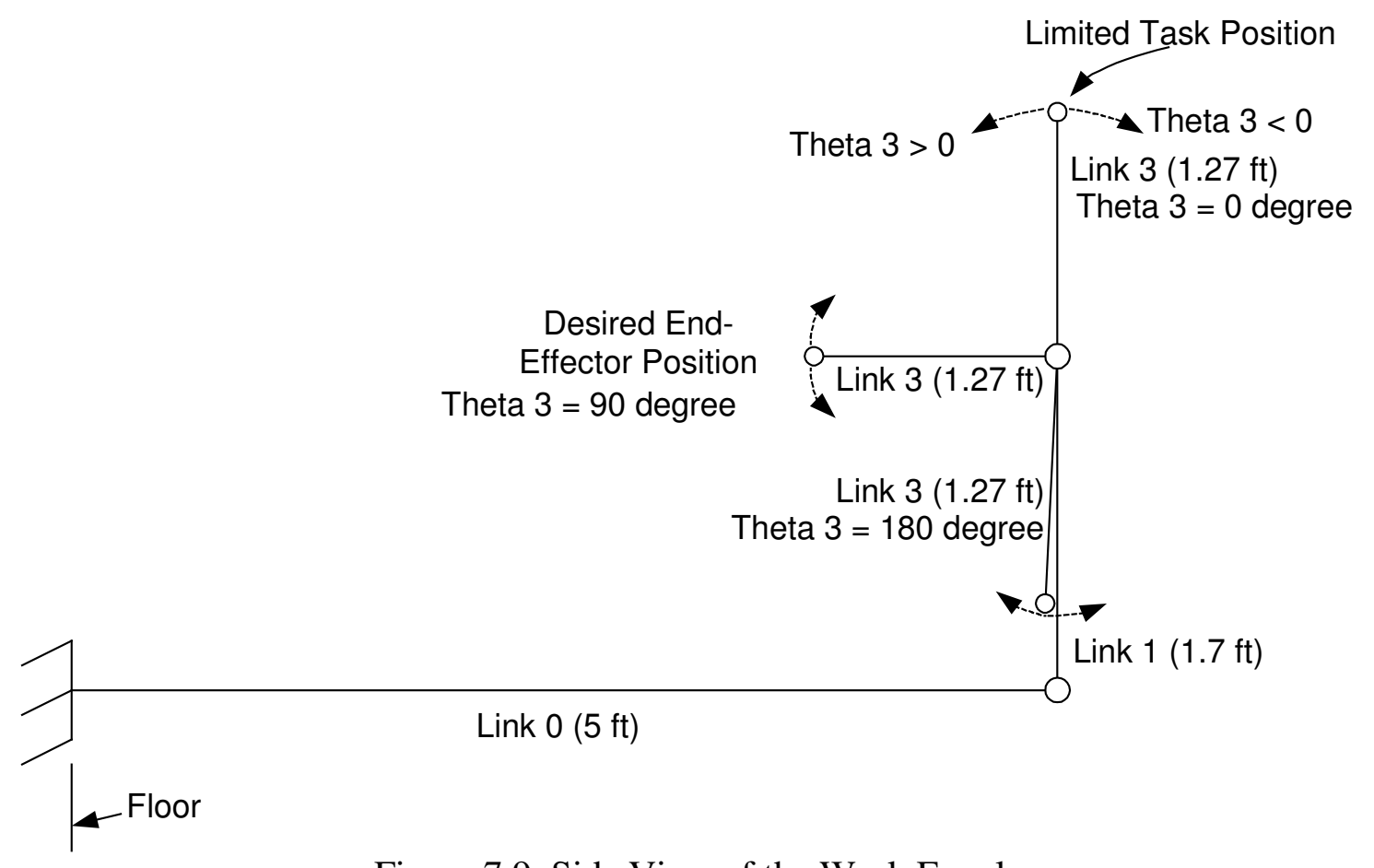

Figure 7.9 Side View of the Work Envelop

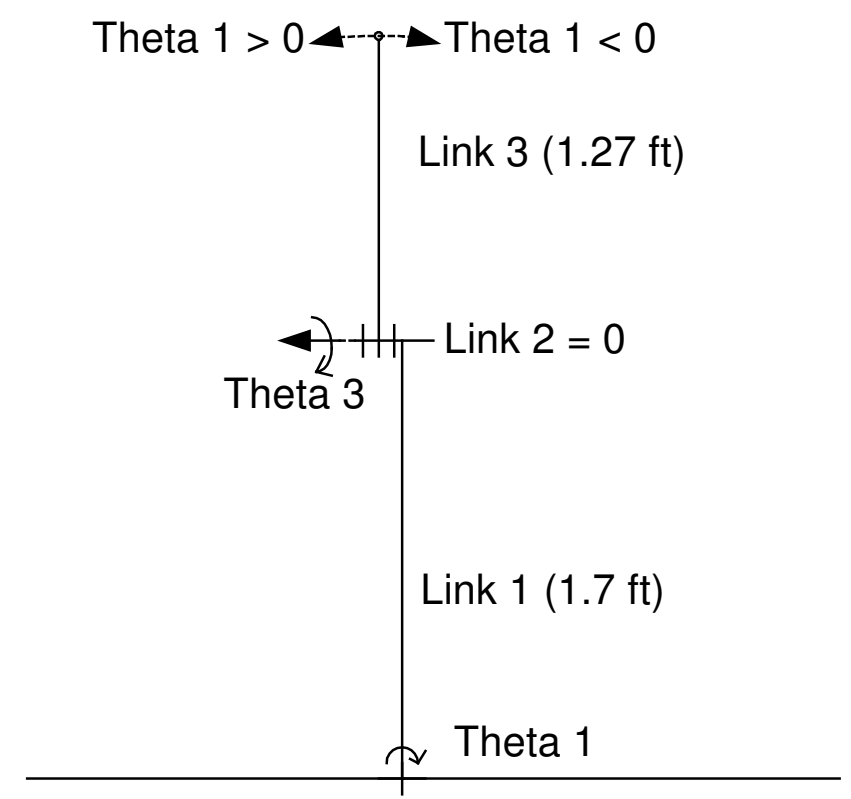

Figure 7.10 Top View of the Work Envelop

$$
\begin{aligned}
& \theta_{1}=0 \text { degrees } \\
& \theta_{2}=\text { N } / \mathrm{A}
\end{aligned}
$$




$$
\begin{aligned}
& \theta_{3}=0 \text { degrees (Extreme position for } \theta_{3} \text { ) } \\
& \theta_{3}=180 \text { degrees (Extreme position for } \theta_{3} \text { ) } \\
& \theta_{3}=90 \text { degrees (Desired position for } \theta_{3} \text { ) }
\end{aligned}
$$

The above studies indicate that any change in the length of the links will change the workspace of the robot. Kinematic study of the robot shows that a length of 0.3 feet can be chosen to have the same kinematics. The change in the length of link 2 from 0.7 feet to 0.3 feet will reduce the workspace. It can be seen from Figure 7.8 that the length of 0.3 feet will save money, but with a little lose of workspace. Hence a balance has to be drawn between choosing the length of link 2 and the workspace of the robot. By eliminating link 2 completely, money can be saved but there is a considerable lose of workspace. It can be concluded that a thin margin can be drawn between length of link 2 and the workspace and it is seen that a length of 0.3 feet will bring the benefits.

\subsection{SUMMARY}

The purpose of this study was to verify the theoretical kinematic model of the SCARA-Type robot. It was verified that the theoretical kinematic model of the SCARAType robot behaves in the same way as the actual robotic system in the glass plant at Davis-Lynch Glass with a 3-4\% error. It was also studied experimentally at Davis-Lynch Glass Plant that a better theoretical controller was designed to perform the pick-to-place task. A theoretical study was done on the SCARA-Type robot by changing the length and material of the link 2 . 


\section{Chapter 8 \\ Conclusions and Contributions}

\subsection{CONTRIBUTIONS}

The main goal of this thesis was to develop a model of the workcell robot and to design joint control schemes for position control of the workcell robot model using a classical approach that would improve the performance of the Laser Glass Cutting Machine workcell. It was discussed in Chapter 7 that $0.3 \mathrm{ft}$ for link 2 will make the work cell robot to behave the same way it does with length of $0.72 \mathrm{ft}$. The only disadvantage for length of link 2 being $0.3 \mathrm{ft}$ is the constraint to manufacture such a small link and installing with other links. In which case the actuator should be very small or it has to be driven by an external actuator.

Listed below are the key contributions for this thesis towards achieving the abovementioned goal.

1. A kinematic model of the manipulator arm was developed. This arm is a modified SCARA robot arm. The link coordinate systems for the robot were defined in order to develop kinematics of the robot arm. Based on the direct kinematics of the robot arm, an inverse kinematic description was developed.

2. A dynamic model of the manipulator was developed. To further assess the behavior of the manipulator arm, the dynamic equations for the robot were derived which yields the torque equations for the three joints. These dynamic equations, which were based on direct kinematics equations, were used to develop the dynamic model of the manipulator arm. Transfer functions for each of the robot joints were developed.

3. A model for the actuator motor was developed. An electro-mechanical model of DC motor was developed in Section 4.5. Key control parameters were identified to develop theoretical model of DC motor. A transfer function for the actuator motor was developed.

4. A PID controller was developed for each joint of the three closed-loop models for the manipulator arm using a classical approach. The performance of the position 
control of the manipulator was analyzed using Bode plots and root locus plots. The PID controller was designed to achieve specified gain and phase margins, over-damped system and zero steady state error.

5. An experimental verification study of the integrated joint model of the manipulator arm and joint actuator was performed. It was determined that the controlled dynamic model behaves about the same way as the actual system.

6. Kinematic study of the SCARA-Type robot was done by changing the length of link 2. It was determined that the performance (maximum acceleration achieved by end-effector) of the robot remains the same even after eliminating link 2 completely.

7. Dynamic study of the SCARA-Type robot was done by changing the element type of the robot. The robot structure was constructed with aluminum. Different materials were selected and a study was done on the torque required by joint 2 . It was determined that steel requires maximum torque at joint 2 and an aluminum alloy requires the least torque at joint 2 .

\subsection{FUTURE RESEARCH AND RECOMMENDATIONS}

The main objective of this thesis was to develop a controller for the SCARA-Type robot using a classical approach that improved the operational performance of the LGCM workcell. Further research could be done to design a controller using state-space approach.

For the dynamics model, the cumbersome Lagrange-Euler method involving $4 \times 4$ homogeneous matrices has been used. This particular method of calculating the torques is not efficient as far a control of the robot arm motion is concerned. The recursive Newton-Euler method could be used for determining the joint torques. Also, the inertias were approximated to determine this torques, since the robot was not dismantled. For better values of torques, the exact values of the inertias have to be determined. 


\section{References}

[1] Glass Project Fact Sheet, "Enhanced Cutting and Finishing of Hand Glass using a Carbon Dioxide Laser", USDOE/OIT, 2pp, February 1999.

[2] Nimbl Loader NL 100 Users Guide, Nimbl Incorporated, 105A-8 Commerce Circle Madison AL, 35758, Rev 2.3 - June 2001.

[3] Nimbl Loader Application Specific Information, Nimbl Incorporated, 105A-8 Commerce Circle Madison AL, 35758, Rev - August 2001.

[4] K.S.Fu, R.C.Gonzalez, and C.S.G.Lee, Robotics: Control, Sensing, Vision, and Intelligence, McGraw-Hill Book Company, 1987.

[5] C.Y.Ho and Jen Sriwattanathamma, Robot Kinematics: Symbolic Automation and Numerical Synthesis, 1989.

[6] Amanpreet Singh, "Kinematics and Dynamics of the GE P60 Process Robot and the Application of the Analysis to Task Planning", Masters Thesis, West Virginia University, Morgantown, 1993.

[7] Tak-Lai Daryl Luk, "Inverse Dynamics for the GE P-50 Robot”, Masters Thesis, West Virginia University, Morgantown, 1987.

[8] Krit Kittiampon, "Kinematics, Dynamics and Control of a Closed Chain Mechanism Manipulator", Ph.D. Dissertation, West Virginia University, Morgantown, 1987.

[9] Joseph Edward Shigley and Larry D. Mitchell, Mechanical Engineering Design: Fourth Edition, McGraw-Hill Series in Mechanical Engineering, 1983.

[10] Raven H. Francis, Automatic Control Engineering: Fifth Edition, McGraw-Hill Series in Mechanical Engineering, 1995.

[11] Gene F. Franklin, J. David Powell and Abbas Emami-Naeini, Feedback Control of Dynamic Systems: Third Edition, 1994.

[12] Mohsen Shahinpoor, A Robot Engineering Textbook, Harper \& Row, Publishers, New York, 1987.

[13] William Robert Ahrendt and C.J. Savant, Jr., Servo-Mechanism Practice: Second Edition, McGraw-Hill Series in Mechanical Engineering, 1960. 
[14] Benjamin C. Kuo, Automatic Control Systems: Fourth Edition, Englewood Cliffs, N.J.: Prentice Hall, 1982.

[15] Gideon Sahar and John M. Hollerbach, "Planning of Minimum-Time Trajectories for Robot Arms", Proceedings of the IEEE Conference on Robotics and Automation, March 1985, pp. 751-758. 


\section{Appendix A \\ Inverse Kinematic Model Verification}

For the pick position of the specified task, $\theta 1=60 \mathrm{deg}, \theta 2=60 \mathrm{deg}, \theta 3=-60 \mathrm{deg}$, $\theta 5=0$ deg.

$\mathrm{T}_{\text {goal }}={ }^{\mathrm{O}} \mathrm{T}_{\mathrm{E}}$

$\left[\begin{array}{ccccc}\text { nx } & \text { ox } & \text { ax } & \text { px } \\ \text { ny } & \text { oy } & \text { ay } & \text { py } \\ \text { nz } & \text { oz } & \text { az } & \text { pz } \\ 0 & 0 & 0 & 1\end{array}\right]=\left[\begin{array}{rrrc}-0.8660 & -0.5000 & 0.0000 & 0.1000 \\ -0.5000 & -0.8660 & 0.0000 & 2.6000 \\ 0.0000 & 0.0000 & -1.000 & 6.0000 \\ 0.0000 & 0.0000 & 0.0000 & 1.0000\end{array}\right]$

where Equation (2.4) has been used to compute ${ }^{\mathrm{O}} \mathrm{T}_{\mathrm{E}}$

Equation the two matrices of Equation (A.2) yields,

$\theta_{1}=\operatorname{Atan} 2\left[\frac{-\mathrm{L} 3^{*} \mathrm{ay} *(\mathrm{H}-\mathrm{pz})-\mathrm{L} 3^{*} \mathrm{oy} *\left(\mathrm{~L}^{2}-(\mathrm{H}-\mathrm{pz})^{2}\right)^{0.5}+\mathrm{py} * \mathrm{~L} 3-\mathrm{L} 2 * \mathrm{~L} 3^{*} \mathrm{oy}}{-\mathrm{L} 3^{*} \mathrm{ax} *(\mathrm{H}-\mathrm{pz})-\mathrm{L} 3^{*} \mathrm{ox} *\left(\mathrm{~L} 3^{2}-(\mathrm{H}-\mathrm{pz})^{2}\right)^{0.5}+\mathrm{px} * \mathrm{~L} 3-\mathrm{L} 2 * \mathrm{~L} 3^{*} \mathrm{ox}}\right]$

$\theta_{2}=\operatorname{Atan} 2\left[\frac{-\mathrm{S} 1 * \mathrm{px}+\mathrm{C} 1 * \mathrm{py}}{\mathrm{C} 1 * \mathrm{px}+\mathrm{S} 1 * \mathrm{py}-\mathrm{L} 1}\right]$

$\theta_{3}=\operatorname{Atan} 2\left[\frac{\mathrm{H}-\mathrm{pz}}{\left(\mathrm{L}^{2}-(\mathrm{H}-\mathrm{pz})^{2}\right)^{\wedge} 0.5}\right]$

$\theta_{4}=90-\theta_{3}$

$\theta_{4}=90-\operatorname{Atan} 2\left(\frac{\mathrm{H}-\mathrm{Pz}}{\left(\mathrm{L}^{2}-(\mathrm{H}-\mathrm{pz})^{2}\right)^{0.5}}\right)$

$\theta_{5}=0$

$\mathrm{px}=0.1000 \mathrm{ft}, \mathrm{py}=2.6000 \mathrm{ft}, \mathrm{pz}=6.0000 \mathrm{ft}, \mathrm{nx}=-0.8660, \mathrm{ny}=-0.5000, \mathrm{nz}=0$,

$\mathrm{ox}=-0.5000, \mathrm{oy}=-0.8660, \mathrm{oz}=0.0000, \mathrm{oy}=0.7500, \mathrm{ax}=0.0000, \mathrm{ay}=0.0000$,

$\mathrm{az}=-1.0000 ;$

Substituting the above values in Equation (A.3) to verify for $\theta_{1}$ : 


$$
\begin{aligned}
& \theta_{1}=\operatorname{Atan} 2\left[\frac{-\mathrm{L} 3 * a y^{*}(\mathrm{H}-\mathrm{pz})-\mathrm{L} 3^{*} \mathrm{oy} *\left(\mathrm{~L}^{2}-(\mathrm{H}-\mathrm{pz})^{2}\right)^{0.5}+\mathrm{py} * \mathrm{~L} 3-\mathrm{L} 2 * \mathrm{~L} 3^{*} \mathrm{oy}}{-\mathrm{L} 3^{*} \mathrm{ax} *(\mathrm{H}-\mathrm{pz})-\mathrm{L} 3^{*} \mathrm{ox} *\left(\mathrm{~L} 3^{2}-(\mathrm{H}-\mathrm{pz})^{2}\right)^{0.5}+\mathrm{px} * \mathrm{~L} 3-\mathrm{L} 2 * \mathrm{~L} 3^{*} \mathrm{ox}}\right]
\end{aligned}
$$

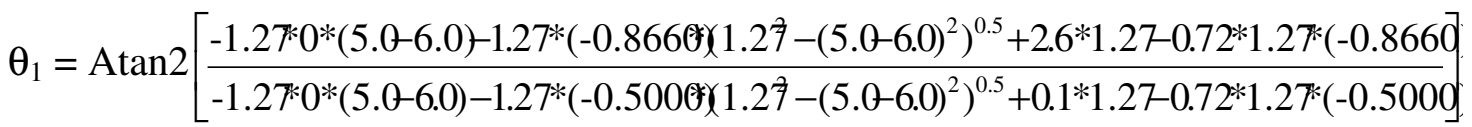

Hence;

$\theta_{1}=60.00$ degrees

Substituting the above values in Equation (A.5) to verify for $\theta_{3}$ :

$\theta_{3}=\operatorname{Atan} 2\left[\frac{\mathrm{H}-\mathrm{pz}}{\left(\mathrm{L}^{2}-(\mathrm{H}-\mathrm{pz})^{2}\right)^{\wedge} 0.5}\right]$

$\theta_{3}=\operatorname{Atan} 2\left[\frac{5.0-6.0}{\left(1.27^{2}-(5.0-6.0)^{2}\right)^{\wedge} 0.5}\right]$

$\theta_{3}=\operatorname{Atan} 2[-1.732]$

Hence;

$\theta_{3}=-59.999$ degrees

Substituting the above values in Equation (A.4) to verify for $\theta_{2}$ :

$\theta_{2}=\operatorname{Atan} 2\left[\frac{-\mathrm{S} 1 * \mathrm{px}+\mathrm{C} 1 * \mathrm{py}}{\mathrm{C} 1 * \mathrm{px}+\mathrm{S} 1 * \mathrm{py}-\mathrm{L} 1}\right]$

$\theta_{2}=\operatorname{Atan} 2\left[\frac{-\operatorname{Sin}(60) * 0.1000+\operatorname{Cos}(60) * 2.6000}{\operatorname{Cos}(60) * 0.1000+\operatorname{Sin}(60) * 2.6000-1.7}\right]$

$\theta_{2}=\operatorname{Atan} 2[1.7384]$

Hence;

$\theta_{2}=60.09$ degrees

Therefore the inverse Kinematic Model has been verified for one location. 


\title{
Appendix B \\ Calculation of Inertia, Coriolis and Centrifugal and Gravitational terms
}

\author{
B.1 Inertial terms \\ $\mathrm{D} 11=$ \\ $0.1065 * \cos (\theta 2)+0.0526 * \cos (\theta 3)+0.3433+0.0636^{*} \cos (\theta 3)^{\wedge} 2+0.1241 * \cos (\theta 2) * \cos (\theta 3)$ \\ $\mathrm{D} 12=\mathrm{D} 21=$ \\ $0.0533 * \cos (\theta 2)+0.0526 * \cos (\theta 3)+0.0636 * \cos (\theta 3)^{\wedge} 2+0.0621 * \cos (\theta 2) * \cos (\theta 3)+0.0315$ \\ $\mathrm{D} 13=\mathrm{D} 31=$ \\ $-0.0621 * \sin (\theta 2) * \sin (\theta 3)$ \\ $\mathrm{D} 22=$ \\ $0.0526 * \cos (\theta 3)+0.0636 * \cos (\theta 3)^{\wedge} 2+0.0315$ \\ $\mathrm{D} 23=\mathrm{D} 32=$ \\ 0 \\ $\mathrm{D} 33=$ \\ 0.0639
}

B.2 Coriolis and Centrifugal terms

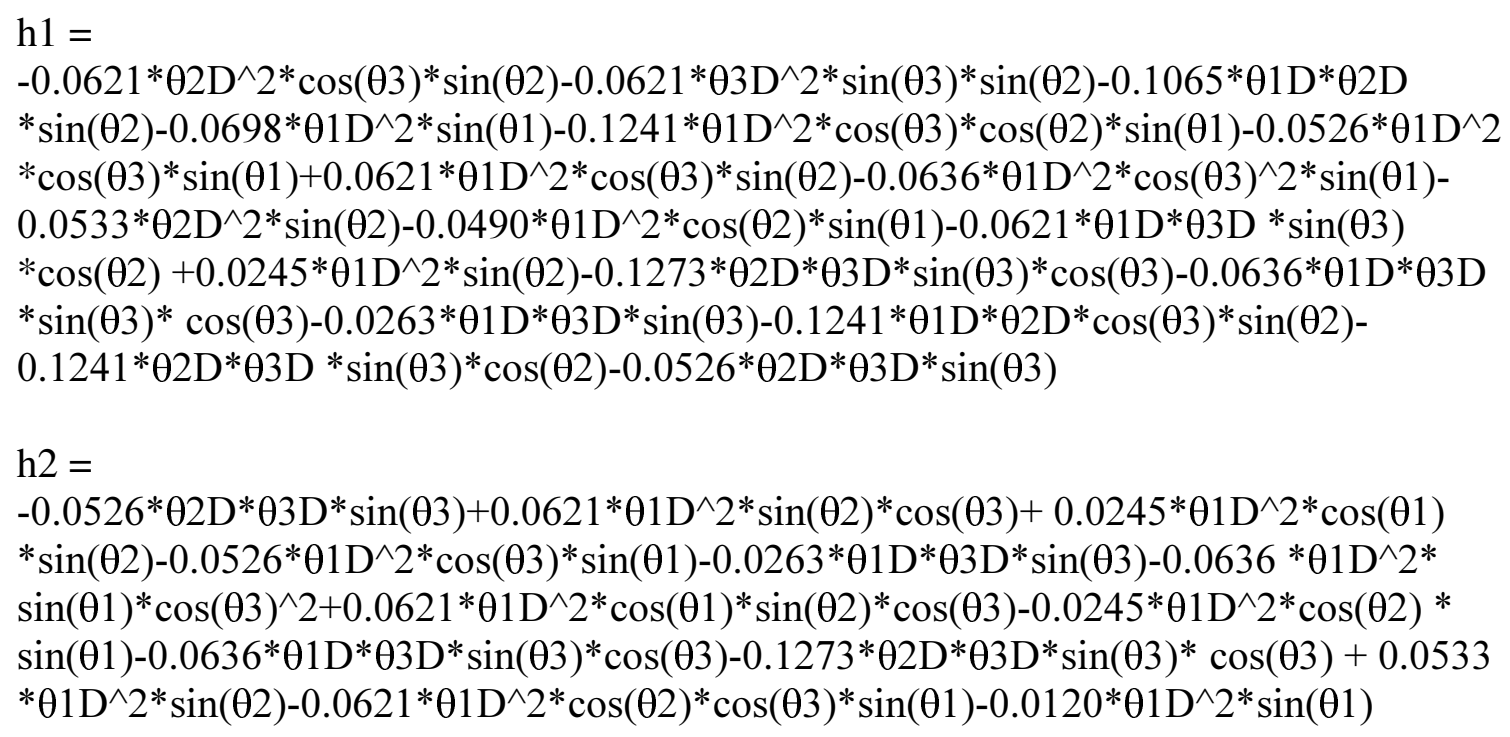


$\mathrm{h} 3=$

$0.0621 * \theta 1 \mathrm{D}^{\wedge} 2 * \sin (\theta 3) * \cos (\theta 1) * \cos (\theta 2)+0.0263 * \theta 2 \mathrm{D}^{\wedge} 2 * \sin (\theta 3)+0.0636^{*} \theta 1 \mathrm{D}^{\wedge} 2 *$ $\sin (\theta 3) * \cos (\theta 1) * \cos (\theta 3)+0.0621 * \theta 1 \mathrm{D}^{\wedge} 2 * \sin (\theta 3) * \cos (\theta 2)+0.1273 * \theta 1 \mathrm{D}^{*} \theta 2 \mathrm{D}^{*} \sin (\theta 3) *$ $\cos (\theta 3)+0.0263 * \theta 1 \mathrm{D}^{\wedge} 2 * \sin (\theta 3) * \cos (\theta 1)+0.0621 * \theta 1 \mathrm{D}^{\wedge} 2 * \sin (\theta 3) * \sin (\theta 2) * \sin (\theta 1)+0.0526$ $* \theta 1 \mathrm{D}^{*} \theta 2 \mathrm{D} * \sin (\theta 3)+0.0636 * \theta 2 \mathrm{D}^{\wedge} 2 * \sin (\theta 3) * \cos (\theta 3)+0.0639 * \theta 3 \mathrm{D}^{\wedge} 2$

where,

$\theta 1 \mathrm{D}=\dot{\theta}_{1} ; \theta 2 \mathrm{D}=\dot{\theta}_{2} ; \theta 3 \mathrm{D}=\dot{\theta_{3}}$

\section{B.3 Gravitational terms}

$$
\begin{aligned}
& \mathrm{c} 1=0 \\
& \mathrm{c} 2=0 \\
& \mathrm{c} 3=-0.4084^{*} \cos (\theta 3)
\end{aligned}
$$




\title{
Appendix C \\ Torque Equations for the Joints
}

\author{
$\mathrm{T} 1=$ \\ $-0.0189 * \theta 2 \mathrm{D}^{\wedge} 2 * \cos (\theta 2)+0.0245 * \theta 1 \mathrm{D}^{\wedge} 2 * \sin (\theta 2)+0.0189 * \theta 1 \mathrm{D}^{\wedge} 2^{*} \cos (\theta 2)-0.0189 * \theta 2 \mathrm{DD}$ \\ $* \sin (\theta 2)+0.0533 * \theta 2 \mathrm{DD}^{*} \cos (\theta 2)-0.0533 * \theta 2 \mathrm{D}^{\wedge} 2^{*} \sin (\theta 2)-0.0716^{*} \theta 1 \mathrm{D}^{\wedge} 2 * \sin (\theta 1)-0.0377$ \\ $* \theta 1 \mathrm{D} 1 * \sin (\theta 2)+0.0141^{*} \theta 3 \mathrm{DD} * \sin (\theta 3)-0.0336^{*} \theta 1 \mathrm{D} * \theta 3 \mathrm{D} * \cos (\theta 3) * \sin (\theta 3)+0.0141$ \\ $* \theta 3 \mathrm{D}^{\wedge} 2 * \sin (\theta 3)-0.0864 * \theta 2 \mathrm{D}^{*} \theta 3 \mathrm{D}^{*} \sin (\theta 3) * \cos (\theta 2)+0.0366^{*} \theta 2 \mathrm{DD} * \cos (\theta 3)+0.3451$ \\ $* \theta 1 \mathrm{DD}+0.0432 * \theta 2 \mathrm{DD} * \cos (\theta 2) * \cos (\theta 3)+0.0336^{*} \theta 2 \mathrm{DD} * \cos (\theta 3)^{\wedge} 2+0.0333 * \theta 2 \mathrm{DD}-$ \\ $0.0673 * \theta 2 \mathrm{D} * \theta 3 \mathrm{D} * \cos (\theta 3) * \sin (\theta 3)+0.1065 * \theta 1 \mathrm{DD} * \cos (\theta 2)-0.0432 * \theta 1 \mathrm{D} * \theta 3 \mathrm{D} * \sin (\theta 3)$ \\ $* \cos (\theta 2)-0.0864 * \theta 1 \mathrm{D} * \theta 2 \mathrm{D} * \sin (\theta 2) * \cos (\theta 3)-0.1065^{*} \theta 1 \mathrm{D} * \theta 2 \mathrm{D} * \sin (\theta 2)-0.0377 * \theta 1 \mathrm{D}$ \\ $* \theta 2 \mathrm{D}^{*} \cos (\theta 2)+0.0366 * \theta 1 \mathrm{DD} * \cos (\theta 3)-0.0490 * \theta 1 \mathrm{D}^{\wedge} 2 * \cos (\theta 2) * \sin (\theta 1)+0.0864 * \theta 1 \mathrm{DD}$ \\ $* \cos (\theta 2) * \cos (\theta 3)-0.0432 * \theta 2 \mathrm{D}^{\wedge} 2 * \sin (\theta 2) * \cos (\theta 3)+0.0336 * \theta 1 \mathrm{DD} * \cos (\theta 3)^{\wedge} 2+$ \\ $0.0377^{*} \theta 1 \mathrm{D}^{\wedge} 2 * \sin (\theta 2) * \sin (\theta 1)-0.0864 * \theta 1 \mathrm{D}^{\wedge} 2 * \cos (\theta 2) * \cos (\theta 3) * \sin (\theta 1)+0.0432$ \\ $* \theta 1 \mathrm{D}^{\wedge} 2 * \sin (\theta 2) * \cos (\theta 3)-0.0432 * \theta 3 \mathrm{DD} * \sin (\theta 3) * \sin (\theta 2)-0.0432 * \theta 3 \mathrm{D}^{\wedge} 2 * \sin (\theta 3)$ \\ $* \sin (\theta 2)-0.0366^{*} \theta 1 \mathrm{D}^{\wedge} 2 * \cos (\theta 3) * \sin (\theta 1)-0.0336 * \theta 1 \mathrm{D}^{\wedge} 2^{*} \cos (\theta 3)^{\wedge} 2^{*} \sin (\theta 1)+0.0015$ \\ $* \theta 1 \mathrm{D} * \theta 3 \mathrm{D} * \cos (\theta 3)-0.0366^{*} \theta 2 \mathrm{D}^{*} \theta 3 \mathrm{D} * \sin (\theta 3)-0.0183 * \theta 1 \mathrm{D}^{*} \theta 3 \mathrm{D} * \sin (\theta 3)$

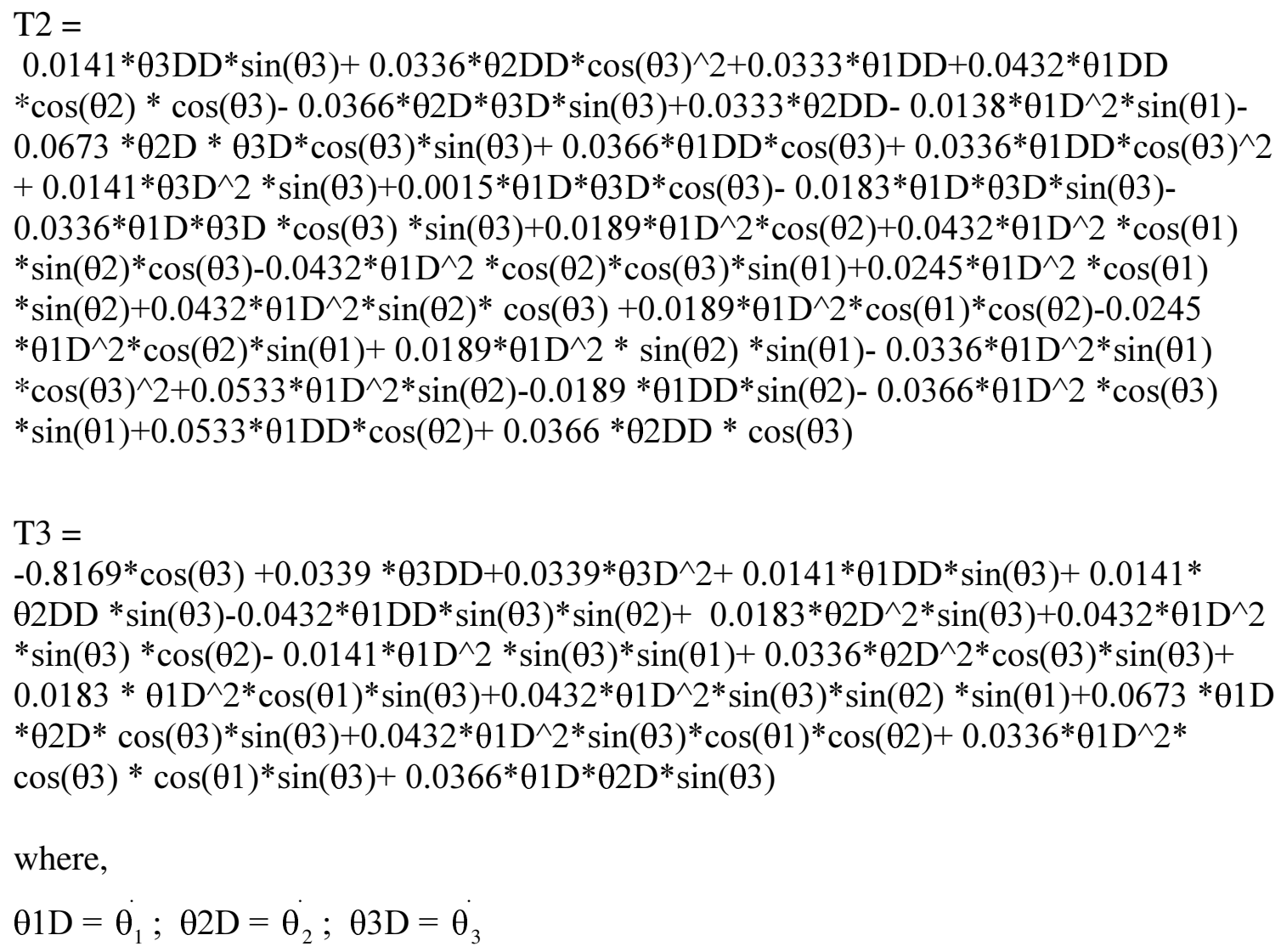

where,

$\theta 1 \mathrm{D}=\theta_{1} ; \theta 2 \mathrm{D}=\theta_{2} ; \theta 3 \mathrm{D}=\theta_{3}$ \\ $\theta 1 \mathrm{DD}=\ddot{\theta_{1}} ; \theta 2 \mathrm{DD}=\ddot{\theta_{2}} ; \theta 3 \mathrm{DD}=\ddot{\theta_{3}}$
}




\section{Appendix D \\ Matlab Code to Calculate Kinematics, Inverse \\ Kinematics, Dynamics and Torques for the SCARA-Type Robot}

syms L1 L2 L3 q1 q2 q3 H nx ox ax px ny oy ay py nz oz az pz m1 m2 m3 g q11 q22 q33 q111 q222 q333;

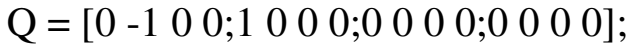

$\mathrm{L} 1=1.7 ; \mathrm{L} 2=0.72 ; \mathrm{L} 3=1.27 ; \mathrm{H}=5 ; \mathrm{m} 1=0.98 ; \mathrm{m} 2=0.513 ; \mathrm{m} 3=0.61 ; \mathrm{g}=32.16 ; \quad \%$ All units in $\mathrm{lb}$ and feet.

$\%$ theta $1=62$, theta $2=35$, theta $3=0$, theta $5=0$;

$\% \mathrm{q} 3+\mathrm{q} 4=90$ degrees.; $\mathrm{q} 4=90-\mathrm{q} 3$.

$\% \mathrm{q} 1=($ theta $1 * \mathrm{pi} / 180), \mathrm{q} 2=($ theta $2 * \mathrm{pi} / 180), \mathrm{q} 3=($ theta $3 * \mathrm{pi} / 180), \mathrm{q} 5=($ theta $5 * \mathrm{pi} / 180)$;

\% Homogeneous Transformation Matrices

$\mathrm{A} 01=[\cos (\mathrm{q} 1),-\sin (\mathrm{q} 1), 0, \mathrm{~L} 1 * \cos (\mathrm{q} 1) ; \sin (\mathrm{q} 1), \cos (\mathrm{q} 1), 0, \mathrm{~L} 1 * \sin (\mathrm{q} 1) ; 0,0,1, \mathrm{H} ; 0,0,0$, 1];

$\mathrm{A} 12=[\cos (\mathrm{q} 2), 0,-\sin (\mathrm{q} 2), \mathrm{L} 2 * \cos (\mathrm{q} 2) ; \sin (\mathrm{q} 2), 0, \cos (\mathrm{q} 2), \mathrm{L} 2 * \sin (\mathrm{q} 2) ; 0,-1,0,0 ; 0,0,0,1] ;$

$\mathrm{A} 23=[\cos (\mathrm{q} 3),-\sin (\mathrm{q} 3), 0, \mathrm{~L} 3 * \cos (\mathrm{q} 3) ; \sin (\mathrm{q} 3), \cos (\mathrm{q} 3), 0, \mathrm{~L} 3 * \sin (\mathrm{q} 3) ; 0,0,1,0 ; 0,0,0,1]$;

$\mathrm{A} 34=[\sin (\mathrm{q} 3),-\cos (\mathrm{q} 3), 0,0 ; \cos (\mathrm{q} 3), \sin (\mathrm{q} 3), 0,0 ; 0,0,1,0 ; 0,0,0,1]$;

$\mathrm{A} 4 \mathrm{E}=[0,-\sin (\mathrm{q} 5), \cos (\mathrm{q} 5), 0 ; 0,-\cos (\mathrm{q} 5),-\sin (\mathrm{q} 5), 0 ; 1,0,0,0 ; 0,0,0,1]$;

Tgoal=[nx ox ax px; ny oy ay py; nz oz az pz; 000 ll];

$\mathrm{T} 0 \mathrm{E}=\mathrm{A} 01 * \mathrm{~A} 12 * \mathrm{~A} 23 * \mathrm{~A} 34 * \mathrm{~A} 4 \mathrm{E}$

$\%$ Tgoal $=\mathrm{T} 0 \mathrm{E}$

$\mathrm{A} 02=\mathrm{A} 01 * \mathrm{~A} 12$

$\mathrm{A} 13=\mathrm{A} 12 * \mathrm{~A} 23$;

$\mathrm{A} 10=\operatorname{inv}(\mathrm{A} 01)$;

A21=inv(A12);

A31=inv(A13);

$\mathrm{A} 32=\operatorname{inv}(\mathrm{A} 23)$;

$\mathrm{A} 03=\mathrm{A} 01 * \mathrm{~A} 12 * \mathrm{~A} 23$;

$\mathrm{A} 0 \mathrm{E}=\mathrm{A} 01 * \mathrm{~A} 12 * \mathrm{~A} 23 * \mathrm{~A} 34 * \mathrm{~A} 4 \mathrm{E}$;

A43=inv(A34);

$\mathrm{AE} 4=\operatorname{inv}(\mathrm{A} 4 \mathrm{E})$; 


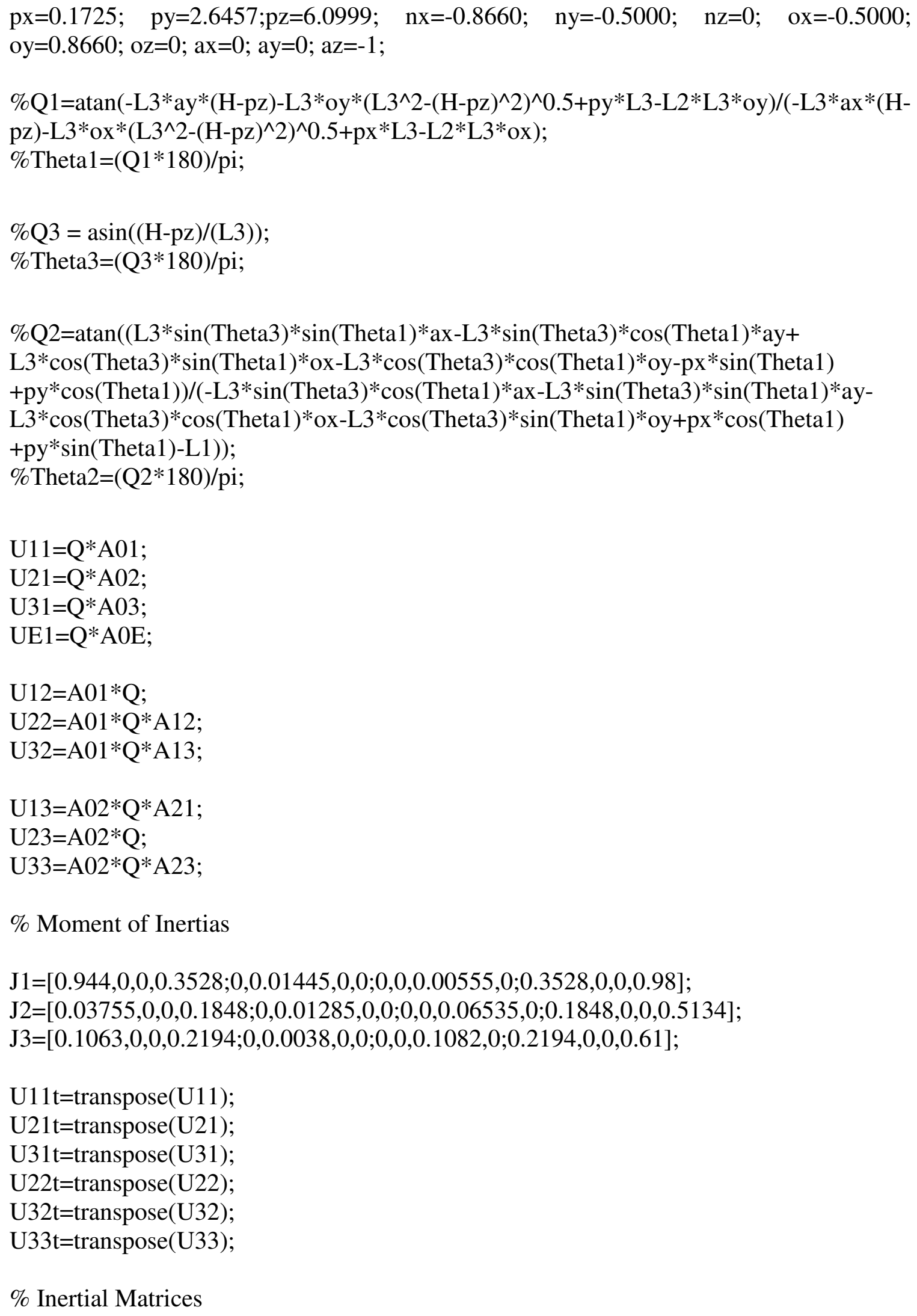




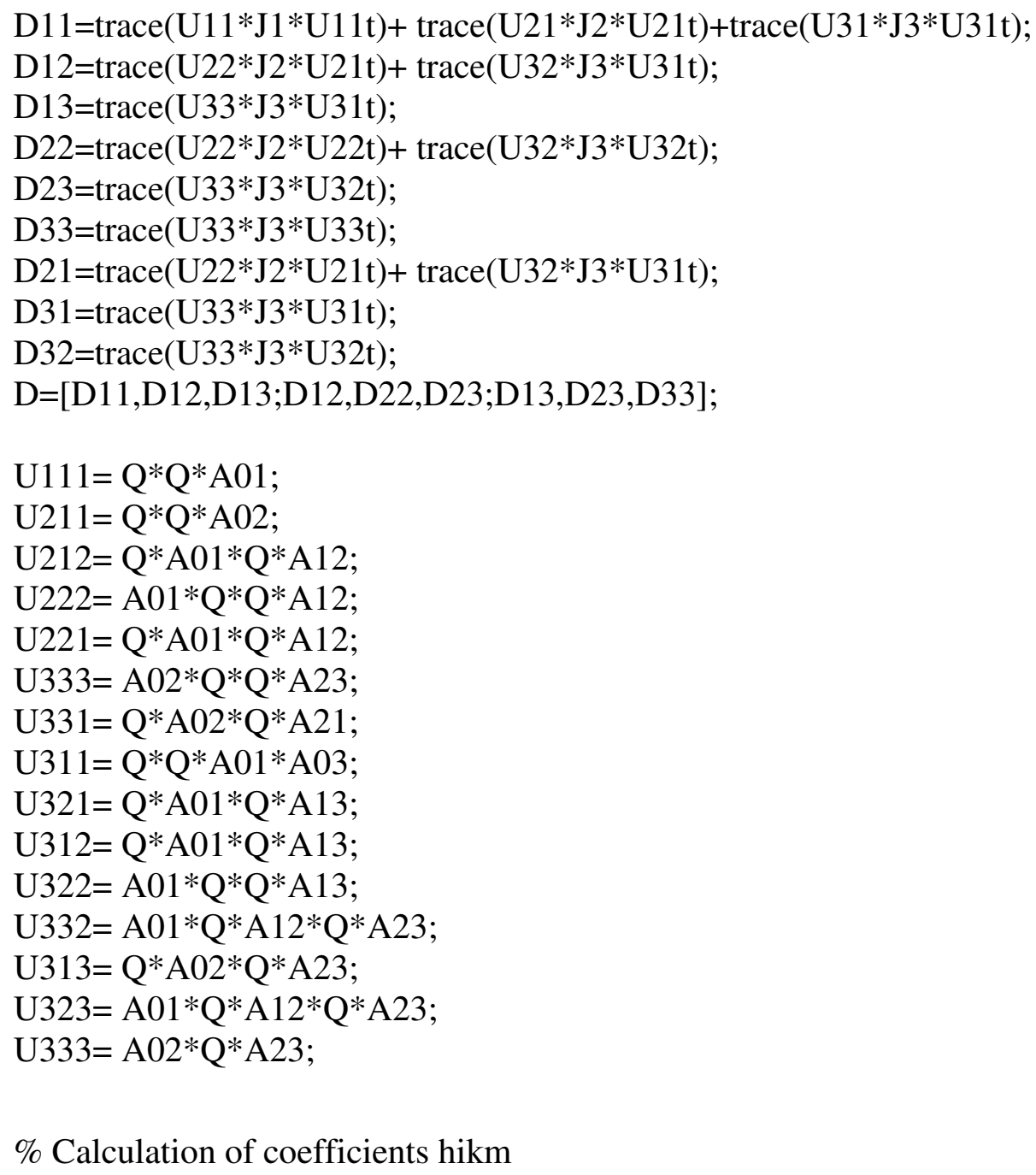

$\%$ Calculation of coefficients hikm

$\mathrm{h} 111=\operatorname{trace}(\mathrm{U} 111 * \mathrm{~J} 1 * \operatorname{transpose}(\mathrm{U} 11))+\operatorname{trace}(\mathrm{U} 211 * \mathrm{~J} 2 * \operatorname{transpose}(\mathrm{U} 21))+\operatorname{trace}(\mathrm{U} 311 * \mathrm{~J} 3 *$ transpose (U31));

h121 =trace $(\mathrm{U} 221 * \mathrm{~J} 2 * \operatorname{transpose}(\mathrm{U} 21))+\operatorname{trace}(\mathrm{U} 321 * \mathrm{~J} 3 * \operatorname{transpose}(\mathrm{U} 31))$;

h131 =trace $(\mathrm{U} 331 * \mathrm{~J} 3 * \operatorname{transpose}(\mathrm{U} 31))$;

h112 $=\operatorname{trace}(\mathrm{U} 212 * \mathrm{~J} 2 * \operatorname{transpose}(\mathrm{U} 21))+\operatorname{trace}(\mathrm{U} 312 * \mathrm{~J} 3 * \operatorname{transpose}(\mathrm{U} 31))$;

h122 $=\operatorname{trace}(\mathrm{U} 222 * \mathrm{~J} 2 * \operatorname{transpose}(\mathrm{U} 21))+\operatorname{trace}(\mathrm{U} 322 * \mathrm{~J} 3 * \operatorname{transpose}(\mathrm{U} 31))$;

h132=trace $(\mathrm{U} 332 * \mathrm{~J} 3 * \operatorname{transpose}(\mathrm{U} 31))$;

$\mathrm{h} 113=\operatorname{trace}(\mathrm{U} 313 * \mathrm{~J} 3 * \operatorname{transpose}(\mathrm{U} 31))$;

$\mathrm{h} 123=\operatorname{trace}(\mathrm{U} 323 * \mathrm{~J} 3 * \operatorname{transpose}(\mathrm{U} 31))$

h133 $=\operatorname{trace}(\mathrm{U} 333 * \mathrm{~J} 3 * \operatorname{transpose}(\mathrm{U} 31))$;

$\mathrm{h} 211=\operatorname{trace}(\mathrm{U} 211 * \mathrm{~J} 2 * \mathrm{U} 22 \mathrm{t})+\operatorname{trace}(\mathrm{U} 311 * \mathrm{~J} 3 * \mathrm{U} 32 \mathrm{t})$;

$\mathrm{h} 221=\operatorname{trace}(\mathrm{U} 221 * \mathrm{~J} 2 * \mathrm{U} 22 \mathrm{t})+\operatorname{trace}(\mathrm{U} 321 * \mathrm{~J} 3 * \mathrm{U} 32 \mathrm{t})$;

$\mathrm{h} 212=\operatorname{trace}(\mathrm{U} 212 * \mathrm{~J} 2 * \mathrm{U} 22 \mathrm{t})+\operatorname{trace}(\mathrm{U} 312 * \mathrm{~J} 3 * \mathrm{U} 32 \mathrm{t})$;

$\mathrm{h} 222=\operatorname{trace}(\mathrm{U} 222 * \mathrm{~J} 2 * \mathrm{U} 22 \mathrm{t})+\operatorname{trace}(\mathrm{U} 322 * \mathrm{~J} 3 * \mathrm{U} 32 \mathrm{t})$;

$\mathrm{h} 233=\operatorname{trace}(\mathrm{U} 333 * \mathrm{~J} 3 * \mathrm{U} 32 \mathrm{t})$;

$\mathrm{h} 231=\operatorname{trace}(\mathrm{U} 331 * \mathrm{~J} 3 * \mathrm{U} 32 \mathrm{t})$;

$\mathrm{h} 213=\operatorname{trace}(\mathrm{U} 313 * \mathrm{~J} 3 * \mathrm{U} 32 \mathrm{t})$; 


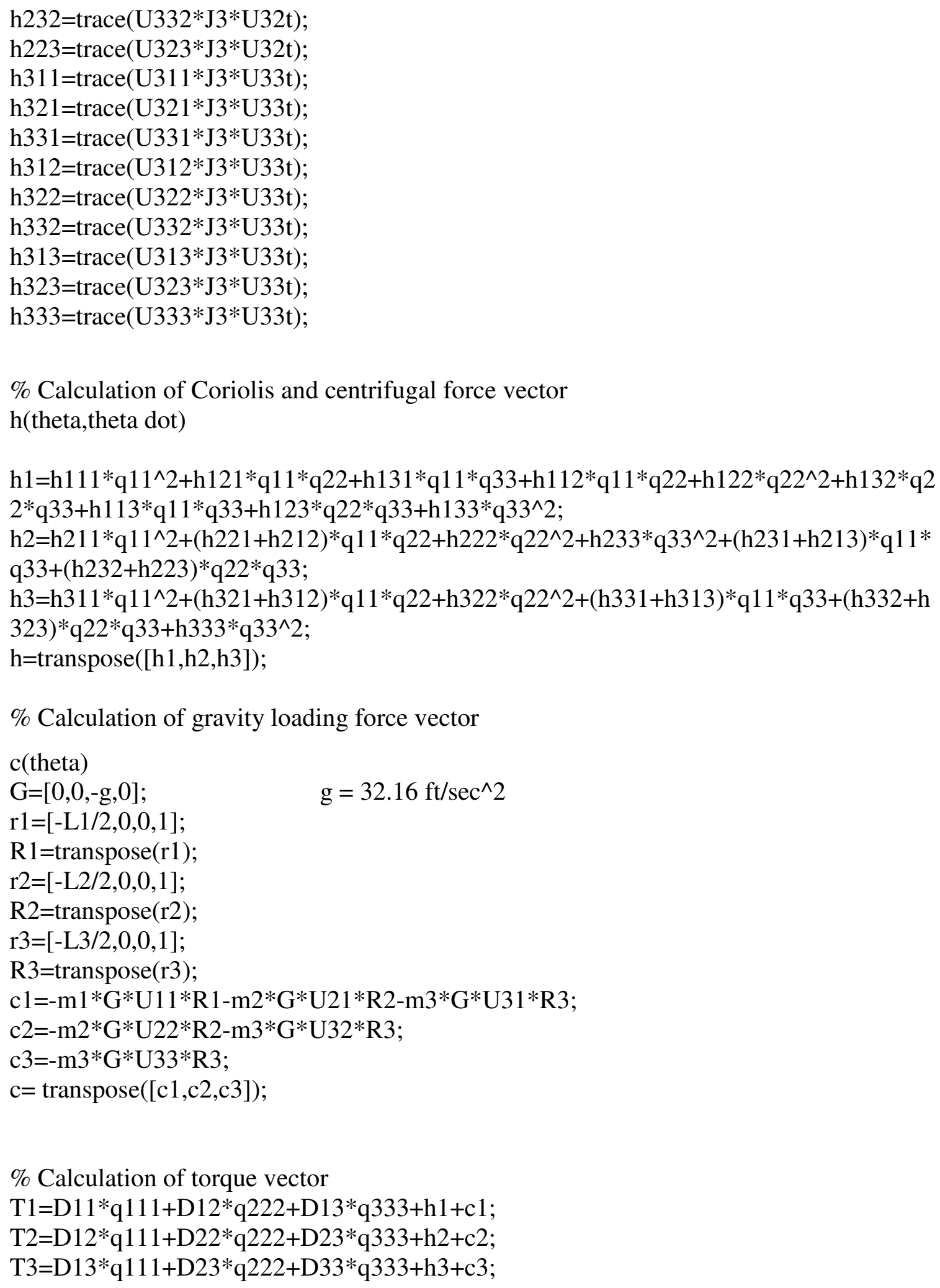

$\%$ Calculation of torque vector

$\mathrm{T} 1=\mathrm{D} 11 * \mathrm{q} 111+\mathrm{D} 12 * \mathrm{q} 222+\mathrm{D} 13 * \mathrm{q} 333+\mathrm{h} 1+\mathrm{c} 1$;

$\mathrm{T} 2=\mathrm{D} 12 * \mathrm{q} 111+\mathrm{D} 22 * \mathrm{q} 222+\mathrm{D} 23 * \mathrm{q} 333+\mathrm{h} 2+\mathrm{c} 2$;

$\mathrm{T} 3=\mathrm{D} 13 * \mathrm{q} 111+\mathrm{D} 23 * \mathrm{q} 222+\mathrm{D} 33 * \mathrm{q} 333+\mathrm{h} 3+\mathrm{c} 3$; 


\section{Appendix E Technical Characteristics of the SCARA-Type Robot}

1. Motion Range

Axis 1

Axis 2

Axis 3

2. Speed Range

Axis 1

Axis 2

Axis 3 \pm 110 degrees

\pm 140 degrees

+20 degrees and -10 degrees

\pm 240 degrees/sec

\pm 240 degrees/sec

\pm 40 degrees/sec

3. Input Voltage: 115 VAC 


\section{Appendix F Technical Characteristics of the Joint Actuators}

The motors in the joints of the SCARA-Type robot are SM series servomotors made by Parker Hannifin Corporation.

1. Resistance $\left(\mathrm{R}_{\mathrm{a}}\right)$

2. Inductance $\left(\mathrm{L}_{\mathrm{a}}\right)$

3. Viscous Damping $\left(\mathrm{B}_{\mathrm{v}}\right) \quad 3.78 \mathrm{E}-3 \mathrm{Nm} / \mathrm{Krpm}$

4. Rotor Inertia $\left(\mathrm{J}_{\mathrm{m}}\right) \quad 1.3 \mathrm{E}-4 \mathrm{~kg}-\mathrm{m}^{2}$

5. Voltage Constant $\left(\mathrm{K}_{\mathrm{b}}\right) \quad 0.484 \mathrm{Volts} / \mathrm{rad} / \mathrm{sec}$

6. Torque Constant $\left(\mathrm{K}_{\mathrm{t}}\right) \quad 0.48 \mathrm{Nm} / \mathrm{Amp} \mathrm{DC}$ 


\section{Appendix G}

A) Matlab Code to determine closed-loop transfer function for Joint 1 with PID controller

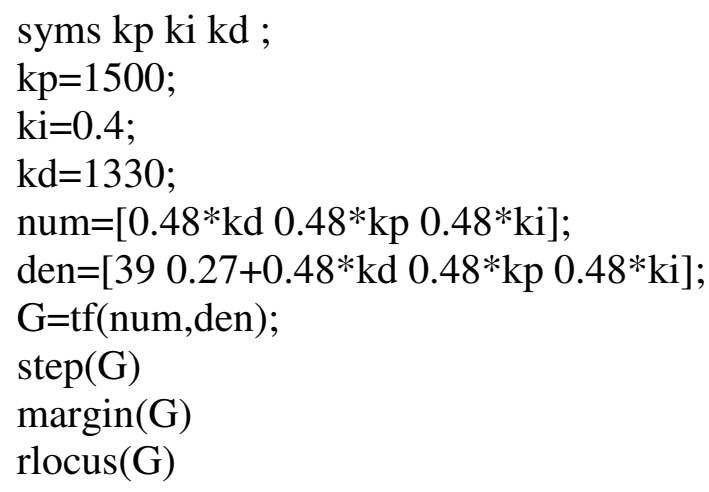

B) Matlab Code to determine closed-loop transfer function for Joint 2 with PID controller

syms kp ki kd;

$\mathrm{kp}=140$;

$\mathrm{ki}=0.4$;

$\mathrm{kd}=160$;

num $=[0.48 * \mathrm{kd} 0.48 * \mathrm{kp} 0.48 * \mathrm{ki}]$;

den $=[4.20 .27+0.48 * \mathrm{kd} 0.48 * \mathrm{kp} 0.48 * \mathrm{ki}]$;

$\mathrm{G}=\mathrm{tf}($ num,den);

$\operatorname{step}(\mathrm{G})$

$\operatorname{margin}(\mathrm{G})$

$\operatorname{rlocus}(\mathrm{G})$

C) Matlab Code to determine closed-loop transfer function for Joint 3 with PID controller

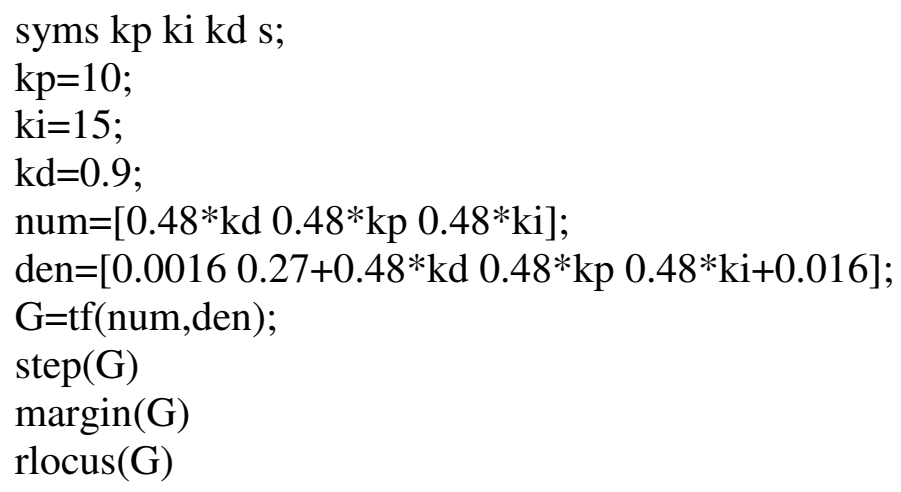




\section{Appendix $\mathrm{H}$ Simulink Model for the Three Joints}

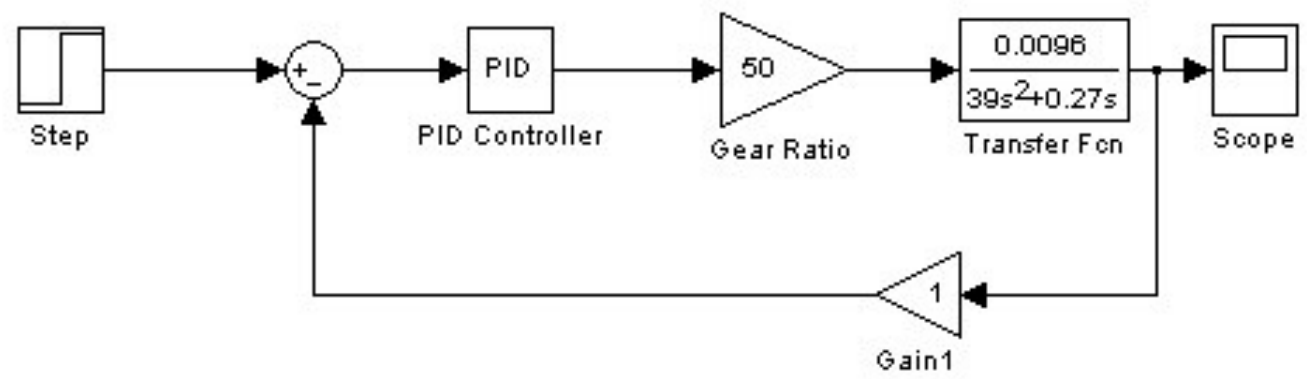

Figure H.1 Controller Design for Joint 1

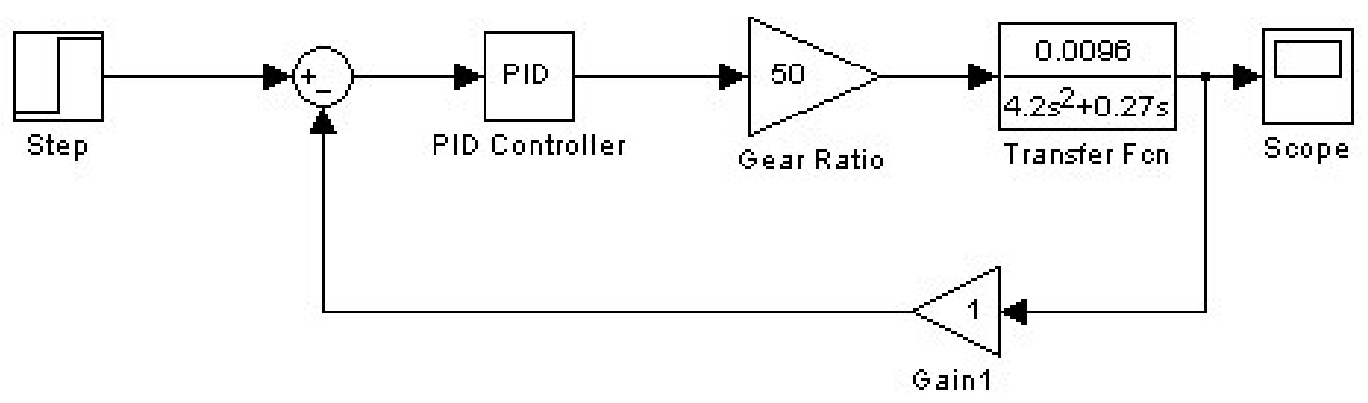

Figure H.2 Controller Design for Joint 2

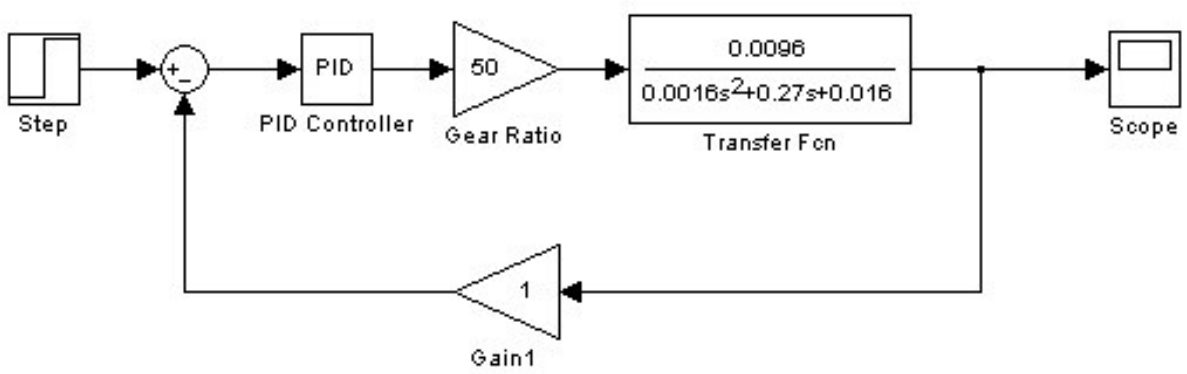

Figure H.3 Controller Design for Joint 3 


\section{Vita}

Asif M. Mohammad was born on October 05, 1977 in Hyderabad India. He did his schooling at The Hyderabad Public School in Hyderabad, India. He received a Bachelor of Engineering Degree in Mechanical Engineering from Osmania Univerisity,

India, in May 1999. He is currently a candidate for Master of Science Degree in Mechanical Engineering Degree from West Virginia University. 